\title{
ELAWD Grout Hopper Mock-Up Testing
}

E.K. Hansen

B.R. Pickenheim

R.A. Leishear

A.D. Marzolf

M.M. Reigel

October 2011

Savannah River National Laboratory Savannah River Nuclear Solutions, LLC Aiken, SC 29808 
SRNL-STI-2011-00465

Revision 0

\section{DISCLAIMER}

This work was prepared under an agreement with and funded by the U.S. Government. Neither the U.S. Government or its employees, nor any of its contractors, subcontractors or their employees, makes any express or implied:

1. warranty or assumes any legal liability for the accuracy, completeness, or for the use or results of such use of any information, product, or process disclosed; or

2. representation that such use or results of such use would not infringe privately owned rights; or

3. endorsement or recommendation of any specifically identified commercial product, process, or service.

Any views and opinions of authors expressed in this work do not necessarily state or reflect those of the United States Government, or its contractors, or subcontractors.

\section{Printed in the United States of America \\ Prepared for \\ U.S. Department of Energy}




\section{REVIEWS AND APPROVALS}

\section{AUTHOR(S):}

E.K. Hansen, Engineering Process Development Date

B. R. Pickenheim, Engineering Process Development Date

R. A. Leishear, Engineering Development Laboratory Date

A.D. Marzolf, Mechanical Systems \& Custom Equipment Development Date

M. M. Reigel, Engineering Process Development Date

\section{TECHNICAL REVIEWERS:}

A. D. Cozzi, Engineering Process Development Date

\section{APPROVERS}

A. B. Barnes, Manager

Date

ERPS/Engineering Process Development

S. L. Marra, Manager,

Date

E\&CPT Research Programs

J. E. Occhipinti, Manager

Date

Waste Solidification Engineering 


\section{EXECUTIVE SUMMARY}

The Saltstone Enhanced Low Activity Waste Disposal project identified the need to replace the existing hopper that connects the READCO mixer and the pumping system at the Saltstone Production Facility to improve processing of Saltstone grout. The Savannah River National Laboratory received a Technical Task Request (TTR) to integrate the proposed hopper design by Saltstone Engineering and the proposed agitator design from Chemineer into a scaled process. This scaled process will be used to determine if this hopper design could be run under vortexing conditions without impacting radar level measurements and be able to incorporate a slug of dry feed into the agitated hopper and be recoverable.

A 30-inch scaled version of the new Saltstone Grout Hopper was designed and constructed to perform a total of nine different tests, using water, $5 \mathrm{~Pa}$ yield stress xanthan gum, $20 \mathrm{~Pa}$ yield stress xanthan gum, and $5 \mathrm{~Pa}$ yield stress grout were performed. These tests included both static and recirculation tests for each fluid and an addition of dry premix into the $5 \mathrm{~Pa}$ grout. The results to the TTR requests are:

1. The size of the vortex will not impact the operation of the radar level instrument given the nominal range of tank operations is between 300 to 330 gallons.

2. The addition of dry premix to the hopper did not cause operational issues with the proposed hopper, given the test conditions, which was a static tank with the addition of dry solids. Review of the grout level data indicates that this addition would be difficult to measure during processing, given that in the actual process, the grout is being pumped out of the vessel as the dry addition is made. The test data indicates that less than 74 seconds was required to incorporate the solids into the fluid, but in the actual process, this time is expected to be much shorter, since operating with a vortex will help entrain the solids.

3. Baffles are not required for any of the fluids that will be processed through the Saltstone Facility. Operating with a vortex is adequate for this hopper design. The intent of this hopper is not to mix the contents, but to keep the vessel in constant motion since mixing of the premix and salt solution is occurring in the READCO mixer.

Additional observations from this testing are:

1. Froude's correlation is applicable to the agitation observed. Due to the absence of baffles, the development of a vortex occurs and became larger as the agitator speed increases.

2. No significant changes in level measurement with the radar sensor were observed during static or recirculation testing. Large spikes in the radar level measurement were noted but were not visually observed. These spikes did not occur often and had little impact on the average radar level reading.

3. The measured level from the radar sensor increased with increasing agitator speed, i.e., increases in level measurement due to vortex generated by the agitation, above the static condition $(20 \mathrm{rpm})$, were observed at increased agitator rotation speeds (greater than 40 rpm).

4. The upper impeller did not greatly influence the vortex. As the agitator speed increased the upper impeller moved with the fluid to a point where the upper impeller was moving with the fluid. As such, the upper impeller may not be required. 
5. Recirculation flow had minimal impact on the agitation of the contents in the tank. The agitator provided more fluid motion than what the recirculation line could provide, hence dominated the agitation.

6. The recirculation flow rate provided a baffling effect, slightly reducing the height of the vortex.

7. As the vortex got deeper during the recirculation flow tests, a higher pump speed was required to maintain the targeted recirculation flow rate. This was not the case for the 20 $\mathrm{Pa}$ xanthan gum, where the pump speed decreased as the agitation increased to maintain flow.

8. The power of the agitator motor ranged between 0.65 to 0.75 horsepower, this includes mechanical losses in the motor and gearbox, power to the fluid, and electrical losses in the motor. Fluid type (water to non-Newtonian) did not seem to impact power consumption.

9. The power numbers used in this design over-estimated the power requirements of the agitation system.

10. Assuming turbulent flow, Froude's correlation and a power of $0.65 \mathrm{hp}$ in the 30 -inch scale, the power for the full scale would be less than $4.16 \mathrm{hp}$. Use of a larger motor, as designed, is not expected to cause any issues.

11. If the agitator blade is not moving and located directly below the radar, it will provide a false level indication if the fluid is below the top impeller. This may be corrected having the agitator rotate at a slow speed or realignment of the radar sensor.

12. Splashing from recirculation will coat the inside of the wetted surfaces of the hopper and was observed with the water and grout fluids.

13. During the dry premix addition into the $5 \mathrm{~Pa}$ grout, changes in tank level and power were not significant enough to determine that this addition occurred.

14. The dry premix was fully incorporated in the $5 \mathrm{~Pa}$ grout in approximately 74 seconds. This measurement was impacted by the dust in the vapor space of the vessel and it is expected that it takes less time to incorporate the solids.

15. Recommended agitator speeds for the 30 -inch hopper are between 50 to $80 \mathrm{rpm}$ for the water to $5 \mathrm{~Pa}$ fluids and 70 to $100 \mathrm{rpm}$ for the $20 \mathrm{~Pa}$ fluid.

16. Using Froude's correlation, the agitator speed for the full scale hopper is between 40 and $60 \mathrm{rpm}$ for fluids with less than $7 \mathrm{~Pa}$ yield stress and 50 to $75 \mathrm{rpm}$ for more viscous fluid.

17. The change in fluid height between a baseline condition (at $20 \mathrm{rpm}$ ) and a vortex just above the top impeller on the 30 -inch hopper using the radar was 1.4 inches. Above this difference, the vortex grows to a point where it is below the hub of the top impeller.

18. As the vortex gets deeper, the top impeller appears to have no effect on the mixing. The impact of the top impeller during the addition of dry solids may contribute to entrainment of the solids.

The recommended agitator speeds for working volumes between 300 to 330 gallons for the new Saltstone Grout Hopper are provided in the table below. It is expected that a majority of Saltstone operations will have fluids that range between water, with a yield stress of $0 \mathrm{~Pa}$, and grouts with yield stresses up to $7 \mathrm{~Pa}$. The agitator must also have the ability to agitate the design basis fluid. Consequently, agitator speeds of up to $75 \mathrm{rpm}$ should be available.

\begin{tabular}{||c|c|}
\hline Fluid Yield Stress $(\mathrm{Pa})$ & Operating Range $(\mathrm{rpm})$ \\
\hline 0 to 7 & 40 to 60 \\
\hline$\sim 20$ & 50 to 75 \\
\hline
\end{tabular}


It should be noted that all recommended operating parameters are based on the nominal operating level in the hopper of 300 gallons. If the nominal level is changed, SRNL recommends verifying the operating parameters, agitator speed, etc., prior to running. When the grout exiting the READCO mixer impacts the surface of the grout in the hopper, splashing will occur and internal surfaces of the hopper will be coated with grout. The method, volume and frequency of flush water required to remove the grout needs to be determined.

The bottom of the bottom impeller should be located at 6 inches from the bottom of the truncated conical section for the full scale hopper. Additional details of the full scale mixing system agitator mixer blade characteristics are provided in Table 2-2. 


\section{TABLE OF CONTENTS}

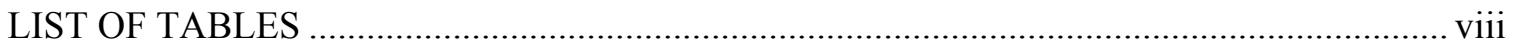

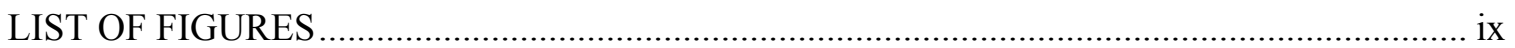

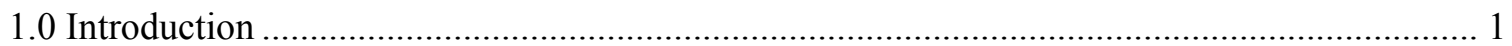

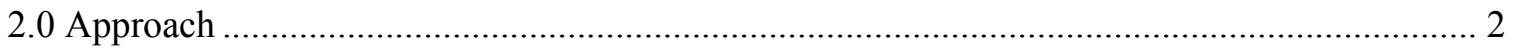

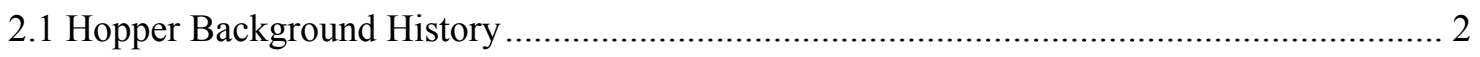

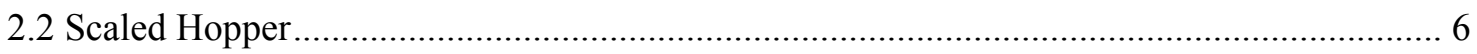

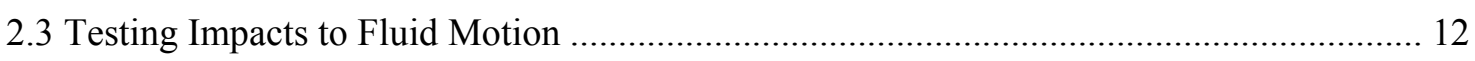

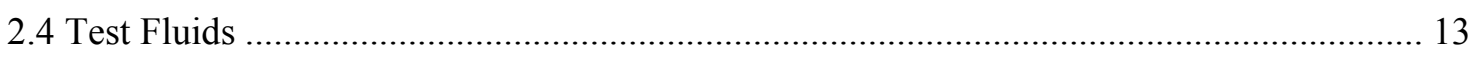

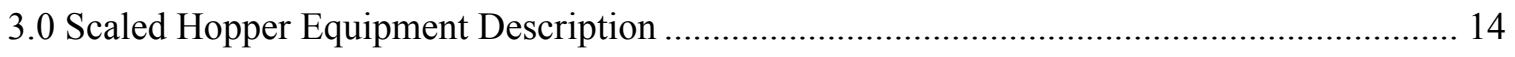

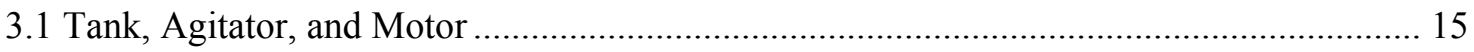

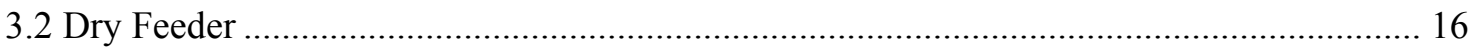

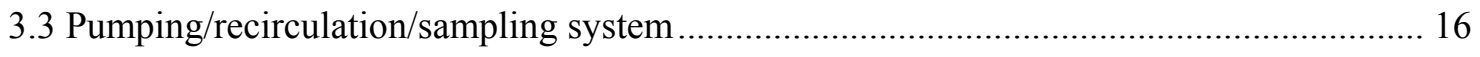

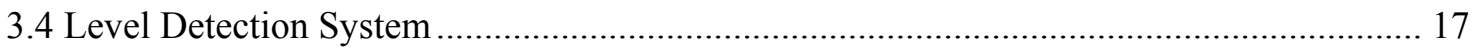

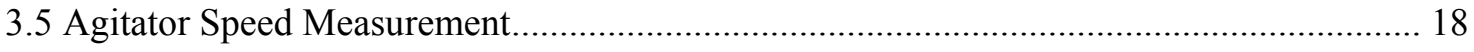

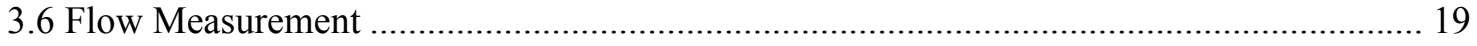

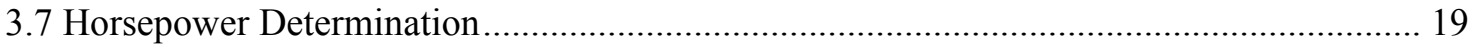

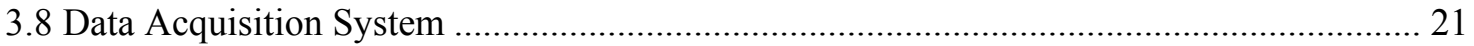

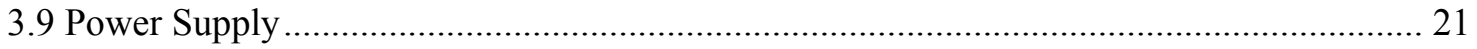

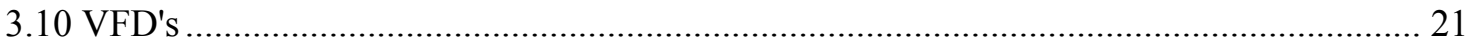

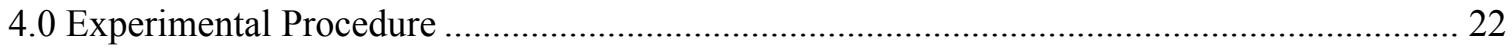

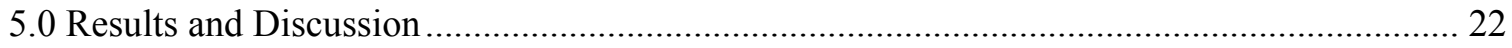

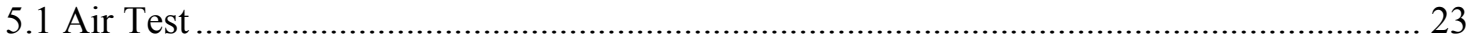

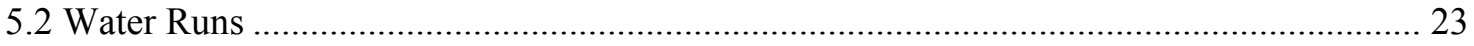

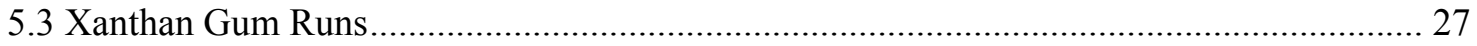

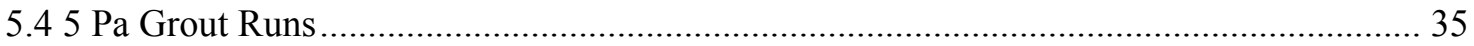

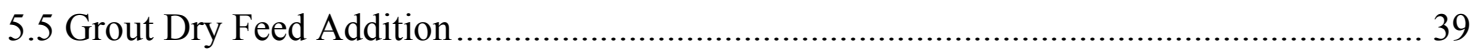

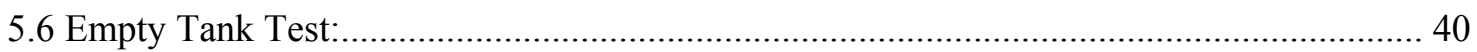

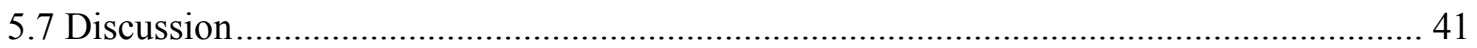

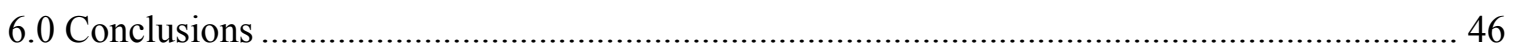

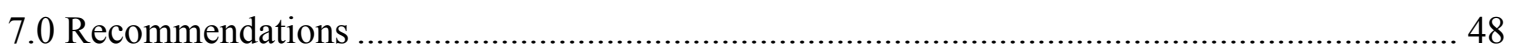

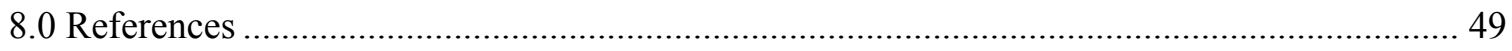

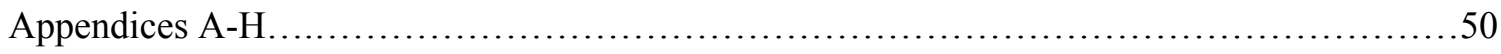




\section{LIST OF TABLES}

Table 2-1. Mechanical agitated hopper, past and future specifications...................................... 3

Table 2-2. Full scale and 30 -inch designed and tested configuration........................................... 8

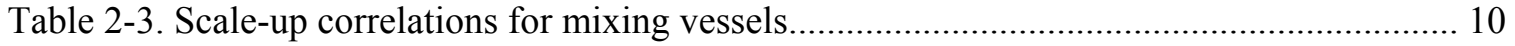

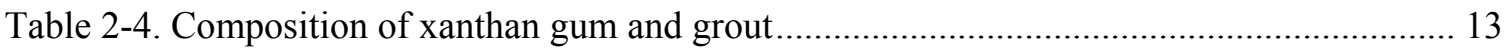

Table 2-5. Fluids and test conditions for 30-inch scaled hopper ............................................... 13

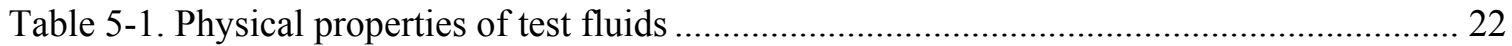

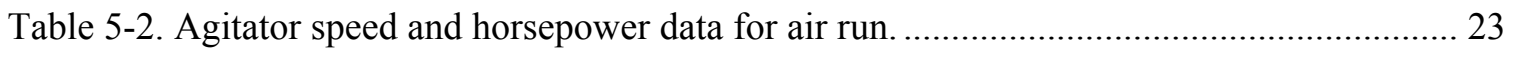

Table 5-3. Static water run: agitator speed and power and tank level data ................................ 24

Table 5-4. Recirculation water run: agitator speed and power, tank level, recirculation flow and

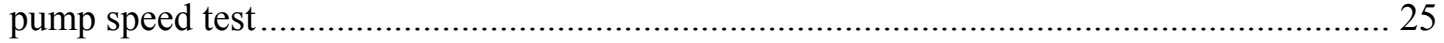

Table 5-5. Static Water Run: Tape Measure and Visual Observation........................................... 26

Table 5-6. Recirculation water run: tape measure and visual observation.................................. 27

Table 5-7. Static $5 \mathrm{~Pa}$ xanthan gum run: agitator speed and power and tank level data. .............. 28

Table 5-8. Agitator speed, tank level, recirculation flow, and pump speed data for $5 \mathrm{~Pa}$ xanthan

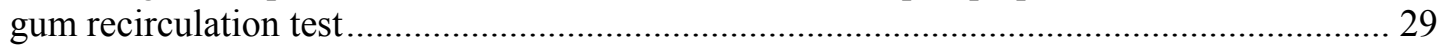

Table 5-9. Static $5 \mathrm{~Pa}$ xanthan gum test: tape measure and visual observation. ........................... 30

Table 5-10. Recirculation 5 Pa xanthan gum run: tape measure and visual observation .............. 31

Table 5-11. Agitator and tank level data for $20 \mathrm{~Pa}$ xanthan gum static runs............................... 31

Table 5-12. Agitator speed, tank level, recirculation flow, and pump speed data for $20 \mathrm{~Pa}$ xanthan

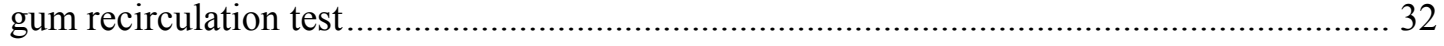

Table 5-13. Static 20 Pa xanthan gum test: tape measure and visual observation ....................... 33

Table 5-14. Recirculation 20 Pa Xanthan Gum Run: Tape Measure and Visual Observation...... 34

Table 5-15. Agitator and tank level data for static 5 Pa grout test. ............................................ 36

Table 5-16. Agitator speed, tank level, recirculation flow, and pump speed data for 5 Pa grout

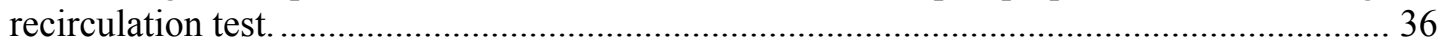

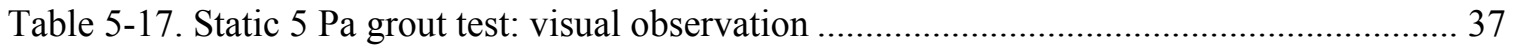

Table 5-18. Recirculation 5 Pa 5 Pa grout test: visual observation.......................................... 38

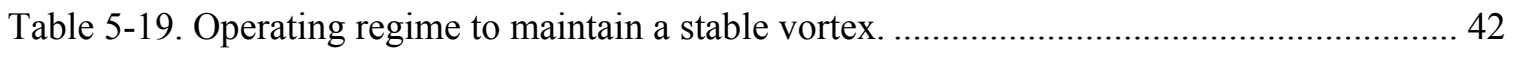

Table 5-20. Turbulent baffled power consumption for the 30 -inch hopper ................................ 44 
Table 7-1. Recommended Agitator Speeds for the New Saltstone Hopper, 300 to 330 gallons of Working Volume 48

\section{LIST OF FIGURES}

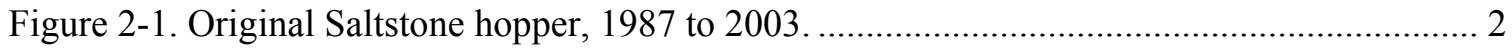

Figure 2-2. Saltstone hold tank insert design, 2003 to 2005 .................................................... 3

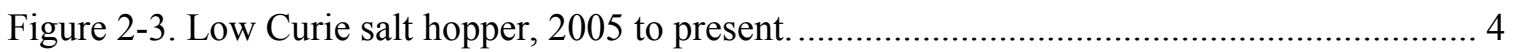

Figure 2-4. Proposed hopper design with 300 gallon working volume....................................... 5

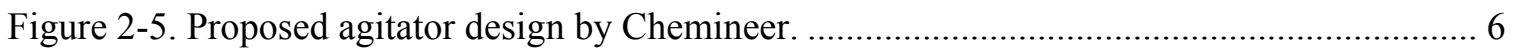

Figure 2-6. Full design and as tested 30-inch scale impeller layout........................................... 11

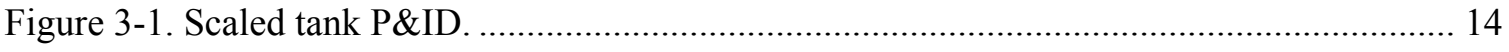

Figure 3-2. Tank and agitator setup in 30-inch hopper test.................................................... 15

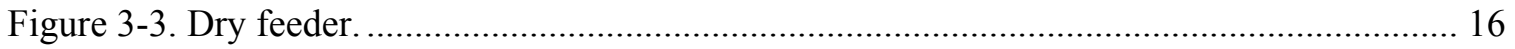

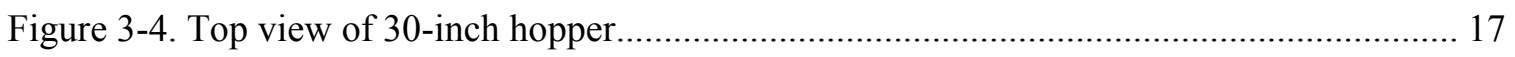

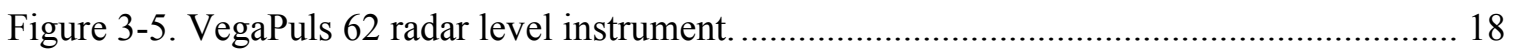

Figure 3-6. Schematic of voltage and amperage measurement module connections.................... 20

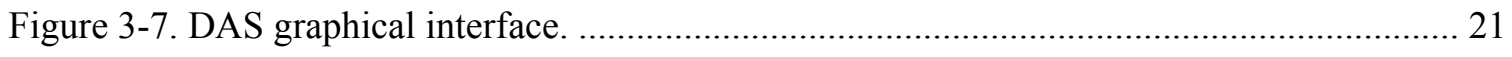

Figure 5-1. Water static run - radar tank level versus agitator speed......................................... 25

Figure 5-2. Water Recirculation Run - Radar Tank Level Versus Agitator Speed...................... 26

Figure 5-3. 5 Pa xanthan gum static run - radar tank level versus agitator speed........................ 29

Figure 5-4. $5 \mathrm{~Pa}$ xanthan gum recirculation run - radar tank level versus agitator speed............. 30

Figure 5-5. $20 \mathrm{~Pa}$ xanthan gum static run - radar tank level versus agitator speed....................... 32

Figure 5-6. $20 \mathrm{~Pa} 20 \mathrm{~Pa}$ xanthan gum recirculation run - radar tank level versus agitator speed. 33

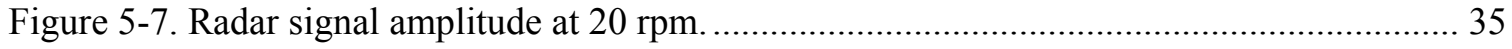

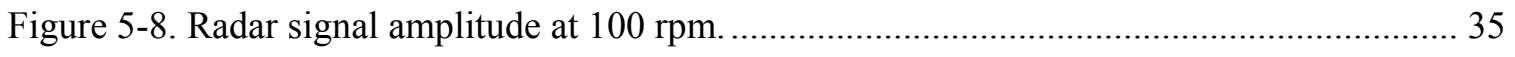

Figure 5-9. 5 Pa grout static run - radar tank level versus agitator speed................................... 36

Figure 5-10. $5 \mathrm{~Pa}$ grout recirculation test - radar tank level versus agitator speed...................... 37 
Figure 5-11. $5 \mathrm{~Pa}$ grout recirculation run, at the end of $90 \mathrm{rpm}$ run, showing grout splatter after approximately 30 minutes of recirculation time. 38

Figure 5-12. Recirculation stream entering hopper during 5 Pa grout run.

Figure 5-13. Radar level measurements (1 sec interval) during a Dry Feed "addition" at an

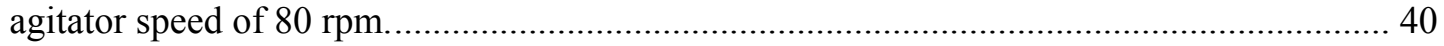

Figure 5-14. Alignment of radar sensor to reduce/eliminate false level measurement from agitator blades.

Figure 5-15. Radar level changes compared to $20 \mathrm{rpm}$ measurements.

Figure 5-16. Power versus Speed for all fluids tested other than air. 45

Figure 5-17. Retreat curve impeller in a conical based vessel. ${ }^{20}$ 45 


\section{LIST OF ABBREVIATIONS}

$\begin{array}{ll}\text { AC } & \text { Alternating Current } \\ \text { ACTL } & \text { Aiken County Technology Laboratory } \\ \text { DAS } & \text { Data Acquisition System } \\ \text { DC } & \text { Direct Current } \\ \text { DK } & \text { Dielectric Constant } \\ \text { ELAWD } & \text { Enhanced Low Activity Waste Disposal } \\ \text { EMF } & \text { Electro-magnetic Flow meter } \\ \text { ID } & \text { Inner Diameter } \\ \text { gpm } & \text { Gallons Per Minute } \\ \text { hp } & \text { Horsepower } \\ \text { P\&ID } & \text { Process and Instrumentation Diagram } \\ \text { LAW } & \text { Low Activity Waste } \\ \text { RCI } & \text { Retreat Curve Impeller } \\ \text { rpm } & \text { Rotations Per Minute } \\ \text { RSD } & \text { Relative Standard Deviation } \\ \text { SDF } & \text { Saltstone Disposal Facility } \\ \text { SE } & \text { Saltstone Engineering } \\ \text { SPF } & \text { Saltstone Production Facility } \\ \text { SRNL } & \text { Savannah River National Laboratory } \\ \text { SRR } & \text { Savannah River Remediation } \\ \text { SD } & \text { Standard Deviation } \\ \text { SWPF } & \text { Salt Waste Processing Facility } \\ \text { TT\&QAP } & \text { Task Technical and Quality Assurance Plan } \\ \text { TTR } & \text { Task Technical Request } \\ \text { VFD } & \text { Variable Frequency Drive } \\ \text { W/P } & \text { Water/Premix Ratio } \\ & \end{array}$




\subsection{Introduction}

A 10-inch READCO mixer is used for mixing the premix (45 (wt \%) fly ash, 45 wt \% slag, and 10 wt \% portland cement) with salt solution in the Saltstone Production Facility (SPF). The Saltstone grout free falls into the grout hopper which feeds the suction line leading to the Watson SPX 100 duplex hose pump. The Watson SPX 100 pumps the grout through approximately 1500 feet of piping prior to being discharged into the Saltstone Disposal Facility (SDF) vaults.

The existing grout hopper has been identified by the Saltstone Enhanced Low Activity Waste Disposal (ELAWD) project for re-design. The current nominal working volume of this hopper is 12 gallons and does not permit handling an inadvertent addition of excess dry feeds. Saltstone Engineering has proposed a new hopper tank that will have a nominal working volume of 300 gallons and is agitated with a mechanical agitator. The larger volume hopper is designed to handle variability in the output of the READCO mixer and process upsets without entering set back during processing.

The objectives of this task involve scaling the proposed hopper design and testing the scaled hopper for the following processing issues:

1. The effect of agitation on radar measurement. Formation of a vortex may affect the ability to accurately measure the tank level. The agitator was run at varying speeds and with varying grout viscosities to determine what parameters cause vortex formation and whether measurement accuracy is affected.

2. A dry feeds over addition. Engineering Calculating X-ESR-Z-00017 ${ }^{1}$ showed that an additional 300 pounds of dry premix added to a 300 gallon working volume would lower the water to premix ratio (W/P) from the nominal 0.60 to 0.53 based on a Salt Waste Processing Facility (SWPF) salt simulant. A grout with a W/P of 0.53 represents the upper bound of grout rheology that could be processed at the facility. A scaled amount of dry feeds will be added into the hopper to verify that this is a recoverable situation.

3. The necessity of baffles in the hopper. The preference of the facility is not to have baffles in the hopper; however, if the initial testing indicates inadequate agitation or difficulties with the radar measurement, baffles will be tested.

This work was requested by Savannah River Remediation (SRR) Task Technical Request (TTR) HLW-SSF-TTR- $0005^{2}$ and the work and quality assurance performed in this task is defined in a Task Technical and Quality Assurance Plan (TT\&QAP) ${ }^{3}$. 


\subsection{Approach}

\subsection{Hopper Background History}

The Saltstone Facility began processing Low Activity Waste (LAW) in 1990 and has had various designs for the grout hopper connecting the READCO mixer to the pumping system. The grout system, specifically the hopper and pumping systems, have been designed for processing grout with a Bingham Plastic yield stress of 21.5 Pascal $(\mathrm{Pa})$, Bingham Plastic viscosity of 42 centipoise $(\mathrm{cP})$, and specific gravity of $1.8 .^{4}$ It should be noted that the physical properties referenced are the maximum expected for Saltstone grout.

The original hopper, shown in Figure 2-1, operated until 2003 prior to the start of low curie feed. This hopper was designed to provide uniform blending of the grout, has a single radial turbine, and operates at a single agitator speed of $178 \mathrm{rpm}$ and a nominal working volume of 160 gallons. ${ }^{4}$ Additional hopper details are provided in Table 2-1. This hopper processed over 4 million gallons of salt solution. ${ }^{5}$ There are no known issues with the operation of this hopper throughout its life.

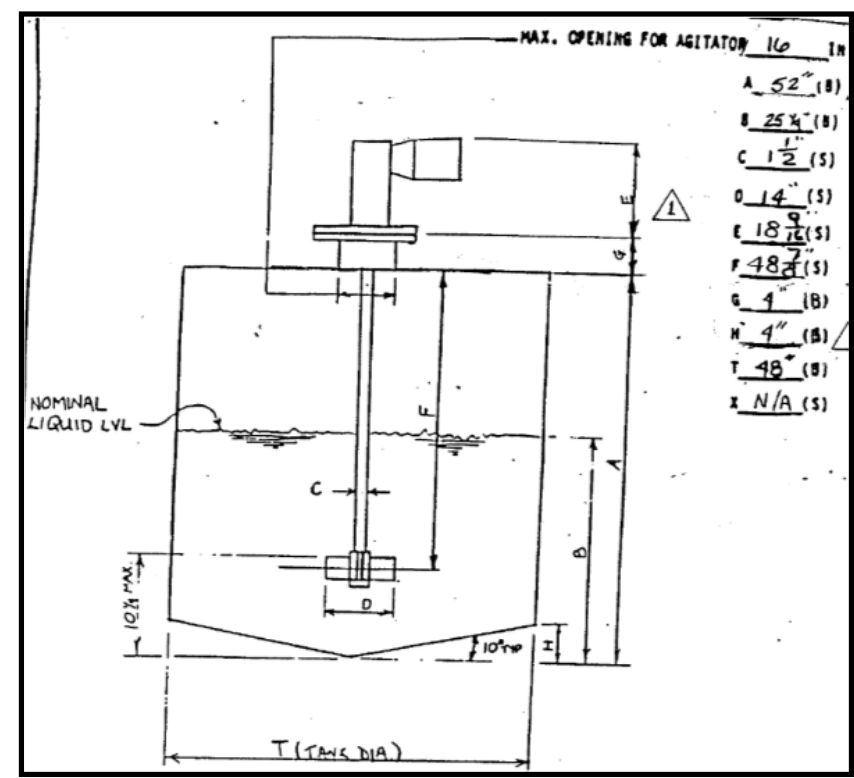

Figure 2-1. Original Saltstone hopper, 1987 to 2003.

In 2003, the original hopper was modified in preparation for low curie salt operations. A conical insert was installed into the existing tank shell as shown in Figure 2-2 and the space between the conical insert and cylindrical section of the tank was filled with grout for radiation shielding. ${ }^{6}$ The same agitator design was utilized; however the impeller location was shifted off center by 2 inches. The maximum working volume of the conical insert is approximately 125 gallons and the nominal working volume is less and not specified on any drawing provided. Additional hopper details are provided in Table 2-1. ${ }^{7}$ The hopper insert operated in 2003, processing approximately 34 thousand gallons of salt solution. ${ }^{5}$ There are no known operating issues related to this design and very little operating experience as compared to the original hopper. 


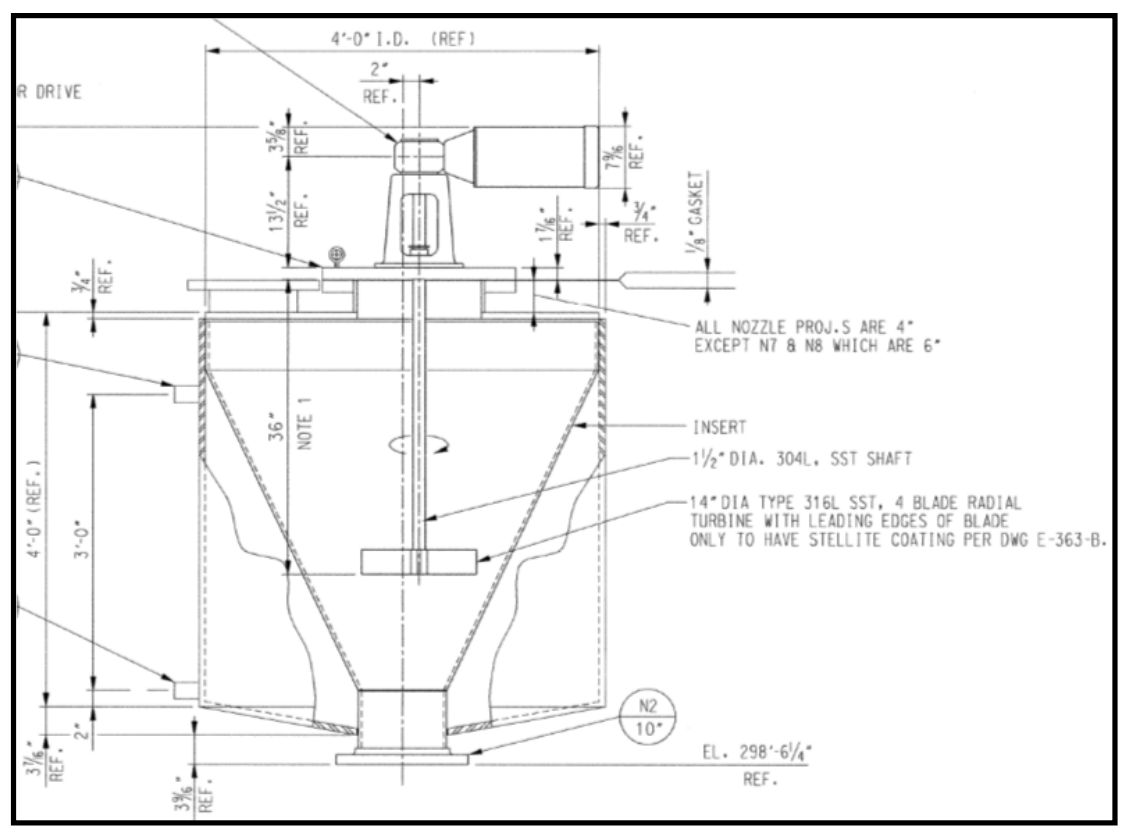

Figure 2-2. Saltstone hold tank insert design, 2003 to 2005.

Table 2-1. Mechanical agitated hopper, past and future specifications.

\begin{tabular}{|c|c|c|c|}
\hline Parameter & Units & Original Hold Tank & $\begin{array}{c}\text { Insert to Hold } \\
\text { Tank }\end{array}$ \\
\hline Operating Year & - & $1988-2003$ & $2003-2005$ \\
\hline Tank Inside Diameter & Inches & 48 & 47.125 \\
\hline $\begin{array}{c}\text { Working height in } \\
\text { cylindrical section }\end{array}$ & Inches & 25.25 & - \\
\hline $\begin{array}{c}\text { Working height of } \\
\text { conical section }\end{array}$ & Inches & 4 & 39 \\
\hline Angle of conical section & Degrees & 10 & 25.45 \\
\hline Working volume & Gallons & 160 & 125 \\
\hline Shaft thickness & Inches & 1.5 & 1.5 \\
\hline $\begin{array}{c}\text { Impeller location }- \\
\text { bottom of impeller to } \\
\text { bottom of tank }\end{array}$ & Inches & 7.25 & 15.625 \\
\hline Type of impeller & Top & 4 -blade, flat & 4 -blade, flat \\
\hline Impeller diameter & Inches & 14 & 14 \\
\hline Impeller width & Inches & 3 & 3 \\
\hline Shaft location & - & Central & 2 " off axis \\
\hline Motor Horsepower & hp & 2 & 2 \\
\hline Agitator speed & $\mathrm{rpm}$ & 173 & 173 \\
\hline
\end{tabular}

The present hopper design used at the SPF is shown in Figure 2-3. ${ }^{8}$ This design was installed to further reduce the potential dose from low curie salt and does not contain a mechanical agitator for blending the grout leaving the READCO mixer. This hopper was originally designed to operate with 23 gallons of grout in the control section (right side of hopper as shown in Figure 2-3). Due to operating issues related to this design, the ELAWD project has decided to replace the current hopper. A total of approximately 4.5 million gallons of salt solution have been processed from 2005 to the present. 


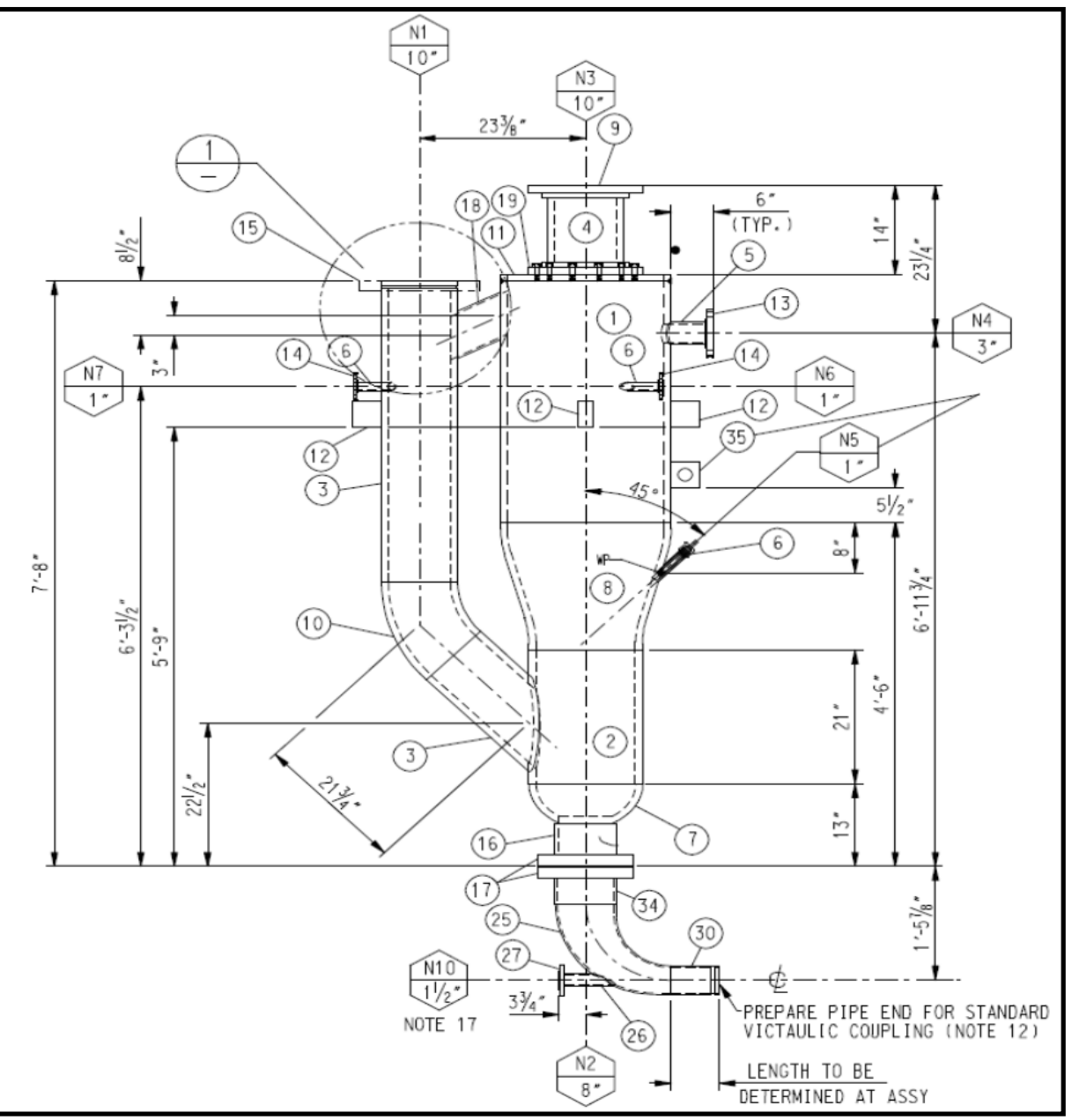

Figure 2-3. Low Curie salt hopper, 2005 to present.

The proposed hopper vessel and agitator design are shown in Figure 2-4 and Figure 2-5, respectively. ${ }^{9,10}$ The hopper vessel is based on a combination of the original and insert hopper designs, where the working volume includes the conical and part of the cylindrical sections of the hopper. The working volume has been increased to approximately 300 gallons to allow for process upsets that could occur in the READCO mixer. ${ }^{1}$

The agitator design, proposed by Chemineer, includes having two impellers on a centrally located shaft, with an angled lower impeller in the conical section and a 45 degree pitch blade in the cylindrical section. Additional details of this design are provided in the scaling section of this document. The agitator design from Chemineer (see Figure 2-5) includes a bottom radial impeller that has been modified so it is parallel to the slope of the conical section of the tank and a 45 degree pitched top impeller located in the cylindrical section of the hopper. The bottom impeller has four blades, the width of each blade is 4 inches, and the impeller has a tip to tip diameter of 30 inches. For calculation purposes (horsepower, cavern size, etc.) the bottom impeller will be treated as a typical radial impeller having four blades, blade width of 4 inches and diameter of 30 inches. The top impeller has four blades, each blade has a projected width of 5 inches and the diameter of the impeller is 28 inches. The drawing shows the bottom and top impellers are located 6 and 33 inches respectively from the bottom of the vessel (where the 
conical section is truncated on the lower end of the cone) relative to the bottom of these impellers and the off-set for the bottom impeller from the wall is 2 inches. These two parameters cannot be satisfied simultaneously given the dimensions of the bottom impeller, shaft size, and the angle of the conical section. Hence, whichever of the two dimensions for the bottom impeller, 6 inches from the bottom of the tank or 2 inches off from the conical section is reached first, the other variable will be determined given the dimensional constraints of the full scale mixing system. In this case, the limiting factor was the 6 inches off the bottom of the tank, resulting in an off-set of the bottom impeller from the conical section of 2.49 inches. Additional details of the full scale dimensions are provided in section 2.2. The Chemineer drawing also shows the installation of submerged baffles to mitigate vortexing and baffles will be tested if required.

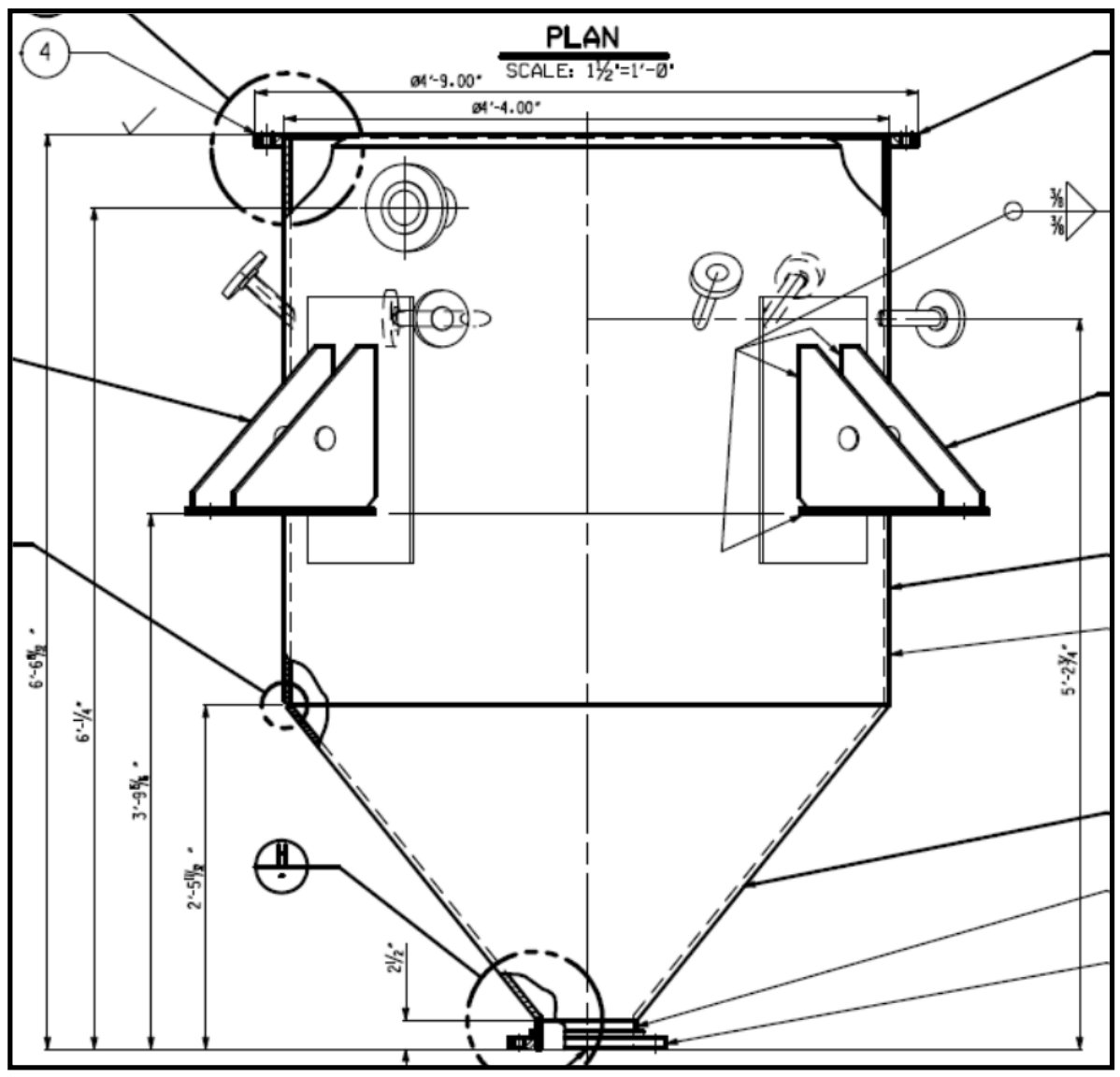

Figure 2-4. Proposed hopper design with 300 gallon working volume. 


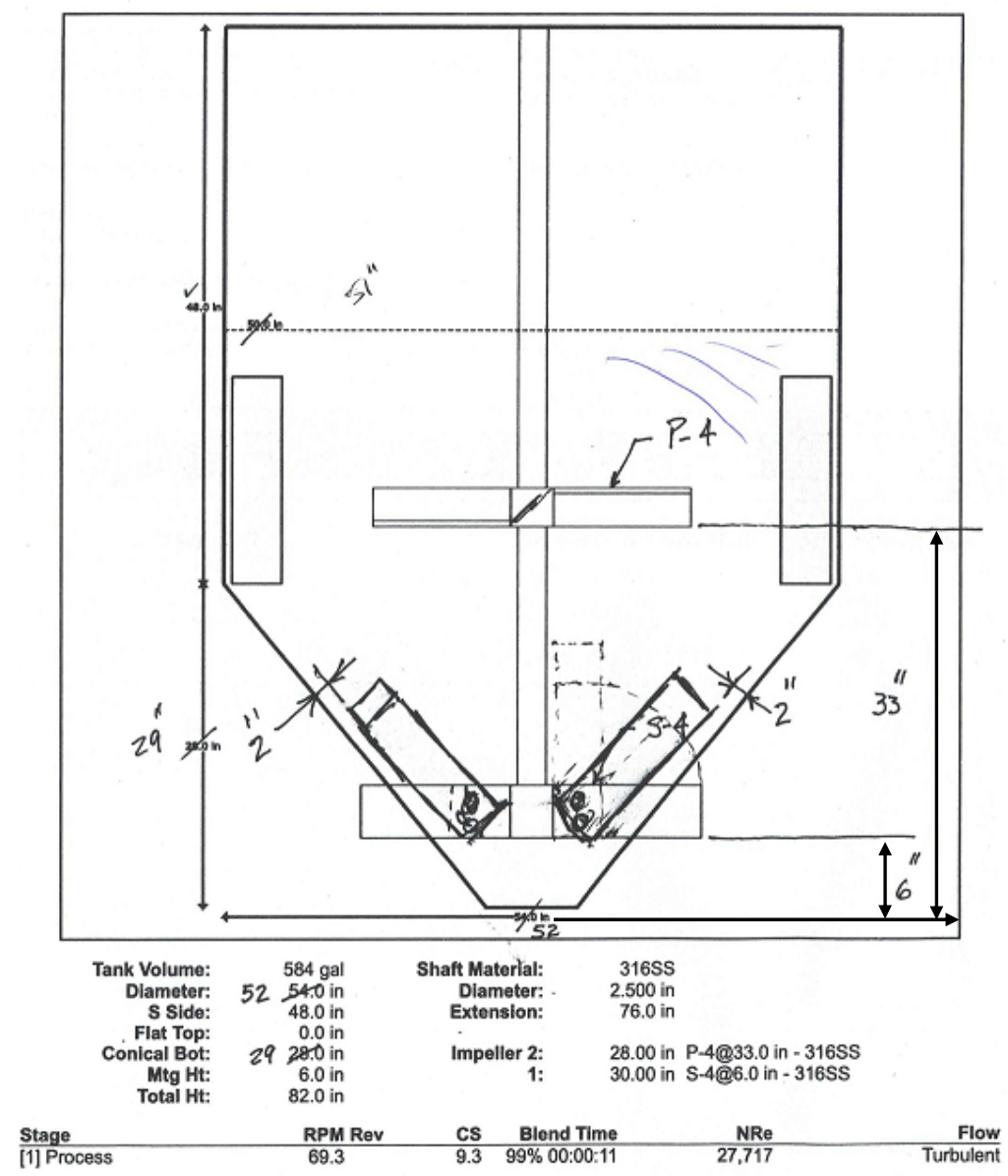

Figure 2-5. Proposed agitator design by Chemineer.

\subsection{Scaled Hopper}

Geometric similarity is essential to ensure both kinematic (tip speed) and dynamic (Reynolds number, Froude number, etc.) similarities between two different scales. ${ }^{11,12,13,14,15}$ Savannah River National Laboratory (SRNL) selected a scale such that the inside diameter (ID) of cylindrical section of the vessel is 30 inches. This selection was based on the operations and placement of the radar level instrument on top of the hopper such that wall effects would not impact its operations. Other vessel scales of 24, 30 and 36 inch ID diameters were considered, however it was determined that 30 inches was the most appropriate scale based on volume of material and functionality of the radar instrument. The inside diameter of the proposed hopper from Saltstone Engineering (SE) has a dimension of 51 inches, ${ }^{9}$ therefore the geometric scaling ratio is $30 / 51$ the ratio of the test vessel diameter divided by the proposed hopper diameter.

The scaled impeller shaft was designed to allow placement of the bottom impeller at the scaled axial positions of 6 or 10 inches from the bottom of the tank while maintaining the same distance between the top and bottom impellers, based on the full scale dimensions.

The scaling parameter (30/51) was applied to the critical dimensions from the SE design and Chemineer drawings and these dimensions are provided in Table 2-2 along with the 30 -inch scale 
target and as-tested dimensions. Differences between the target and as-tested 30-inch scale dimensions are as follows:

- Tank discharge diameter of the as-tested is smaller than targeted. A 4-inch schedule 40 pipe was selected due to availability and it was the pipe dimension most similar to the calculated discharge value. This resulted in the depth of the conical section in the 30 inch scale to be deeper than the targeted value (Figure 2-6). The drawing on the left of Figure 2-6 shows how the 4 -inch schedule 40 pipe is scaled up to the full scale, which shows the bottom (truncated conical) to be lower with a smaller discharge. The drawing on the right of Figure 2-6 shows where the bottom reference point is considered in the 30 -inch scaled hopper.

- The placement of the impeller is slightly greater than the 6-inch placement. Impeller placement was confirmed after testing was completed and is consistent with the measured off-set of the bottom impellers from the conical wall.

- The shaft is 0.4 inches off-center (e). The eccentricity ( $\mathrm{e} / \mathrm{T}$, where $\mathrm{T}=\operatorname{tank}$ diameter) of this shaft is $0.4 / 30$ or 0.0133 . Review of literature ${ }^{16,17}$ for unbaffled tanks indicates that an increase in eccentricity will cause an increase in power consumption and decrease in agitation time, but typically the eccentricity must be at least 0.05 or greater for power consumption to increase by $10 \%$. As the impeller to tank diameter ratio increases, the power consumption increases. Due to the close tolerance between the bottom impeller and conical tank wall, it is expected that the power recorded will be conservative and the agitation profile will be minimally impacted. The eccentricity and close wall tolerance could provide additional off-axis loads to the impeller shaft.

Table 2-2 also provides the full scale placement of the agitators based on what was actually tested on the 30-inch scale and this information is in the last column of this table. Testing was performed close to the 6-inch bottom off-set based on the full scaled vessel. 
Table 2-2. Full scale and 30-inch designed and tested configuration

\begin{tabular}{|c|c|c|c|c|c|}
\hline \multirow[b]{2}{*}{ Parameter } & \multirow[b]{2}{*}{ Units } & \multirow[b]{2}{*}{$\begin{array}{l}\text { Full } \\
\text { Scale }\end{array}$} & \multicolumn{2}{|c|}{ 30-inch Scale } & \multirow{2}{*}{$\begin{array}{c}\text { Full Scale } \\
\text { From As- } \\
\text { Tested } 30 \text {-inch } \\
\text { Scale }\end{array}$} \\
\hline & & & Targeted & As-Tested & \\
\hline Tank Inside Diameter & Inches & 51 & 30 & 30 & 51 \\
\hline $\begin{array}{l}\text { Nominal Working Height } \\
\text { in Cylindrical Section }\end{array}$ & Inches & 23.7 & 13.95 & 14 to 15 & 23.7 \\
\hline Conical Height & Inches & 27.04 & 15.9 & $17.6^{*}$ & 27.04 \\
\hline Angle of conical section & Degrees & 51.5 & 51.5 & 51.5 & 51.5 \\
\hline Nominal Working volume & Gallons & 305 & 62 & 62 to 67 & 305 \\
\hline Shaft thickness & Inches & 3 & $2 * *$ & 2 & 3 \\
\hline $\begin{array}{l}\text { Impeller location - bottom } \\
\text { of impeller to bottom of } \\
\text { tank }\end{array}$ & Inches & 6 & 3.52 & 3.75 & 6.38 \\
\hline $\begin{array}{c}\text { Impeller location - bottom } \\
\text { of impeller to apex }\end{array}$ & Inches & 10.97 & 6.45 & 6.68 & 11.36 \\
\hline $\begin{array}{c}\text { Distance between top and } \\
\text { bottom impeller }\end{array}$ & Inches & 27 & 15.88 & 15.88 & 27 \\
\hline Bottom Impeller & - & \multicolumn{4}{|c|}{51.5 degrees angled radial turbine } \\
\hline Impeller diameter & Inches & 30 & 17.65 & 17.65 & 30 \\
\hline Impeller width & Inches & 4 & 2.35 & 2.35 & 4 \\
\hline Off-set from conical section & Inches & 2.49 & 1.46 & $1.61 *$ & 2.73 \\
\hline Top Impeller & - & \multicolumn{4}{|c|}{45 degree pitch blade } \\
\hline Impeller diameter & Inches & 28 & 17.65 & 17.65 & 28 \\
\hline Impeller width & Inches & 5 & 2.94 & 2.94 & 5 \\
\hline \multicolumn{6}{|c|}{ Other Information } \\
\hline Shaft location & - & Central & Central & $\begin{array}{l}\text { Off-axis by } 0.4 \\
\text { inches* }\end{array}$ & Central \\
\hline Motor Horsepower & hp & 5 & 3 & 3 & - \\
\hline Shaft Speed & $\mathrm{rpm}$ & 78 & $161 * *$ & TBD & - \\
\hline Tank Discharge diameter & Inches & 7.98 & 4.69 & $4.026 *$ & 7.98 \\
\hline
\end{tabular}

* These differences are described in section 2.2

** Shaft size was provided and determined acceptable for testing only

$\mathrm{TBD}=$ to be determined during testing

Figure 2-6 shows the SRNL design using the input from SE and Chemineer's drawing for the full scale as well as the 30 -inch scale impeller systems.

A 2-inch diameter 316 stainless steel agitator shaft was used for testing the 30 -inch hopper. The maximum impeller speed was calculated from the maximum shaft speed assuming all the available horsepower was used. Torque and moment calculations were performed to determine the minimum shaft thickness required to support testing of the 30 -inch scale. The equations used in these calculations were obtained from chapters 6 and 21 of Reference 18 . The following assumptions and methods were also used to make these determinations:

- Turbulent flow conditions

- Fluid density of $1.8 \mathrm{~g} / \mathrm{ml}$.

- Turbulent power numbers for bottom radial blade is 3.96 and 1.27 for top 45 degree pitch blade for fully baffled conditions. 
- Horsepower from each impeller was determined using the following equation:

$$
P_{i}=\frac{N_{P, i} \rho\left(\frac{N}{60}\right)^{3} D_{i, m}^{5}}{745.7}
$$

Where: $P_{i}=$ power from the $i^{\text {th }}$ impeller $[\mathrm{hp}]$

$\mathrm{N}_{\mathrm{P}, \mathrm{i}}=$ turbulent power number [unitless]

$\rho=$ density of fluid $\left[\mathrm{kg} / \mathrm{m}^{3}\right]$

$\mathrm{L}_{\mathrm{i}}=$ distance from the bottom drive bearing to the $\mathrm{i}^{\text {th }}$ impeller [inches]

$\mathrm{D}_{\mathrm{i}, \mathrm{m}}=$ diameter of the $\mathrm{i}^{\text {th }}$ impeller [meters]

$\mathrm{N}=$ rotational speed $[\mathrm{rpm}]$

- Maximum impeller speed was calculated as $161 \mathrm{rpm}$ given that $3 \mathrm{hp}$ is available.

- Torque generated from each impeller:

$\mathrm{T}_{\mathrm{i}(\max )}=63025 \frac{\mathrm{P}_{\mathrm{i}}}{\mathrm{N}}$

Where: $\mathrm{T}_{\mathrm{i}(\max )}=$ the torque $\left[\mathrm{in}-1 \mathrm{~b}_{\mathrm{f}}\right]$

$\mathrm{P}_{\mathrm{i}}=$ the power from the impeller [hp]

- Maximum bending moment:

$\mathrm{M}_{\max }=\sum_{\mathrm{i}=1}^{\mathrm{n}} \frac{19000 \mathrm{P}_{\mathrm{i}} \mathrm{L}_{\mathrm{i}} \mathrm{f}_{\mathrm{H}_{\mathrm{i}}}}{\mathrm{ND}_{\mathrm{i}}}$

Where: $\mathrm{M}_{\max }=$ maximum bending moment $\left[\mathrm{in}-\mathrm{lb}_{\mathrm{f}}\right]$

$\mathrm{P}_{\mathrm{i}}=$ power from the $\mathrm{i}^{\text {th }}$ impeller [hp]

$\mathrm{L}_{\mathrm{i}}=$ distance from the bottom drive bearing to the $\mathrm{i}^{\text {th }}$ impeller [inches]

$\mathrm{D}_{\mathrm{i}}=$ diameter of the ith impeller [inches]

$\mathrm{f}_{\mathrm{H}_{\mathrm{i}}}=$ hydraulic service factor [see Table 21-2 for all conditions]

- The hydraulic service factor ranges from 1 to 7 in a continuous flow stream. A hydraulic service factor of 5 was used for this task, since this task was not a continuous process and testing was to last for 10 hours of operations. A hydraulic service factor of 7 is recommended for continuous service. Using of a safety factor of 7 and a $5 \mathrm{hp}$ motor results in a 3-inch agitator shaft for the full scale hopper.

- Allowable stresses for 316 stainless steel were obtained from Table 21-3.

- Equations 21-5 and 21-6 were used to determine the maximum shaft size, the larger of the two values calculated using these equations was the minimum shaft size requirement. The 2-inch shaft was determined to be acceptable.

The cavern model, equation [4] $]^{18}$, assumes that for a yield stress material and density, there is a critical agitator speed where fluid motion exists everywhere between the agitator shaft and walls of the vessel. This relation assumes that cavern height to diameter ratio is 0.4 and the impeller is located centrally in the cavern. The critical agitator speed was determined for a fluid with a yield stress of $21.5 \mathrm{~Pa}$ and density of $1.8 \mathrm{~g} / \mathrm{ml}$, power number and diameter of the impeller, and diameter of the tank vessel for both scales. For the full scale system, the rotational speed is 54 rpm, which is below the $67 \mathrm{rpm}$ specified by Chemineer. For the 30 -inch scaled system, the rotational speed is $92 \mathrm{rpm}$ and 0.77 horsepower, which is achievable with the motor/gearbox available for this testing. 


$$
\mathrm{N}_{\mathrm{C}}=\left(\frac{\pi^{2} \tau_{\mathrm{y}} \mathrm{T}^{3}}{1.36 \mathrm{~N}_{\mathrm{P}, \mathrm{i}} \rho \mathrm{D}^{5}}\right)^{\frac{1}{2}}
$$

Where: $\mathrm{N}_{\mathrm{C}}=$ Critical agitator speed for the cavern to reach the walls of the vessel (rpm)

Based on the results from testing and the type of agitation phenomena that is observed, scale-up relationships can be utilized to relate the two scales, based on either kinematic or dynamic correlations. A list of such correlations is provided in Table 2-3. The scale-up exponents in Table 2-3 are used in equation [5] to estimate the operating speed at full scale that would yield the same type of fluid phenomena observed in the smaller scale. Based on testing, only the correlation(s) that are applicable will be discussed in more detail in section 5.0 of this document.

$$
\mathrm{N}_{2}=\mathrm{N}_{1}\left(\frac{\mathrm{D}_{1}}{\mathrm{D}_{2}}\right)^{\mathrm{n}}
$$

Where: $\mathrm{N}_{\mathrm{i}}=$ Shaft rotational speed (rpm)

$\mathrm{D}_{\mathrm{i}}=$ Impeller diameter (inches)

$\mathrm{i}=$ scale $(1=$ scale, $2=$ full $)$

$\mathrm{n}=$ scale-up exponent

Table 2-3. Scale-up correlations for mixing vessels

\begin{tabular}{|c|c|c|}
\hline Parameter & Function & Scale-up Exponent \\
\hline Circulation time & $\frac{1}{N}$ & $\mathrm{n}=0$ \\
\hline Froude Number & $\frac{D N^{2}}{g}$ & $\mathrm{n}=1 / 2$ \\
\hline Power/volume (turbulent flow) & $\frac{N^{3} D^{5}}{D^{3}}$ & $\mathrm{n}=2 / 3$ \\
\hline Solids suspension & $N D^{3 / 4}$ & $\mathrm{n}=3 / 4$ \\
\hline Tip Speed or Cavern Mixing & $N D$ & $\mathrm{n}=1$ \\
\hline Weber Number & $\frac{\rho N^{2} D^{3}}{\sigma}$ & $\mathrm{n}=3 / 2$ \\
\hline Reynolds Number & $\frac{\rho N D^{2}}{\mu}$ & $\mathrm{n}=2$ \\
\hline
\end{tabular}




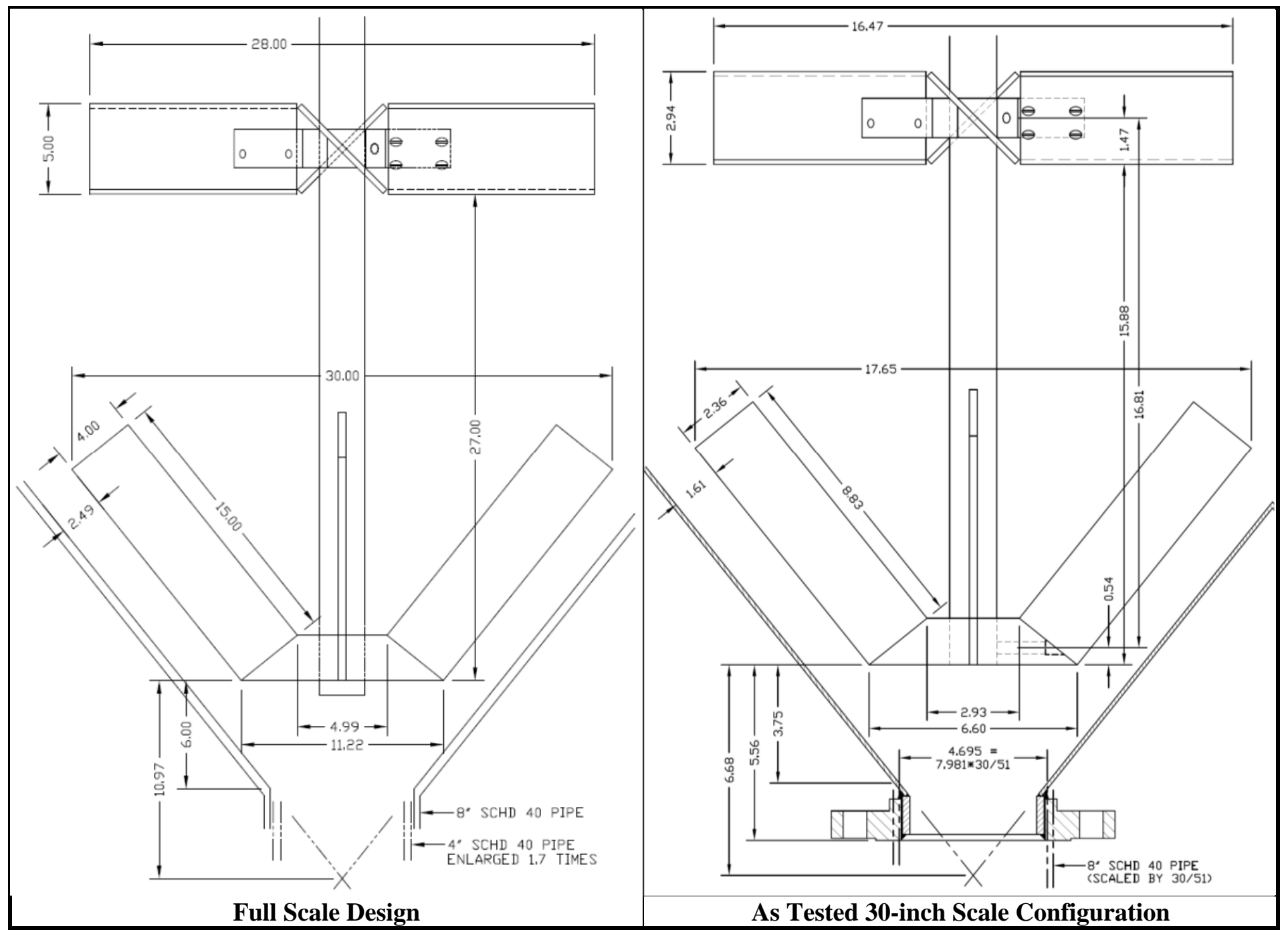

Figure 2-6. Full design and as tested 30-inch scale impeller layout. 


\subsection{Testing Impacts to Fluid Motion}

Agitator tests were performed in both static and dynamic conditions, to determine any differences in the fluid motion provided by the agitator as a result of differing processing conditions. In these tests, the recirculation rate for the scaled system was determined by maintaining approximately the same turnover ratio of the contents in the tank and is provided by equation [6]. The discharge rate of grout in the Saltstone facility ranges between 150 to $180 \mathrm{gpm}$. Using equation [6] and information from Table 2-2, the recirculation flow rate in the 30-inch scaled hopper will be between 30 to $37 \mathrm{gpm}$. These recirculation tests mimic the additions from the READCO mixer in the full scale; however the method of grout addition by the READCO mixer compared to the enlarged pipe used in the 30-inch scale is not a direct comparison. Methods for separating the recirculation flow into a splatter type of return into the 30-inch scale vessel was considered, but questions would still exist as to whether such a splatter device is representative of the READCO discharge characteristics. The pipe return will provide a steady and concentrated stream as compared to the READCO discharge.

$$
\frac{\mathrm{V}_{1}}{\dot{\mathrm{Q}}_{1}}=\frac{\mathrm{V}_{2}}{\dot{\mathrm{Q}}_{2}}
$$

Where: $\mathrm{V}_{\mathrm{i}}=$ Volume in tank (gallons)

$$
\dot{\mathrm{Q}}_{\mathrm{i}}=\text { Flow rate leaving vessel (gallons/min) }
$$

Maintaining the above relation results in an average velocity moving across the impeller on the 30 -inch scale to be $1.7(51 / 30)$ times smaller than the full scale.

A second test was performed to determine if the addition (dry addition) of dry premix into the hopper could be incorporated into the grout without causing a process upset. During this test, the radar and variable frequency drive (VFD) were monitored to determine if these instruments are sensitive enough to detect grout level and agitator response changes as a result of this process anomaly. It is assumed the dry addition occurs when the grout is at the nominal working volume and nominal operating conditions in the hopper.

Reference 1 is a calculation that determined 284 pounds of dry premix could be added to a working volume of 300 gallon for the full scale hopper. The mass addition of premix to the 30 inch scale was determined using equation [7], which assumes the same mass fraction of premix and density of grout in both scales (note that the result is that the densities cancel, assuming the densities are the same in the full and scaled processes at the start). The targeted quantity of premix added to the 30 -inch scale was 58 pounds. The dry premix is first added to the dry feeder with the slide gate closed. During the dry addition test, the slide gate was opened to its full position to discharge the premix as quickly as possible.

$$
\frac{\mathrm{m}_{\text {Pre }, 1}}{\mathrm{~V}_{1}}=\frac{\mathrm{m}_{\text {Pre }, 2}}{\mathrm{~V}_{2}}
$$

Where: $\mathrm{m}_{\text {Pre,i }}=$ mass of dry premix addition (pounds) 


\subsection{Test Fluids}

The 30-inch scaled hopper was tested and characterized with fluids having different physical properties that bound the expected properties of grout in the hopper (Table 2-4). Table 2-5 indicates the purpose of using each fluid during these tests. Fluids used in this task are air, water, xanthan gum, and grout. The non-Newtonian fluids, xanthan gum and Saltstone grout, were developed in the lab and their physical properties were measured using a Haake VT550 rheometer and density cup. These methods are consistent with the present methods for characterizing simulant grout properties. The properties of air and water were not recorded during these tests since their properties are well known. Flow tests were performed on the non-Newtonian fluids using 2-inch by 3-inch tall sections of piping on Lexan ${ }^{\mathrm{TM}}$ panels. The density of xanthan gum solution is similar to water and was not measured. Xanthan gum simulants were made to target 5 and $20 \mathrm{~Pa}$ fluids. From this point forward in the report, a fluid reported in units of Pa refers to Bingham Plastic yield stress unless otherwise noted. The water based grout was developed to provide a yield stress of approximately $5 \mathrm{~Pa}$ and to have a static gel time in excess of 1 hour by adding Daratard 17 (a set retarder and water reducer) to permit the performance of multiple tests (Table 2-4). The premix in the grout contains $10 \mathrm{wt} \%$ portland cement, $45 \mathrm{wt} \%$ fly ash, and 45 wt $\%$ slag and the water to premix ratio was 0.65 . The physical properties of the non-Newtonian fluids used during the actual tests are listed in Table 2-5. The rheological properties of the $5 \mathrm{~Pa}$ yield stress grout was tested before and after the dry feed addition to ensure that the additional dry feeds did not exceed the design yield stress of 21.5 Pa.

Table 2-4. Composition of xanthan gum and grout

\begin{tabular}{|c|c|c|c|}
\hline Fluid & Water (wt \%) & \multicolumn{2}{|c|}{ Xanthan Gum (wt \%) } \\
\hline 20 Pa Xanthan Gum & 98.00 & \multicolumn{2}{|c|}{2.00} \\
\hline 5 Pa Xanthan Gum & 99.25 & \multicolumn{2}{|c|}{0.75} \\
\hline Fluid & Water (wt \%) & Premix (wt \%) & $\begin{array}{c}\text { Daratard 17 } \\
\text { (wt \%) }\end{array}$ \\
\hline 5 Pa grout & 39.38 & 60.59 & 0.03 \\
\hline
\end{tabular}

Table 2-5. Fluids and test conditions for 30-inch scaled hopper

\begin{tabular}{|c|c|c|c|c|}
\hline $\begin{array}{c}\text { Test } \\
\#\end{array}$ & $\begin{array}{c}\text { Test } \\
\text { Condition }\end{array}$ & Fluid & $\begin{array}{c}\text { Yield Stress } \\
(\mathrm{Pa})\end{array}$ & $\begin{array}{l}\text { Density } \\
(\mathrm{g} / \mathrm{mL})\end{array}$ \\
\hline 0 & Static & Air & $\mathrm{n} / \mathrm{a}$ & $\approx 0.0012$ \\
\hline 1 & Static & Water & $\mathrm{n} / \mathrm{a}$ & $\approx 1.0$ \\
\hline 2 & Recirculation & Water & $\mathrm{n} / \mathrm{a}$ & $\approx 1.0$ \\
\hline 3 & Static & $\begin{array}{c}20 \text { Pa Xanthan } \\
\text { Gum }\end{array}$ & \multirow{2}{*}{$\sim 20$} & $\approx 1.0$ \\
\hline 4 & Recirculation & $\begin{array}{c}20 \mathrm{~Pa} \text { Xanthan } \\
\text { Gum }\end{array}$ & & $\approx 1.0$ \\
\hline 5 & Static & 5 Pa Xanthan Gum & \multirow{2}{*}{$\sim 5$} & 1.0 \\
\hline 6 & Recirculation & 5 Pa Xanthan Gum & & 1.0 \\
\hline 7 & Static & $5 \mathrm{~Pa}$ grout & \multirow{2}{*}{$\sim 5$} & 1.65 \\
\hline 8 & Recirculation & $5 \mathrm{~Pa}$ grout & & 1.65 \\
\hline 9 & Dry Addition & $5 \mathrm{~Pa}$ grout & $>5$ & 1.65 \\
\hline
\end{tabular}




\subsection{Scaled Hopper Equipment Description}

The scaled hopper system consists of a 30-inch ID tank and a re-circulation loop. The return from the recirculation loop is intended to simulate the grout entering the hopper from the READCO Mixer (see section 2.3 for additional details). The use of a recirculation loop instead of a once through process will significantly decrease the amount of grout and xanthan gum needed, generate less waste, and require less equipment to operate.

The Process and Instrumentation Diagram (P\&ID) for the 30-inch scaled hopper is shown in Figure 3-1. In addition to the tank and recirculation loop, the system includes a dry feeder for bulk additions to the tank, radar for level detection, a transfer pump (P2), and associated instrumentation and piping. Horizontal locations on top of the tank were scaled from the full scale drawings for the radar, the agitator, and the inlet to the tank (+/- $1 / 8 ")$. The final vertical elevation for the radar was established in the field so that its performance was optimized. The dry feeder was not scaled as it has no analog in the actual system. It was located as far as possible from the radar to minimize dust effects on radar performance at small scale.

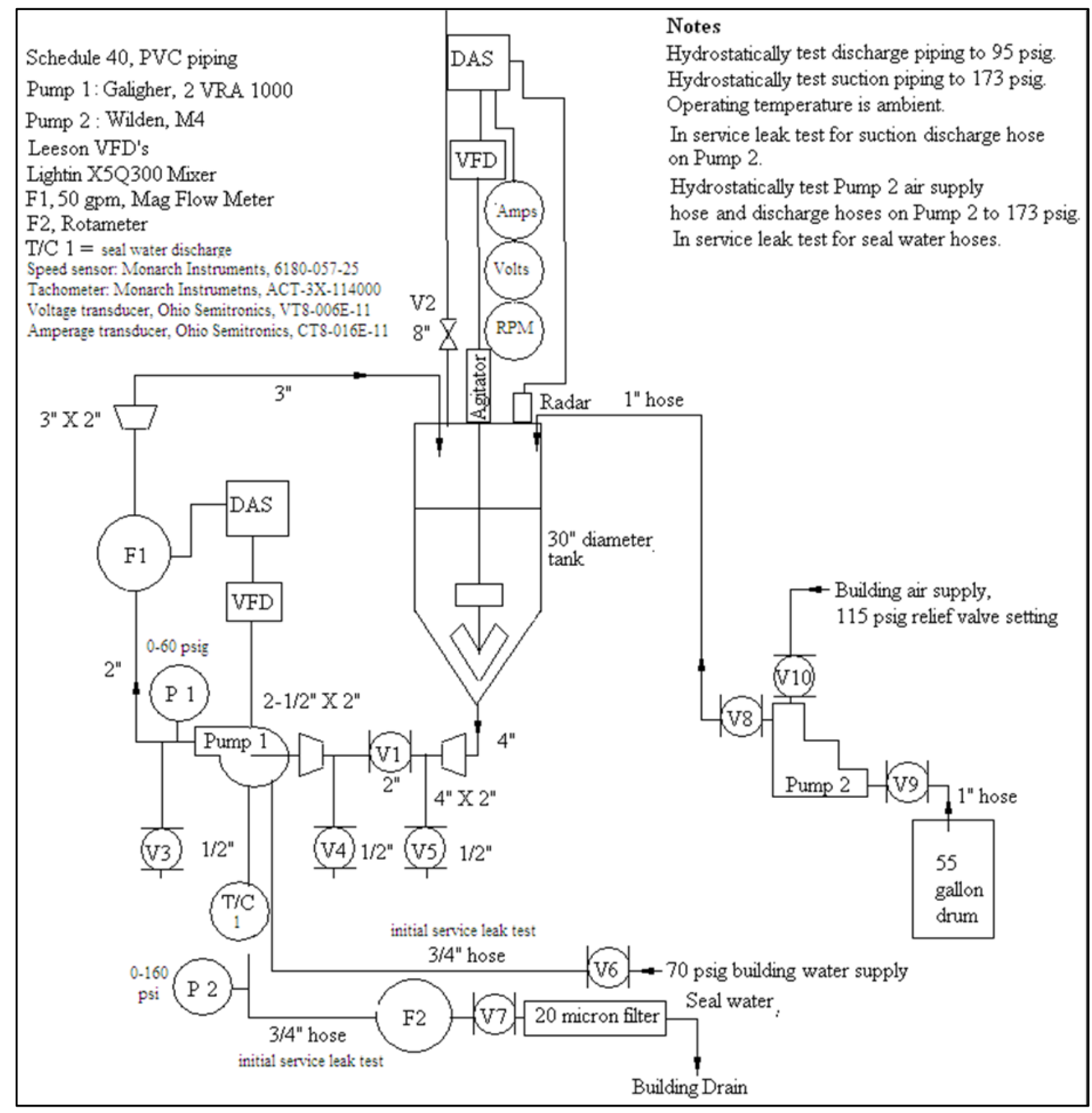

Figure 3-1. Scaled tank P\&ID. 


\subsection{Tank, Agitator, and Motor}

The hopper set up and the impellers are shown in Figure 3-2. The impellers and shaft are made of stainless steel and the tank is made of carbon steel. Details about the critical tank dimensions and impellers are provided in section 2.2. A 3 horsepower, 208 volt AC, $350 \mathrm{rpm}$ gearbox/motor (geared down from $1725 \mathrm{rpm}, 1800 \mathrm{rpm}$ rated) was used. The scaled agitator allows for the blade heights to be varied during testing to two different axial positions while maintaining the same distance between the impeller blades. Baffles were designed to be used in case the vortex caused inadequate fluid motion or created problems with the level sensor. The agitator shaft was designed using a hydraulic service factor of 5 at 3 horsepower (analyzed at 90 and $161 \mathrm{rpm}$ ) to compensate a locked rotor torque for a highly mixed tank with baffles installed. The simulants were added and removed via the discharge piping leaving the tank.

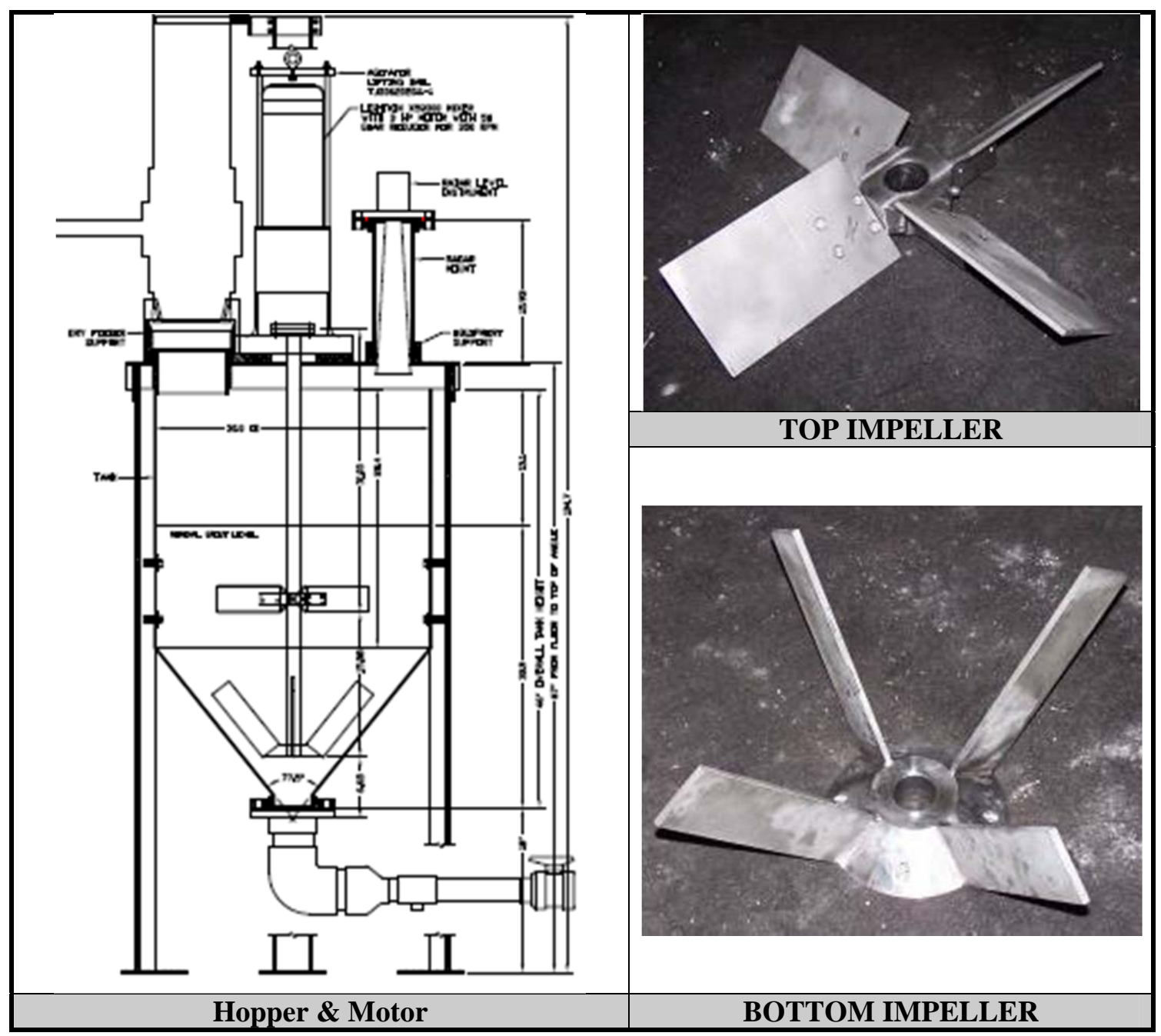

Figure 3-2. Tank and agitator setup in 30-inch hopper test. 


\subsection{Dry Feeder}

The dry feed addition was added using the dry feeder shown in Figure 3-3. The 8-inch knife valve was closed while the dry premix was added to the top of the dry feeder. The dry feeds were added to the feeder the day of testing in order to minimize the effect of bridging or packing of the dry solids. The bridging or packing of solids would disrupt the quick discharge of solids in to the tank, which can lead to inaccurate results regarding the incorporation of the solids into the grout. The dry feeder is attached to a connection on top of the tank, see Figure 3-4. The dry solids are discharged into the tank by opening the knife valve.

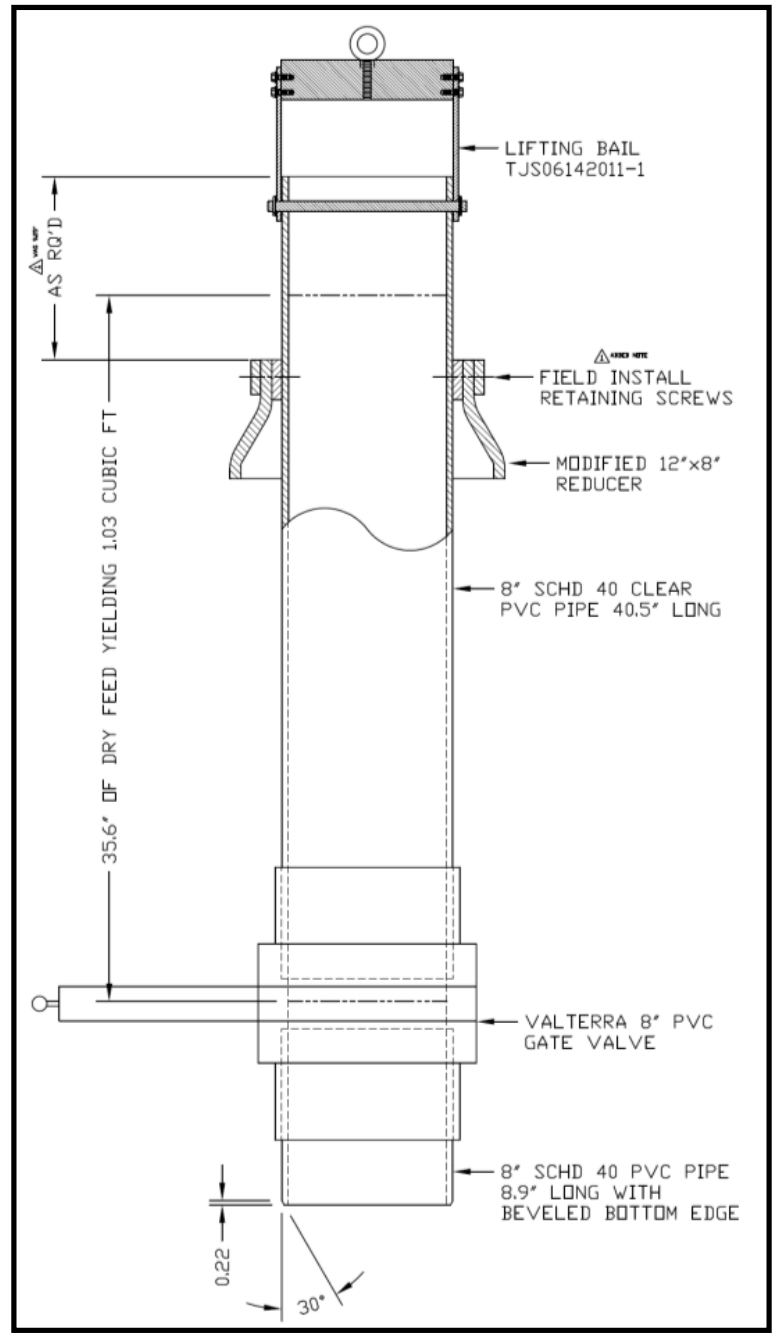

Figure 3-3. Dry feeder.

\subsection{Pumping/recirculation/sampling system}

A Galigher 2VRA1000 elastomer lined centrifugal pump was used to provide recirculation flow for all the fluids. The pump is located downstream of the 4-inch tank discharge line. The 2-inch discharge line exiting the pump is fitted with a magnetic flow meter. The pipe then expands to 4 inches prior to discharging the fluid at the top of the tank top as shown in Figure 3-4. Samples of the fluid are collected from the discharge location using a $500 \mathrm{~mL}$ beaker that can slide under the 
fluid leaving the recirculation line. Samples were pulled via the sampling port and analyzed for rheology, flow, and temperature.

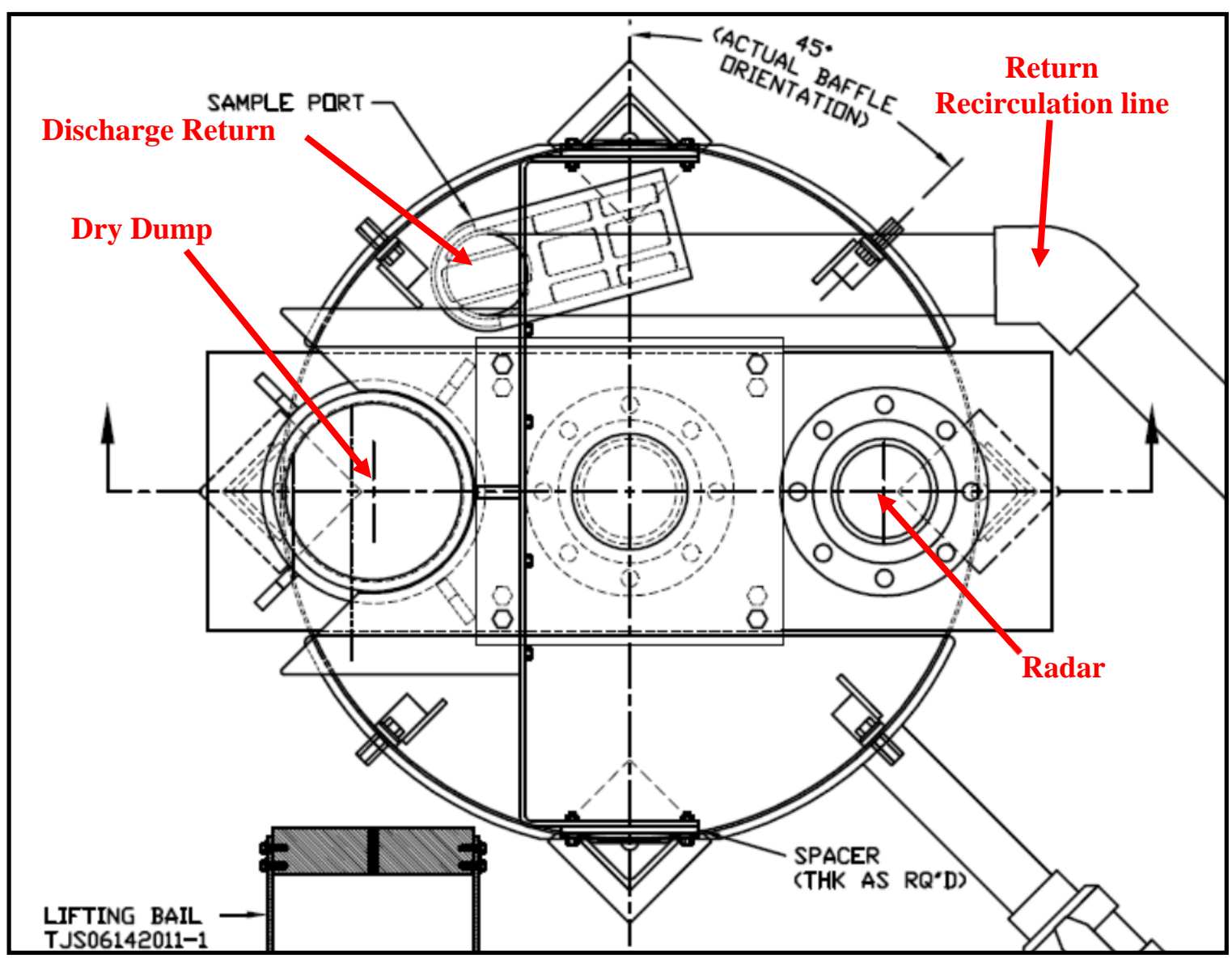

Figure 3-4. Top view of 30-inch hopper.

\subsection{Level Detection System}

The radar level sensor used in this task is a VegaPuls Series 62 Radar Level Sensor. The sensor was installed on the top of the hopper as shown in Figure 3-2 and Figure 3-4. The radar sensor has a stainless steel antenna horn, which has a $95 \mathrm{~mm}$ diameter (x), $480 \mathrm{~mm}$ in length (y), and projects an 8 degree angle beam, inclusive, at a frequency of $26 \mathrm{GHz}$ as shown in Figure 3-5. Radar level sensors use a microwave pulse (e.g. $26 \mathrm{GHz}$ ) that is transmitted from the antenna to determine the measured level of a solution (see Figure 3-5). The pulse travels to the surface of the solution and is reflected back to the antenna system. The radar sensor uses "Time of Flight" to determine the level measurement, i.e., the time for the signal to strike the surface of the solution and return. The returned signal strength of the radar is dependent upon the dielectric constant (Dk) of the solution in the vessel (microwaves are absorbed by low Dk products causing a loss of signal strength), the distance to the measured solution, the type of radar antenna system, foaming on the surface of the solution, and surface conditions (agitation or sparging). Excessive foaming and/or agitation can dampen and weaken the return signal. Radar energy can also be lost due to angles of repose of the solution surface. Other process conditions such as changes in temperature, pressure, vapor and/or condensation have minimal affect and therefore will not attenuate the radar signal strength. 
A measuring tape was mounted on the inside of the tank wall to provide a tank level at the wall of the vessel. The smaller the tape reading in inches, the higher the level of the fluid is against the tank wall.

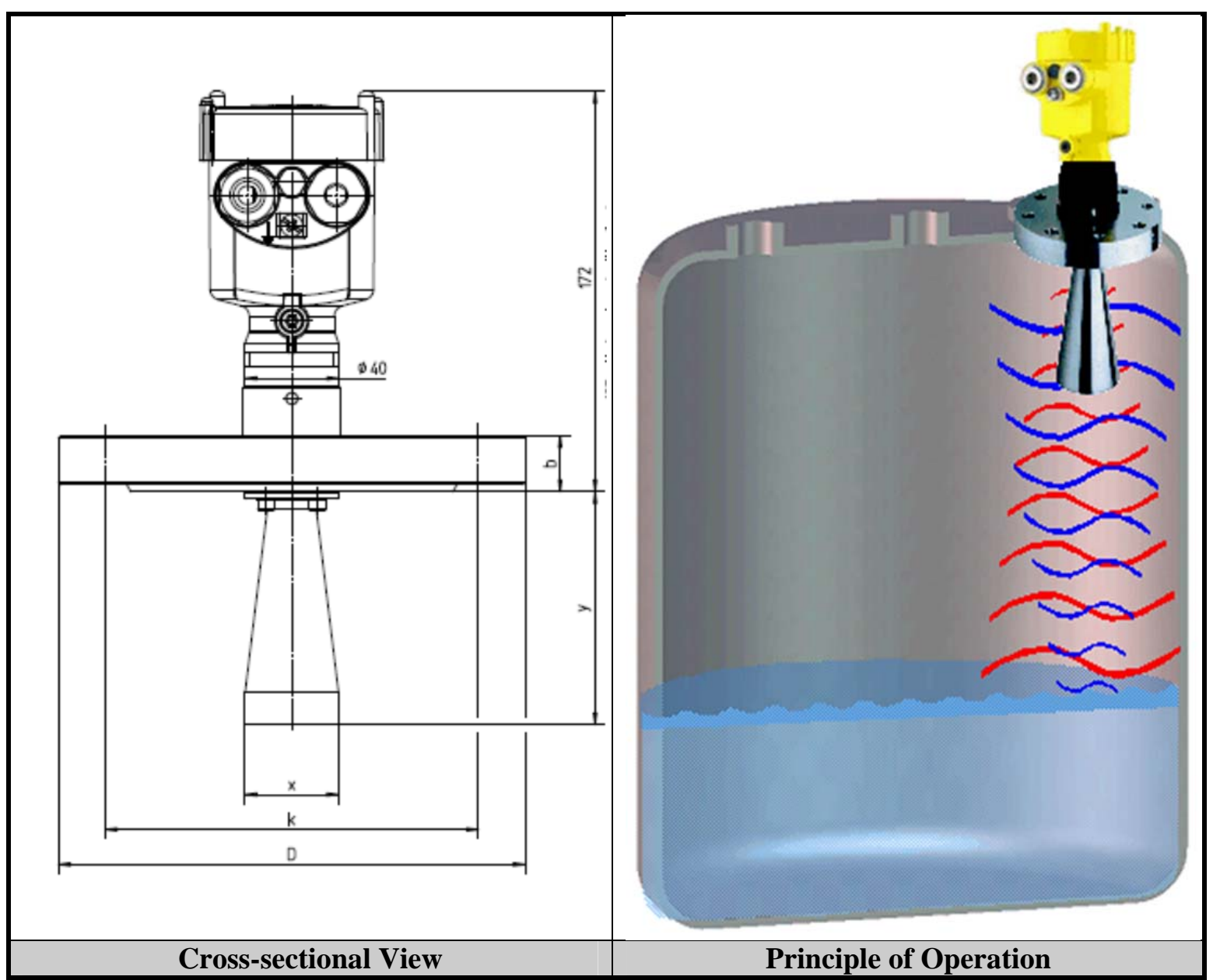

Figure 3-5. VegaPuls 62 radar level instrument.

\section{5 $\underline{\text { Agitator Speed Measurement }}$}

A ROS remote optical speed sensor (ROS-P) was used to measure the true rpm of the agitator motor. Reflective tape was placed on the shaft of the agitator motor and the sensor was optically aligned to provide a pulsed output for each revolution of the agitator shaft. The pulsed output of the sensor was connected to a digital panel meter which was configured to provide a speed measurement display in rpm and visual verification of rotation can be confirmed via a light pulse on the back side of the ROS-P as it passes the reflective tape. An SRNL calibration of the speed sensor and the digital meter (M\&TE\# 3-6072) was successfully performed with an accuracy of $+/-1 \mathrm{rpm}$. The $4-20 \mathrm{~mA}$ signal generated by the digital meter was interfaced to the process controller for monitoring and recording speed measurement information using the process control software. A scaling calibration was performed to verify that the speed measurement display and the information provided by the process controller were identical. 


\subsection{Flow Measurement}

An ABB Mini-Mag ${ }^{\circledR}$ electro-magnetic flow meter (EMF) was used to measure the flow rate of the fluids in the recirculation loop during the grout hopper testing. This flow meter consists of a non-ferromagnetic measuring tube with an electrically insulating inner surface, and magnetic coils and electrodes that are arranged diametrically on the tube and are in contact with the process liquid through the tube wall. The field coils of the EMF primary are excited with pulsed DC current to establish a magnetic field with induction perpendicular to the longitudinal axis of the tube. This magnetic field penetrates the measuring tube and the process liquid flowing through it, which must be electrically conductive. A voltage is induced in the process liquid which is proportional to the flow velocity of the process liquid. This signal voltage is picked up by electrodes and converted by a signal converter to a flow indication appropriate with the process.

The EMF is ideal to measure flow rates of process liquids or slurries with a specific minimum electrical conductivity as low as $50 \mu \mathrm{S} / \mathrm{cm}$. This flow meter was selected for this application due to resistance to abrasion and chemical corrosion (Tefzel ${ }^{\circledR}$ liner) and an accuracy of $(+/-0.1 \%$ of span) for completely filled pipes. Errors in measurement can occur due to entrained air and poorly-mixed media which cause unevenly distributed electrical conductivity. Since the EMF is a volumetric flow meter, any air dispersed in the liquid is measured as volume, and the total volume is displayed. Air entrainment can cause the displayed flow rate appear too high and may be unsteady. Locating the EMF on the delivery side of pump (not the suction side) will compress the entrained air so the real volumetric proportion of the air and the variations between measured total volume (including air) and actually transported volume of liquid are minimized.

The Series 10D1475J/S has a digital display integral with the flow meter for display of the flow rate (gpm). The flow rate is also converted to a 4-20 mA signal for interfacing to the process controller. A scaling calibration for the flow rate span $(0-50 \mathrm{gpm})$ was performed to verify that the flow meter display and the information recorded and displayed by the process controller were identical.

\subsection{Horsepower Determination}

To determine the horsepower (hp) required for moving fluids in a vessel, the shaft torque and rotational speed are required. The power calculated in this report for all test cases also include the mechanical loses in the gear box and bearing as well as inefficiencies in the VFD and agitator motor.

Voltage and amperage measurement modules were used to measure the line voltage and current of the agitator pump as shown in Figure 3-6. The Ohio Semitronics voltage module (model \#VT8-006E-11) and current module (model \#CT8-016E-11) provided a 4 - $20 \mathrm{~mA}$ output signal that was proportional to the measurement voltage and current. The signal was interfaced to the process controller for continuous display and recording. The theoretical hp for a 3-phase load can be calculated by using equation [8].

$$
h p_{\text {theoretical }}=\frac{V * I * 3^{(1 / 2)}}{746}
$$

Where: $\mathrm{V}=$ measured voltage (volts)

$\mathrm{I}=$ measured amperage (amps)

$\mathrm{hp}_{\text {theortetical }}=$ Calculated horsepower (hp) 
The theoretical hp value is significantly higher than the actual hp since the power factor of the agitator motor load is assumed to be unity.

A Leeson VFD was used to control the speed of the agitator motor and also provide an approximate measurement of the agitator load (hp). To enable measurement of the hp required for operation of the agitator motor, an analog output signal $\left(0-10 \mathrm{~V}_{\mathrm{dc}}\right)$ was available at the signal output terminal block of the VFD. This signal, which is proportional to the agitator motor load, was interfaced to the process controller. Since the drive output current rating (16.9 Amps at 208 $\mathrm{V}_{\mathrm{ac}}$ ) is higher than the motor full load current rating (8.2 Amps at $208 \mathrm{~V}_{\mathrm{ac}}$, the drive will not display the actual agitator motor load. The approximate $\mathrm{hp}$ of the agitator motor can be determined from the ratio of the drive output current rating to the motor full load current rating. For this application, the agitator motor was rated at $3 \mathrm{hp} \mathrm{(8.2} \mathrm{Amps} \mathrm{at} 208 \mathrm{~V}_{\mathrm{ac}}$ ), and therefore a load multiplier of 2.06 was used with the Leeson output to obtain the approximate agitator motor load and this value of horsepower is reported.

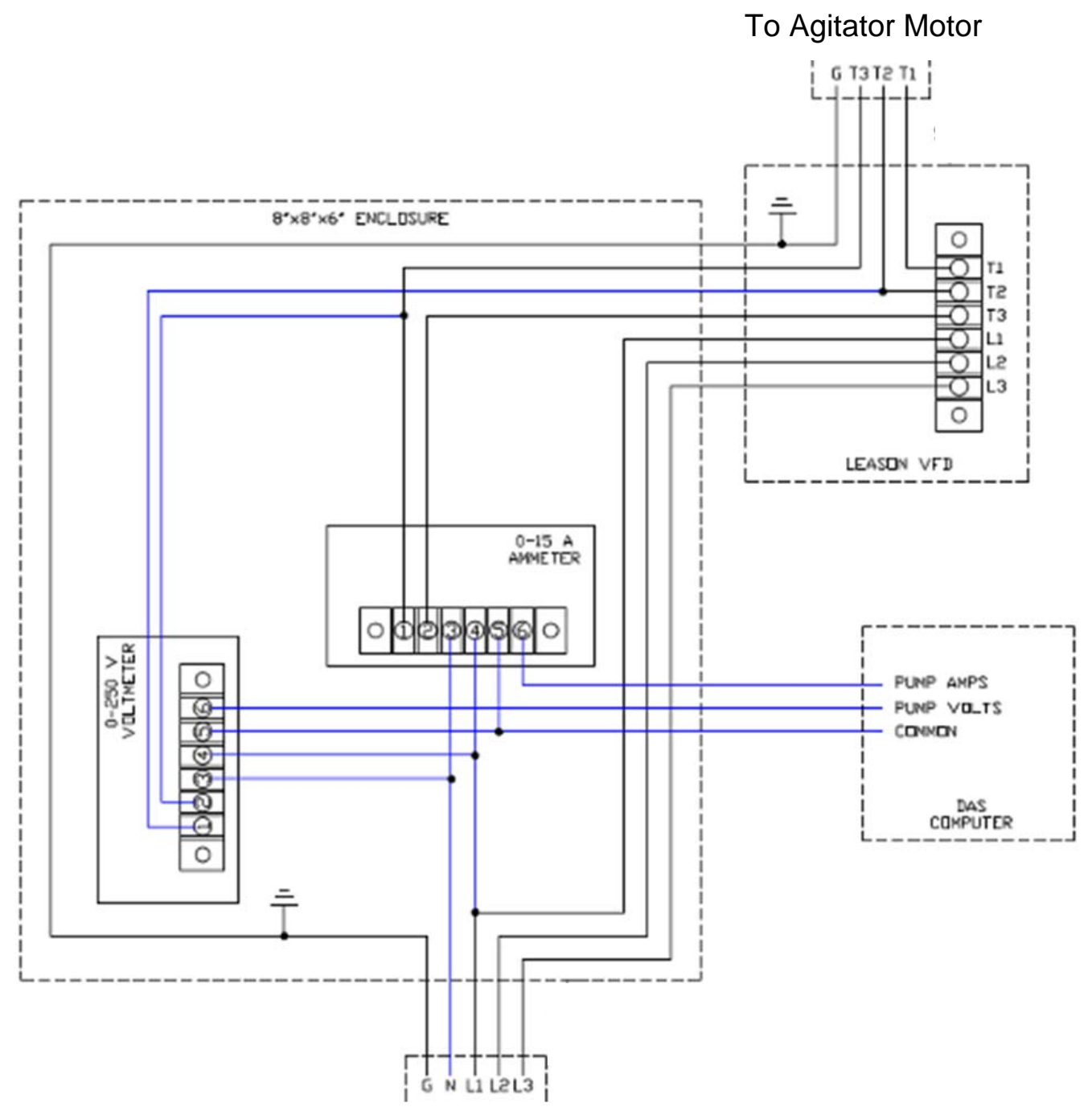

Figure 3-6. Schematic of voltage and amperage measurement module connections. 


\subsection{Data Acquisition System}

A Data Acquisition System (DAS), Figure 3-7, was used to control equipment and record data. The DAS controlled the agitator speed and pump speed using the variable speed drives. The following data was recorded in the DAS: recirculation flow rate, pump speed, tank level, agitator rpm's, agitator voltage, current, and horsepower. Temperature increases in the tank through mechanical or chemical means were expected to be negligible and as such, temperature in the tank was not measured. The temperatures of collected samples were measured.

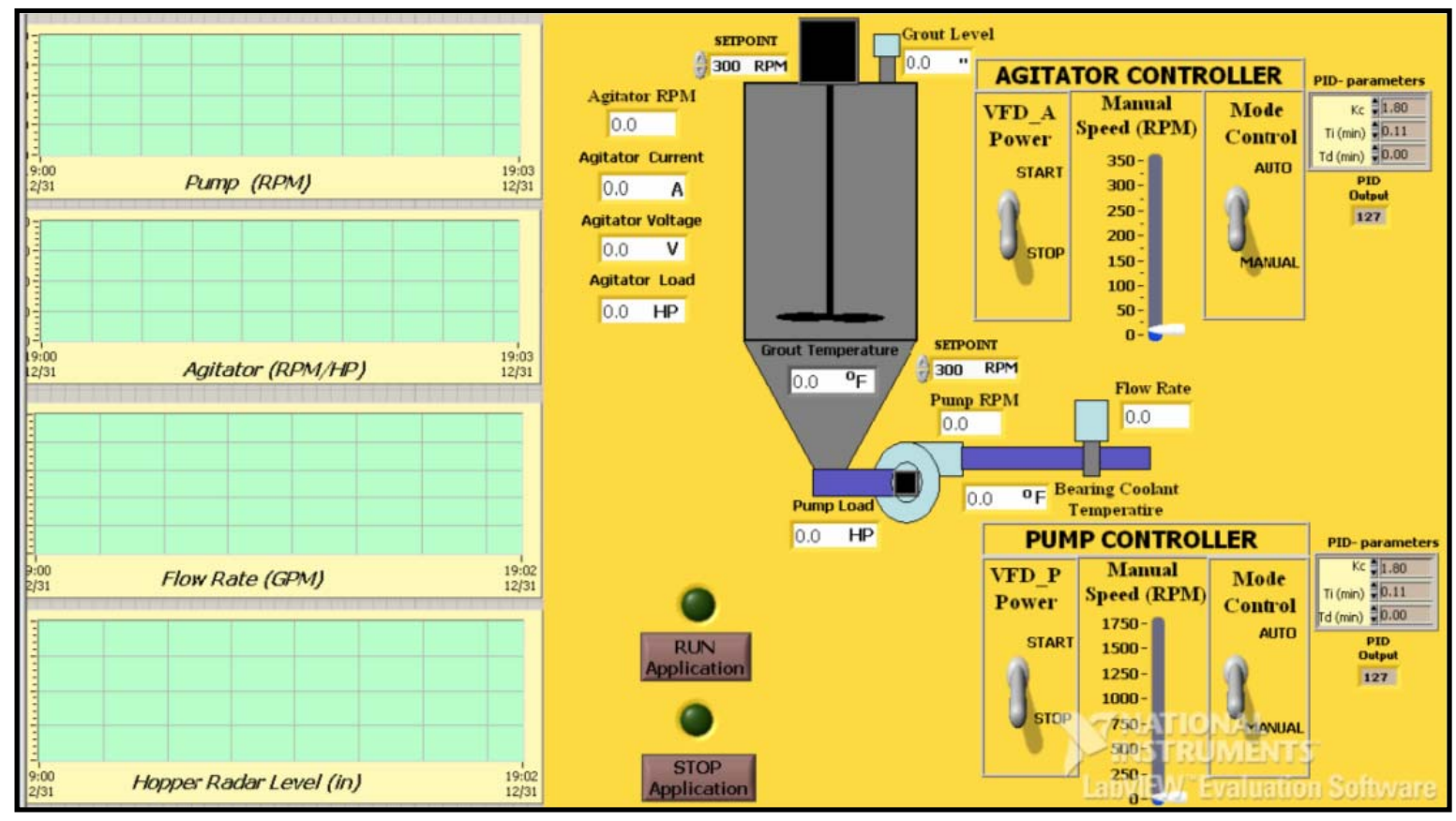

Figure 3-7. DAS graphical interface.

\subsection{Power Supply}

Power was supplied at 24 volt direct current (dc) and 120, 208, and 480 volt alternating current (ac) as needed. Power can be interrupted to the agitator and motor by manual STOP buttons on the DAS, a STOP button on the electrical panel supplied for this task, or STOP buttons on the VFD's. A splash screen was erected to protect 480 volt components from unexpected piping leaks.

\subsection{VFD's}

The maximum frequency parameter for VFD's to the pump motor was set at $60 \mathrm{~Hz}$, which set the maximum speed for the pump at $1750 \mathrm{rpm}$. For the agitator, the maximum speed was set to 146 rpm for additional conservatism. Over-speed controls to prevent runaway or inadvertent operations above design motor speeds are programmed into the VFD controller separate from the DAS.

Speed ramp-up for motors were used to control motor in-rush currents, high shaft torques, and fluid transients during start-ups. The "Accel" parameter within the VFDs was set to control the ramp up of the motor speed. A 30 second ramp-up to speed was implemented. 


\subsection{Experimental Procedure}

A total of six different fluids will be used for testing; air, water, 20 Pa xanthan gum, 5 Pa xanthan gum, $5 \mathrm{~Pa}$ grout, and $+5 \mathrm{~Pa}$ grout (having dry premix added to $5 \mathrm{~Pa}$ grout) in that order. For each of these fluids, other than the air, static and recirculation runs were performed. For the air run, a static run was performed to obtain baseline information on the initial installation conditions of the agitator. The $5 \mathrm{~Pa}$ xanthan gum fluid was obtained from the $20 \mathrm{~Pa}$ xanthan gum fluid after completing the $20 \mathrm{~Pa}$ xanthan gum runs. Fluid (20 Pa xanthan gum) was removed from the 30 inch tank and water added to bring the targeted xanthan gum concentration to the levels stated in Table 2-4. Due to air entrainment from the $20 \mathrm{~Pa}$ xanthan gum runs, antifoam (Dow Corning $3183 \mathrm{~A}$ ) was added (quantity not recorded) to accelerate the removal of bubbles. Fluid properties of this $5 \mathrm{~Pa}$ xanthan gum were measured for test conditions.

All tests were performed using an unbaffled vessel. Agitator speed was increased in $10 \mathrm{rpm}$ increments and was increased to the point where the fluid cleared the area just below the hub of the top impeller (air was an exception). The recirculation flow rate was targeted between 30 and 38 gallons per minute. The data was recorded using the DAS system. The fluid surface was monitored visually to determine if surface conditions would impact the tank radar level measurements. Baffles were available if the vortex was observed to affect the level measurements.

\subsection{Results and Discussion}

The physicals properties, flow cone results, and temperatures of the fluids tested in the 30 -inch hopper are provided in Table 5-1.

Table 5-1. Physical properties of test fluids

\begin{tabular}{|c|c|c|c|c|c|c|c|}
\hline Test & Condition & Fluid & $\begin{array}{c}\text { Plastic } \\
\text { Viscosity or } \\
\text { viscosity } \\
(\mathrm{cP})\end{array}$ & $\begin{array}{c}\text { Yield } \\
\text { Stress } \\
(\mathrm{Pa})\end{array}$ & $\begin{array}{c}\text { Density } \\
(\mathrm{g} / \mathrm{mL})\end{array}$ & $\begin{array}{c}\text { Flow } \\
\text { cone } \\
(\mathrm{cm})\end{array}$ & $\begin{array}{c}\text { Temp. } \\
\left({ }^{\circ} \mathrm{C}\right)\end{array}$ \\
\hline 0 & Static & Air & $\approx 0.001$ & $\mathrm{n} / \mathrm{a}$ & $\approx 0.001$ & $\mathrm{n} / \mathrm{a}$ & $\mathrm{n} / \mathrm{a}$ \\
\hline 1 & Static & Water & $\approx 1.0$ & $\mathrm{n} / \mathrm{a}$ & 1.0 & $\mathrm{n} / \mathrm{a}$ & $\mathrm{n} / \mathrm{a}$ \\
\hline 2 & Recirculation & Water & $\approx 1.0$ & $\mathrm{n} / \mathrm{a}$ & 1.0 & $\mathrm{n} / \mathrm{a}$ & $\mathrm{n} / \mathrm{a}$ \\
\hline 3 & Static & $\begin{array}{c}20 \text { Pa Xanthan } \\
\text { Gum }\end{array}$ & 55.6 & 18.9 & 1.0 & 18.5 & 29.2 \\
\hline 4 & Recirculation & $\begin{array}{c}20 \text { Pa Xanthan } \\
\text { Gum }\end{array}$ & 55.6 & 18.9 & 1.0 & 17.0 & 29.4 \\
\hline 5 & Static & $\begin{array}{c}5 \text { Pa Xanthan } \\
\text { Gum }\end{array}$ & 22.0 & 7.0 & 1.0 & 27.5 & 30.8 \\
\hline 6 & Recirculation & $\begin{array}{c}5 \text { Pa Xanthan } \\
\text { Gum }\end{array}$ & 22.0 & 7.0 & 1.0 & 28.0 & 31.2 \\
\hline 7 & Static & 5 Pa grout & 24.1 & 4.3 & 1.65 & 36.5 & 30.7 \\
\hline 8 & Recirculation & 5 Pa grout & 24.1 & 4.3 & 1.65 & 41.5 & 29.8 \\
\hline 9 & Dry Addition & +5 Pa grout & 41.5 & 7.6 & 1.65 & 36.5 & 30.2 \\
\hline
\end{tabular}


Data for both static and dynamic runs include the agitator speed and agitator power and tank level, including the average and standard deviation (SD). The percent standard deviation is also provided for the tank level. The dynamic runs also included the recirculation flow rate and pump speed (average and SD). The data sets for the dynamic runs were obtained from a pump speed run where the pump speeds were stable, since changes in pump speed occurred to maintain recirculation flow rate.

\subsection{Air Test}

During the air test, critical shaft speed (calculated at $325 \mathrm{rpm}$ ) as well as visual run out of the impeller/shaft were observed to determine proper installation. There were no instabilities or abnormal shaft deflections noted during this test. The speed and horsepower measured during this run are provided in Table 5-2. Additionally, when the impellers are rotating, the level instrumentation indicated an empty hopper. This is not the case when the impeller blades are not rotating and are directly below the radar level horn, resulting in a false level indication due to the agitator impeller.

Note that the horsepower consumption during the air test is greater than that of all the other runs. During this test, the bottom of the tank was open to the atmosphere (not connected to the recirculation line); hence it provided a path for air to be pulled through the vessel. The air movement generated by the agitator was noted at the observation port and this air movement was not present during the other fluid tests (e.g. surface motion on top of the vessel generated by the fluid did not translate to observable air motion at the observation port).

Table 5-2. Agitator speed and horsepower data for air run.

\begin{tabular}{|c|c|c|c|c|}
\hline \multicolumn{3}{|c|}{ Agitator Speed (rpm) } & \multicolumn{2}{c|}{ Power (hp) } \\
\hline Target & Avg. & SD & Avg. & SD \\
\hline 20 & 20.16 & 0.01 & 1.07 & 0.03 \\
\hline 30 & 29.84 & 0.01 & 0.95 & 0.02 \\
\hline 40 & 39.46 & 0.02 & 0.88 & 0.01 \\
\hline 50 & 49.16 & 0.02 & 0.84 & 0.00 \\
\hline 60 & 59.75 & 0.02 & 0.79 & 0.02 \\
\hline 70 & 70.50 & 0.03 & 0.78 & 0.00 \\
\hline 80 & 81.21 & 0.19 & 0.77 & 0.00 \\
\hline 90 & 89.88 & 0.03 & 0.77 & 0.00 \\
\hline 100 & 99.53 & 0.04 & 0.77 & 0.00 \\
\hline 110 & 110.19 & 0.04 & 0.77 & 0.00 \\
\hline 120 & 119.82 & 0.08 & 0.77 & 0.00 \\
\hline 130 & 129.55 & 0.27 & 0.77 & 0.00 \\
\hline 140 & 141.33 & 0.06 & 0.78 & 0.01 \\
\hline
\end{tabular}

\subsection{Water Runs}

During initial testing with water, the level was increased in approximately $25 \mathrm{lb}$ increments (approximately 1 inch of tank level) once the water level in the grout hopper reached the cylindrical section of the tank. The results for the static and dynamic water runs are provided in Table 5-3 and Table 5-4 respectively. The radar tank level compared to agitator speed is provided in Figure 5-1 and Figure 5-2 for the static and dynamic runs. 
Visual observations and manual level measurements of the water level at the side of the tank are provide in Table 5-5 and Table 5-6 and pictures for each condition of agitation are provided in Appendix A for the static runs and Appendix B for the recirculation runs. Review of the tables and figures are:

- Visual observations from both tests showed that as the agitator speed increased, a central vortex starts to develop to a point where the top impeller was exposed. This occurred at approximately $90 \mathrm{rpm}$.

- The radar level versus agitator speed shows that as the agitator speed increases, the general trend was an increased variation in the level measurement. Note: Radar level measurements were recorded at 1 second intervals without averaging, therefore the variation in level measurement was more apparent.

- The agitator power for the static test continually decreased as the agitator speed increased.

- The agitator power for the recirculation test initially decreased and then slightly increased to a stable value.

- During the recirculation test, as the agitator speed increased, the recirculation flow rate decreased while maintaining the same pump speed. To maintain the required recirculation flow rate, a higher pump speed was required as the agitator speed increased.

- Pump speed increased to maintain flow rate as the agitator speed increased. The recirculation loop could be exacerbating air entrainment.

- The level in the grout hopper, indicated by a measuring tape within the tank, was compared to the radar level measurement. All static level measurements indicated by the radar sensor were within $+/-13 \mathrm{~mm}$.

- The large tank level outliers in the Figure 5-1 and Figure 5-2, such as 37 to 39 inches of tank level recorded by the radar were not visually observed during testing. In addition, the vortex shape did not vary more than one inch in height at any given speed.

- Splashing occurred during the recirculation run and wetted the internal surfaces of the tank.

- For agitator speeds between 50 to $80 \mathrm{rpm}$ without recirculation, the tank level changed 0.5 to 1.5 inches (using the tape measure). Using the radar, tank level indication changed between 0.83 to 1.41 inches in height. The reference measurement is the level of the fluid at $20 \mathrm{rpm}$.

- For agitator speeds between 50 to $80 \mathrm{rpm}$ with recirculation, the tank level changed 0.75 to 1.875 inches (using the tape measure). Using the radar, tank level indication changed between 0.65 to 1.45 inches. The reference measurement is the level of the fluid at $20 \mathrm{rpm}$.

- As the vortex gets deeper, the top impeller does not appear to aid in keeping the fluid in motion throughout the vessel.

Table 5-3. Static water run: agitator speed and power and tank level data

\begin{tabular}{|c|c|c|c|c|c|c|c|}
\hline \multicolumn{3}{|c|}{ Agitator Speed (rpm) } & \multicolumn{2}{c|}{ Agitator Power (hp) } & \multicolumn{3}{c|}{ Tank Level (inches) } \\
\hline Target & Avg. & SD & Avg. & SD & Avg. & SD & RSD \\
\hline 20 & 20.35 & 0.03 & 0.69 & 0.02 & 32.38 & 0.03 & 0.1 \\
\hline 30 & 30.00 & 0.02 & 0.63 & 0.01 & 32.59 & 0.08 & 0.2 \\
\hline 40 & 40.62 & 0.02 & 0.59 & 0.01 & 32.94 & 0.09 & 0.3 \\
\hline 50 & 50.32 & 0.03 & 0.55 & 0.00 & 33.21 & 0.21 & 0.7 \\
\hline 60 & 60.94 & 0.03 & 0.55 & 0.00 & 33.39 & 0.25 & 0.7 \\
\hline 70 & 70.58 & 0.03 & 0.53 & 0.00 & 33.53 & 0.48 & 1.4 \\
\hline 80 & 80.30 & 0.03 & 0.53 & 0.00 & 33.79 & 0.38 & 1.1 \\
\hline 90 & 89.91 & 0.04 & 0.53 & 0.00 & 34.18 & 0.83 & 2.4 \\
\hline 100 & 99.59 & 0.03 & 0.54 & 0.01 & 34.48 & 0.80 & 2.3 \\
\hline 110 & 111.12 & 0.04 & 0.55 & 0.00 & 34.84 & 0.61 & 1.7 \\
\hline
\end{tabular}


Table 5-4. Recirculation water run: agitator speed and power, tank level, recirculation flow and pump speed test

\begin{tabular}{|c|c|c|c|c|c|c|c|c|c|c|c|}
\hline \multicolumn{4}{|c|}{ Agitator Speed (rpm) } & \multicolumn{2}{c|}{$\begin{array}{c}\text { Agitator Power } \\
\text { (hp) }\end{array}$} & \multicolumn{2}{c|}{ Grout Level (inches) } & \multicolumn{2}{c|}{$\begin{array}{c}\text { Flow Rate } \\
(\text { gpm) }\end{array}$} & \multicolumn{2}{c|}{$\begin{array}{c}\text { Pump Speed } \\
\text { (rpm) }\end{array}$} \\
\hline Target & Avg. & SD & Avg. & SD & Avg. & SD & RSD & Avg. & SD & Avg. & SD \\
\hline 20 & 20.27 & 0.02 & 0.68 & 0.02 & 31.71 & 0.19 & 0.6 & 31.8 & 0.5 & 500.3 & 0.0 \\
\hline 30 & 30.89 & 0.02 & 0.62 & 0.01 & 31.80 & 0.18 & 0.6 & 30.6 & 0.1 & 500.2 & 0.0 \\
\hline 40 & 40.48 & 0.02 & 0.60 & 0.00 & 32.05 & 0.18 & 0.5 & 29.8 & 0.2 & 500.2 & 0.0 \\
\hline 50 & 50.15 & 0.02 & 0.56 & 0.01 & 32.36 & 0.23 & 0.7 & 29.0 & 0.2 & 500.2 & 0.0 \\
\hline 60 & 60.77 & 0.02 & 0.55 & 0.00 & 32.44 & 0.36 & 1.1 & 32.6 & 0.4 & 521.9 & 0.0 \\
\hline 70 & 70.40 & 0.02 & 0.54 & 0.01 & 32.84 & 0.32 & 1.0 & 31.3 & 0.1 & 521.8 & 0.0 \\
\hline 80 & 80.12 & 0.03 & 0.53 & 0.01 & 33.16 & 0.38 & 1.2 & 30.2 & 0.1 & 521.8 & 0.0 \\
\hline 90 & 90.68 & 0.04 & 0.54 & 0.01 & 33.70 & 0.90 & 2.7 & 34.1 & 0.6 & 546.9 & 0.5 \\
\hline 100 & 100.31 & 0.05 & 0.55 & 0.00 & 33.80 & 0.39 & 1.1 & 32.6 & 0.2 & 546.0 & 0.9 \\
\hline 110 & 109.94 & 0.04 & 0.55 & 0.00 & 34.27 & 0.90 & 2.6 & 30.8 & 0.1 & 546.5 & 0.9 \\
\hline
\end{tabular}

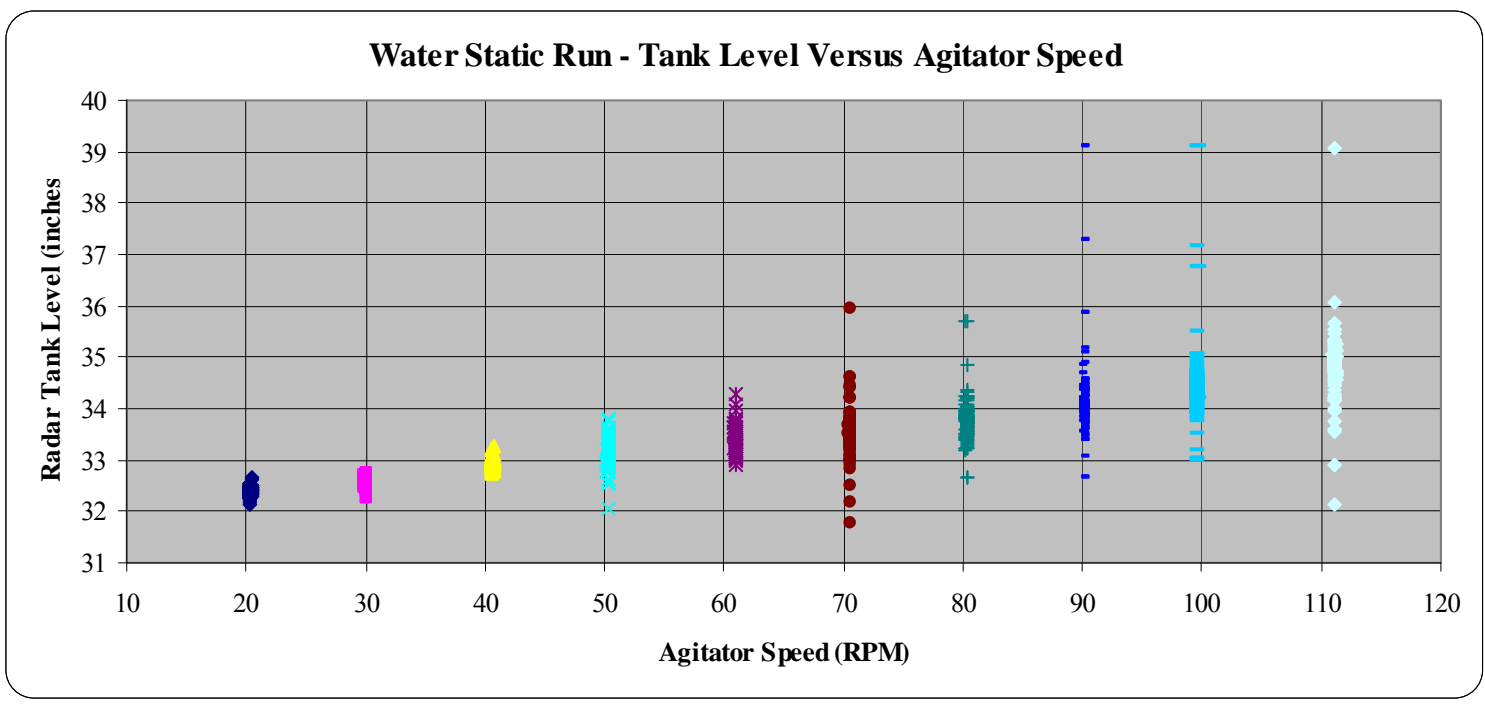

Figure 5-1. Water static run - radar tank level versus agitator speed. 


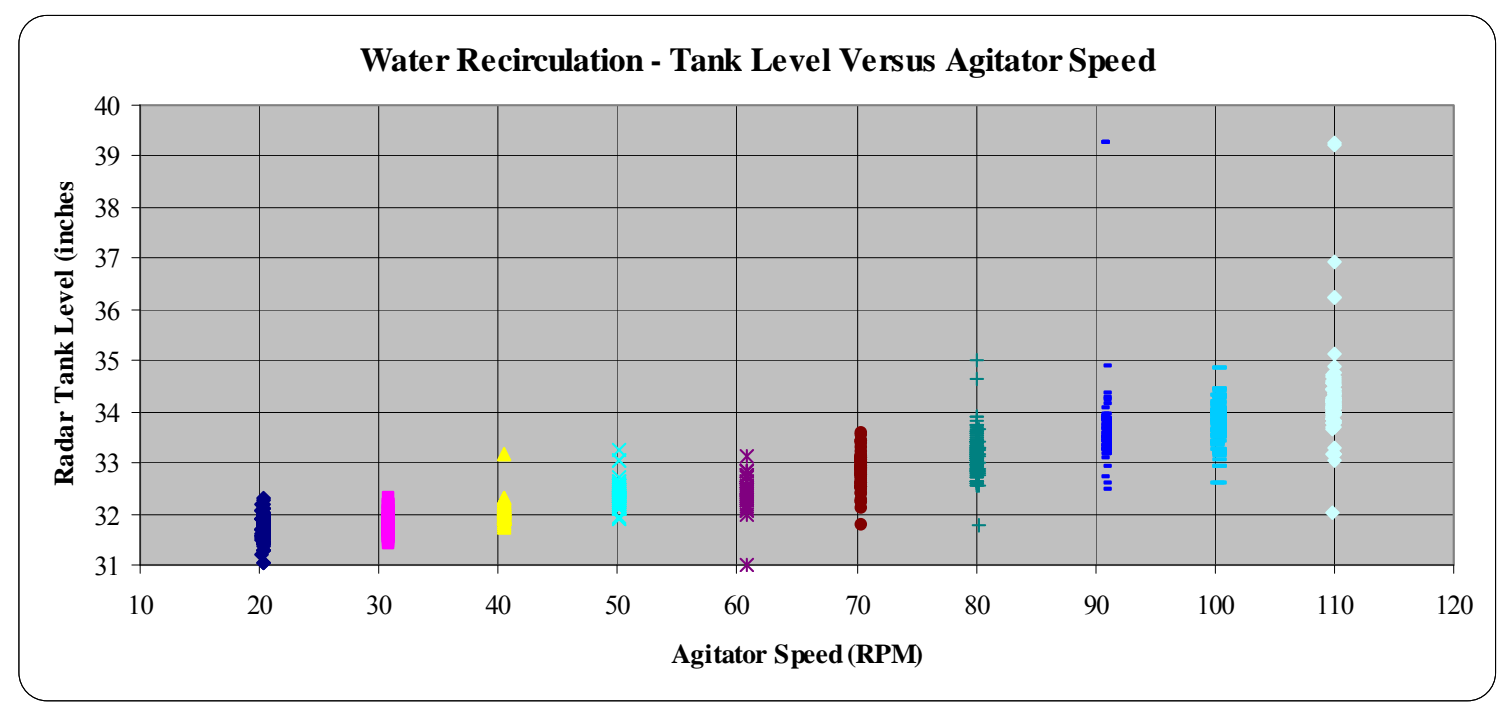

Figure 5-2. Water Recirculation Run - Radar Tank Level Versus Agitator Speed

Table 5-5. Static Water Run: Tape Measure and Visual Observation.

\begin{tabular}{|c|c|l|}
\hline rpm & $\begin{array}{c}\text { Tape level } \\
\text { (in) }\end{array}$ & \multicolumn{1}{|c|}{$\begin{array}{l}\text { Visual Observations and Notes } \\
\text { (as recorded in the notebook and commentary on videos taken during testing) }\end{array}$} \\
\hline 20 & 13.0 & $\begin{array}{l}\text { Fluid motion throughout, surface is moving, though not rapidly, no observable } \\
\text { vortex. }\end{array}$ \\
\hline 30 & 13.0 & Overall fluid motion has increased as compared to 20 rpm, no observable vortex. \\
\hline 40 & 12.625 & $\begin{array}{l}\text { Very defined surface flow field starting at the wall and moving towards the shaft, } \\
\text { very slight vortex. }\end{array}$ \\
\hline 50 & 12.5 & Flow field on surface is strong, vortex is slightly larger. \\
\hline 60 & 12.0 & $\begin{array}{l}\text { Agitation is more intense as compared to 50 rpm. The centrally located vortex is } \\
\text { well-defined. }\end{array}$ \\
\hline 70 & 11.75 & The vortex is defined without any air entrainment. \\
\hline 80 & 11.5 & $\begin{array}{l}\text { The vortex is still above top impeller, no active air entrainment. Oscillation of the } \\
\text { surface was noted and is potentially due to slight off set of the agitator shaft. }\end{array}$ \\
\hline 90 & 10.75 & \begin{tabular}{l} 
The vortex is at the top of the top impeller hub, no active air entrainment. \\
\hline 100
\end{tabular} \\
10.25 & $\begin{array}{l}\text { The vortex is below the top impeller hub, active air entrainment can be observed and } \\
\text { heard. }\end{array}$ \\
\hline 110 & 9.5 & $\begin{array}{l}\text { Vortex is now below a good fraction of the top impeller and the shaft below top } \\
\text { impeller is exposed. The top impeller is essentially doing no agitation or impacting } \\
\text { the vortex. }\end{array}$ \\
\hline
\end{tabular}


Table 5-6. Recirculation water run: tape measure and visual observation.

\begin{tabular}{|c|c|l|}
\hline rpm & $\begin{array}{c}\text { Tape level } \\
\text { (in) }\end{array}$ & \multicolumn{1}{c|}{$\begin{array}{c}\text { Visual Observations and Notes } \\
\text { (as recorded in the notebook and commentary on videos taken during testing) }\end{array}$} \\
\hline 20 & 13.875 & $\begin{array}{l}\text { Fluid motion throughout, surface is moving, though not rapidly, no observable } \\
\text { vortex. The recirculation flow returning to the top of the tank is generating more } \\
\text { surface motion and generating air bubbles below surface. Bubbles generated } \\
\text { from recirculation line seem to easily disengage from the water. Splashing is also } \\
\text { occurring. }\end{array}$ \\
\hline 30 & 13.625 & $\begin{array}{l}\text { Overall fluid motion has increased as compared to 20 rpm, no observable vortex } \\
\text { or air entrainment. }\end{array}$ \\
\hline 50 & 13.375 & $\begin{array}{l}\text { Very defined surface flow field starting at the wall and moving towards the shaft, } \\
\text { very slight vortex. Agitator flow seems to be taking over the surface motion and } \\
\text { air entrainment could be occurring. }\end{array}$ \\
\hline 60 & 12.875 & $\begin{array}{l}\text { Flow field on surface is strong, vortex is slightly larger. More air seems to be } \\
\text { entrained. }\end{array}$ \\
\hline 70 & 12.5 & $\begin{array}{l}\text { Agitation is more intense as compared to 50 rpm. The centrally located vortex is } \\
\text { well-defined. More air seems to be entrained due to bubbles generated by the } \\
\text { recirculation line and entrained by the flow generated by the agitator. }\end{array}$ \\
\hline 80 & 12.0 & $\begin{array}{l}\text { Well defined vortex, hard to say if bubbles at the surface are being entrained by } \\
\text { this vortex. }\end{array}$ \\
\hline 90 & 11.75 & $\begin{array}{l}\text { The vortex is just above the top impeller. The recirculation line seems to impact } \\
\text { the size of the central vortex, baffle-like response. }\end{array}$ \\
\hline 100 & 11.25 & The vortex is at the top of the top impeller hub. \\
\hline 110 & 10.5 & $\begin{array}{l}\text { The vortex is below the top impeller hub. } \\
\text { impeller is exposed. The top impeller is essentially doing no agitation or } \\
\text { impacting the vortex. Tank internals are wet from splashing. }\end{array}$ \\
\hline
\end{tabular}

\subsection{Xanthan Gum Runs}

The $5 \mathrm{~Pa}$ xanthan gum results are provided in Table 5-7 and Table 5-8, the radar level versus agitator speed in Figure 5-3 and Figure 5-4, and visual observations of the static and recirculation runs in Table 5-9 and Table 5-10, respectively. The same general observations as noted in the water runs (section 5.2) were observed during the xanthan gum runs. The only differences were more power was required to mix the $5 \mathrm{~Pa}$ xanthan gum than water and the xanthan gum did not wet the surfaces as well as water, due to the rheology of the fluid. Photos of the agitated surface for the $5 \mathrm{~Pa}$ results are provided in Appendix $\mathrm{C}$ and Appendix $\mathrm{D}$ for the static and recirculation runs, respectively.

The results for the $20 \mathrm{~Pa}$ xanthan gum are provided in Table 5-11 and Table 5-12. The radar level versus agitator speed is shown in Figure 5-5 and Figure 5-6, and visual observations are documented in Table 5-13 and Table 5-14 for both the static and recirculation runs. The same general observations as that noted in the water runs (Section 5.2) and $5 \mathrm{~Pa}$ runs were observed.

The differences were:

- More power was required to mix while achieving the same performance as compared to water or the $5 \mathrm{~Pa}$ xanthan gum.

- The vortex to the top impeller was not reached until $120 \mathrm{rpm}$ as compared to $90 \mathrm{rpm}$ for the water and $5 \mathrm{~Pa}$ xanthan gum.

- The recirculation pump speed decreased with increasing agitator speed, opposite to what occurred in the water and $5 \mathrm{~Pa}$ xanthan gum. A speculative reason is large bubbles can be 
entrained and the pressure on the discharge of the pump is not sufficient to compress the bubble, affecting the flow meter.

- A cavern calculation was performed using the rheological properties of the $20 \mathrm{~Pa}$ xanthan gum to determine the agitator speed at which the cavern reaches the wall. It was determined that at $36 \mathrm{rpm}$, motion would be observed on top surface. This is close to the observed value of $40 \mathrm{rpm}$ (Table 5-13).

- Agitation at $20 \mathrm{rpm}$ distributed large bubbles that were entrained during the recirculation test, showing that cavern agitation is occurring.

- $5 \mathrm{~Pa}$ xanthan gum, agitator speeds between 50 to $80 \mathrm{rpm}$ : Without recirculation, the tank level increased from 0.2 to 0.9 inches and the radar indicated a level increase from 0.3 to 1.0 inches. With recirculation, the tank level increased from 0.4 to 1.1 inches and the radar recorded an increased tank level from 0.1 to 1.0 inches. The reference measurement is the level of the fluid at $20 \mathrm{rpm}$.

- $20 \mathrm{~Pa}$ xanthan gum, agitator speeds between 70 to $100 \mathrm{rpm}$ : Without recirculation, the tank level increased from 0.4 to 1.4 inches and the radar indicated a level increase from 0.1 to 1.1 inches. With recirculation, the tank level increased from 0.0 to 0.9 inches and the radar recorded an increased tank level from 0.4 to 1.1 inches. The reference measurement is the level of the fluid at $20 \mathrm{rpm}$.

- As the vortex gets bigger, the top impeller seems to have no effect on the fluid motion. The impact of the top impeller during the addition of dry solids may contribute to entrainment of the solids.

Photos of the agitated surface of the $20 \mathrm{~Pa}$ xanthan gum static and recirculation runs are provided in Appendix E and Appendix F, respectively.

Table 5-7. Static 5 Pa xanthan gum run: agitator speed and power and tank level data.

\begin{tabular}{|c|c|c|c|c|c|c|c|}
\hline \multicolumn{3}{|c|}{ Agitator Speed (rpm) } & \multicolumn{2}{c|}{ Power (hp) } & \multicolumn{3}{c|}{ Tank Level (inches) } \\
\hline Target & Avg. & SD & Avg. & SD & Avg. & SD & RSD \\
\hline 20 & 20.32 & 0.02 & 0.70 & 0.01 & 31.28 & 0.08 & 0.27 \\
\hline 30 & 30.81 & 0.01 & 0.64 & 0.01 & 31.24 & 0.08 & 0.27 \\
\hline 40 & 40.45 & 0.02 & 0.61 & 0.01 & 31.31 & 0.08 & 0.25 \\
\hline 50 & 49.93 & 0.02 & 0.60 & 0.00 & 31.57 & 0.11 & 0.35 \\
\hline 60 & 60.60 & 0.03 & 0.57 & 0.01 & 31.88 & 0.11 & 0.36 \\
\hline 70 & 70.23 & 0.06 & 0.57 & 0.02 & 32.52 & 0.27 & 0.84 \\
\hline 80 & 80.85 & 0.04 & 0.58 & 0.01 & 31.98 & 0.69 & 2.17 \\
\hline 90 & 90.43 & 0.04 & 0.59 & 0.01 & 31.54 & 1.15 & 3.64 \\
\hline 100 & 100.96 & 0.04 & 0.60 & 0.00 & 32.78 & 0.26 & 0.79 \\
\hline 110 & 110.60 & 0.04 & 0.60 & 0.02 & 33.35 & 0.41 & 1.22 \\
\hline
\end{tabular}


Table 5-8. Agitator speed, tank level, recirculation flow, and pump speed data for 5 Pa xanthan gum recirculation test

\begin{tabular}{|c|c|c|c|c|c|c|c|c|c|c|c|}
\hline \multicolumn{4}{|c|}{ Agitator Speed (rpm) } & \multicolumn{2}{c|}{ Power (hp) } & \multicolumn{2}{c|}{ Grout Level (inches) } & \multicolumn{2}{c|}{$\begin{array}{c}\text { Flow Rate } \\
\text { (gpm) }\end{array}$} & \multicolumn{2}{c|}{ Pump Speed (rpm) } \\
\hline Target & Avg. & SD & Avg. & SD & Avg. & SD & RSD & Avg. & SD & Avg. & SD \\
\hline 20 & 20.34 & 0.01 & 0.70 & 0.01 & 32.42 & 0.17 & 0.51 & 33.08 & 2.00 & 682.2 & 0.0 \\
\hline 30 & 30.86 & 0.09 & 0.63 & 0.01 & 32.39 & 0.06 & 0.18 & 32.49 & 0.54 & 716.9 & 0.0 \\
\hline 40 & 39.50 & 0.02 & 0.61 & 0.01 & 32.38 & 0.08 & 0.23 & 33.16 & 0.70 & 704.1 & 0.8 \\
\hline 50 & 50.95 & 0.02 & 0.60 & 0.00 & 32.55 & 0.08 & 0.25 & 34.42 & 1.06 & 702.1 & 3.5 \\
\hline 60 & 60.57 & 0.02 & 0.59 & 0.01 & 32.74 & 0.11 & 0.33 & 33.13 & 1.38 & 695.1 & 0.0 \\
\hline 70 & 70.22 & 0.02 & 0.59 & 0.02 & 33.13 & 0.24 & 0.74 & 31.13 & 0.95 & 703.8 & 0.0 \\
\hline 80 & 80.81 & 0.04 & 0.59 & 0.01 & 33.45 & 0.30 & 0.91 & 30.70 & 0.87 & 723.7 & 6.6 \\
\hline 90 & 90.41 & 0.03 & 0.60 & 0.00 & 33.87 & 0.45 & 1.32 & 30.98 & 0.74 & 738.4 & 0.0 \\
\hline 100 & 100.93 & 0.04 & 0.60 & 0.00 & 33.88 & 0.37 & 1.08 & 33.03 & 1.37 & 742.7 & 0.0 \\
\hline 110 & 110.51 & 0.05 & 0.61 & 0.01 & 34.19 & 0.50 & 1.47 & 34.72 & 1.42 & 745.9 & 0.7 \\
\hline
\end{tabular}

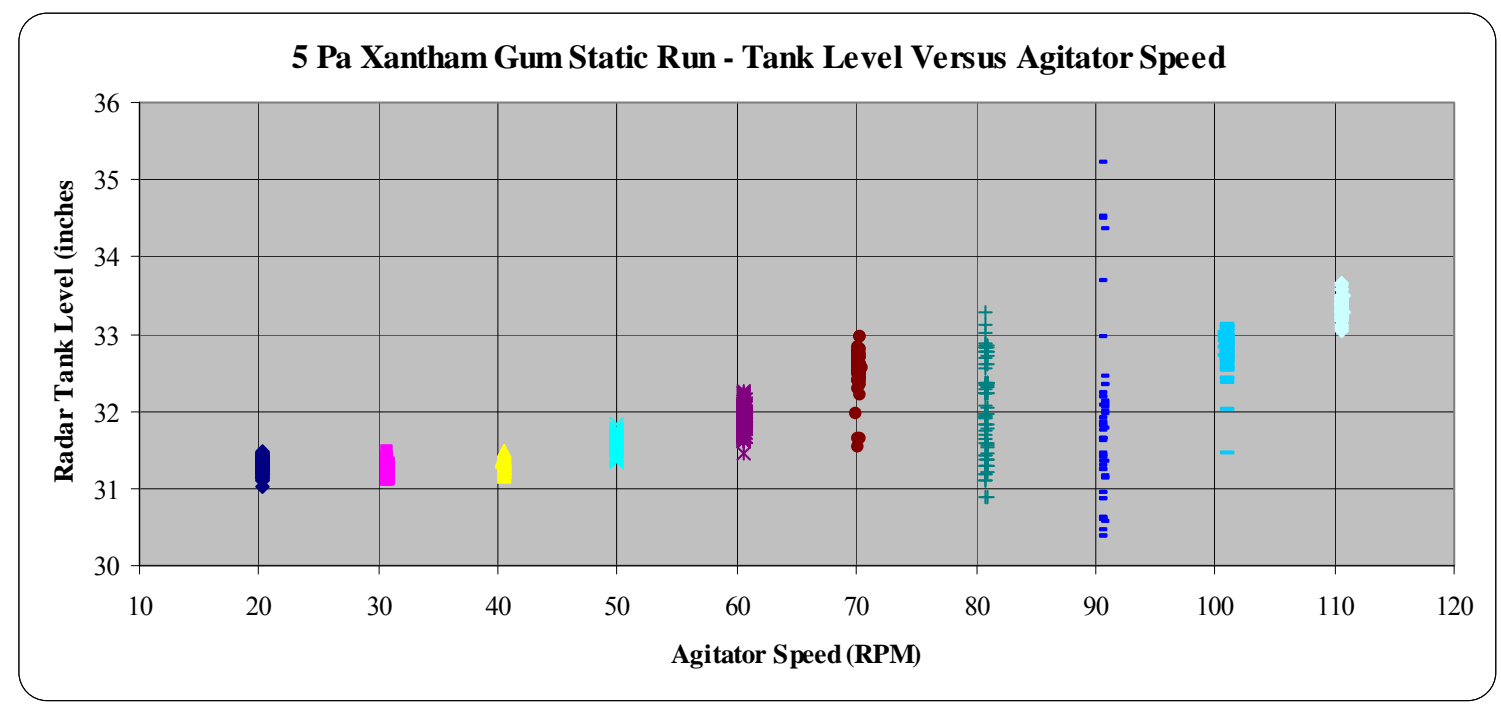

Figure 5-3. 5 Pa xanthan gum static run - radar tank level versus agitator speed. 


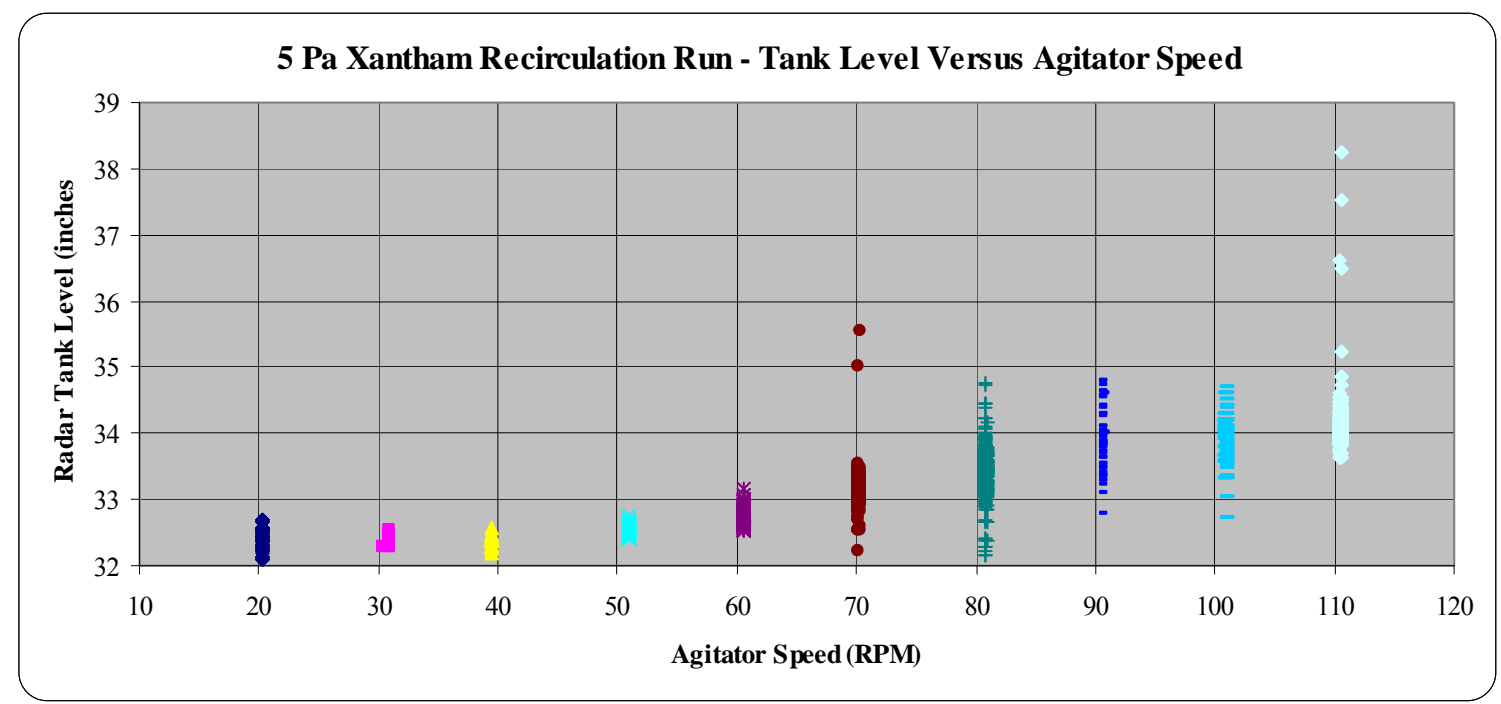

Figure 5-4. 5 Pa xanthan gum recirculation run - radar tank level versus agitator speed.

Table 5-9. Static 5 Pa xanthan gum test: tape measure and visual observation.

\begin{tabular}{|c|c|c|}
\hline rpm & $\begin{array}{l}\text { Tape level } \\
\text { (in) }\end{array}$ & $\begin{array}{l}\text { Visual Observations and Notes } \\
\text { (as recorded in the notebook and commentary on videos taken during testing) }\end{array}$ \\
\hline 20 & 14.125 & $\begin{array}{l}\text { No visual motion observed, possibly due to bubbles on surface. Air bubbles from } 20 \\
\text { Pa testing and dilution are on the surface. }\end{array}$ \\
\hline 30 & 14.125 & $\begin{array}{l}\text { Surface motion is observed and bubbles on surface are migrating towards center of } \\
\text { shaft. }\end{array}$ \\
\hline 40 & 14.125 & Surface motion is well-defined, moving from wall to shaft. \\
\hline 50 & 13.9375 & Surface motion more rapid, hard to see vortex at shaft due to bubbles. \\
\hline 60 & 13.75 & $\begin{array}{l}\text { Very good surface motion, vortex is defined, bubbles impacting the ability to obtain } \\
\text { depth of vortex visually at the shaft. }\end{array}$ \\
\hline 70 & 13.625 & Good surface motion, not rapid, vortex is larger. \\
\hline 80 & 13.25 & Vortex is larger, shadows of top impeller is visible. \\
\hline 90 & 12.875 & Vortex is just at the top of the top impeller, no visible air entrainment. \\
\hline 100 & 12.5 & $\begin{array}{l}\text { Top impeller is exposed, no active air entrainment is observed. Top impeller is not } \\
\text { performing any agitation function. }\end{array}$ \\
\hline 110 & 11.875 & $\begin{array}{l}\text { Large fraction of top impeller and shaft below top impeller exposed. No active air } \\
\text { entrainment (visual or audible). Agitator speed returned to } 20 \mathrm{rpm} \text { read the same } \\
\text { level at the start of the test. }\end{array}$ \\
\hline
\end{tabular}


Table 5-10. Recirculation 5 Pa xanthan gum run: tape measure and visual observation

\begin{tabular}{|c|c|c|}
\hline rpm & $\begin{array}{l}\text { Tape level } \\
\text { (in) }\end{array}$ & $\begin{array}{c}\text { Visual Observations and Notes } \\
\text { (as recorded in the notebook and commentary on videos taken during testing) }\end{array}$ \\
\hline 20 & 13.375 & $\begin{array}{l}\text { No splashing, motion on surface is observed, additional air being entrained due to } \\
\text { recirculation. Splashing not an issue. }\end{array}$ \\
\hline 30 & 13.375 & Bubble generation due to recirculation affecting visual. \\
\hline 40 & 13.25 & $\begin{array}{l}\text { Surface motion (wall to center), though surface area opposite of recirculation line is } \\
\text { stagnant due to bubbles? not moving on the surface. Bubbles are bursting at the } \\
\text { surface. }\end{array}$ \\
\hline 50 & 13.0 & Surface motion throughout, except surface area opposite of recirculation line. \\
\hline 60 & 12.875 & $\begin{array}{l}\text { Surface motion throughout and visual vortex. The air pulled in via the recirculation } \\
\text { line is being entrained or vented out the surface. }\end{array}$ \\
\hline 70 & 12.625 & $\begin{array}{l}\text { Vortex is visual, but due to bubbles near the shaft, hard to determine how deep the } \\
\text { vortex is near the shaft. }\end{array}$ \\
\hline 80 & 12.25 & $\begin{array}{l}\text { Recirculation seems to provide baffling, large air bubbles are visually popping out of } \\
\text { the surface. Vortex is well-defined, but cannot see top impeller. }\end{array}$ \\
\hline 90 & 11.875 & $\begin{array}{l}\text { Shadow of top impeller is visible. Shadow is due to the fact that xanthan gum is not } \\
100 \% \text { transparent, }\end{array}$ \\
\hline 100 & 11.5 & Top impeller is exposed part of the impellers near the hub can be seen. \\
\hline 110 & 11.0 & $\begin{array}{l}\text { Vortex is below top impeller hub. Agitation does not seem to cause air entrainment } \\
\text { as compared to the recirculation line. }\end{array}$ \\
\hline
\end{tabular}

Table 5-11. Agitator and tank level data for 20 Pa xanthan gum static runs

\begin{tabular}{|c|c|c|c|c|c|c|c|}
\hline \multicolumn{3}{|c|}{ Agitator Speed (rpm) } & \multicolumn{2}{c|}{ Power (hp) } & \multicolumn{3}{c|}{ Tank Level (inches) } \\
\hline Target & Avg. & SD & Avg. & SD & Avg. & SD & RSD \\
\hline 20 & 20.11 & 0.01 & 0.68 & 0.02 & 31.81 & 0.11 & 0.34 \\
\hline 30 & 30.47 & 0.01 & 0.62 & 0.00 & 31.81 & 0.08 & 0.24 \\
\hline 40 & 39.83 & 0.02 & 0.60 & 0.00 & 31.84 & 0.07 & 0.21 \\
\hline 50 & 49.94 & 0.02 & 0.60 & 0.00 & 31.89 & 0.09 & 0.27 \\
\hline 60 & 60.16 & 0.02 & 0.60 & 0.00 & 31.99 & 0.09 & 0.29 \\
\hline 70 & 69.54 & 0.02 & 0.60 & 0.00 & 32.26 & 0.12 & 0.37 \\
\hline 80 & 80.65 & 0.03 & 0.62 & 0.00 & 32.88 & 0.21 & 0.65 \\
\hline 90 & 90.17 & 0.04 & 0.63 & 0.01 & 33.01 & 0.50 & 1.53 \\
\hline 100 & 100.59 & 0.03 & 0.64 & 0.01 & 32.47 & 0.62 & 1.92 \\
\hline 110 & 110.05 & 0.04 & 0.69 & 0.00 & 33.35 & 0.64 & 1.92 \\
\hline 120 & 120.67 & 0.05 & 0.70 & 0.01 & 33.60 & 0.19 & 0.57 \\
\hline 130 & 130.28 & 0.05 & 0.71 & 0.00 & 34.08 & 0.20 & 0.60 \\
\hline
\end{tabular}


Table 5-12. Agitator speed, tank level, recirculation flow, and pump speed data for 20 Pa xanthan gum recirculation test

\begin{tabular}{|c|c|c|c|c|c|c|c|c|c|c|c|}
\hline \multicolumn{4}{|c|}{ Agitator Speed (rpm) } & \multicolumn{2}{c|}{ Power (hp) } & \multicolumn{2}{c|}{ Grout Level (inches) } & \multicolumn{2}{c|}{$\begin{array}{c}\text { Flow Rate } \\
\text { (gpm) }\end{array}$} & \multicolumn{2}{c|}{$\begin{array}{c}\text { Pump Speed } \\
\text { (rpm) }\end{array}$} \\
\hline Target & Avg. & SD & Avg. & SD & Avg. & SD & RSD & Avg. & SD & Avg. & SD \\
\hline 20 & 20.16 & 0.01 & 0.67 & 0.02 & 33.20 & 0.07 & 0.20 & 31.36 & 0.77 & 877.3 & 0.1 \\
\hline 30 & 29.70 & 0.02 & 0.62 & 0.00 & 33.31 & 0.08 & 0.24 & 31.69 & 0.45 & 894.6 & 0.0 \\
\hline 40 & 40.15 & 0.02 & 0.60 & 0.00 & 33.39 & 0.08 & 0.24 & 32.43 & 0.51 & 903.2 & 0.0 \\
\hline 50 & 50.51 & 0.02 & 0.60 & 0.00 & 33.46 & 0.07 & 0.21 & 32.90 & 0.50 & 903.2 & 0.0 \\
\hline 60 & 59.89 & 0.02 & 0.60 & 0.00 & 33.41 & 0.08 & 0.25 & 34.40 & 0.83 & 903.2 & 0.0 \\
\hline 70 & 70.28 & 0.04 & 0.60 & 0.01 & 33.56 & 0.07 & 0.22 & 33.03 & 0.67 & 881.5 & 0.0 \\
\hline 80 & 80.68 & 0.02 & 0.62 & 0.00 & 33.97 & 0.19 & 0.57 & 32.21 & 0.57 & 864.1 & 0.0 \\
\hline 90 & 90.07 & 0.03 & 0.64 & 0.00 & 33.77 & 0.18 & 0.53 & 33.43 & 0.52 & 864.1 & 0.0 \\
\hline 100 & 100.67 & 0.04 & 0.64 & 0.00 & 34.15 & 0.28 & 0.83 & 33.12 & 0.89 & 842.4 & 0.0 \\
\hline 110 & 110.14 & 0.04 & 0.69 & 0.00 & 34.54 & 0.47 & 1.37 & 33.58 & 1.08 & 773.0 & 0.0 \\
\hline 120 & 120.75 & 0.05 & 0.69 & 0.01 & 34.56 & 0.17 & 0.50 & 33.84 & 0.53 & 751.3 & 0.0 \\
\hline 130 & 130.41 & 0.05 & 0.71 & 0.00 & 34.95 & 0.09 & 0.27 & 32.95 & 0.43 & 742.7 & 0.0 \\
\hline
\end{tabular}

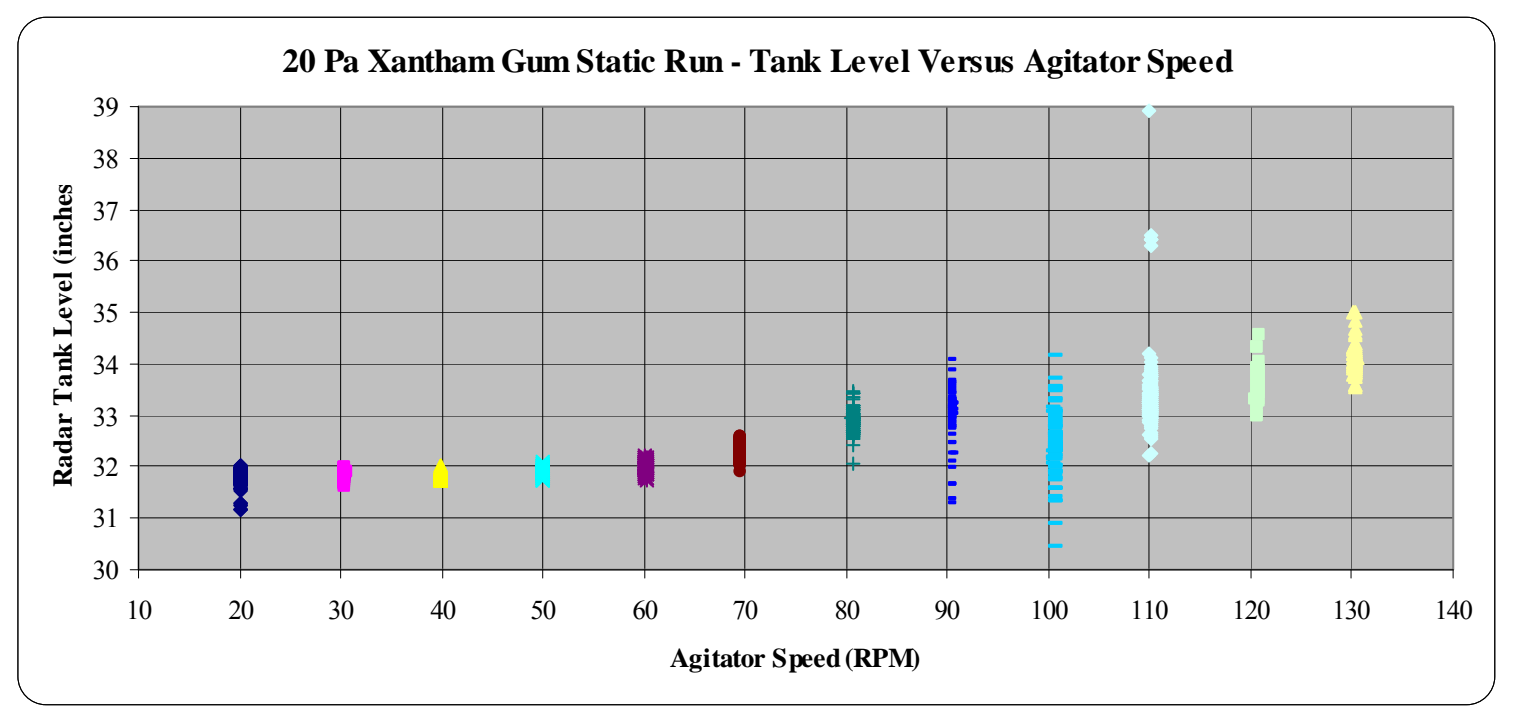

Figure 5-5. 20 Pa xanthan gum static run - radar tank level versus agitator speed. 


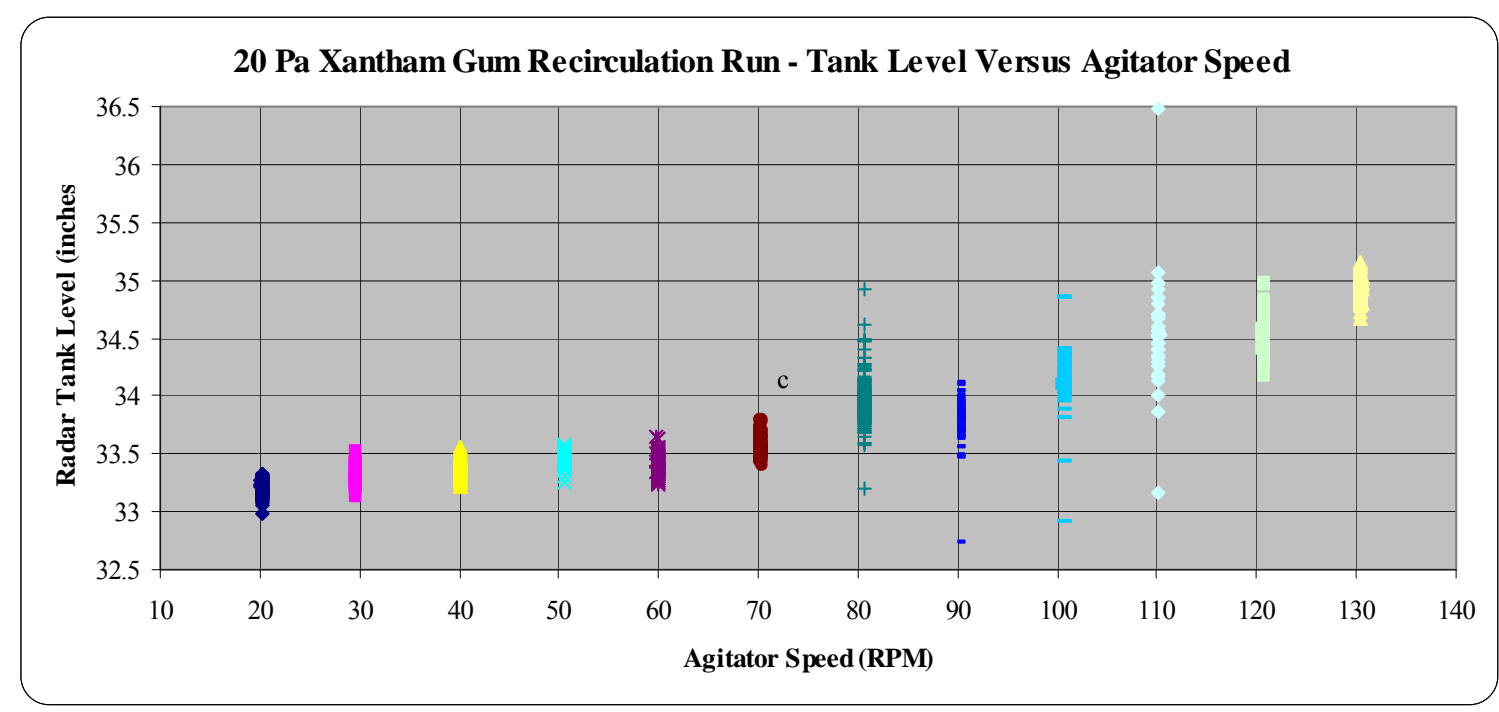

Figure 5-6. 20 Pa 20 Pa xanthan gum recirculation run - radar tank level versus agitator speed.

Table 5-13. Static 20 Pa xanthan gum test: tape measure and visual observation

\begin{tabular}{|c|c|l|}
\hline rpm & $\begin{array}{c}\text { Tape } \\
\text { level (in) }\end{array}$ & $\begin{array}{l}\text { Visual Observations and Notes } \\
\text { (as recorded in the notebook and commentary on videos taken during testing) }\end{array}$ \\
\hline 20 & 13.875 & No surface motion. \\
\hline 30 & 13.875 & $\begin{array}{l}\text { No surface motion. Surface was moving in an up and down motion, but } \\
\text { there was no visual shearing of the surface due to flow. }\end{array}$ \\
\hline 40 & 13.875 & Very slight surface motion occurring. \\
\hline 50 & 13.875 & $\begin{array}{l}\text { Surface motion increasing, higher towards the center of the hub. Upper } \\
\text { impeller affecting this flow behavior. No vortex is observed. }\end{array}$ \\
\hline 60 & 13.875 & Good surface and up/down motion, though no vortex. \\
\hline 70 & 13.5 & Good surface motion, not rapid, vortex has developed. \\
\hline 80 & 13.25 & Very good surface motion and well defined vortex. \\
\hline 90 & 12.78 & Vortex getting large, fluid motion is good. \\
\hline 100 & 12.5 & Vortex is larger, top impeller shadows can be observed through the fluid. \\
\hline 110 & 12.125 & $\begin{array}{l}\text { Part of the top hub is exposed as well as impellers. Good vortex, no air } \\
\text { entrainment. Top impeller seems to have no influence on fluid motion. }\end{array}$ \\
\hline 120 & 11.75 & $\begin{array}{l}\text { Area below the top hub and larger fraction of impeller is exposed. No air } \\
\text { entrainment due to the vortex is observed. }\end{array}$ \\
\hline 130 & 11.125 & Shaft below top impeller exposed. \\
\hline
\end{tabular}


Table 5-14. Recirculation 20 Pa Xanthan Gum Run: Tape Measure and Visual Observation.

\begin{tabular}{|c|c|c|}
\hline rpm & $\begin{array}{c}\text { Tape } \\
\text { level (in) }\end{array}$ & $\begin{array}{l}\text { Visual Observations and Notes } \\
\text { (as recorded in the notebook and commentary on videos taken during testing) }\end{array}$ \\
\hline 20 & 12.375 & $\begin{array}{l}\text { Recirculation line entraining air into the fluid, no surface motion, but } \\
\text { agitation seems to be sufficient in moving fluid (hence bubbles) in the lower } \\
\text { section via observation of large bubbles leaving the surface throughout. } \\
\text { Splashing is not an issue. }\end{array}$ \\
\hline 30 & 12.375 & See above comment at $20 \mathrm{rpm}$, no surface motion other than bubbles. \\
\hline 40 & 12.375 & See above comment at $20 \mathrm{rpm}$, very slight surface motion occurring. \\
\hline 50 & 12.375 & $\begin{array}{l}\text { See above comment at } 20 \mathrm{rpm} \text {. Surface motion increasing, especially toward } \\
\text { the hub, upper impeller influencing flow. }\end{array}$ \\
\hline 60 & 12.375 & $\begin{array}{l}\text { Good surface and up/down motion, though no vortex, large bubble surfacing } \\
\text { throughout the vessel surface. Flow is somewhat stagnant immediately } \\
\text { downstream of the recirculation line entering the tank contents. Baffle } \\
\text { effect. }\end{array}$ \\
\hline 70 & 12.375 & $\begin{array}{l}\text { See } 60 \text { rpm comment, surface fluid motion is better and very slight vortex is } \\
\text { observed. }\end{array}$ \\
\hline 80 & 12.0 & Defined vortex, agitation throughout. Surface motion throughout. \\
\hline 90 & 11.75 & $\begin{array}{l}\text { Vortex is large, agitation is good and bubbles are definitely following flow } \\
\text { field. }\end{array}$ \\
\hline 100 & 11.5 & $\begin{array}{l}\text { Good vortex, large bubbles entrained due to recirculation line seem to be } \\
\text { quickly relieved out of the system. }\end{array}$ \\
\hline 110 & 11.125 & $\begin{array}{l}\text { See above, shadow of upper impeller is clouded by bubbles gathering at the } \\
\text { shaft. Shadow is due to the fact that xanthan gum is not } 100 \% \text { transparent, }\end{array}$ \\
\hline 120 & 10.75 & See above. Tops of the top impeller can be seen. \\
\hline 130 & 10.125 & $\begin{array}{l}\text { See above, top impeller is now exposed near the hub. Cannot tell if vortex is } \\
\text { below the hub, due to bubbles. }\end{array}$ \\
\hline
\end{tabular}

The amplitude of the reflection on the radar measurements was significantly reduced with increasing agitation as shown in Figure 5-7 and Figure 5-8. This amplitude reduction, due to the increased vortex formation of the fluid, did not affect the ability of the radar sensor to continue tracking the tank level. The radar sensor was able to track the changing tank level during the filling and draining of the grout hopper with and without agitation. No significant changes in level measurement with the radar sensor were observed during recirculation of xanthan gum. The changes in level measurement between the static and recirculation conditions, shown in Figure 5-5 and Figure 5-6 are due to the addition of simulant when performing the recirculation testing. No "drop-outs" in level measurement were observed during the testing. 


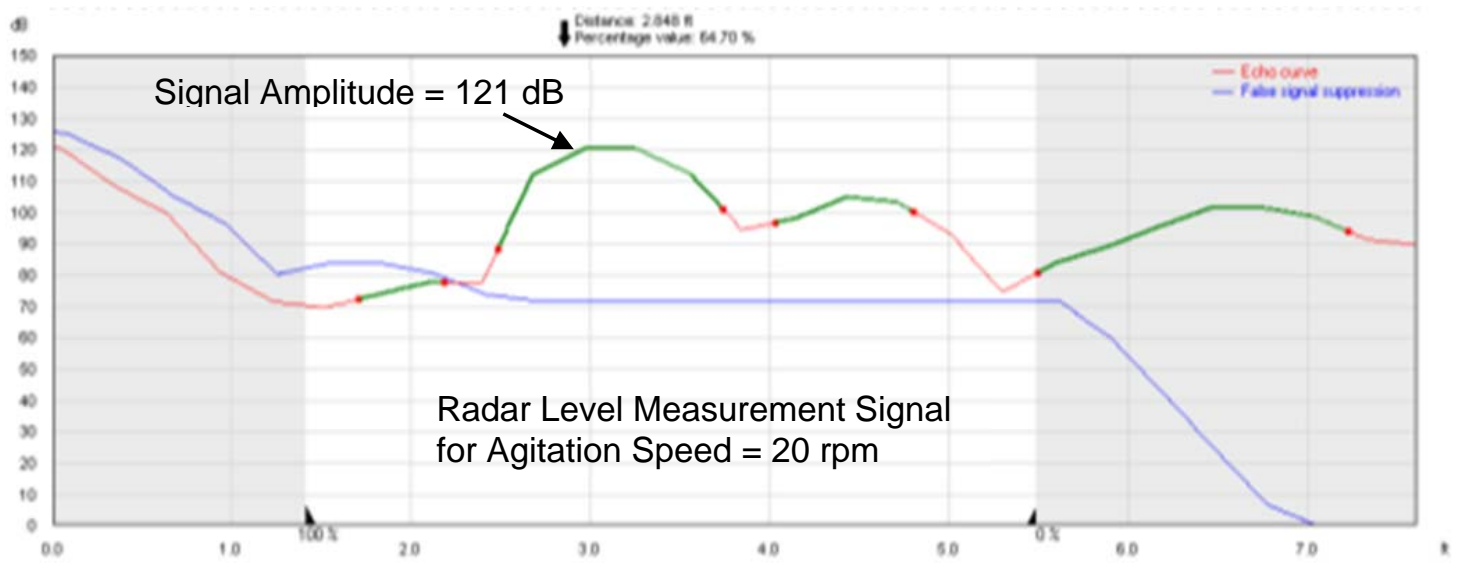

Figure 5-7. Radar signal amplitude at $20 \mathrm{rpm}$.

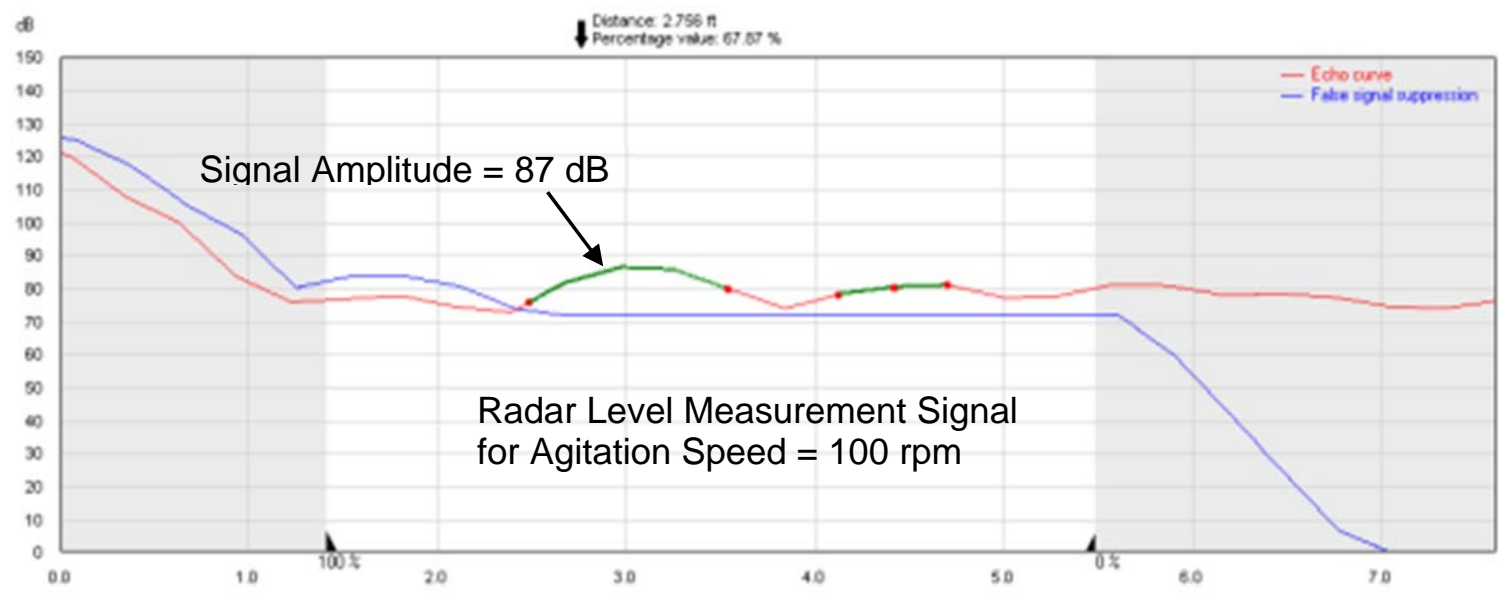

Figure 5-8. Radar signal amplitude at $100 \mathrm{rpm}$.

\section{$5.4 \underline{5 \mathrm{~Pa} \text { Grout Runs }}$}

The results for the $5 \mathrm{~Pa}$ grout runs are provided in Table 5-15 and Table 5-16, the radar level versus agitator speed in Figure 5-9 and Figure 5-10, and visual observations in Table 5-17 and Table 5-18 for the static and recirculation runs, respectively. The same general observations noted in the water runs (section 5.2) were observed. The power required to agitate the $5 \mathrm{~Pa}$ grout was similar to that of the $5 \mathrm{~Pa}$ xanthan gum. The most significant difference was the splashing of the grout during the recirculation run, sticking to the exposed internal surfaces (Figure 5-11 and Figure 5-12). Photos of the agitated surface for the grout runs are provided in Appendix $G$ and Appendix $\mathrm{H}$ for the static and recirculation runs, respectively. 
Table 5-15. Agitator and tank level data for static 5 Pa grout test.

\begin{tabular}{|c|c|c|c|c|c|c|c|}
\hline \multicolumn{3}{|c|}{ Agitator Speed (rpm) } & \multicolumn{2}{c|}{ Power (hp) } & \multicolumn{3}{c|}{ Tank Level (inches) } \\
\hline Target & Avg. & SD & Avg. & SD & Avg. & SD & RSD \\
\hline 20 & 20.30 & 0.01 & 0.71 & 0.01 & 31.66 & 0.07 & 0.22 \\
\hline 30 & 30.88 & 0.03 & 0.64 & 0.01 & 31.70 & 0.05 & 0.16 \\
\hline 40 & 40.44 & 0.04 & 0.62 & 0.00 & 31.92 & 0.11 & 0.33 \\
\hline 50 & 50.08 & 0.06 & 0.60 & 0.00 & 32.34 & 0.22 & 0.69 \\
\hline 60 & 60.60 & 0.04 & 0.60 & 0.00 & 32.81 & 0.30 & 0.91 \\
\hline 70 & 70.16 & 0.04 & 0.60 & 0.00 & 32.82 & 0.45 & 1.38 \\
\hline 80 & 79.77 & 0.05 & 0.60 & 0.00 & 33.00 & 0.68 & 2.07 \\
\hline 90 & 90.24 & 0.06 & 0.60 & 0.00 & 33.53 & 1.11 & 3.30 \\
\hline 100 & 99.78 & 0.07 & 0.61 & 0.01 & 33.91 & 0.99 & 2.91 \\
\hline 110 & 110.17 & 0.08 & 0.62 & 0.01 & 34.19 & 0.74 & 2.16 \\
\hline
\end{tabular}

Table 5-16. Agitator speed, tank level, recirculation flow, and pump speed data for 5 Pa grout recirculation test.

\begin{tabular}{|c|c|c|c|c|c|c|c|c|c|c|c|}
\hline \multicolumn{4}{|c|}{ Agitator Speed (rpm) } & \multicolumn{2}{c|}{ Power (hp) } & \multicolumn{3}{c|}{ Grout Level (inches) } & \multicolumn{2}{c|}{$\begin{array}{c}\text { Flow Rate } \\
\text { (gpm) }\end{array}$} & \multicolumn{2}{c|}{$\begin{array}{c}\text { Pump Speed } \\
\text { (rpm) }\end{array}$} \\
\hline Target & Avg. & SD & Avg. & SD & Avg. & SD & RSD & Avg. & SD & Avg. & SD \\
\hline 20 & 20.34 & 0.01 & 0.70 & 0.01 & 31.87 & 0.12 & 0.38 & 32.39 & 0.24 & 505.4 & 0.1 \\
\hline 30 & 30.92 & 0.02 & 0.64 & 0.01 & 31.98 & 0.14 & 0.45 & 30.92 & 0.28 & 504.5 & 0.0 \\
\hline 40 & 40.46 & 0.02 & 0.61 & 0.01 & 32.15 & 0.16 & 0.48 & 30.27 & 0.40 & 508.8 & 0.0 \\
\hline 50 & 51.01 & 0.03 & 0.60 & 0.00 & 32.36 & 0.24 & 0.73 & 32.14 & 0.19 & 522.0 & 0.5 \\
\hline 60 & 60.62 & 0.02 & 0.60 & 0.00 & 32.78 & 0.30 & 0.90 & 31.39 & 0.18 & 521.8 & 0.2 \\
\hline 70 & 70.21 & 0.03 & 0.60 & 0.03 & 32.96 & 0.51 & 1.54 & 32.27 & 0.21 & 534.7 & 0.0 \\
\hline 80 & 80.72 & 0.05 & 0.60 & 0.00 & 33.16 & 0.59 & 1.79 & 32.49 & 0.39 & 539.0 & 0.0 \\
\hline 90 & 90.31 & 0.04 & 0.60 & 0.00 & 33.48 & 0.43 & 1.27 & 31.88 & 0.52 & 543.3 & 0.0 \\
\hline 100 & 100.78 & 0.06 & 0.61 & 0.01 & 33.80 & 0.36 & 1.07 & 31.55 & 0.54 & 547.7 & 0.0 \\
\hline
\end{tabular}

5 Pa Grout Static Run - Tank Level Versus Agitator Speed

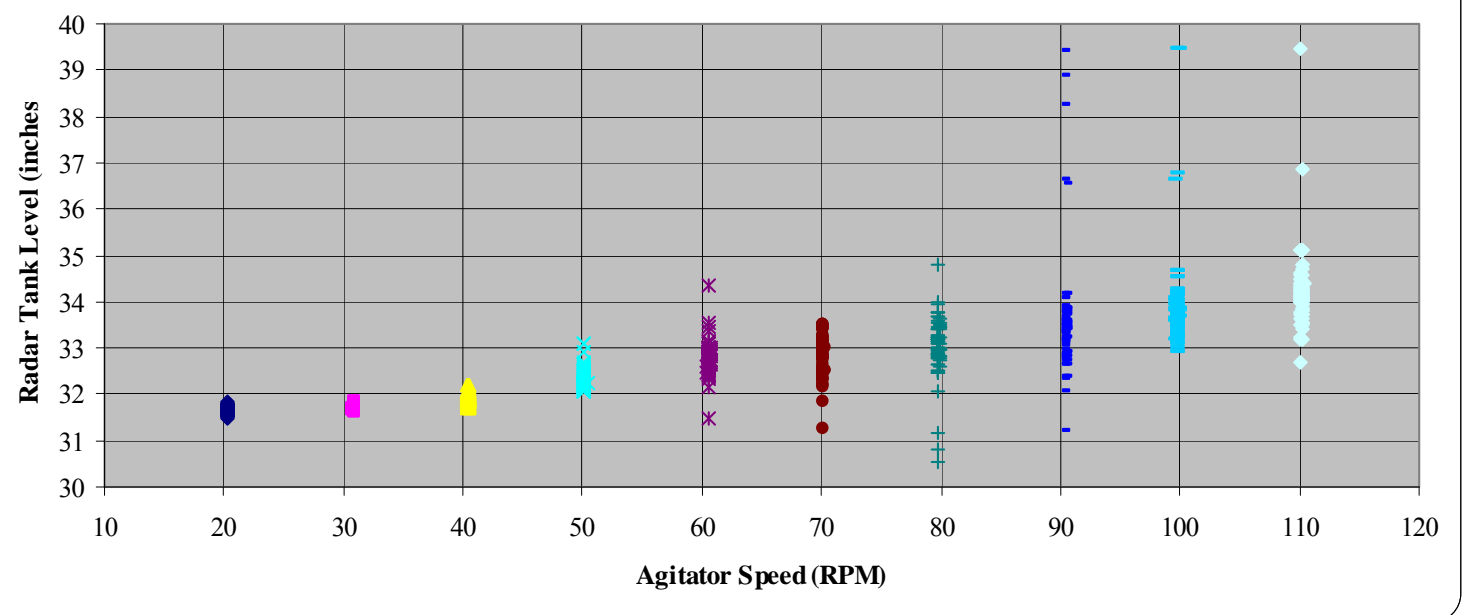

Figure 5-9. 5 Pa grout static run - radar tank level versus agitator speed. 


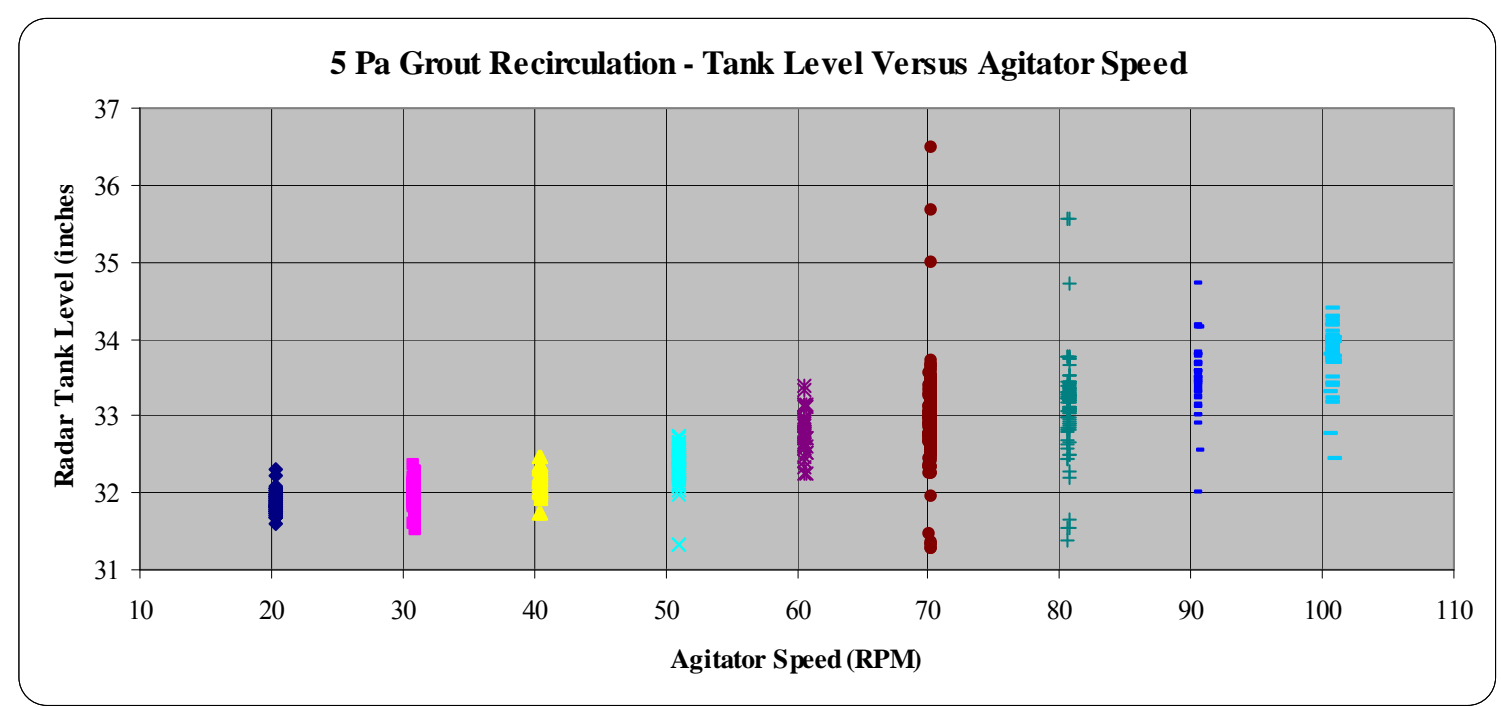

Figure 5-10. 5 Pa grout recirculation test - radar tank level versus agitator speed.

Table 5-17. Static 5 Pa grout test: visual observation

\begin{tabular}{|c|l|}
\hline rpm & \multicolumn{1}{|c|}{$\begin{array}{c}\text { Visual Observations and Notes } \\
\text { (as recorded in the notebook and commentary on videos taken during testing) }\end{array}$} \\
\hline 20 & $\begin{array}{l}\text { Surface motion. Does not appear there is much radial motion occurring on the surface. } \\
\text { Carbon floating on surface, near shaft. }\end{array}$ \\
\hline 30 & Better surface motion, no vortex. \\
\hline 40 & Very slight vortex is forming. Vortex does not seem to entrain carbon. \\
\hline 50 & Vortex is a little better defined. Carbon still floating. \\
\hline 60 & $\begin{array}{l}\text { Better vortex, carbon seems to show the layout of the hub/blades of the top impeller. } \\
\text { Carbon floats on the surface and does not easily incorporate into the grout. }\end{array}$ \\
\hline 70 & $\begin{array}{l}\text { Vortex is still above top impeller. Difficult to determine if the carbon is being } \\
\text { entrained, but the fluid motion is creating small vortices near the impeller. }\end{array}$ \\
\hline 80 & $\begin{array}{l}\text { Vortex seems to be just above the top impeller, carbon being entrained, but still have } \\
\text { floaters. }\end{array}$ \\
\hline 90 & $\begin{array}{l}\text { Vortex is at the top of the top impeller, air mixing with grout can be heard, all carbon } \\
\text { has been incorporated. }\end{array}$ \\
\hline 100 & Vortex has exposed part of the top impeller, air mixing with grout can be heard. \\
\hline 110 & $\begin{array}{l}\text { Vortex is below top impeller, shaft below hub can be observed. Air mixing with grout } \\
\text { can be heard. }\end{array}$ \\
\hline
\end{tabular}


Table 5-18. Recirculation 5 Pa 5 Pa grout test: visual observation

\begin{tabular}{|c|l|}
\hline rpm & \multicolumn{1}{|c|}{$\begin{array}{c}\text { Visual Observations and Notes } \\
\text { (as recorded in the notebook and commentary on videos taken during testing) }\end{array}$} \\
\hline 20 & $\begin{array}{l}\text { Recirculation line causing surface to push floating carbon to other side of tank. A lot of } \\
\text { splashing and grout is being splattered to all exposed surfaces. No observable stagnant } \\
\text { zones. }\end{array}$ \\
\hline 30 & $\begin{array}{l}\text { Surface motion throughout, see above } 20 \text { rpm for additional info. Carbon ring near } \\
\text { shaft and towards wall opposite side of recirculation line. }\end{array}$ \\
\hline 40 & See above, but surface motion is better. \\
\hline 60 & $\begin{array}{l}\text { More surface motion with a slight vortex, carbon being pushed to the wall. Can see } \\
\text { large bubbles rising out of the grout and smaller bubbles generated from the } \\
\text { recirculation line or existing small bubbles being drawn into the top impeller region due } \\
\text { to the fluid motion created by the agitators. Cannot state if the upper impeller is } \\
\text { responsible for the entrainment or general recirculation generated from the mixing } \\
\text { system. }\end{array}$ \\
\hline 70 & Vortex is better defined, more rapid surface motion, see above. \\
\hline 80 & $\begin{array}{l}\text { Vortex getting larger, floating carbon is better entrained, so are the bubbles. } \\
\text { recirculation line seems to be drawn into the grout. }\end{array}$ \\
\hline 90 & Vortex is at the top of the top impeller. See above for additional info. \\
\hline 100 & $\begin{array}{l}\text { Top of top impeller is exposed. Agitator seems to be entraining more air, along with } \\
\text { that introduced by the recirculation line. Splatter is still an issue. }\end{array}$ \\
\hline
\end{tabular}

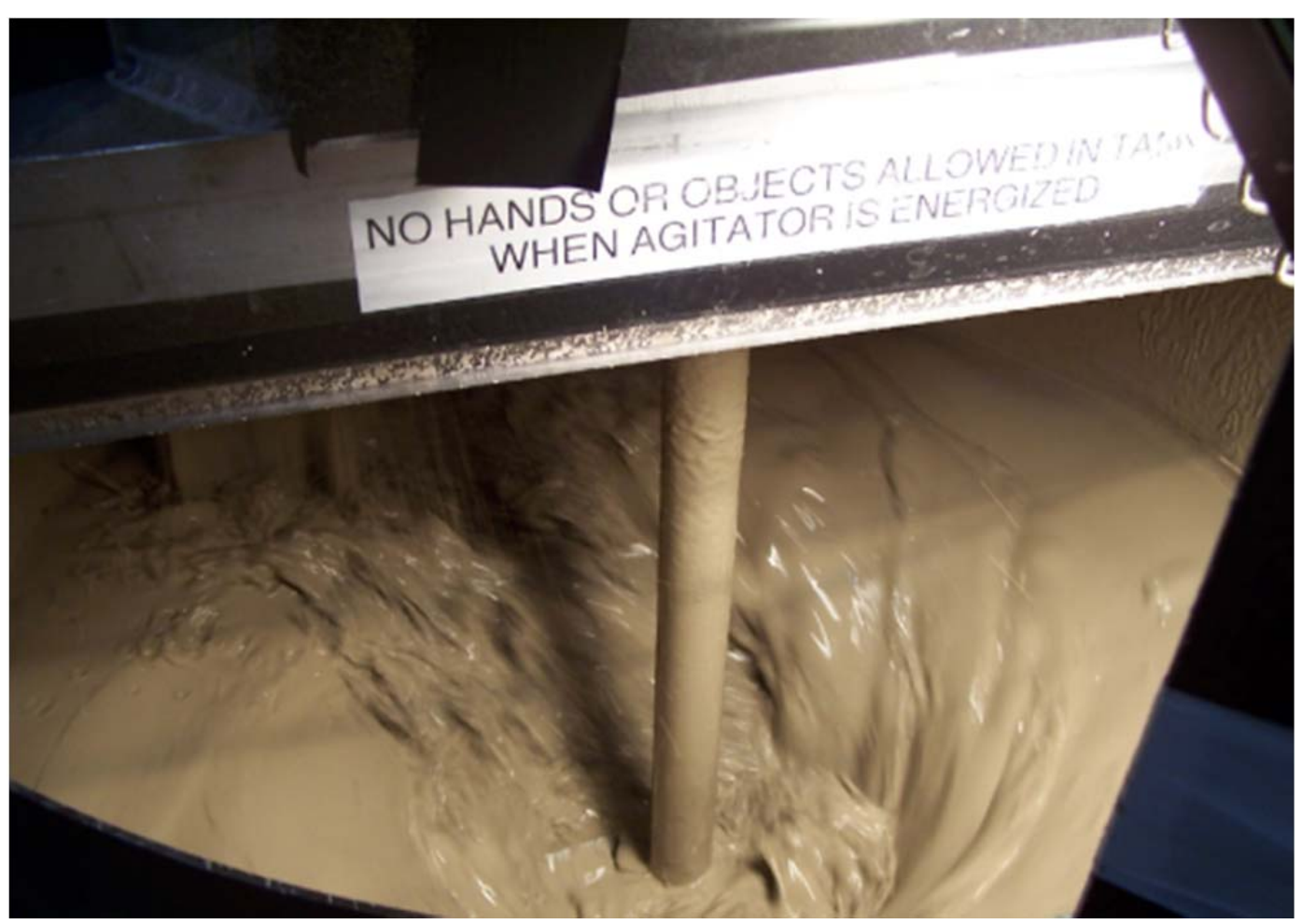

Figure 5-11. 5 Pa grout recirculation run, at the end of $90 \mathrm{rpm}$ run, showing grout splatter after approximately $\mathbf{3 0}$ minutes of recirculation time. 


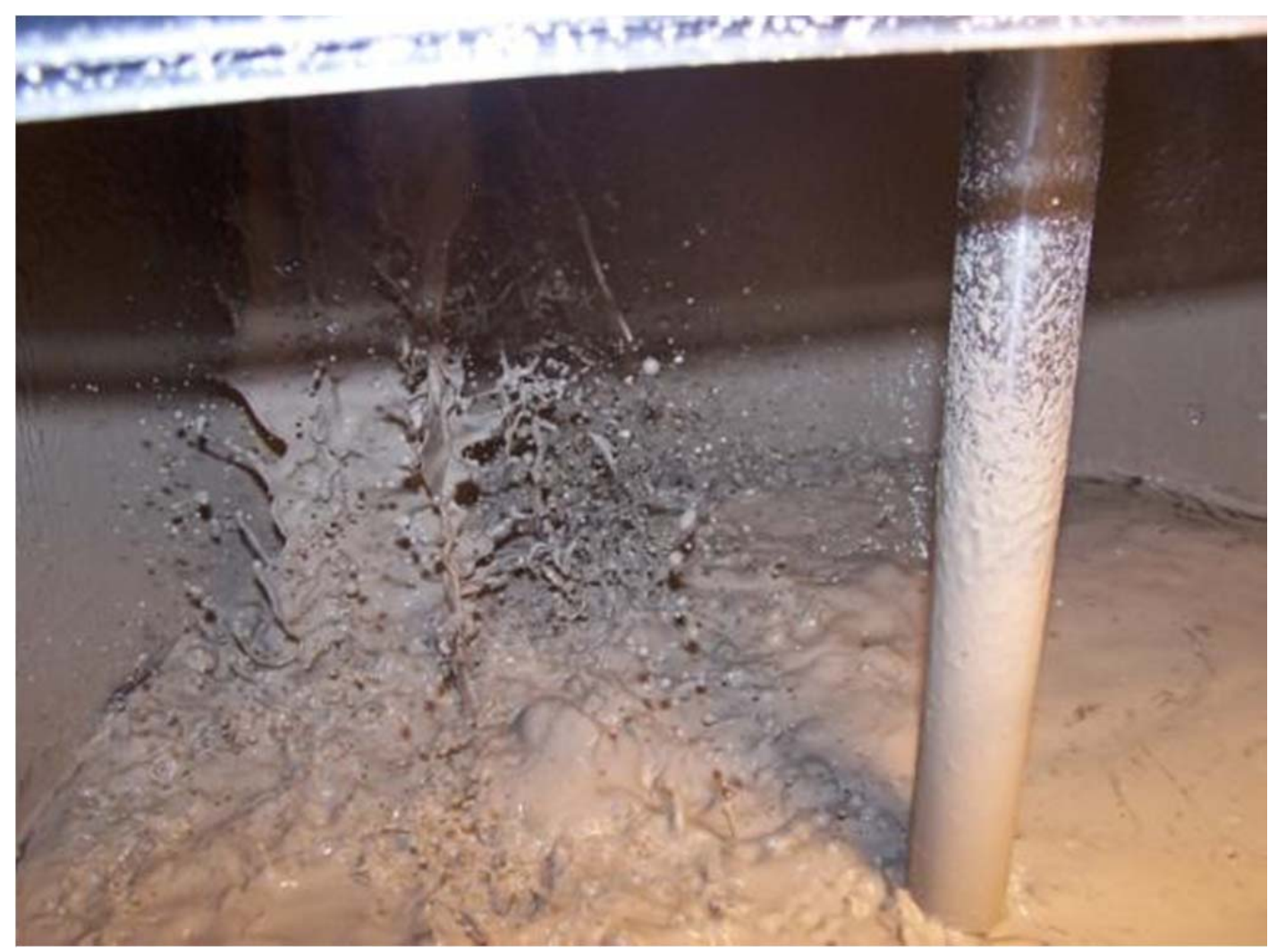

Figure 5-12. Recirculation stream entering hopper during 5 Pa grout run.

\subsection{Grout Dry Feed Addition}

The dry addition test was performed at the end of the $5 \mathrm{~Pa}$ grout recirculation test. During this test, the agitator speed was set at $80 \mathrm{rpm}$ with no recirculation and a starting tank level of 14 inches as noted on the measuring tape in the tank. The agitator speed for the addition was select at $80 \mathrm{rpm}$, based upon the results of the testing of water, $5 \mathrm{~Pa}$ xanthan gum solution and $5 \mathrm{~Pa}$ grout. The addition completed within seconds and Figure 5-13 shows the change in radar level and power. The dry solids were added and were incorporated in less than 74 seconds and no unusual noises or agitator vibrations were noted. The timing is based on obtaining a visual indication that no solids remained on top of the fluid surface. It was impossible to obtain a visual indication until dust in the vessel head space had cleared enough to see the fluid surface. The radar did indicate a slight level increase due to the addition of the dry solids, but after the solids were incorporated, there was little difference in level measurement between the dry solids addition and final tank level. In normal Saltstone operations, the tank level will be continuously pumped out, hence it is expected that if dry solids are added, radar or agitator power will not provide data indicating a dry addition. The final product obtained in this test would be different than that in actual operations, since the solids were allowed to fully incorporate. 


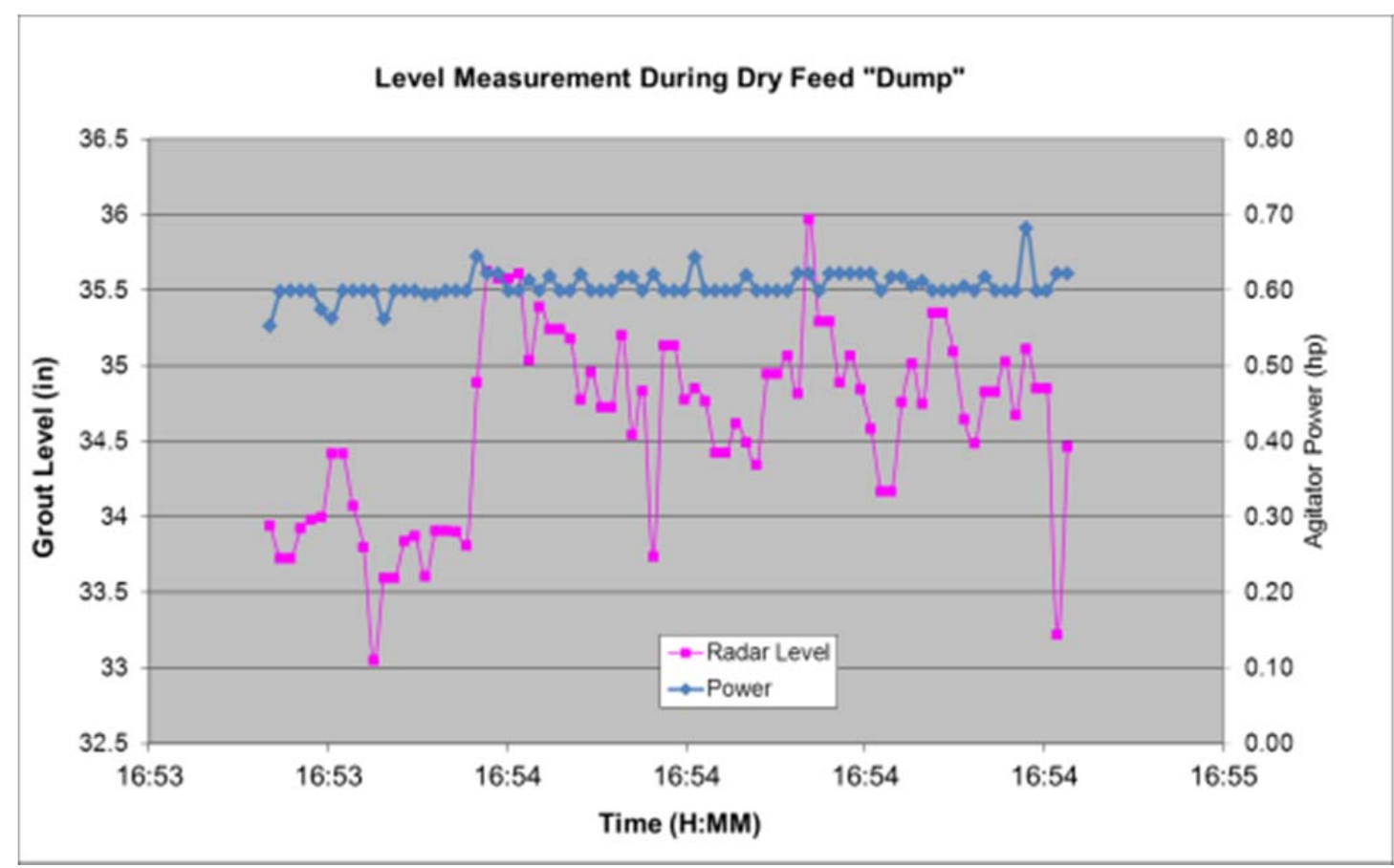

Figure 5-13. Radar level measurements (1 sec interval) during a Dry Feed “addition” at an agitator speed of $80 \mathrm{rpm}$.

\subsection{Empty Tank Test:}

The tank was emptied and the radar level measurements were recorded while the agitator was rotated manually. It was observed that the radar level increased to an approximate level reading of 11.8 inches when one of the agitator blades was located directly beneath the radar antenna. When the agitator blade was turned approximately $40-50$ degrees clockwise or counter-clockwise, the radar level measurement decreased to an approximate level reading of 3.4 inches. This level measurement was repeated for each blade as the agitator was rotated a complete 360 degrees.

This false level indication due to the agitator blade can be undesirable following the processing of grout, since an empty tank can provide a "false" level measurement as a result of the location of the agitator blades. The "false" level indication from the agitator blade was eliminated by rotating the radar sensor flange approximately 20 degrees as illustrated in Figure 5-14. To permit this adjustment in the field, additional holes would have to be placed in the radar sensor mounting flange and the flange of the tank or a sanitary type of connection would be required. 
SRNL-STI-2011-00465

Revision 0

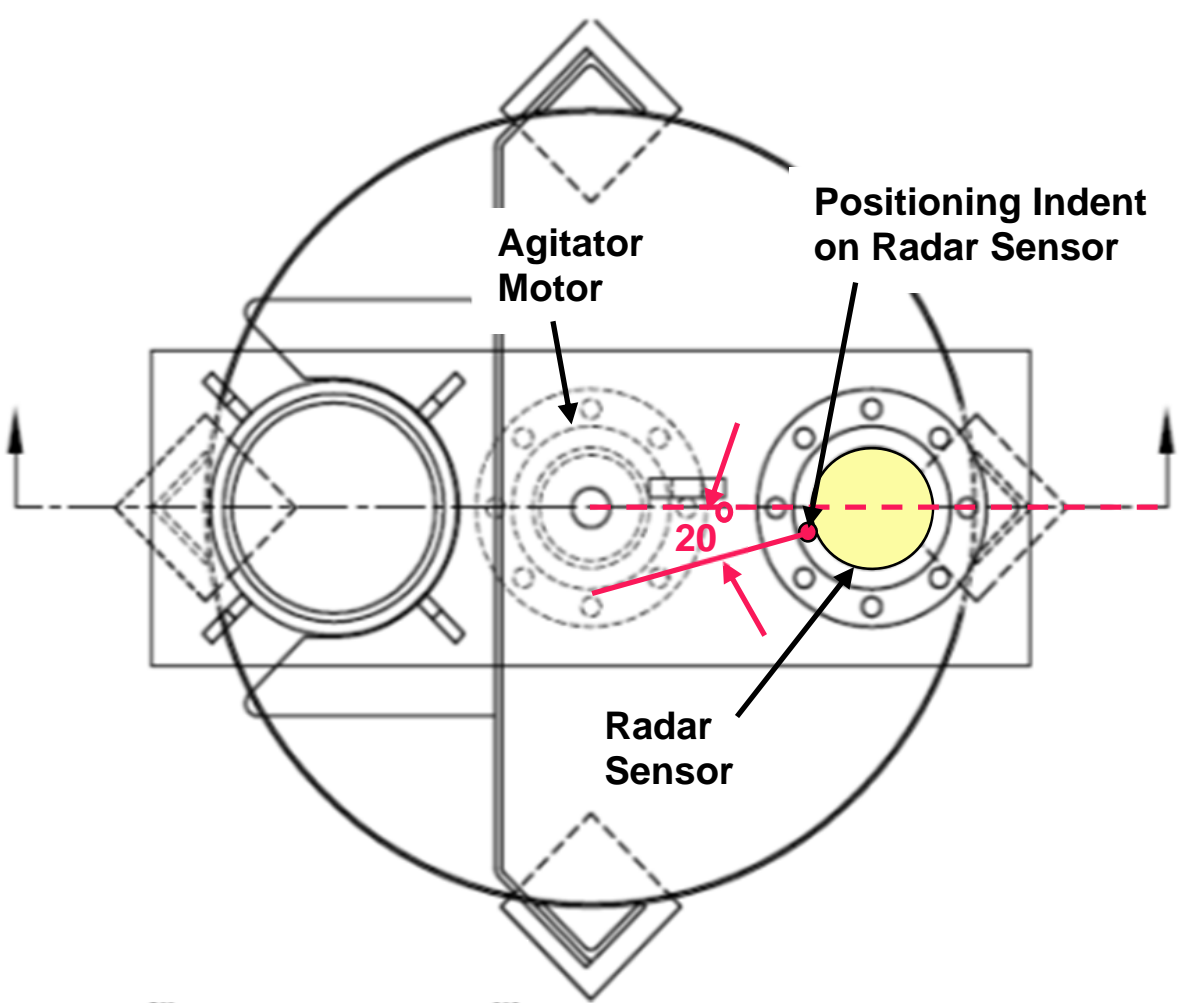

Figure 5-14. Alignment of radar sensor to reduce/eliminate false level measurement from agitator blades.

\subsection{Discussion}

Table 5-19 shows where the vortex on the shaft was approximately one inch below the surface (motion was observed to be present throughout the top surface of the hopper) and approximately one-half to one inch above the top impeller. The vortex size in this range was determined to be acceptable for continuous operations since there was no active air entrainment from the vortex. Air entrainment may become more prevalent as the agitator speed increases due to the addition of grout from the READCO mixer; however the results in the recirculation tests are not conclusive as to how much air entrainment may be experienced. The tank level with respect to the top of the hopper without any vortex formation is provided as a reference point. The level change at the tank wall and the radar measurements for the no-vortex case are also provided in Table 5-19. The operating range for all the fluids other than the $20 \mathrm{~Pa}$ xanthan gum was 50 to $80 \mathrm{rpm}$. The range for the $20 \mathrm{~Pa}$ xanthan gum was 70 to $100 \mathrm{rpm}$. Figure 5-15 shows the tank level changes compared to the baseline condition (at $20 \mathrm{rpm}$ ) using the radar level detector. This data indicates that once a condition is found without agitation, operating about 1.4 inches above the baseline could provide a good fluid motion condition for the 30-inch hopper. 
Table 5-19. Operating regime to maintain a stable vortex.

\begin{tabular}{|c|c|c|c|c|c|c|c|c|c|}
\hline \multirow{3}{*}{$\begin{array}{l}\text { Approximate } \\
\text { Vortex } \\
\text { height }\end{array}$} & \multirow{3}{*}{ Parameter } & \multicolumn{8}{|c|}{ Fluid } \\
\hline & & \multicolumn{2}{|c|}{ Water } & \multicolumn{2}{|c|}{$20 \mathrm{~Pa}$ Xanthan } & \multicolumn{2}{|c|}{5 Pa Xanthan } & \multicolumn{2}{|c|}{5 Pa Grout } \\
\hline & & Static & Recir & Static & Recir* & Static & Recir & Static & Recir \\
\hline \multirow{2}{*}{$\begin{array}{l}\text { No vortex } \\
\text { (Initial } \\
\text { condition) }\end{array}$} & $\begin{array}{l}\text { Initial Fluid } \\
\text { Level from } \\
\text { Top of } \\
\text { Tank(inches) }\end{array}$ & 13.0 & 13.9 & 13.9 & 12.4 & 14.1 & 13.4 & 14.0 & 14.0 \\
\hline & $\begin{array}{c}\text { Radar level } \\
\text { (inches) }\end{array}$ & 31.2 & 32.4 & 31.8 & 33.2 & 31.3 & 32.4 & 33.2 & 31.7 \\
\hline \multirow{3}{*}{$\begin{array}{l}1 " \text { below } \\
\text { surface }\end{array}$} & $\begin{array}{c}\text { Agitator } \\
\text { Speed (rpm) }\end{array}$ & 50 & 50 & 70 & 80 & 50 & 60 & 50 & 50 \\
\hline & $\begin{array}{l}\text { Level } \\
\text { Change at } \\
\text { Tank Wall } \\
\text { (inches) }\end{array}$ & 0.5 & 0.8 & 0.4 & 0.4 & 0.2 & 0.5 & $\mathrm{n} / \mathrm{a}$ & $\mathrm{n} / \mathrm{a}$ \\
\hline & $\begin{array}{l}\text { Radar } \\
\text { Change } \\
\text { (inches) }\end{array}$ & 0.95 & 0.53 & 0.48 & 0.23 & 0.27 & 0.21 & 0.63 & 0.49 \\
\hline \multirow{3}{*}{$\begin{array}{l}1 / 2 \text { to } 1 " \\
\text { above upper } \\
\text { impeller }\end{array}$} & $\begin{array}{c}\text { Agitator } \\
\text { Speed (rpm) }\end{array}$ & 80 & 80 & 100 & 110 & 80 & 90 & 80 & 80 \\
\hline & $\begin{array}{c}\text { Level } \\
\text { Change at } \\
\text { Tank Wall } \\
\text { (inches) }\end{array}$ & 1.5 & 1.9 & 1.4 & 1.0 & 0.9 & 1.5 & $\mathrm{n} / \mathrm{a}$ & $\mathrm{n} / \mathrm{a}$ \\
\hline & $\begin{array}{l}\text { Radar } \\
\text { Change } \\
\text { (inches) } \\
\end{array}$ & 1.55 & 1.48 & 0.68 & 0.69 & 0.71 & 1.29 & 1.32 & 1.32 \\
\hline
\end{tabular}

* The recirculation line was very defined and entered the top of the surface like a continuous stream, creating a baffling effect. See the figures in Appendix F (20 Pa test) for such effect. Tank level was approximately 0.5 " greater than the maximum targeted. 


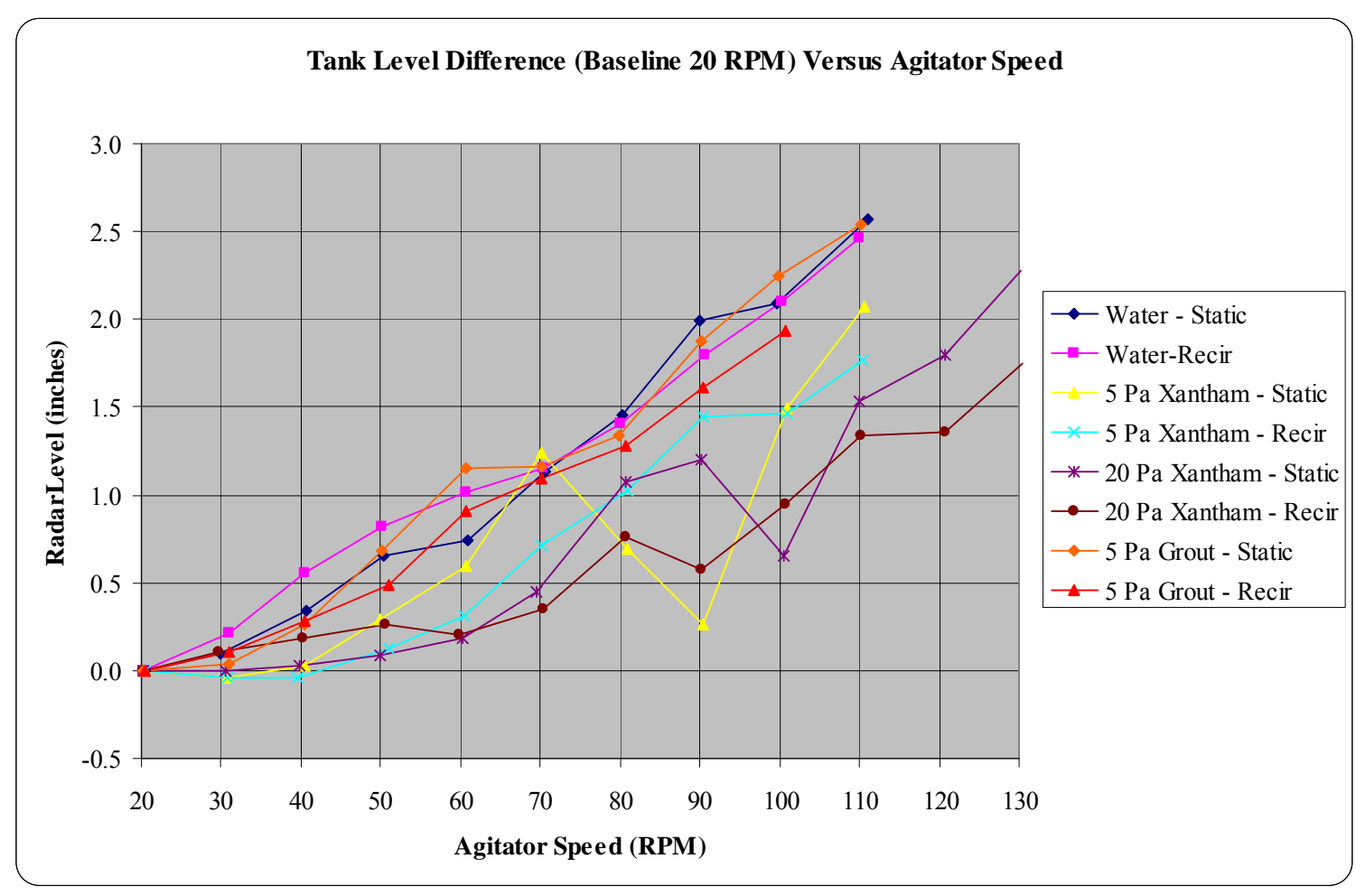

Figure 5-15. Radar level changes compared to 20 rpm measurements.

The primary mixing phenomena of interest is vortex generation from a centrally located agitator in an unbaffled tank. The scale up correlation between the 30-inch hopper and the 51-inch hopper is the Froude correlation and is used to provide the operating speed.

In the nominal tank level range between 13 and 14 inches, the data is fairly consistent as shown in Table 5-19. For water and the $5 \mathrm{~Pa}$ fluids, the data suggests that fluid properties do not have a significant impact on vortex formation and the operating range is between 50 to $80 \mathrm{rpm}$. For the $20 \mathrm{~Pa}$ fluid, a higher operating range is required, 70 to $100 \mathrm{rpm}$, but this range does overlap with the higher operating speeds of the rheologically thinner fluids.

Using equation [5], where $\frac{D_{1}}{D_{2}}=\frac{30}{51}$ and $n=1 / 2$ (Froude), the operating range for the 51-inch hopper ranges between 40 to $60 \mathrm{rpm}$ for the water and $5 \mathrm{~Pa}$ fluids. For the $20 \mathrm{~Pa}$ fluid, the range is between 50 to $75 \mathrm{rpm}$.

For all the fluids tested (other than air), the VFD power (including both mechanical and electrical losses) ranged between 0.52 to 0.71 horsepower (Figure 5-16). Table 5-20 is the power from the impellers (section 2.2) using turbulent power numbers for the 45 degree pitch and flat blade (assuming lower impeller can be treated as such) and for a baffled tank condition at various agitator speeds. The results indicate that the power numbers used are overestimating the power requirements for the motor. Typically, the power numbers for impellers in unbaffled vessels are 2 to 10 times smaller than that of baffled vessels in turbulent conditions. ${ }^{13,19}$ A somewhat similar design of the bottom blade used in this design is the retreat curve impeller (RCI) typically used by the pharmaceutical industry (Figure 5-17). ${ }^{20}$ The power number for one to four baffles for the 
RCI configuration ranges between 0.5 to 1.0 respectively and this is lower than the 3.96 used for the bottom impeller in this calculation.

Table 5-20. Turbulent baffled power consumption for the 30 -inch hopper

\begin{tabular}{|c|c|c|c|}
\hline $\mathrm{Rpm}$ & $\begin{array}{c}\text { Power } \\
(\mathrm{hp})\end{array}$ & $\mathrm{rpm}$ & $\begin{array}{c}\text { Power } \\
\text { (hp) }\end{array}$ \\
\hline 24 & 0.009 & 84 & 0.399 \\
\hline 30 & 0.018 & 90 & 0.490 \\
\hline 36 & 0.031 & 96 & 0.595 \\
\hline 42 & 0.050 & 102 & 0.714 \\
\hline 48 & 0.074 & 108 & 0.847 \\
\hline 54 & 0.106 & 114 & 0.997 \\
\hline 60 & 0.145 & 120 & 1.162 \\
\hline 66 & 0.193 & 126 & 1.346 \\
\hline 72 & 0.251 & 132 & 1.547 \\
\hline 78 & 0.319 & & \\
\hline
\end{tabular}

Given the impeller power relationship, equation [1], and substituting in Froude's correlation, the power in the full scale can be estimated using equation [9]. Using equation [9] and $0.65 \mathrm{hp}$ for the 31-inch hopper test, the power for the 51-inch hopper is calculated to be $4.16 \mathrm{hp}$. Using equation [9.7] in reference 12 for the power number for an unbaffled tank, it would yield a slightly lower horsepower requirement for the larger scale, but the coefficients in the gravitational effects are unknown.

$$
\mathrm{P}_{2}=\mathrm{P}_{1}\left(\frac{\mathrm{D}_{2}}{\mathrm{D}_{1}}\right)^{\frac{7}{2}}
$$




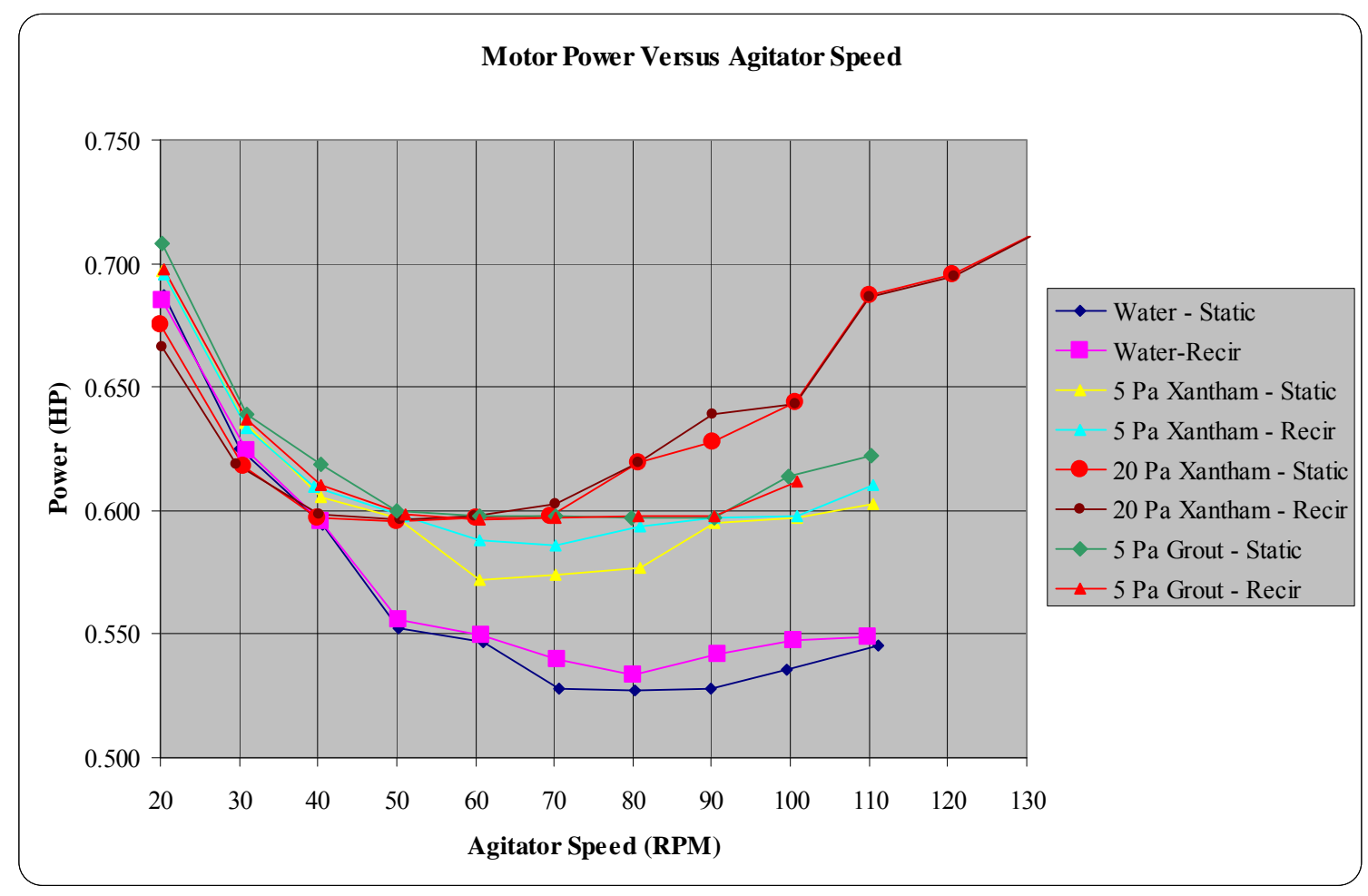

Figure 5-16. Power versus Speed for all fluids tested other than air.

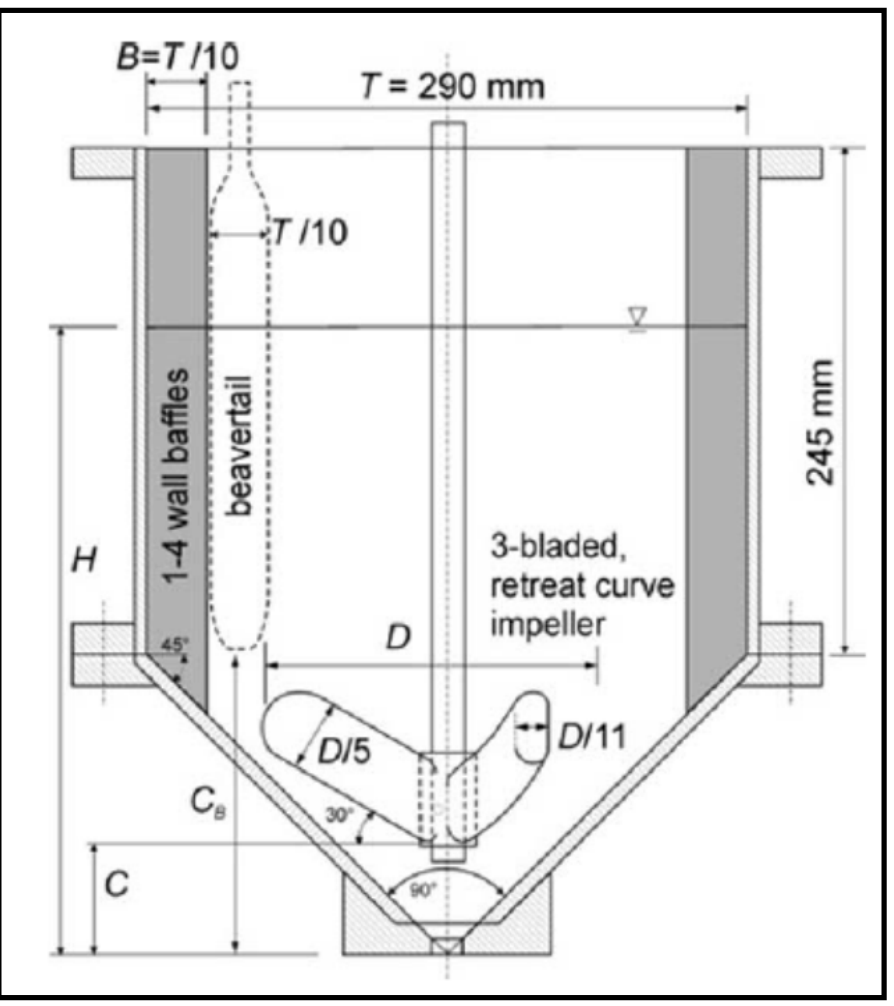

Figure 5-17. Retreat curve impeller in a conical based vessel. ${ }^{20}$ 


\subsection{Conclusions}

A total of 9 tests, using water, 5 Pa xanthan gum, 20 Pa xanthan gum, 5 Pa grout were performed. These tests included both static and recirculation tests for each fluid and a dry addition of premix into the 5 Pa grout. The testing addresses the questions in the TTR;

1. The size of the vortex will not impact the operation of the radar level instrument given the nominal range of tank operations is between 300 to 330 gallons.

2. The addition of dry premix to the hopper did not cause operational issues with the proposed hopper, given the test conditions, which was a static tank with the addition of dry solids. Review of the grout level data indicates that this addition would be difficult to measure during processing, given that in the actual process, the grout is being pumped out of the vessel as the dry addition is made. The test data indicates that less than 74 seconds was required to incorporate the solids into the fluid, but in the actual process, this time is expected to be much shorter, since operating with a vortex will help entrain the solids.

3. Baffles are not required for any of the fluids that will be processed through the Saltstone Facility. Operating with a vortex is adequate for this hopper design. The intent of this hopper is not to mix the contents, but to keep the vessel in constant motion since mixing of the premix and salt solution is occurring in the READCO mixer.

Additional observations from this testing are:

1. Froude's correlation is applicable to the agitation observed. Due to the absence of baffles, the development of a vortex occurs and became larger as the agitator speed increases.

2. No significant changes in level measurement with the radar sensor were observed during static or recirculation testing. Large spikes in the radar level measurement were noted but were not visually observed. These spikes did not occur often and had little impact on the average radar level reading.

3. The measured level from the radar sensor increased with increasing agitator speed, i.e., increases in level measurement due to vortex generated by the agitation, above the static condition $(20 \mathrm{rpm})$, were observed at increased agitator rotation speeds (greater than 40 $\mathrm{rpm})$.

4. The upper impeller did not greatly influence the vortex. As the agitator speed increased the upper impeller moved with the fluid to a point where the upper impeller was moving with the fluid. As such, the upper impeller may not be required.

5. Recirculation flow had minimal impact on the agitation of the contents in the tank. The agitator provided more flow than what the recirculation line could provide, hence dominated the agitation.

6. The recirculation flow rate provided a baffling effect, slightly reducing the height of the vortex.

7. As the vortex got deeper during the recirculation flow tests, a higher pump speed was required to maintain the targeted recirculation flow rate. This was not the case for the 20 $\mathrm{Pa}$ xanthan gum, where the pump speed decreased as the agitation increased to maintain flow.

8. The power of the agitator motor ranged between 0.65 to 0.75 horsepower, this includes mechanical losses in the motor and gearbox, power to the fluid, and electrical losses in 
the motor. Fluid type (water to non-Newtonian) did not seem to impact power consumption.

9. The power numbers used in this design over-estimated the power requirements of the agitation system.

10. Assuming turbulent flow, Froude's correlation and a power of $0.65 \mathrm{hp}$ in the 30 -inch scale, the power for the full scale would be less than $4.16 \mathrm{hp}$. Use of a larger motor, as designed, is not expected to cause any issues.

11. If the agitator blade is not moving and located directly below the radar, it will provide a false level indication if the fluid is below the top impeller. This may be corrected having the agitator rotate at a slow speed or realignment of the radar sensor.

12. Splashing from recirculation will coat the inside of the wetted surfaces of the hopper and was observed with the water and grout fluids.

13. During the dry premix addition into the $5 \mathrm{~Pa}$ grout, changes in tank level and power were not significant enough to determine that this addition occurred.

14. The dry premix was fully incorporated in the $5 \mathrm{~Pa}$ grout in approximately 74 seconds. This measurement was impacted by the dust in the vapor space of the vessel and it is expected that it takes less time to incorporate the solids.

15. Recommended agitator speeds for the 30-inch hopper are between 50 to $80 \mathrm{rpm}$ for the water to $5 \mathrm{~Pa}$ fluids and 70 to $100 \mathrm{rpm}$ for the $20 \mathrm{~Pa}$ fluid.

16. Using Froude's correlation, the agitator speed for the full scale hopper is between 40 and $60 \mathrm{rpm}$ for fluids with less than $7 \mathrm{~Pa}$ yield stress and 50 to $75 \mathrm{rpm}$ for more viscous fluid.

17. The change in fluid height between a baseline condition (at $20 \mathrm{rpm}$ ) and a vortex just above the top impeller on the 30 -inch hopper using the radar was 1.4 inches. Above this difference, the vortex grows to a point where it is below the hub of the top impeller.

18. As the vortex gets deeper, the top impeller appears to have no effect on the mixing. The impact of the top impeller during the addition of dry solids may contribute to entrainment of the solids. 


\subsection{Recommendations}

The recommended agitator speed for a working volume between 300 to 330 gallons for the new Saltstone Grout Hopper is provided in Table 7-1. It is expected that a majority of Saltstone operations will have fluids that range between water to grouts having an upper yield stress of approximately $7 \mathrm{~Pa}$. The agitator must also have the ability to mix the design basis fluid; hence agitator speeds of up to $75 \mathrm{rpm}$ should be available.

Table 7-1. Recommended Agitator Speeds for the New Saltstone Hopper, 300 to 330 gallons of Working Volume

\begin{tabular}{||c|c|}
\hline Fluid Yield Stress (Pa) & Operating Range (rpm) \\
\hline 0 to 7 & 40 to 60 \\
\hline$\sim 20$ & 50 to 75 \\
\hline
\end{tabular}

It should be noted that all recommended operating parameters are based on the nominal operating level in the hopper of 300 gallons. If the nominal level will be changed, SRNL recommends verifying the operating parameters, agitator speed, etc., prior to running. When the grout leaving the READCO mixer hits the surface of the grout in the hopper, splashing will occurring and internal surfaces of the hopper will be coated with grout. The method, volume and frequency of process water required to remove the splatter grout needs to be determined.

The bottom of the bottom impeller should be located at 6 inches from the bottom of the truncated conical section for the full scale hopper. Additional details of the full scale mixing system agitator mixer blade characteristics are provided in Table 2-2. 
SRNL-STI-2011-00465

Revision 0

\subsection{References}

${ }^{1}$ Pickenheim, B.R. Saltstone ELAWD Dry Feed Over-Addition Calculation; X-ESR-Z-00017, Rev. 0; Savannah River Site; Aiken, SC, 2011

${ }^{2}$ Pickenheim, B.R., ELAWD Grout Hopper Mock-Up Testing; HLW-SSF-TTR-0005 Rev. 0; Savannah River Site; Aiken, SC, 2011.

${ }^{3}$ Pickenheim, B.R., Task Technical and Quality Assurance Plan for ELAWD Grout Hopper Mock-Up Testing; SRNL-RP-2011-00944 Rev. 0; Savannah River National Laboratory; Aiken, SC, 2011.

4 13239-MH-21124-58(1)-7, Agitator Data Sheet, 12/16/1986

${ }^{5}$ Crapse, K. P., Culbertson, B. H., Chandler, T. E., and Cook, J. R., "FY2005 Annual Review - Saltstone Disposal Facility (Z-Area) Performance Assessment (Covering the Performance Period FY 2005), WSRCRP-2006-00568, April, 2006

${ }^{6}$ P-PM-Z-00006, Rev. 0, CBU - Waste Solidification Projects Saltstone Facility, Saltstone Hold Tank Agitator Modification, 9/12/2003

${ }^{7}$ P-PM-X-0004, Rev. 0, "CBU - Waste Solidification Projects Saltstone Facility Saltstone Hold Tank, Tank Modification and Insert Details", 9/12/2003

${ }^{8}$ P-PM-Z-00015, Rev. 1, CBU - Waste Solidification Projects Saltstone Facility, 0.2 Cl/gal Low Curie Salt Modifications Process Room Grout Hopper, 2/24/2010

${ }^{9}$ M-MF-Z-00001, Sheets 1 through 4, Revision A., Savannah River Plant - 200Z Area Saltstone Process Building - 210Z Process Room Grout Pump Hopper Details

${ }^{10}$ Chemineer Proposed Design, March 24, 2011

${ }^{11}$ Oldshue, J. Y., "Fluid Mixing Technology", Chemical Engineering McGraw-Hill Publication Company, $1^{\text {st }}$ edition, 1983

12 Skelland, A. H., "Non-Newtonian Flow and Heat Transfer", John Wiley \& Sons, $1^{\text {st }}$ edition, 1967

${ }^{13}$ Uhl, V. W. and Gray, J. B., "Mixing Theory and Practice - Volume 1", Academic Press, Inc., $1^{\text {st }}$ edition, 1966

14 Tatterson, G. B., "Scaleup and Design of Industrial Mixing Proceses", McGraw-Hill Inc., $1^{\text {st }}$ edition, 1994

15 Dickey, D. S., "Dimensional Analysis, Similarity and Scale-Up", Process Mixing - Chemical and Biochemical Applications: Part II, AIChE Symposium Series, No. 293, Vol. 89, pp 143 - 150

${ }^{16}$ Karcz, J, Cudak, M., and Szoplik, J., "Stirring of a liquid in a stirred tank with an eccentrically located impeller”, Chemical Engineering Science, Vol. 60, pgs 2369-2390, 2005

${ }^{17}$ Uhl, V. W. and Gray, J. B., "Mixing Theory and Practice - Volume I", Academic Press, Inc, $1^{\text {st }}$ edition, 1966

${ }^{18}$ Paul, E. L., Atiemo-Obeng, V. A. and Kresta, S. M., "Handbook of Industrial Mixing - Science and Practice", Wiley - Interscience. 2004

${ }^{19}$ Skelland, A. H. P., "Non-Newtonian Flow and Heat Transfer", John Wiley \& Sons, 1967

${ }^{20}$ Rielly, C. D., Habib, M. , and Sherlock, J. -P, "Flow and Mixing Characteristics of a Retreat Curve Impeller in a Conical-Based Vessel”, Vol. 85, pp 953-962, Trans IChemE, Part A, Chemical Engineering Research and Design, 2007 
SRNL-STI-2011-00465

Revision 0

\section{APPENDIX A: FLUID MOTION PICTURES FOR STATIC WATER} RUNS 


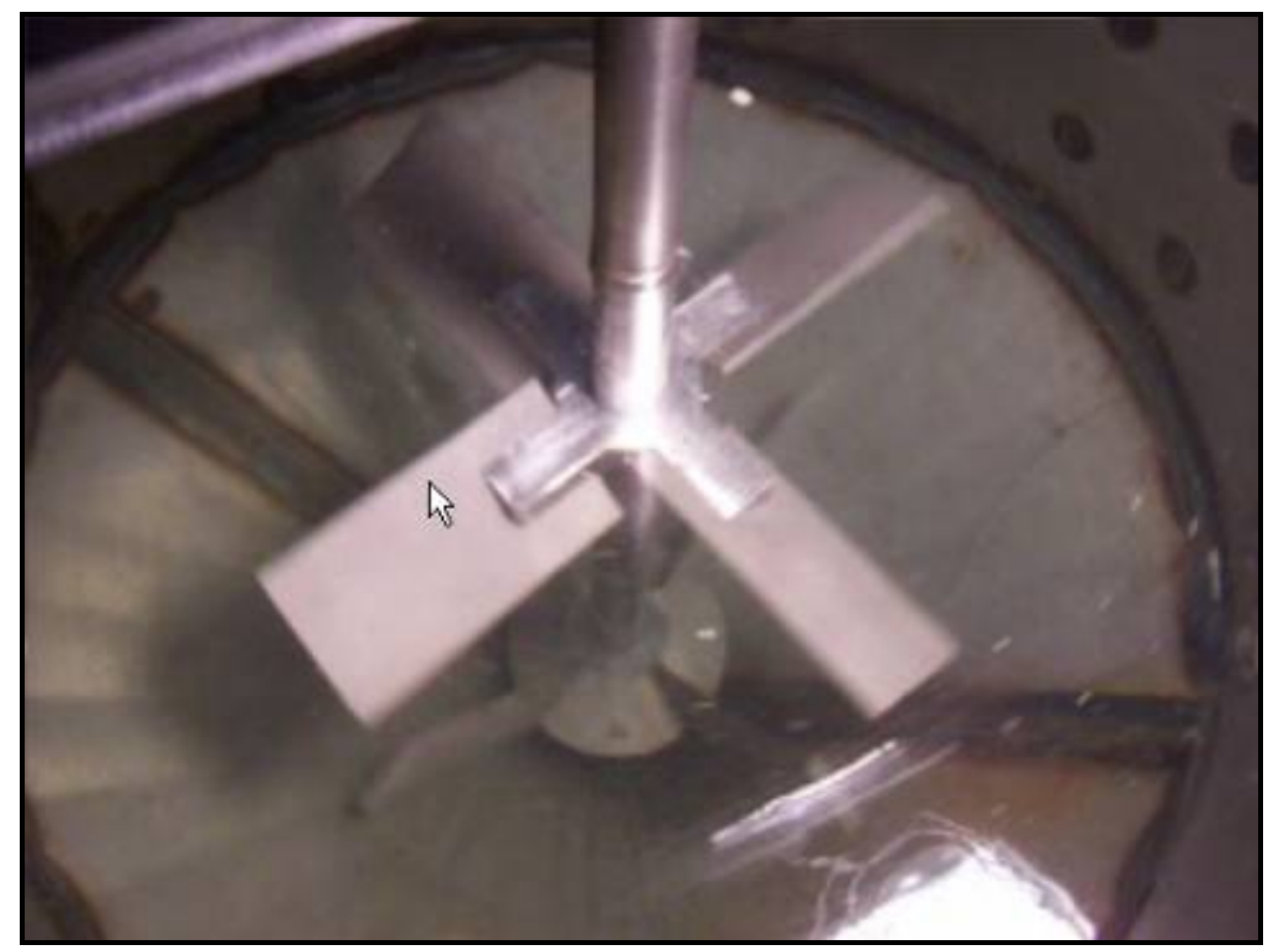

Figure A - 1 Water, 20 RPM, Static

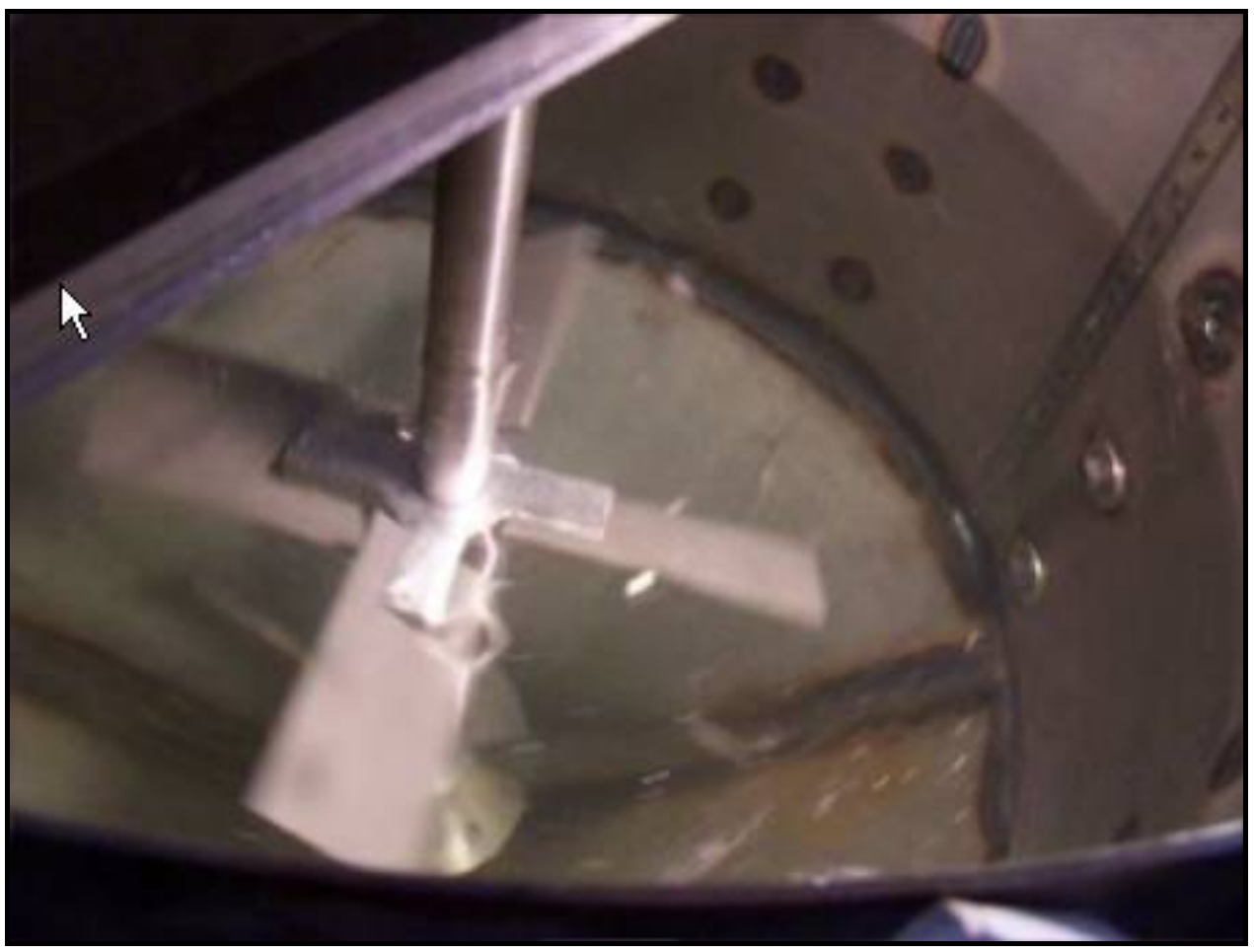

Figure A - 2 Water, 30 RPM, Static 


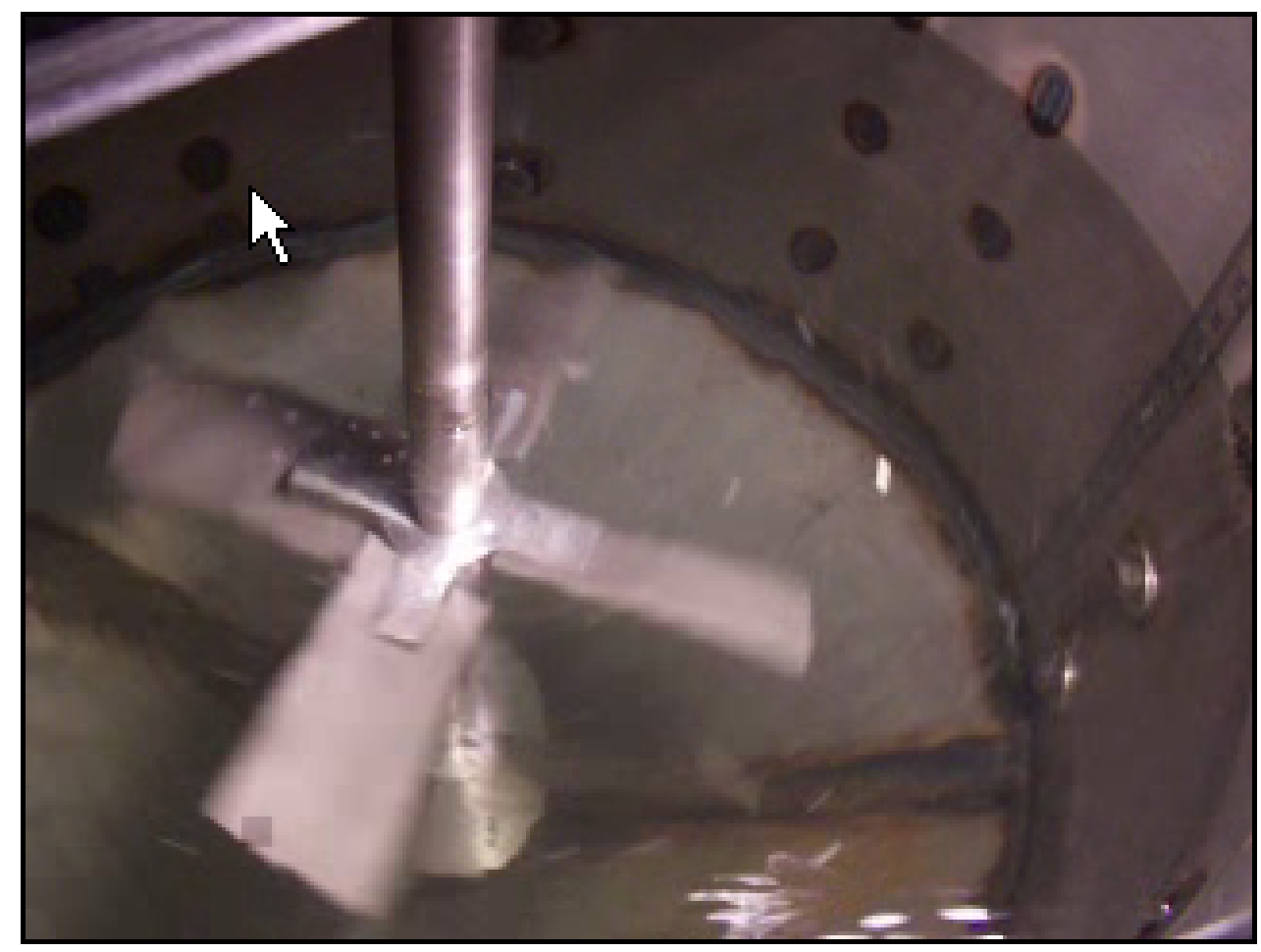

Figure A - 3 Water, 40 RPM, Static

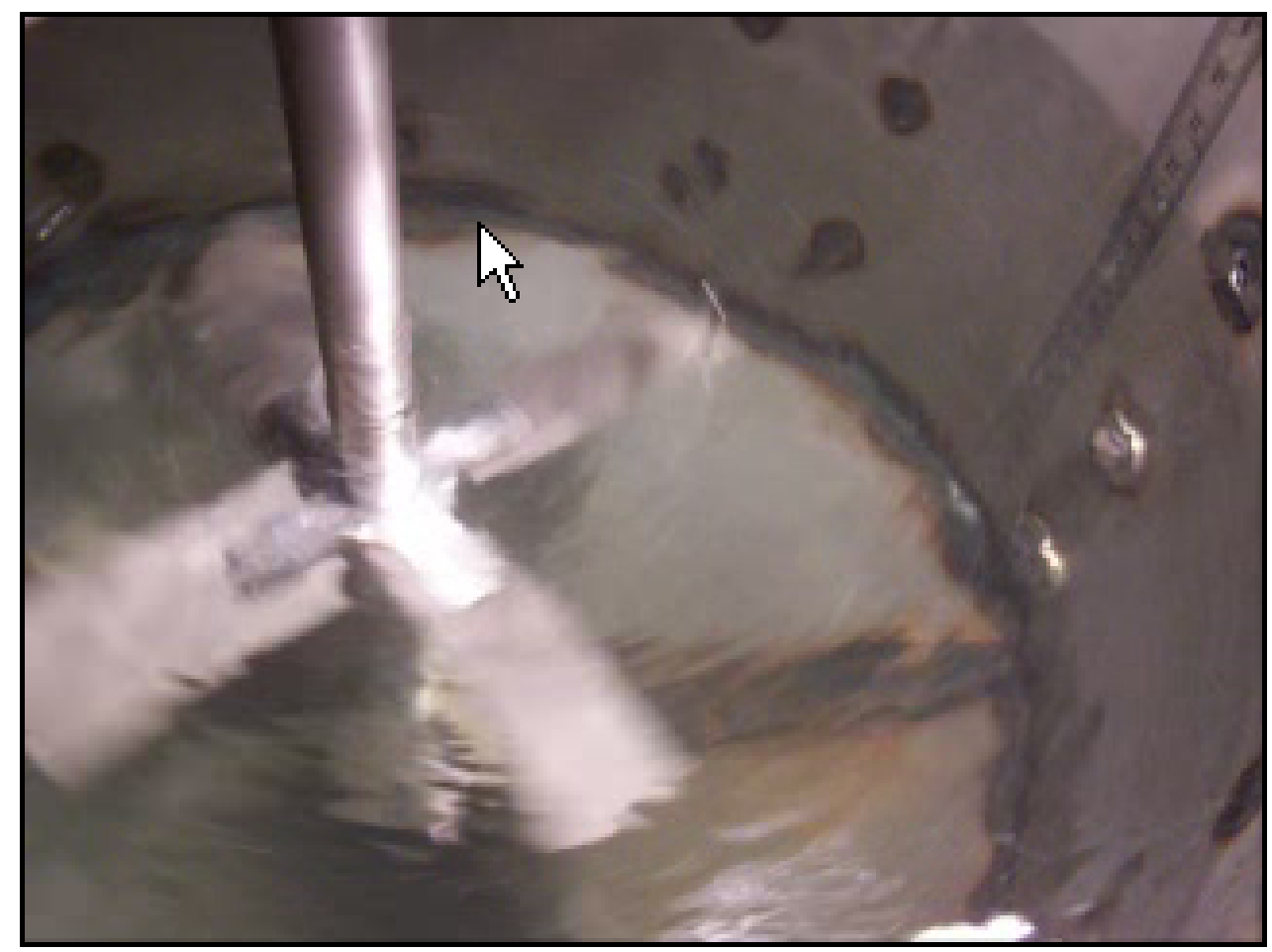

Figure A - 4 Water, 50 RPM, Static 


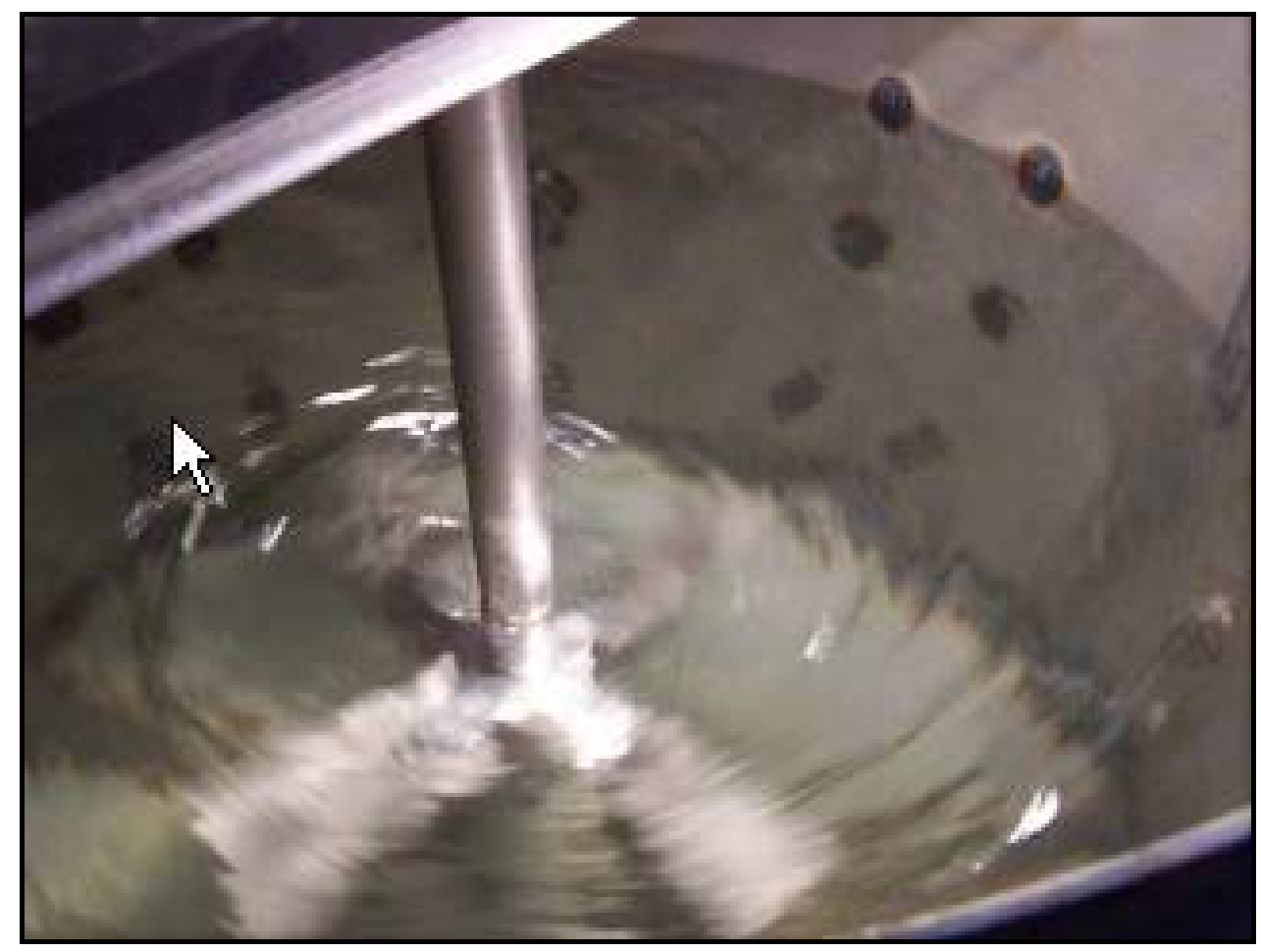

Figure A - 5 Water, 60 RPM, Static

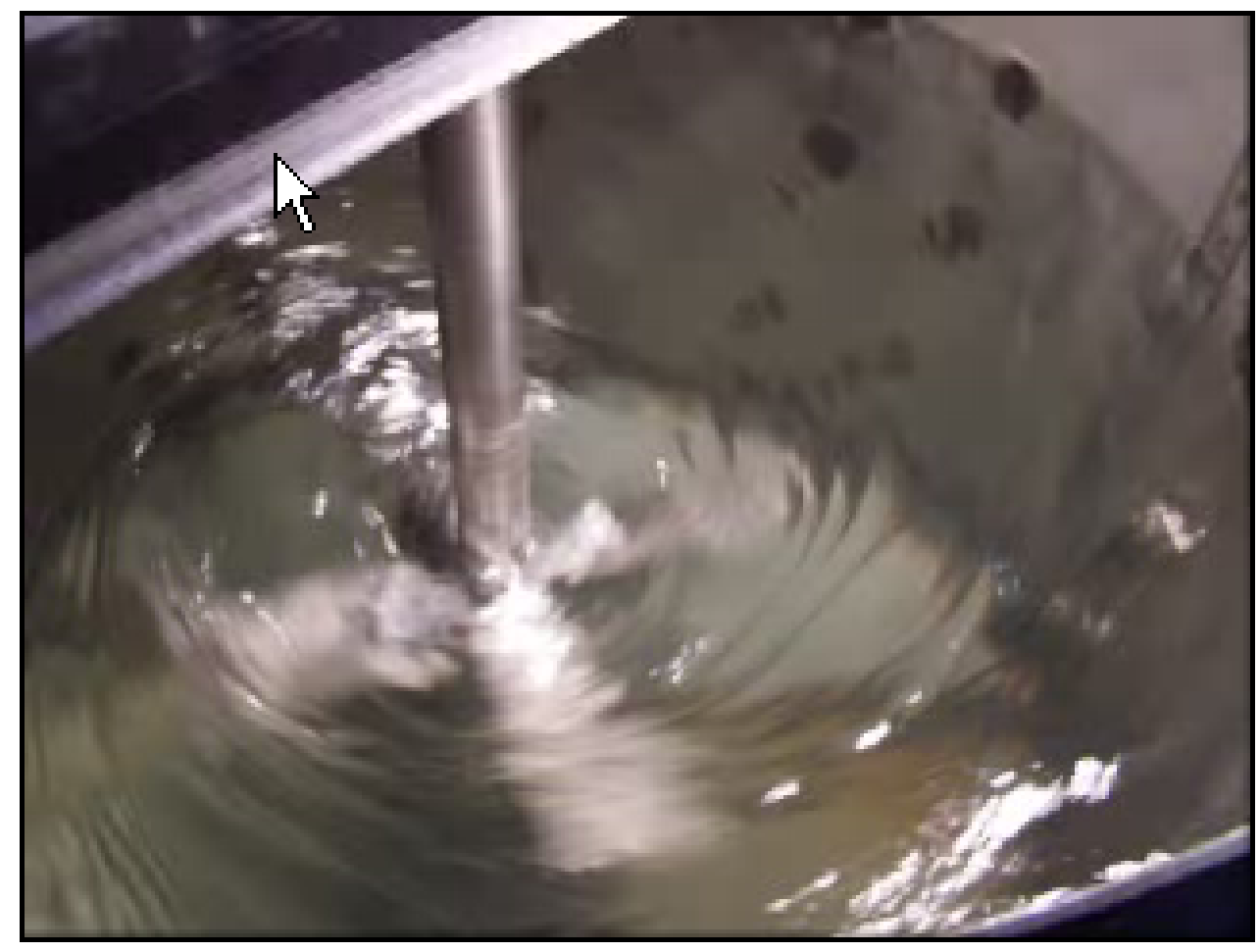

Figure A - 6 Water, 70 RPM, Static 


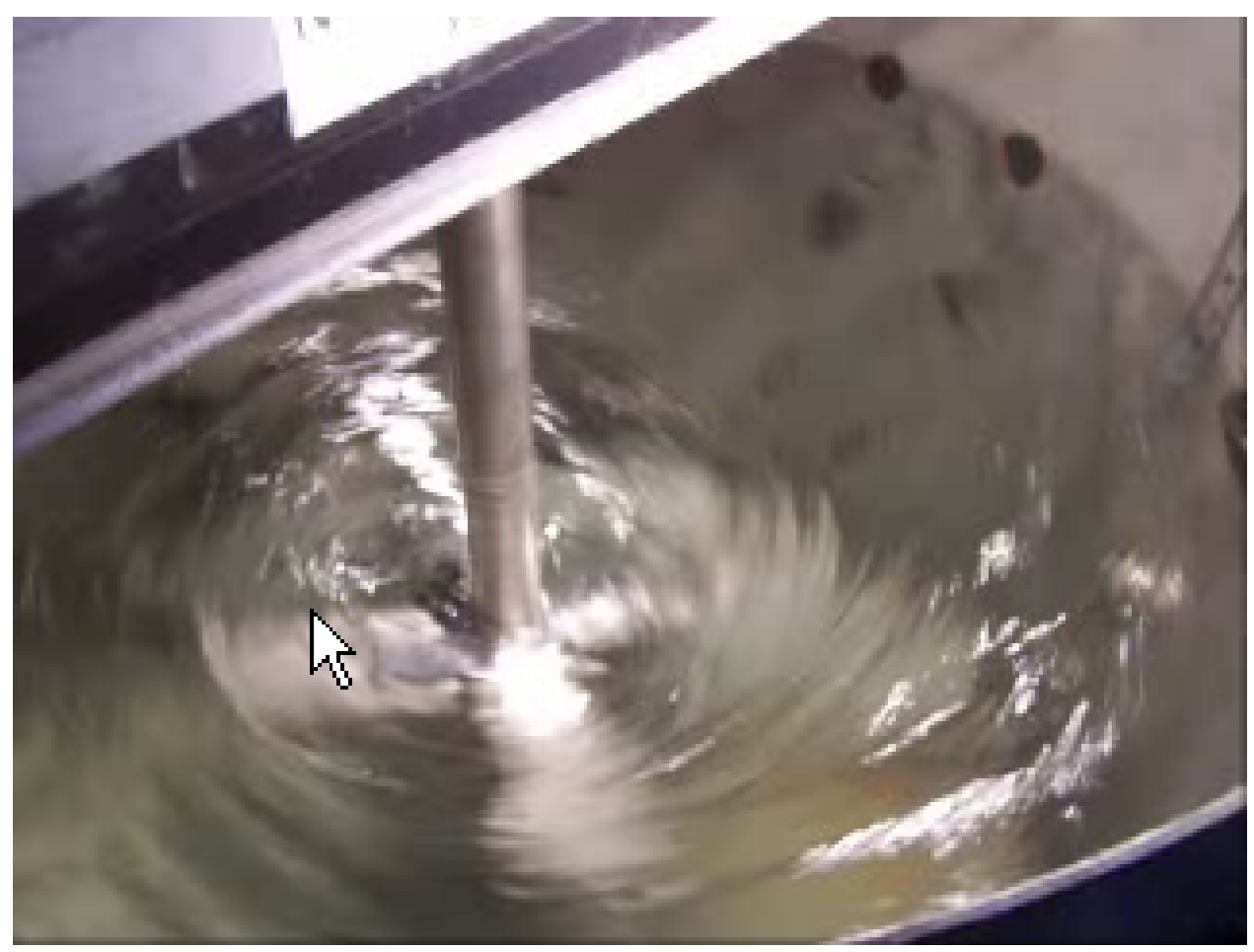

Figure A - 7 Water, 80 RPM, Static

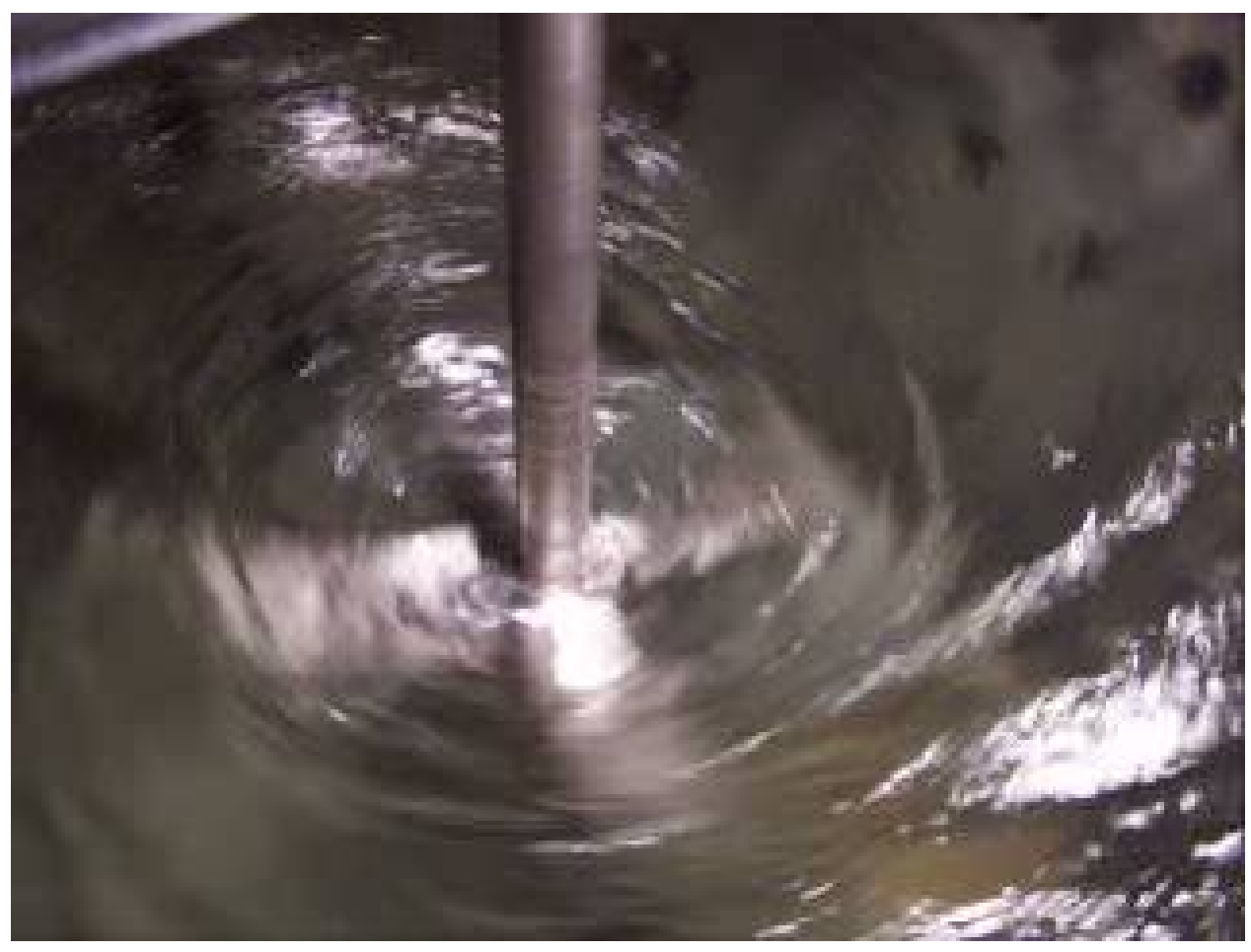

Figure A - 8 Water, 90 RPM, Static 


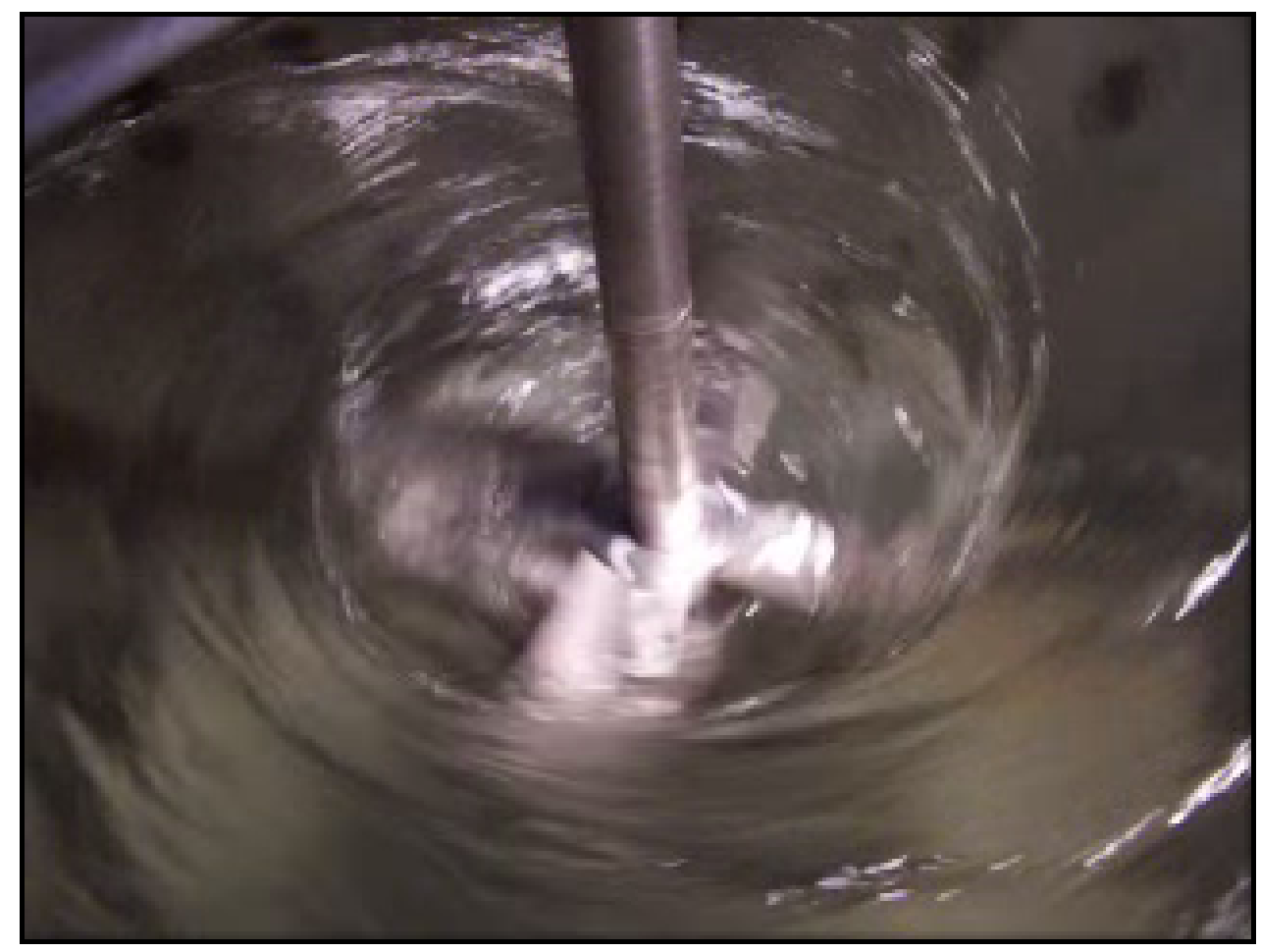

Figure A - 9 Water, 100 RPM, Static

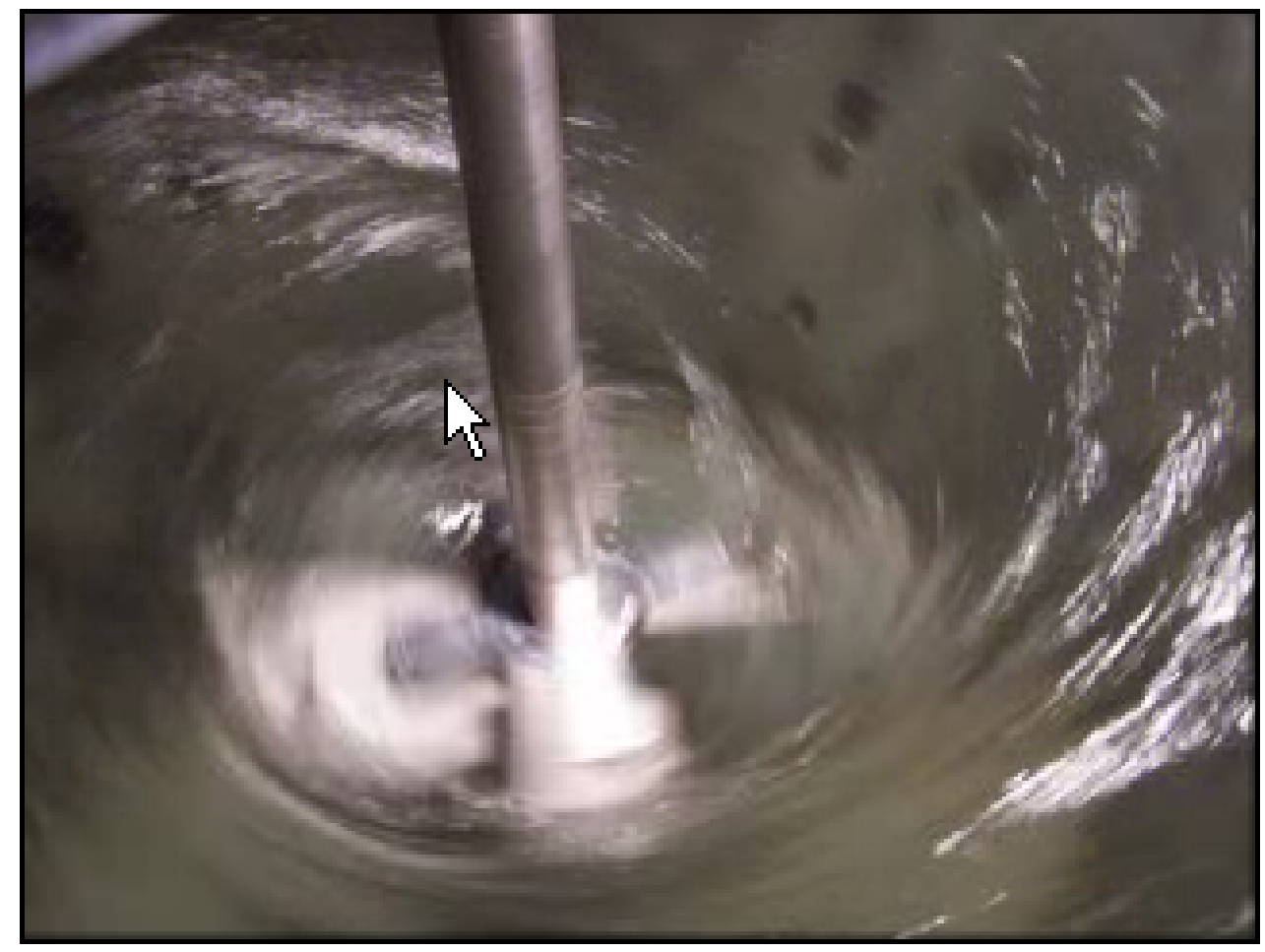

Figure A - 10 Water, 110 RPM, Static 
SRNL-STI-2011-00465

Revision 0

\section{APPENDIX B: MIXING PICTURES FOR RECIRCULATION WATER RUNS}




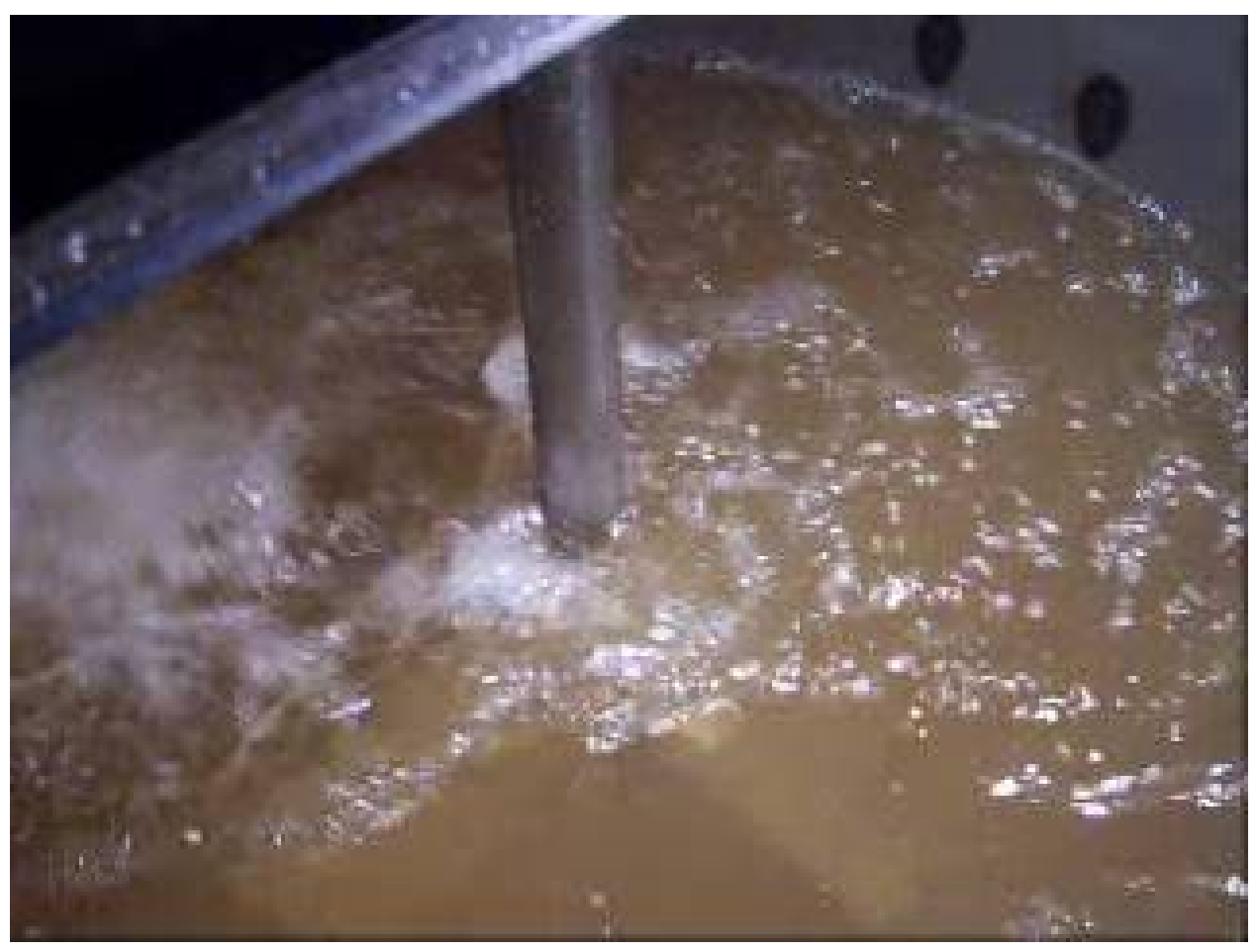

Figure B - 1 Water, 20 RPM, Recirculation

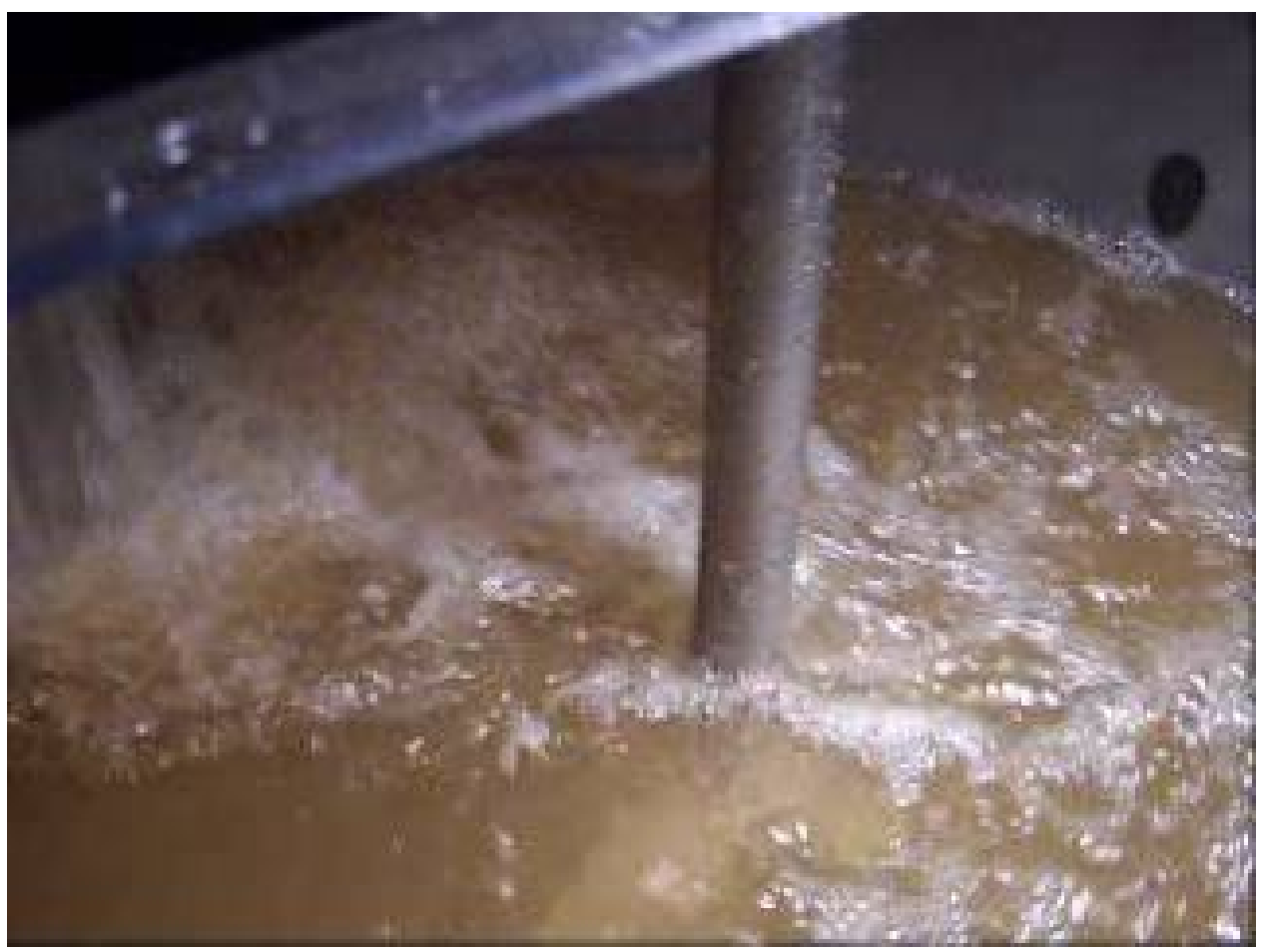

Figure B - 2 Water, 30 RPM, Recirculation 


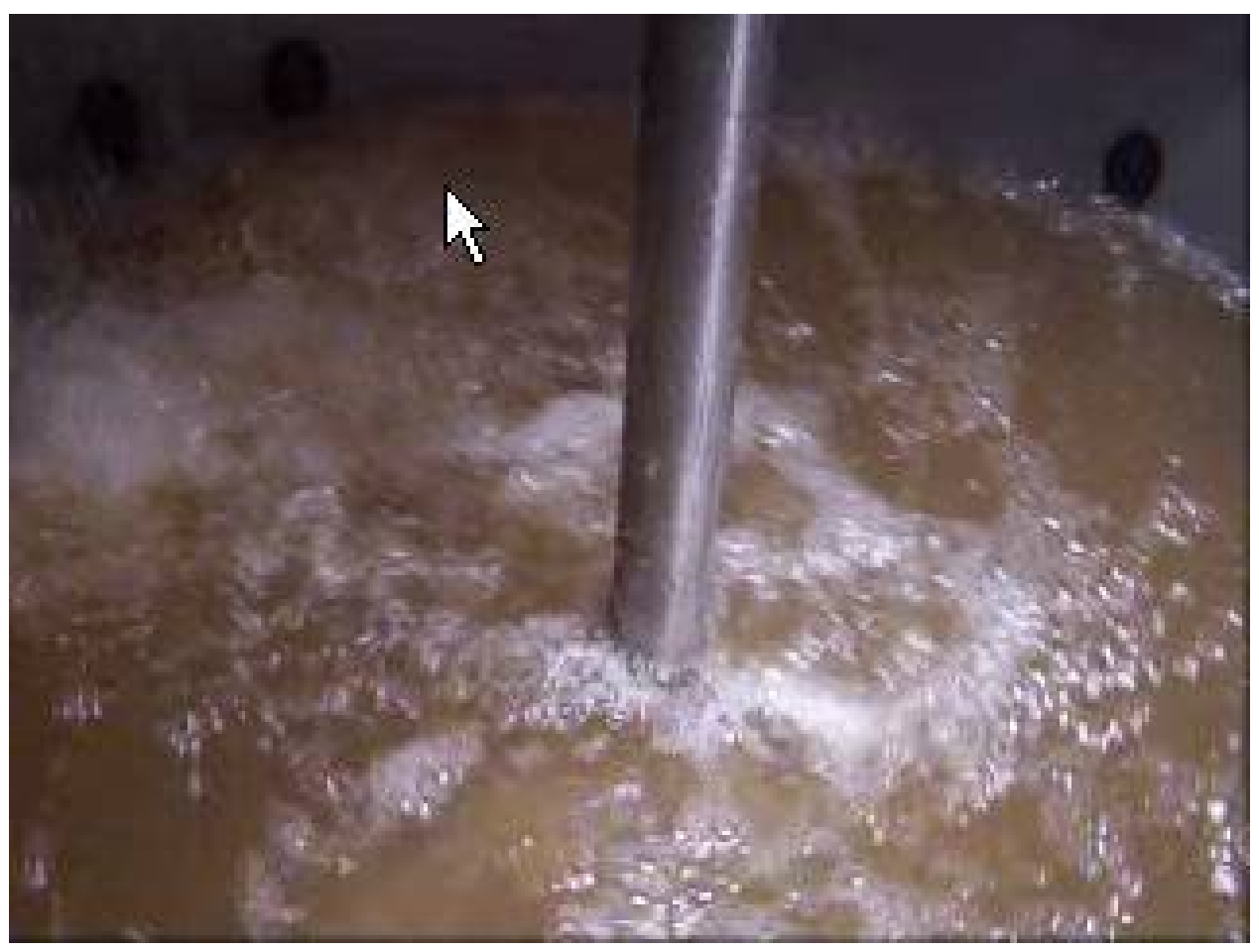

Figure B - 3 Water, 40 RPM, Recirculation

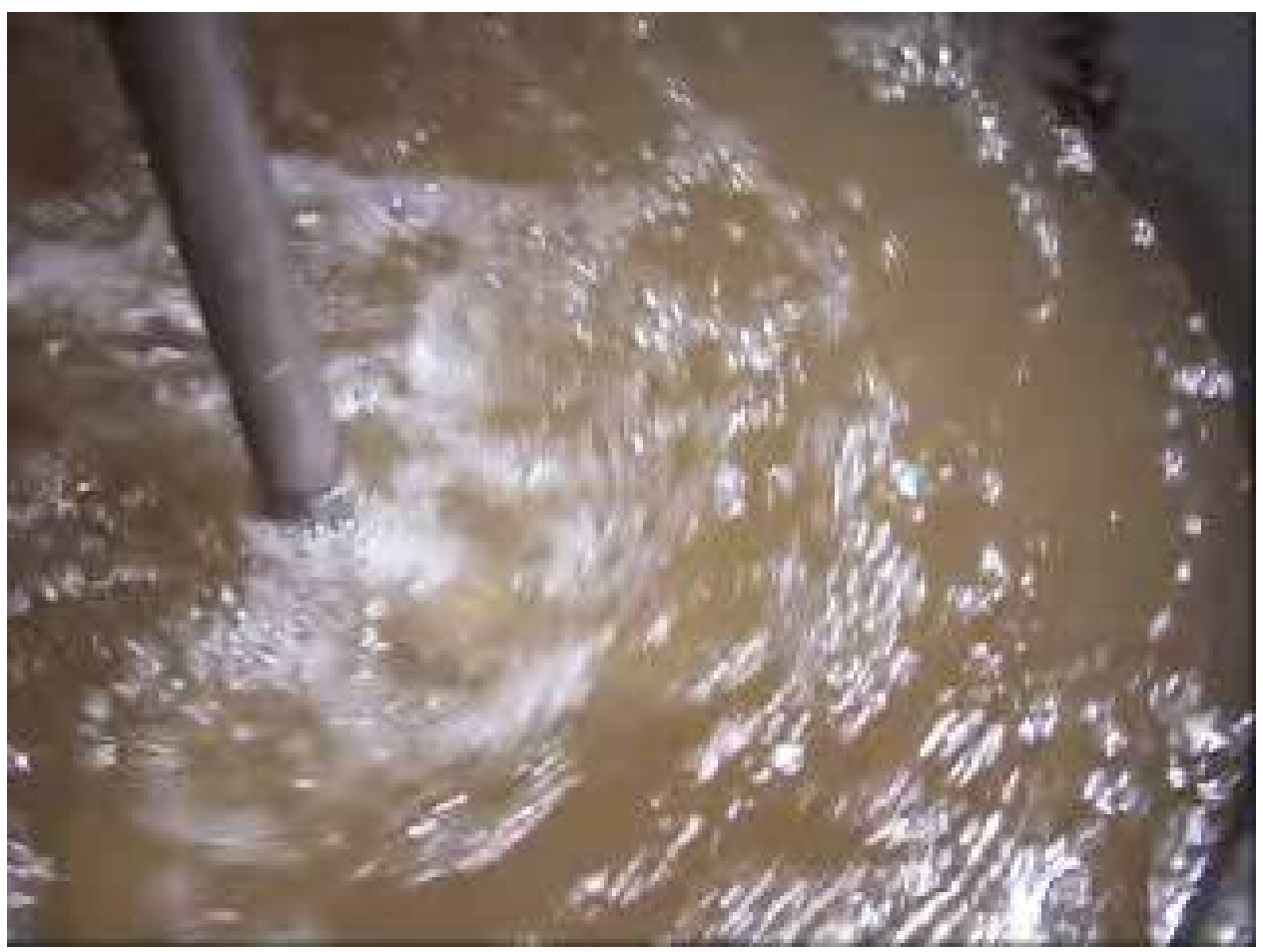

Figure B - 4 Water,50 RPM, Recirculation 


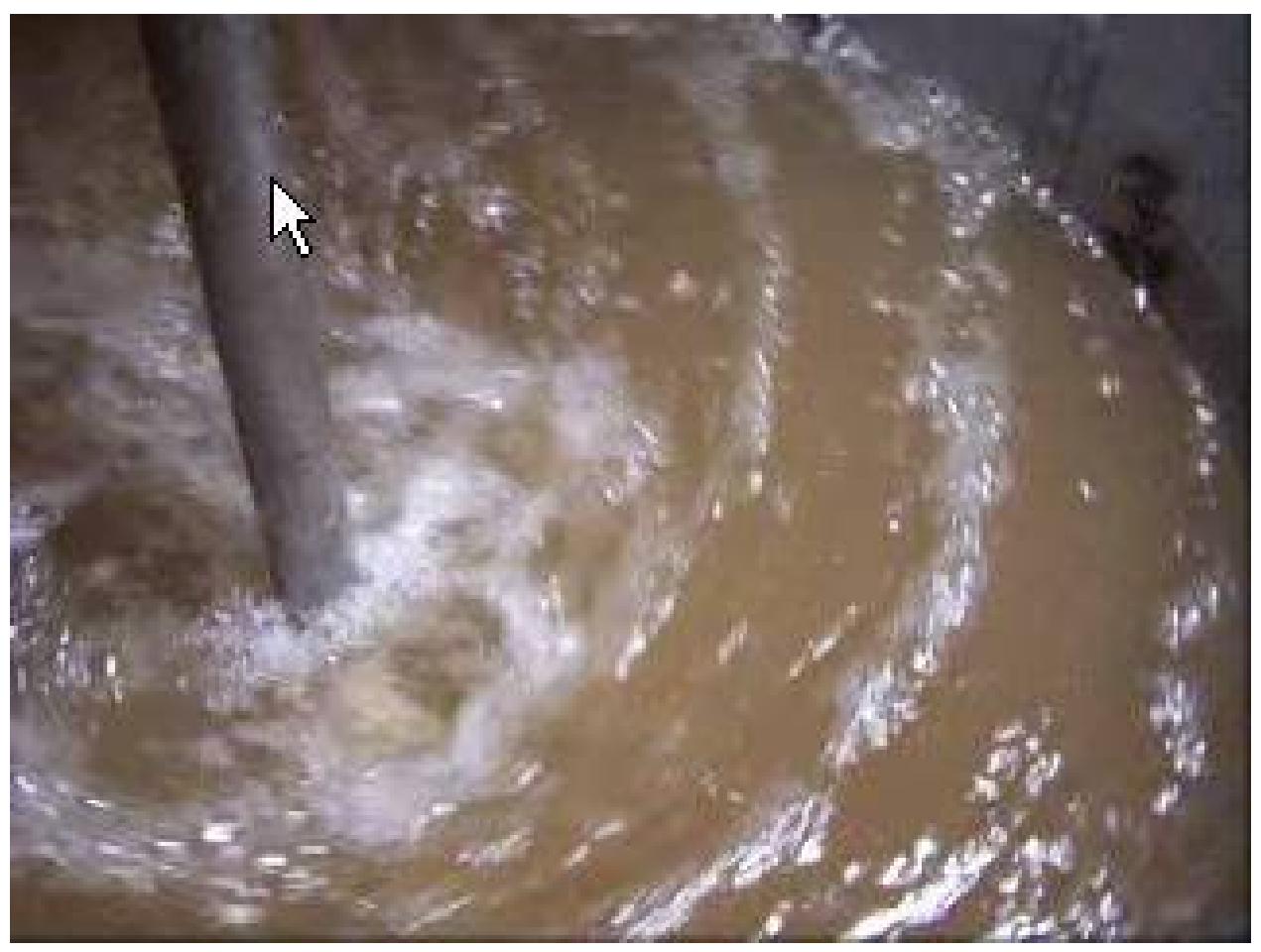

Figure B - 5 Water, 60 RPM, Recirculation

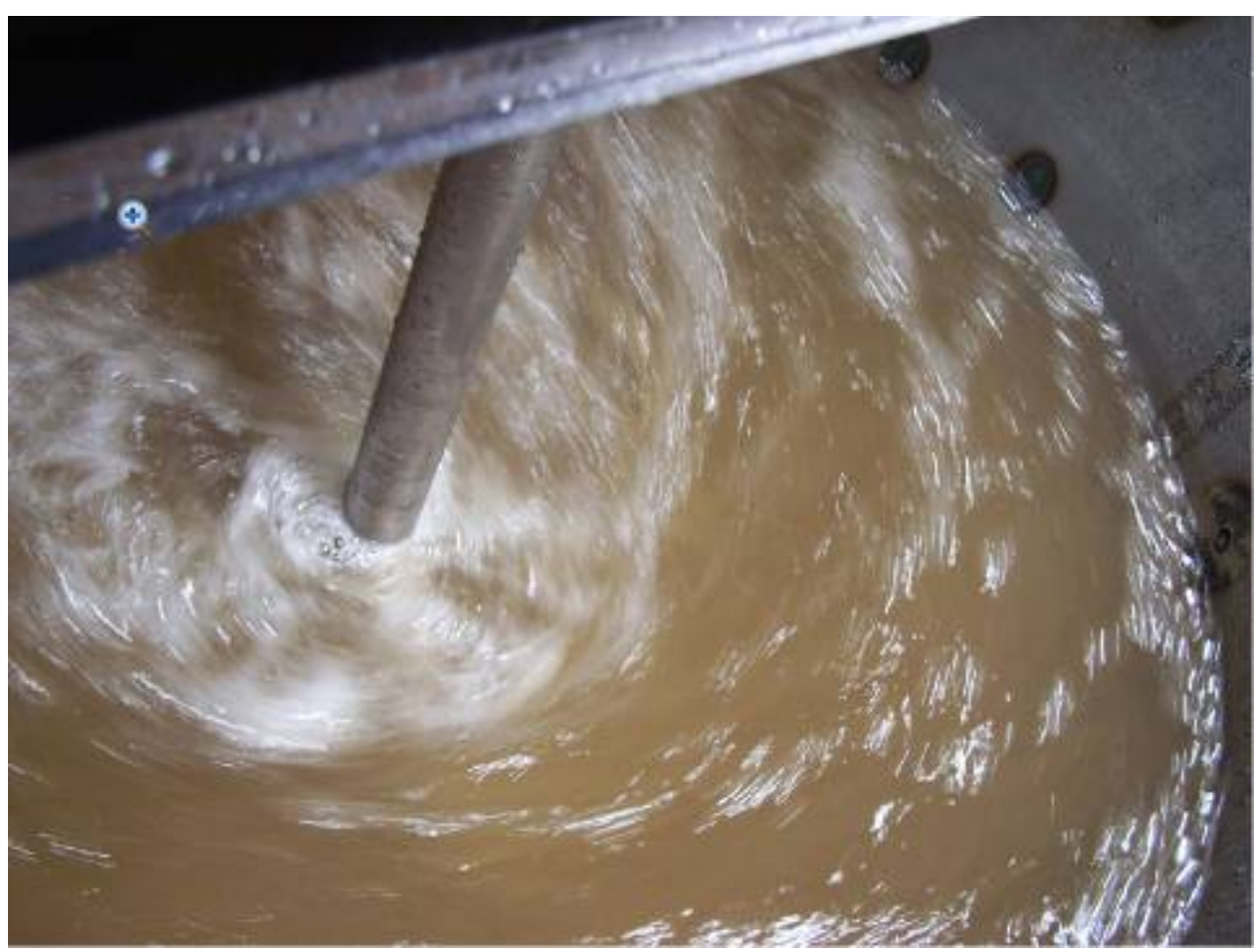

Figure B - 6 Water, 70 RPM, Recirculation 


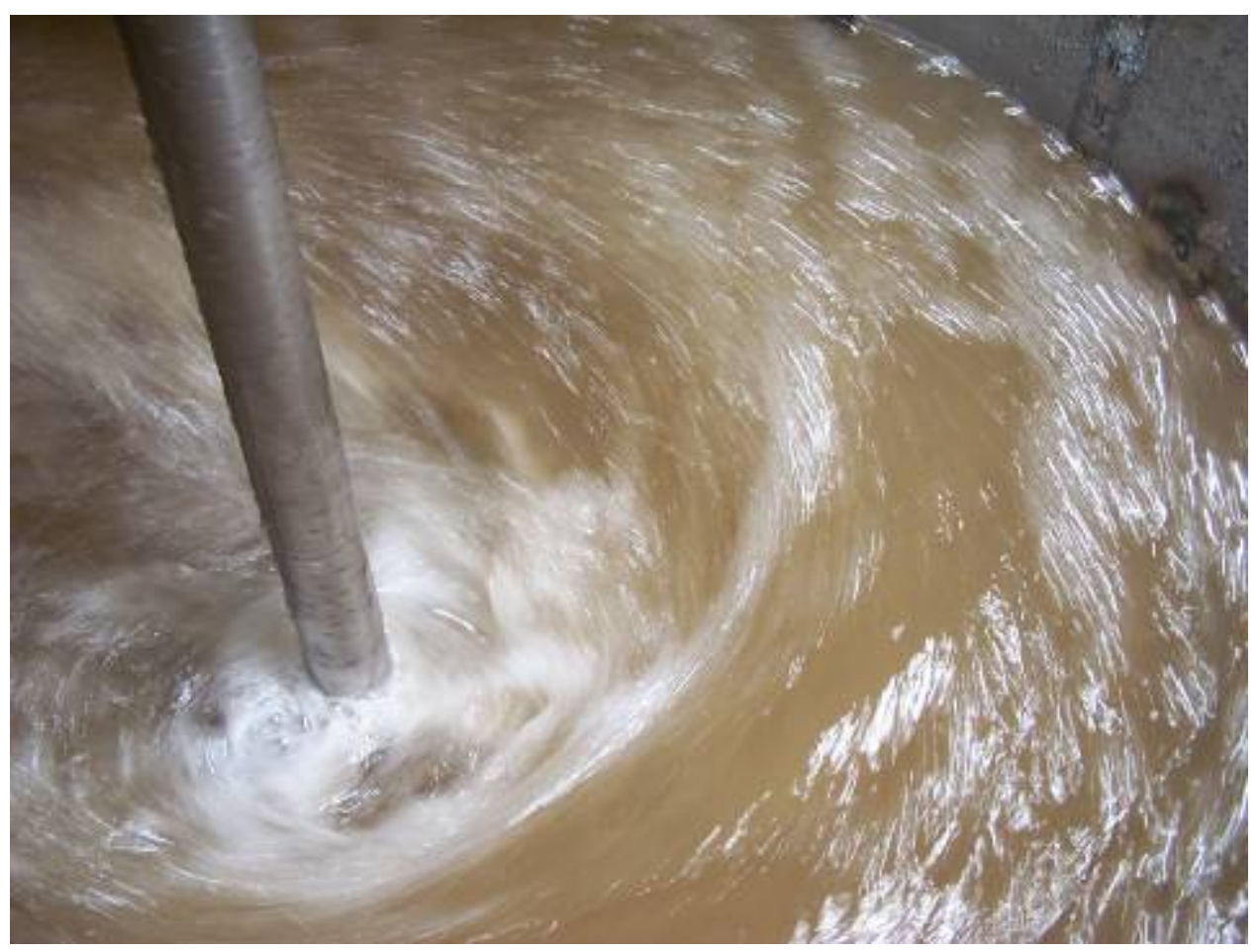

Figure B - 7 Water, 80 RPM, Recirculation

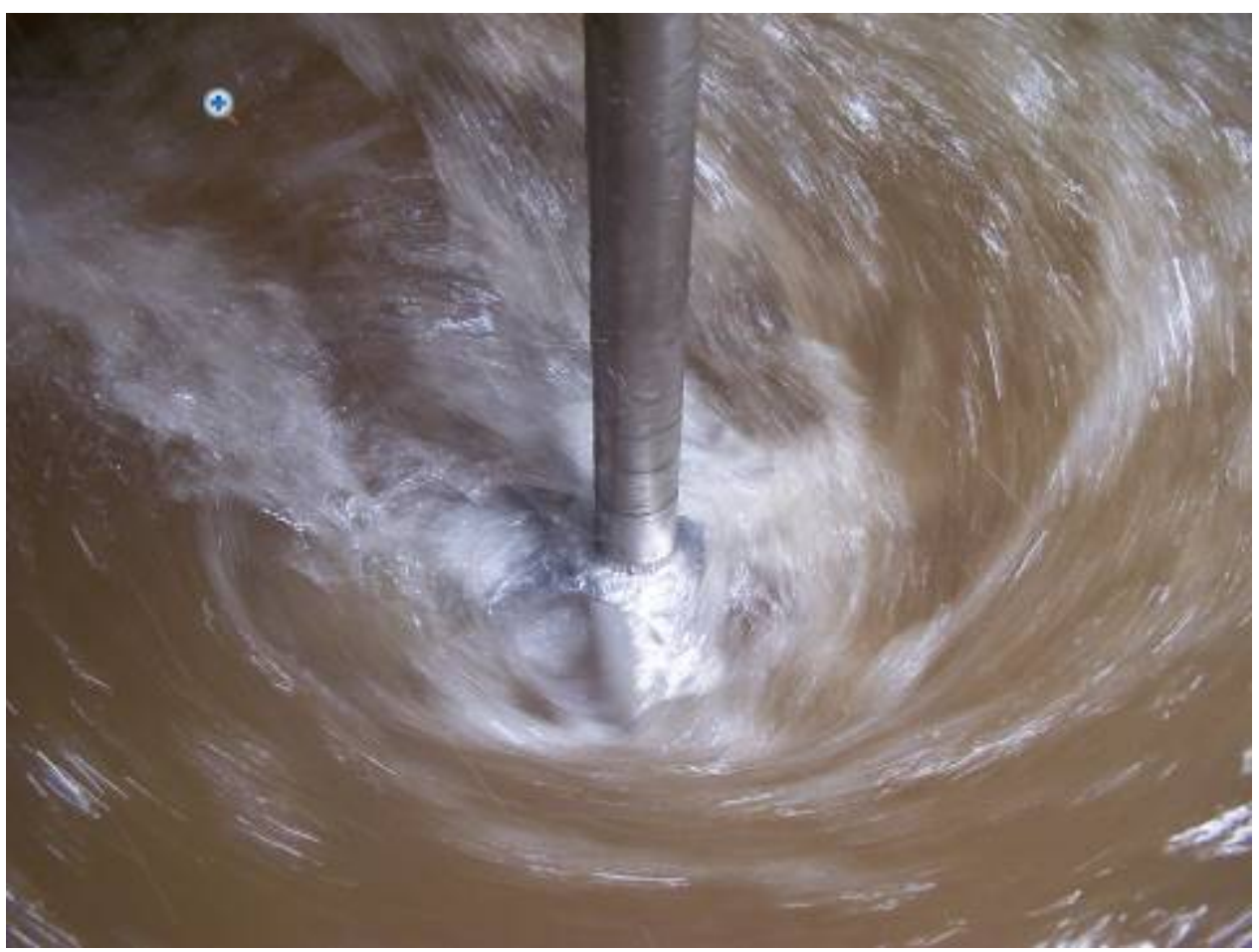

Figure B - 8 Water, 90 RPM, Recirculation 


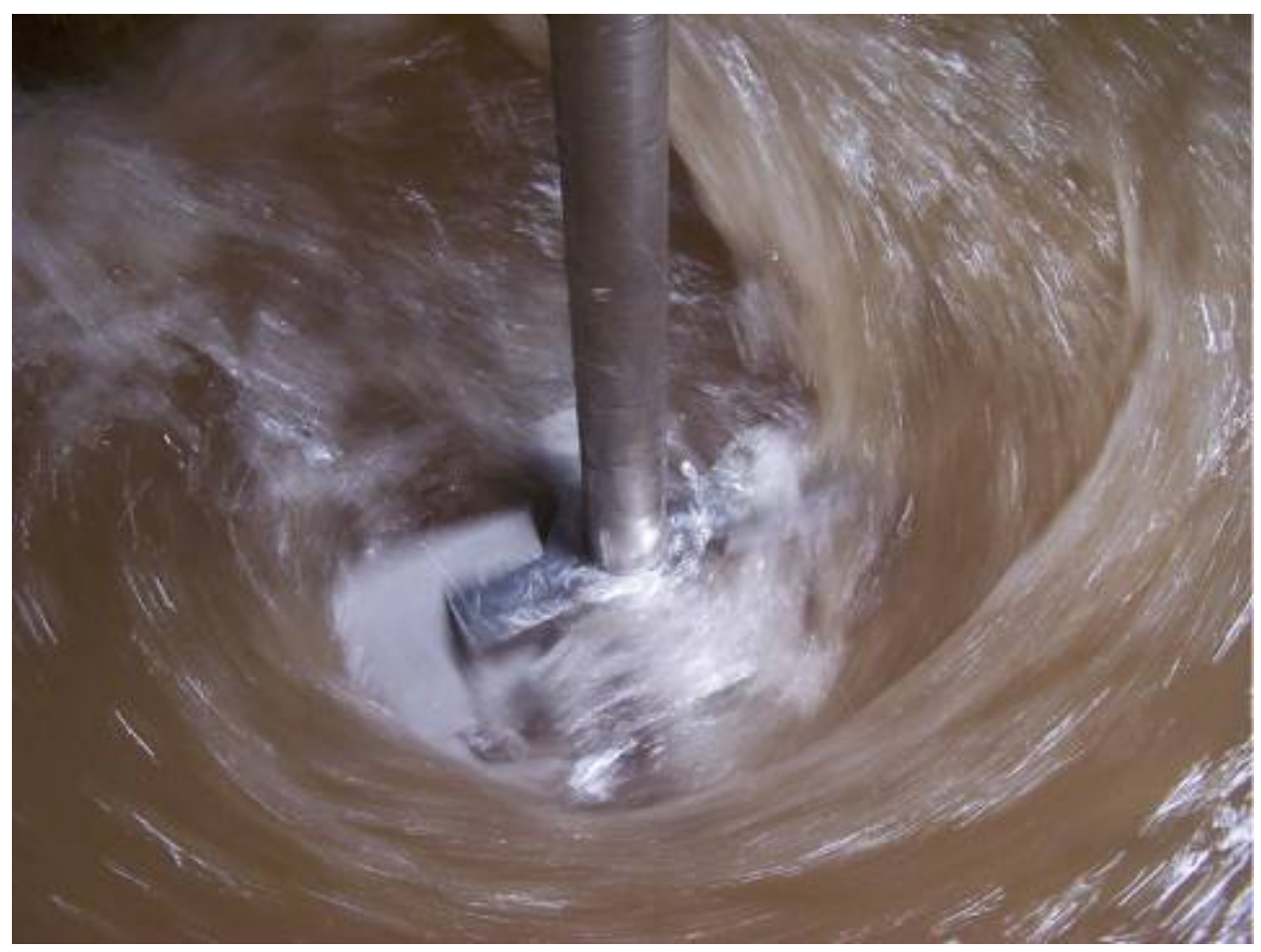

Figure B - 9 Water, 100 RPM, Recirculation

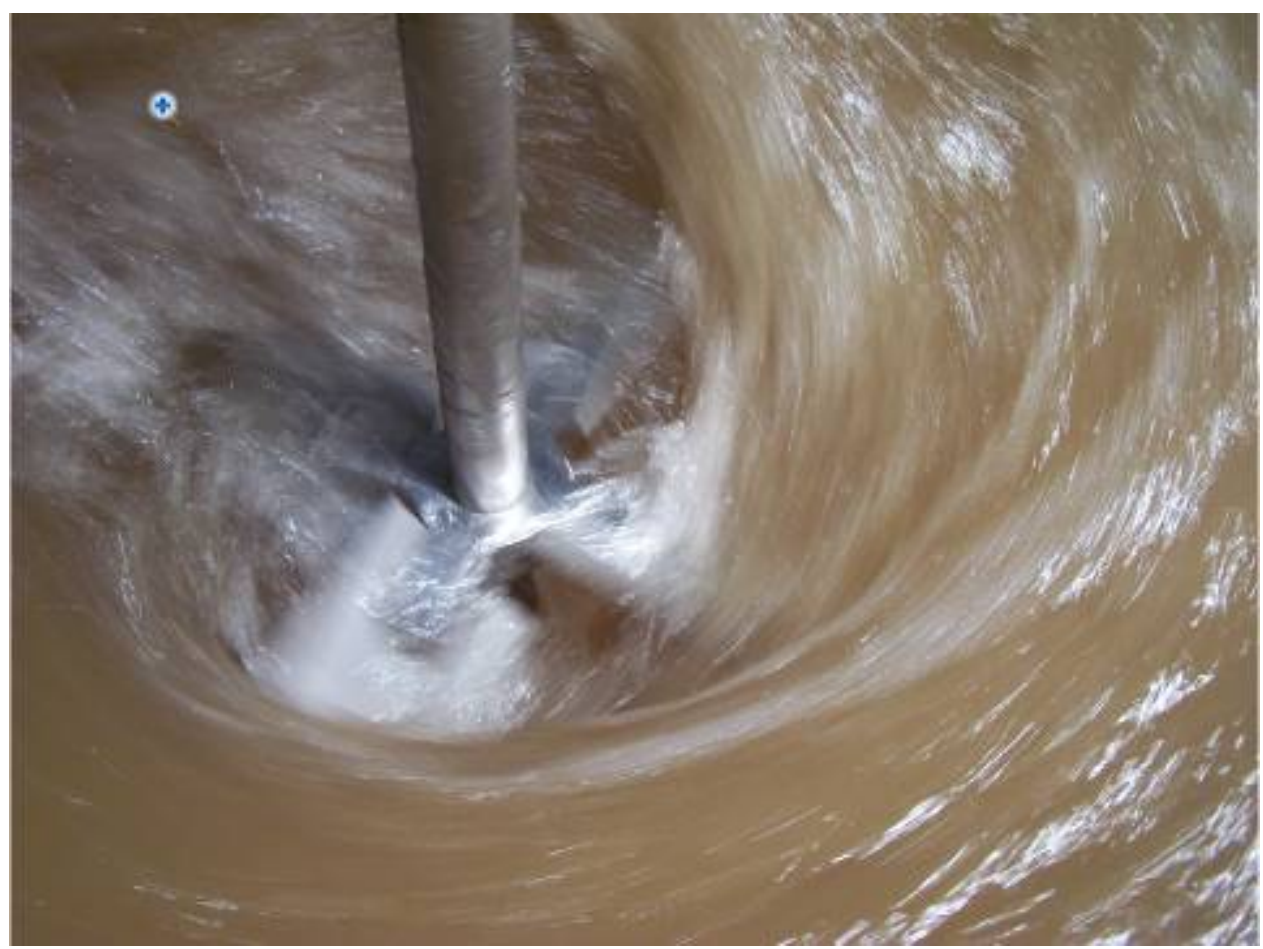

Figure B - 10 Water, 110 RPM, Recirculation 
SRNL-STI-2011-00465

Revision 0

\section{APPENDIX C: MIXING PICTURES FOR STATIC 20 PA XANTHAN GUM RUNS}




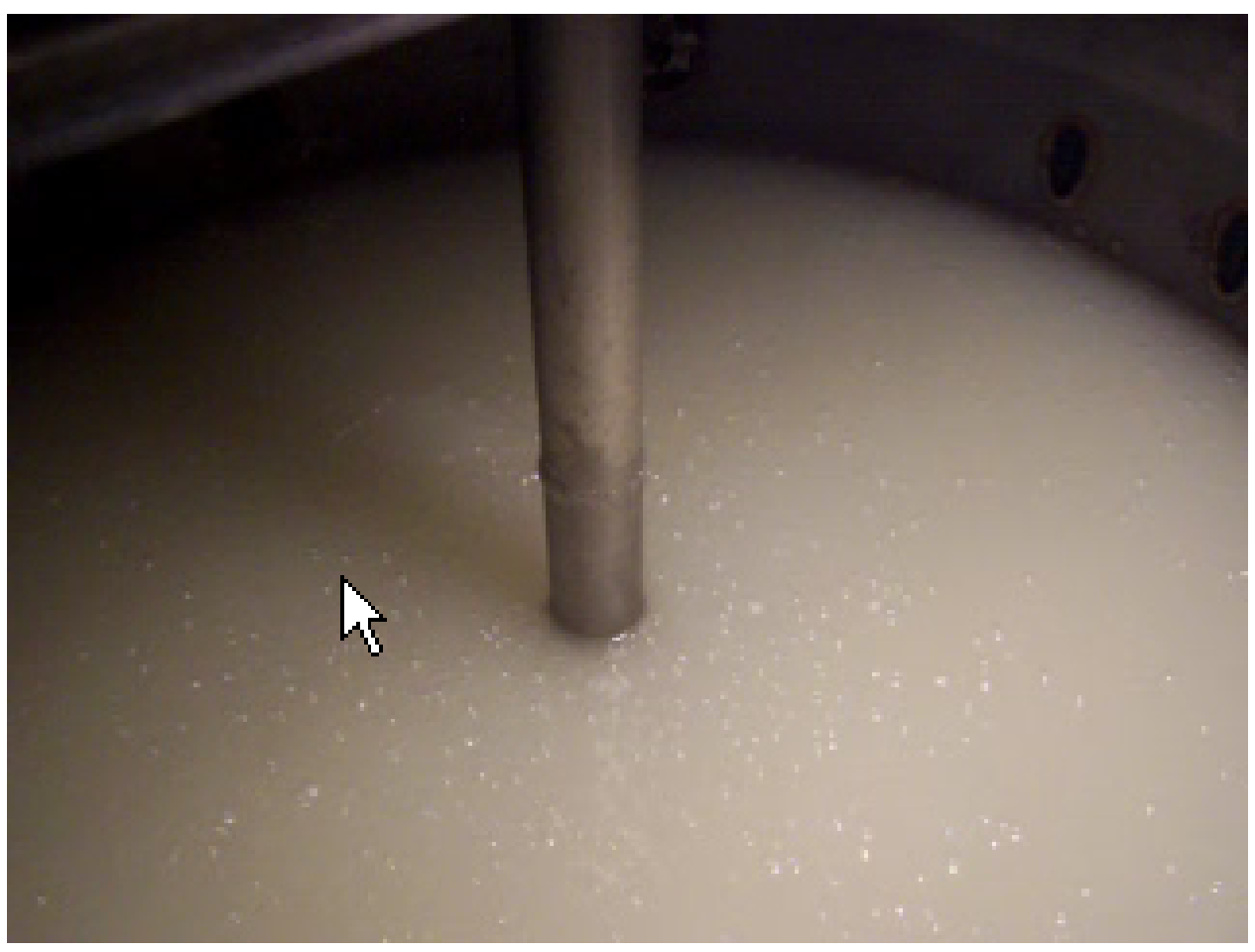

Figure C - 15 Pa Xanthan Gum, 20 RPM, Static

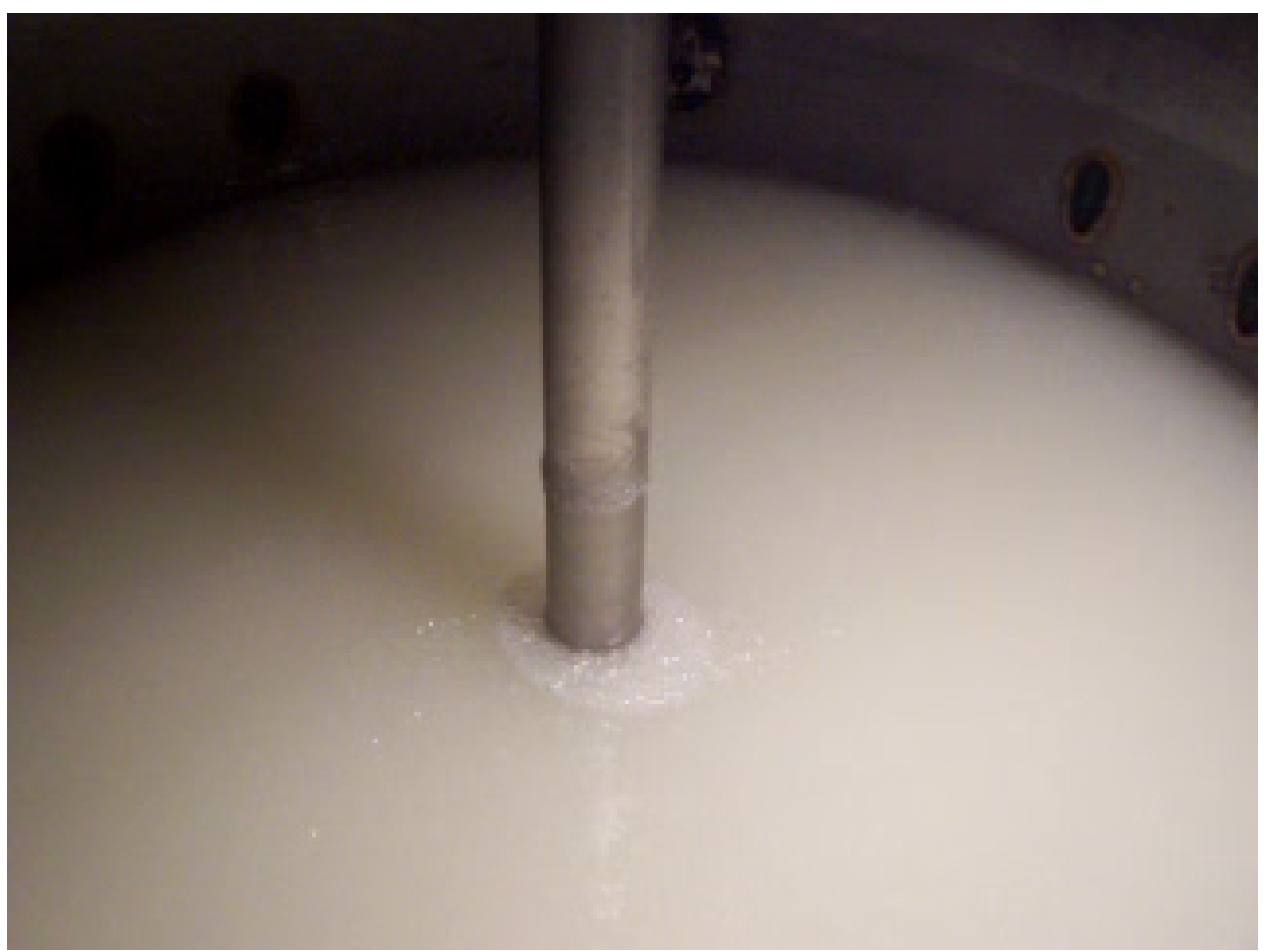

Figure C - 25 Pa Xanthan Gum, 30 RPM, Static 


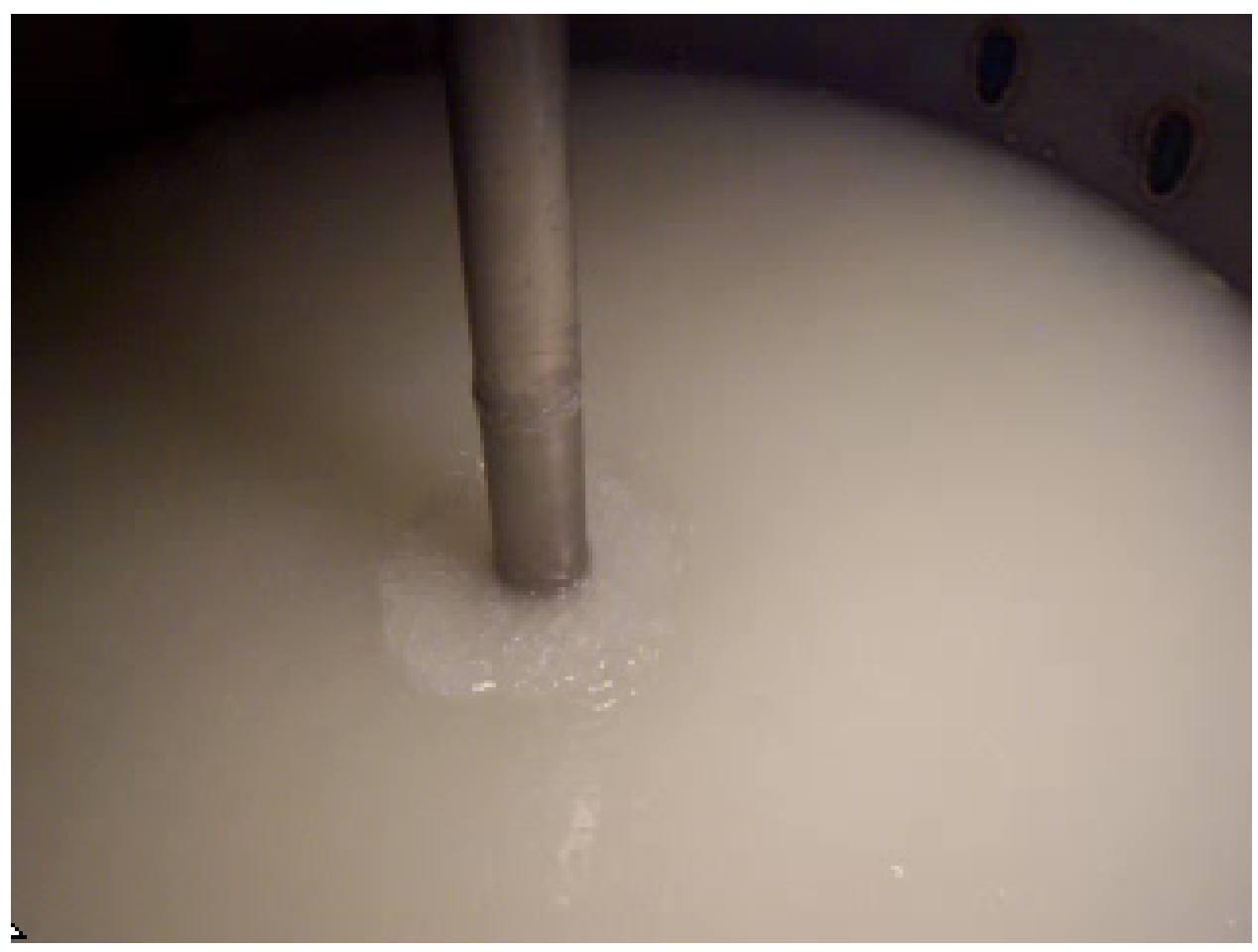

Figure C - 35 Pa Xanthan Gum, 40 RPM, Static

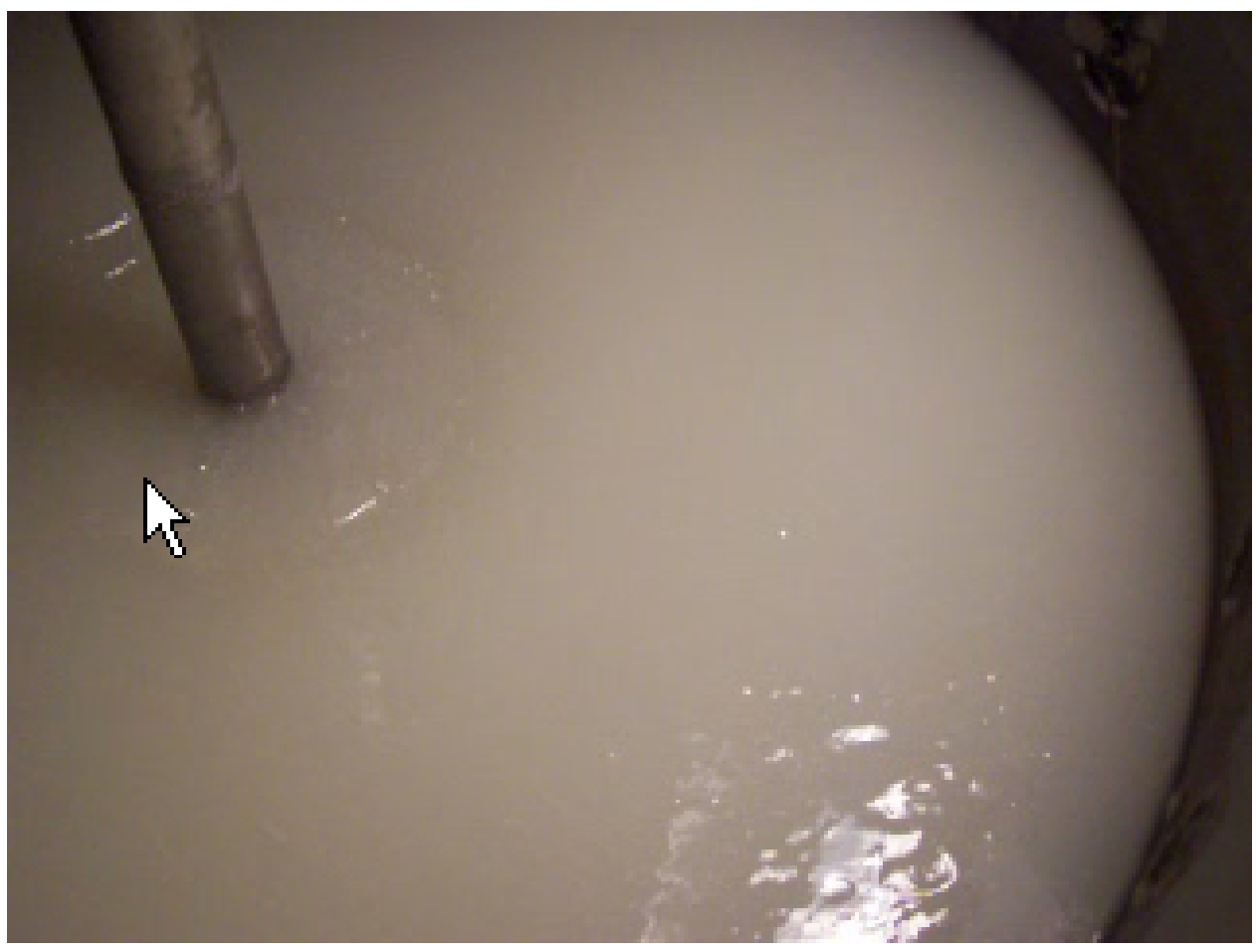

Figure C - 45 Pa Xanthan Gum, 50 RPM, Static 


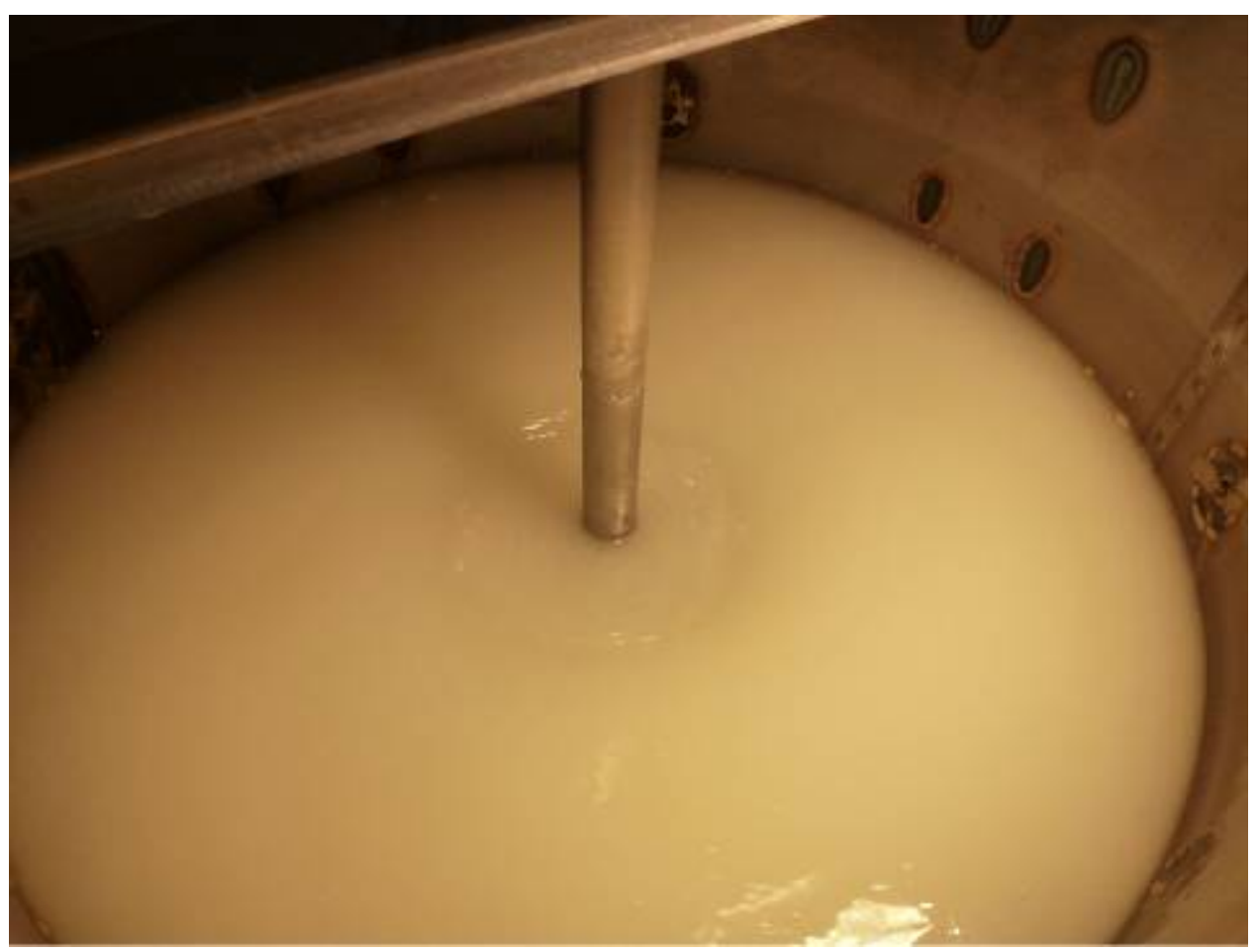

Figure C - 55 Pa Xanthan Gum, 60 RPM, Static

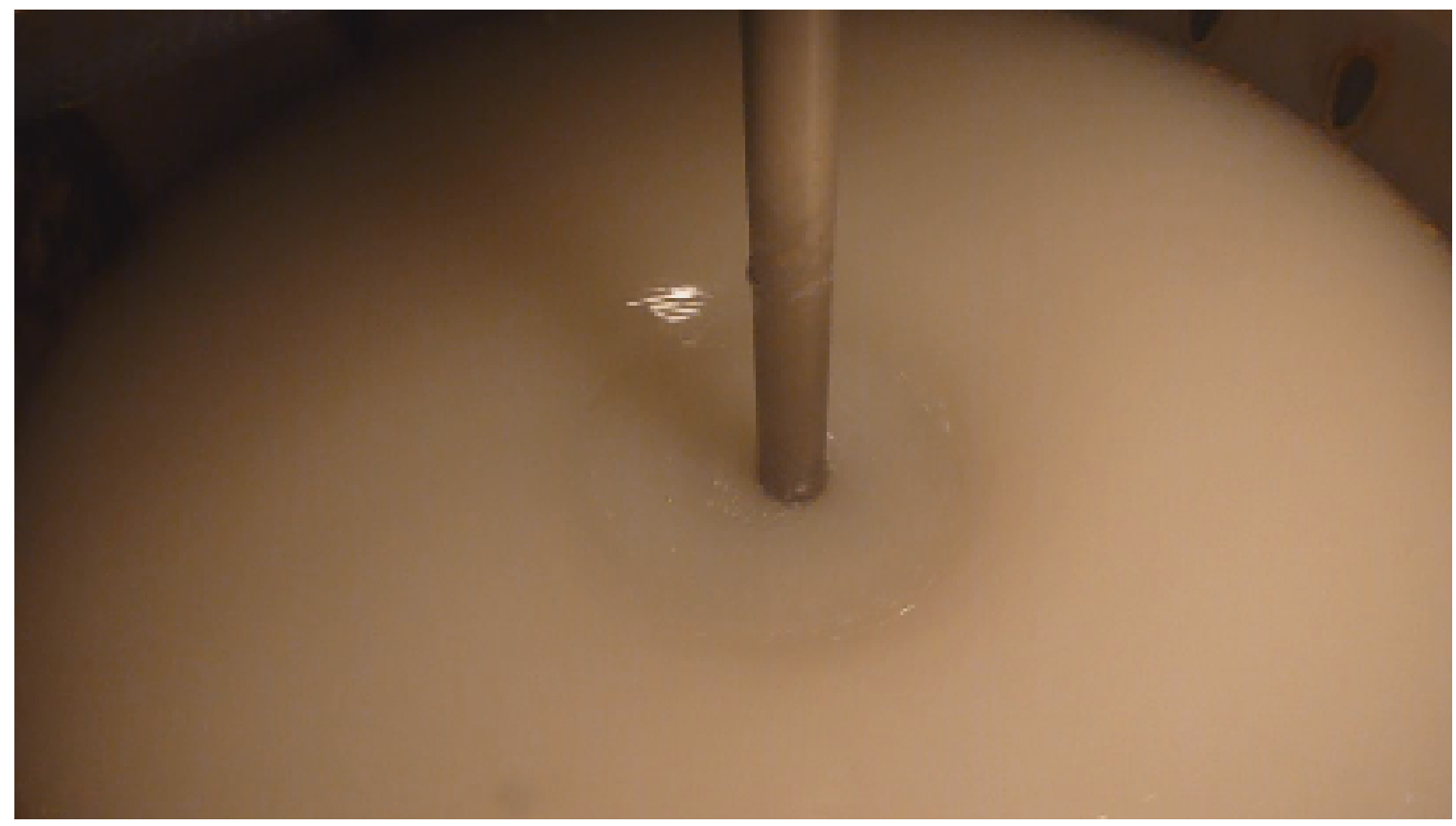

Figure C - 65 Pa Xanthan Gum, 70 RPM, Static 


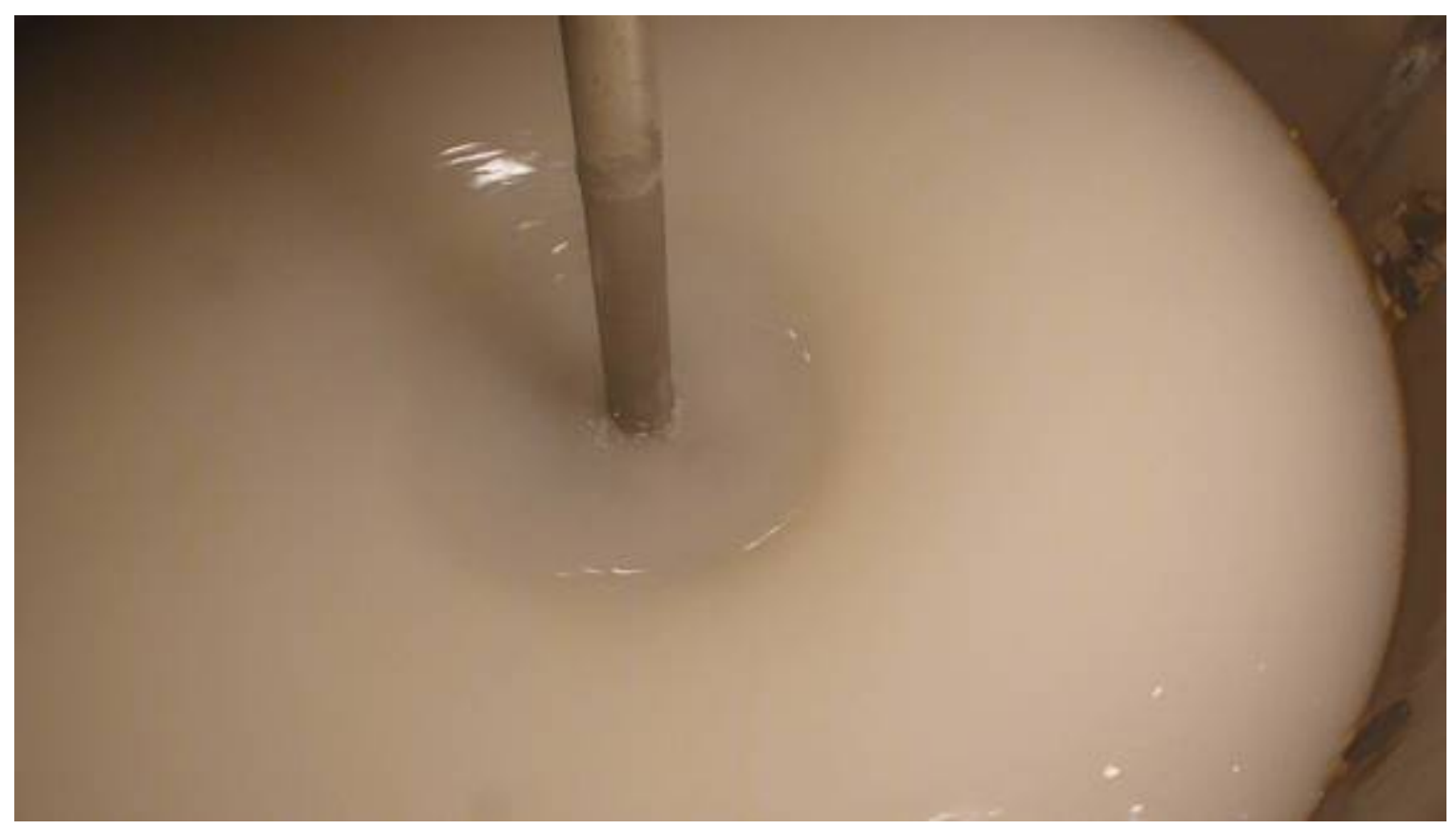

Figure C - 75 Pa Xanthan Gum, 80 RPM, Static

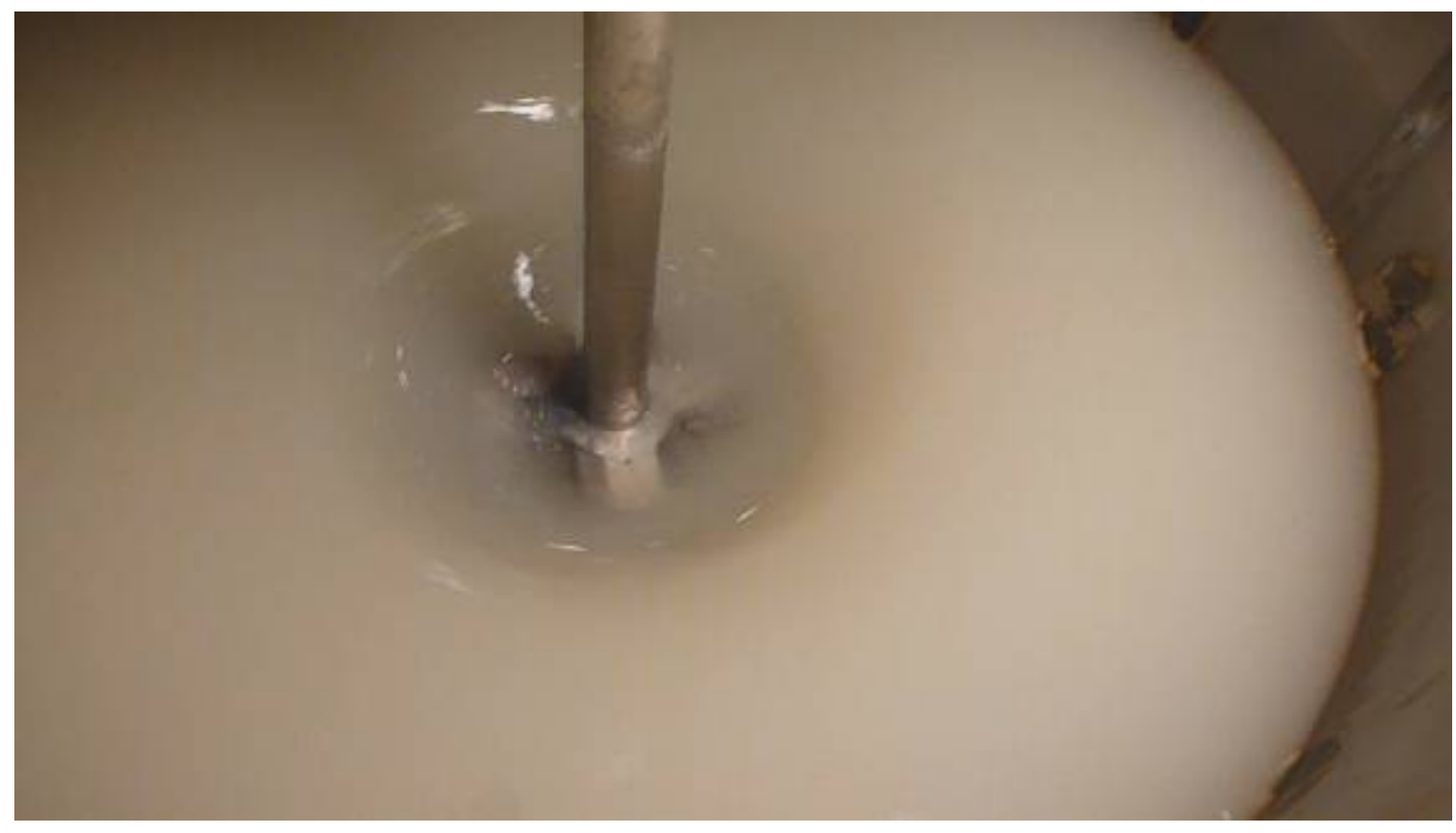

Figure C - 85 Pa Xanthan Gum, 90 RPM, Static 


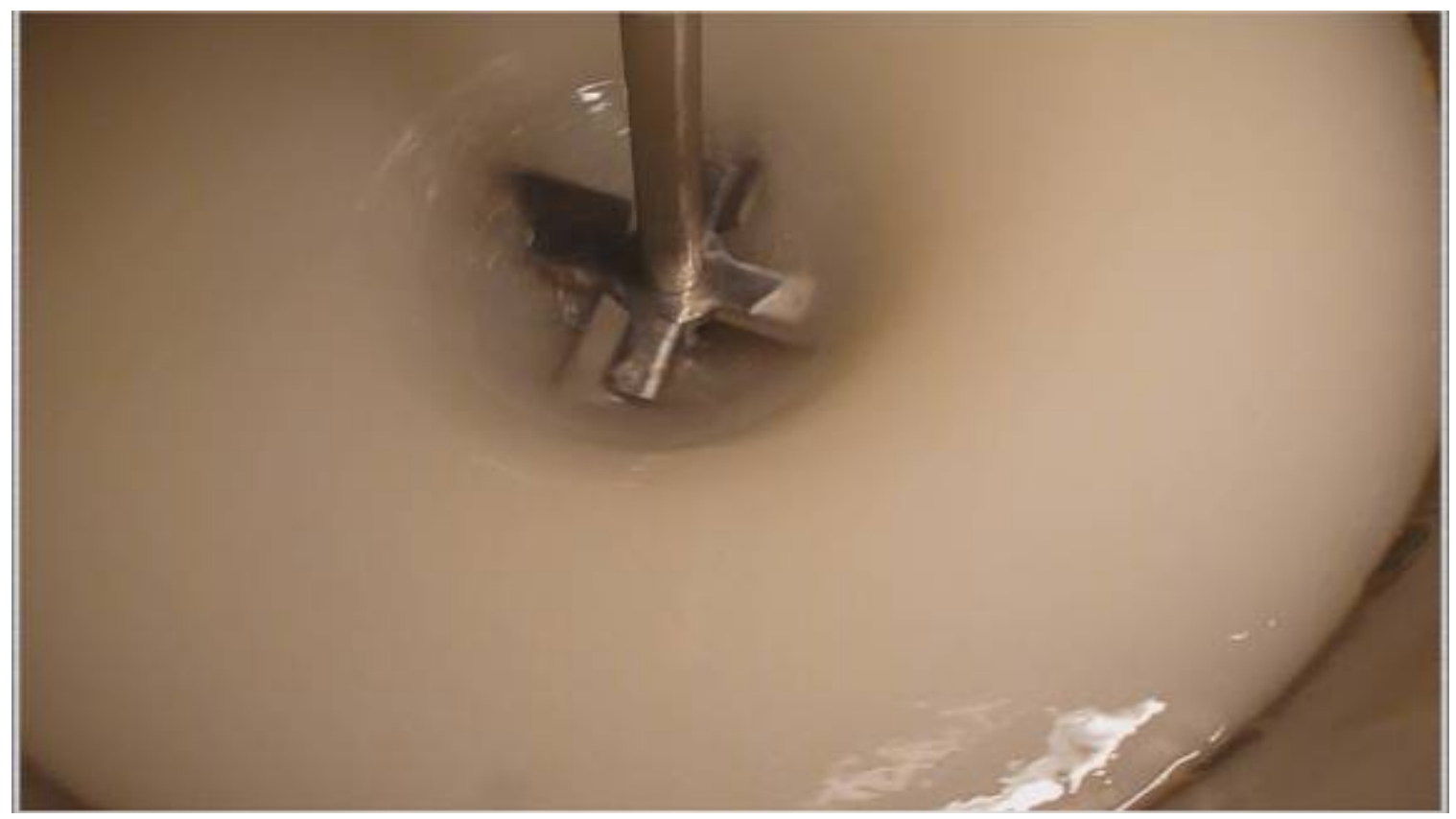

Figure C - 95 Pa Xanthan Gum, 100 RPM, Static

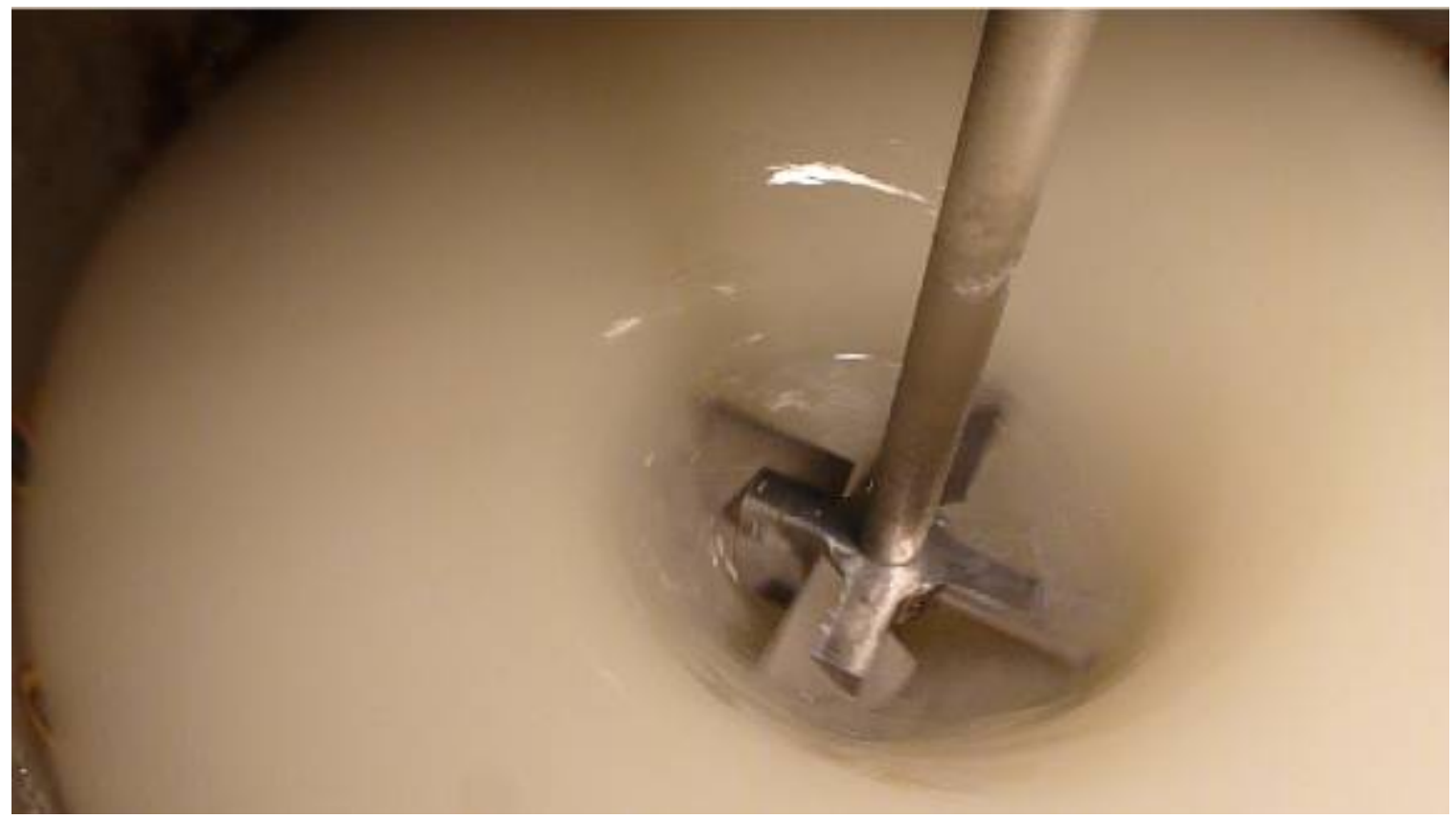

Figure C - 105 Pa Xanthan Gum, 110 RPM, Static 
SRNL-STI-2011-00465

Revision 0

\section{APPENDIX D: MIXING PICTURES FOR RECIRCULATION 5 PA} XANTHAN GUM RUNS 


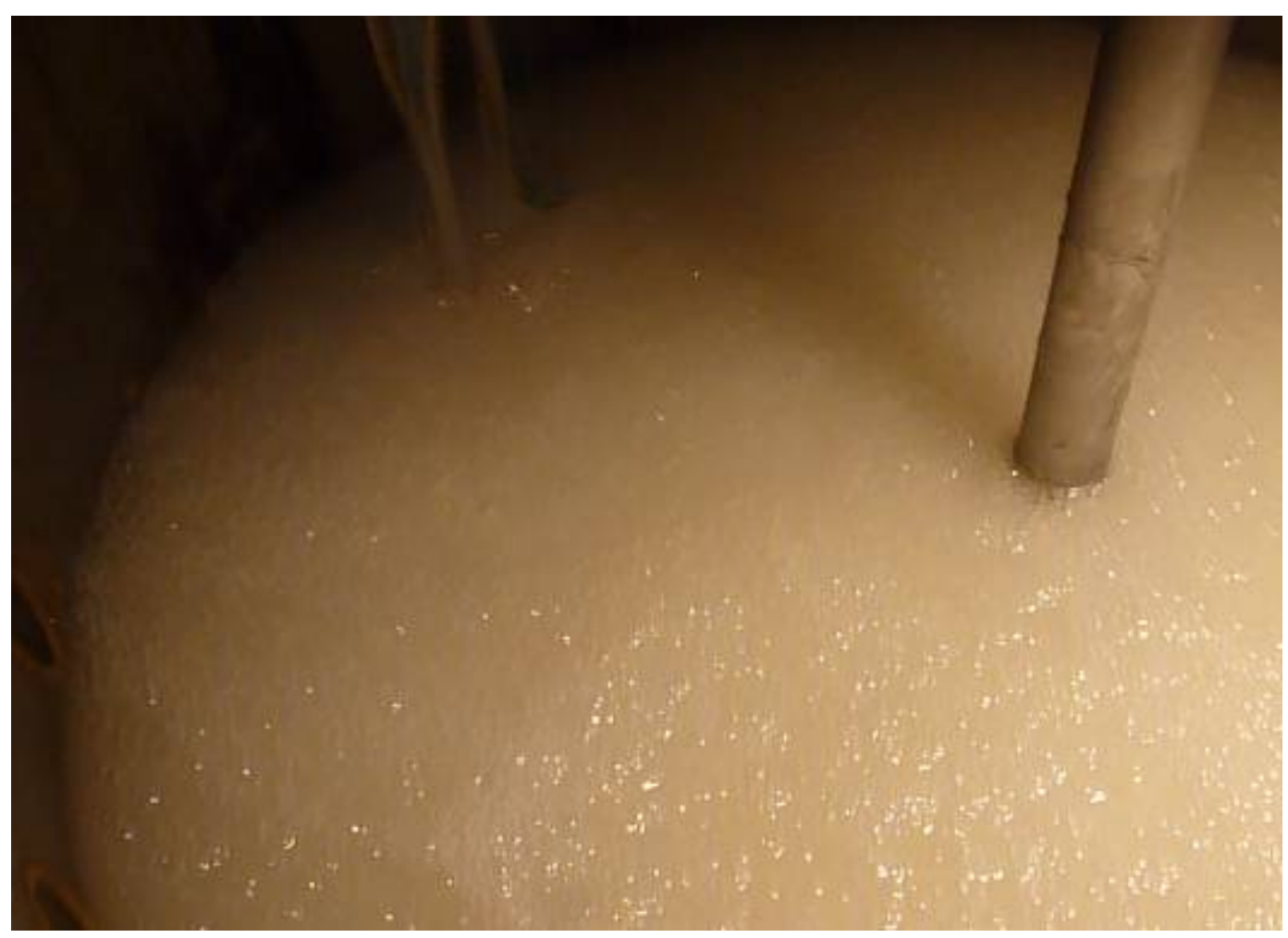

Figure D - 15 Pa Xanthan Gum, 20 RPM, Recirculation

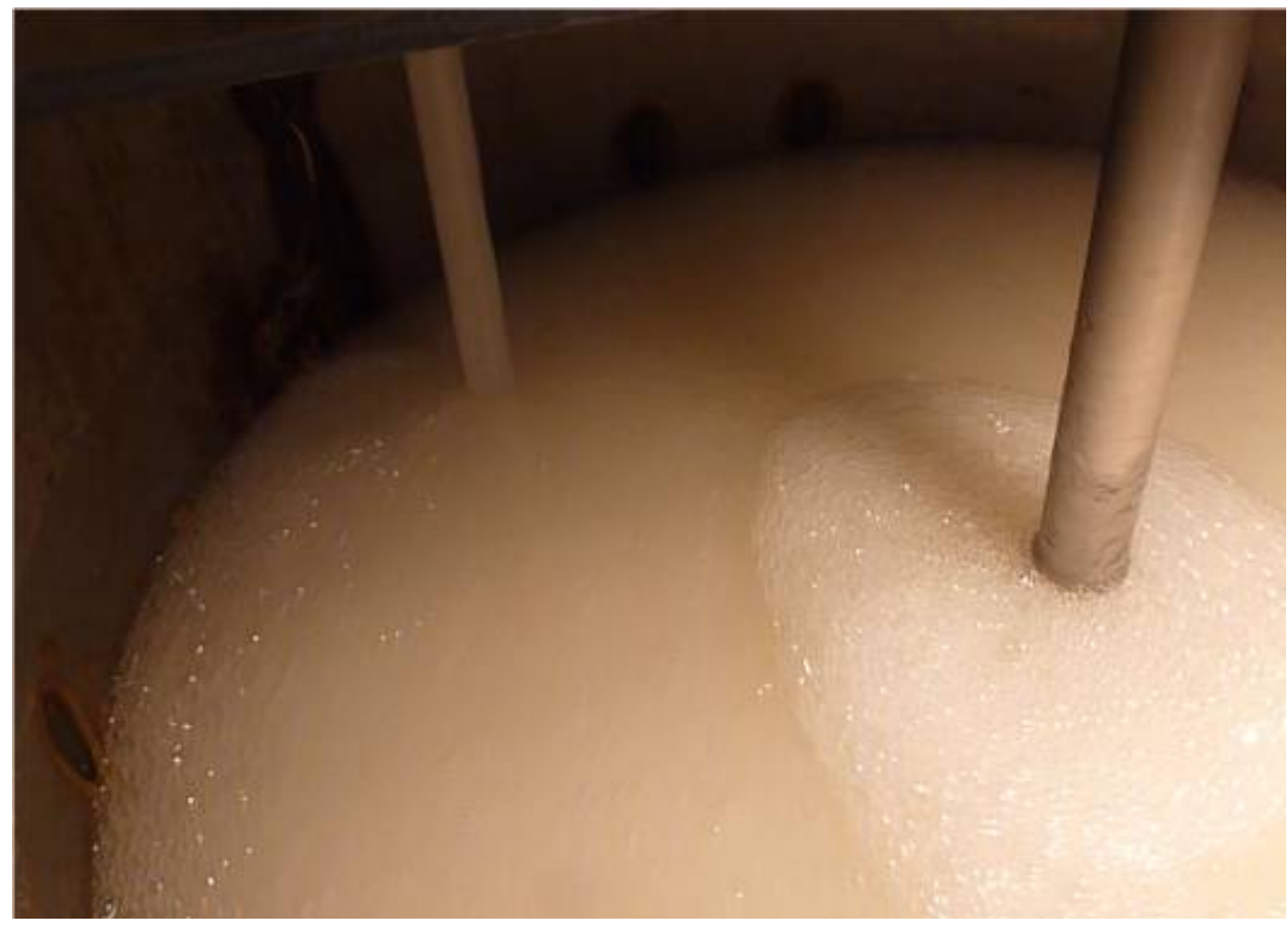

Figure D - 25 Pa Xanthan Gum, 30 RPM, Recirculation 


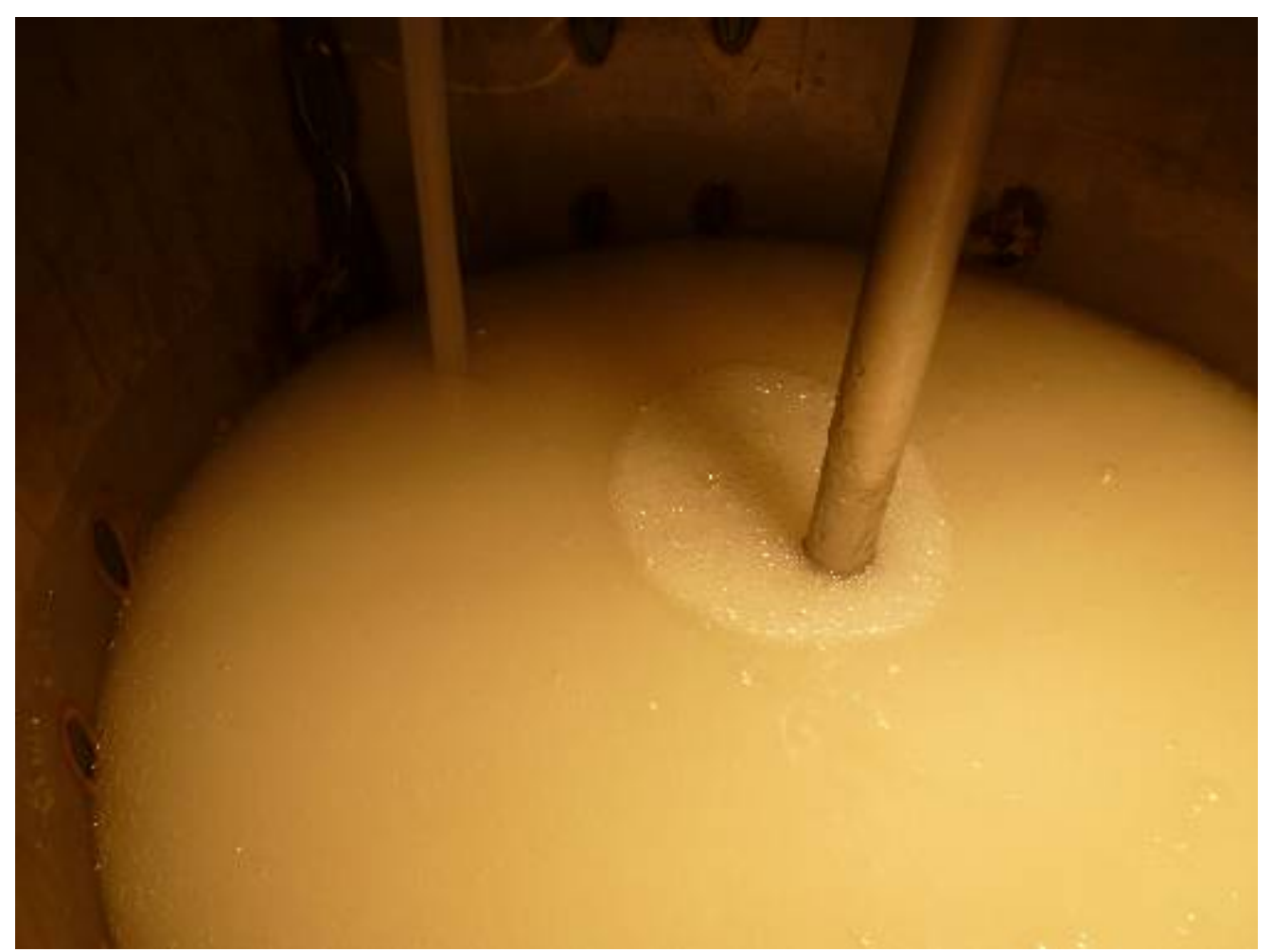

Figure D - 35 Pa Xanthan Gum, 40 RPM, Recirculation

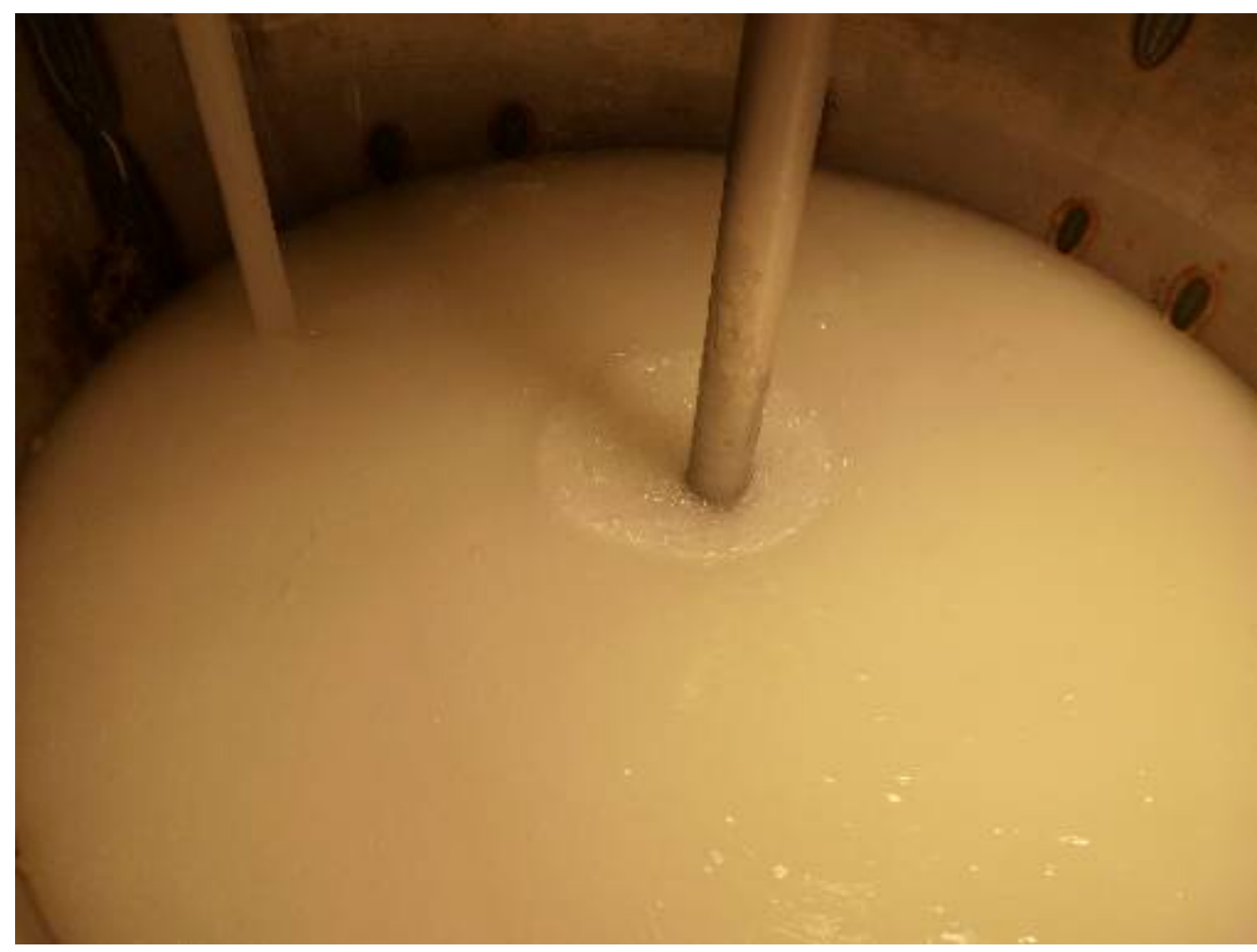

Figure D - 45 Pa Xanthan Gum, 50 RPM, Recirculation 


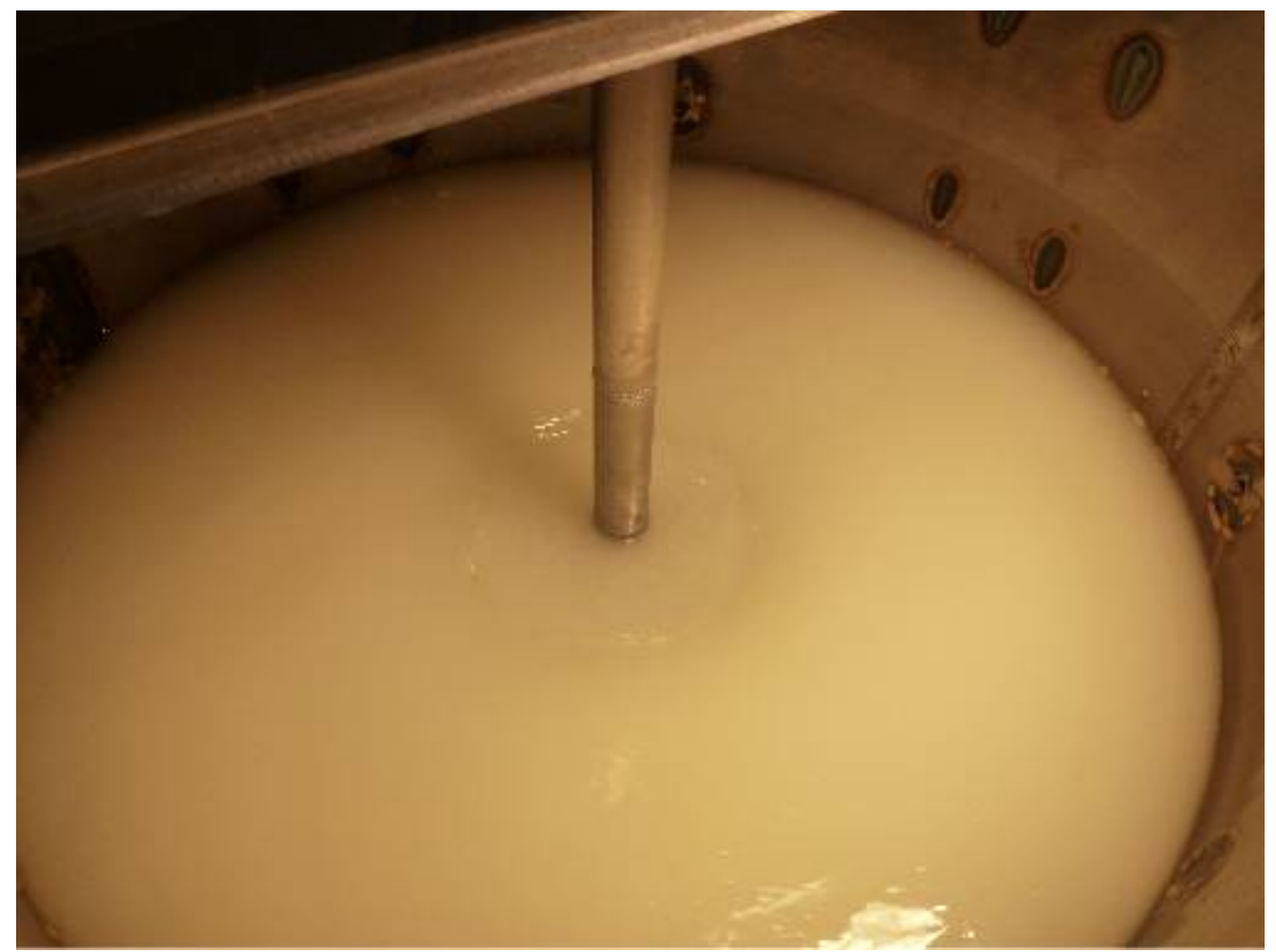

Figure D - 55 Pa Xanthan Gum, 60 RPM, Recirculation

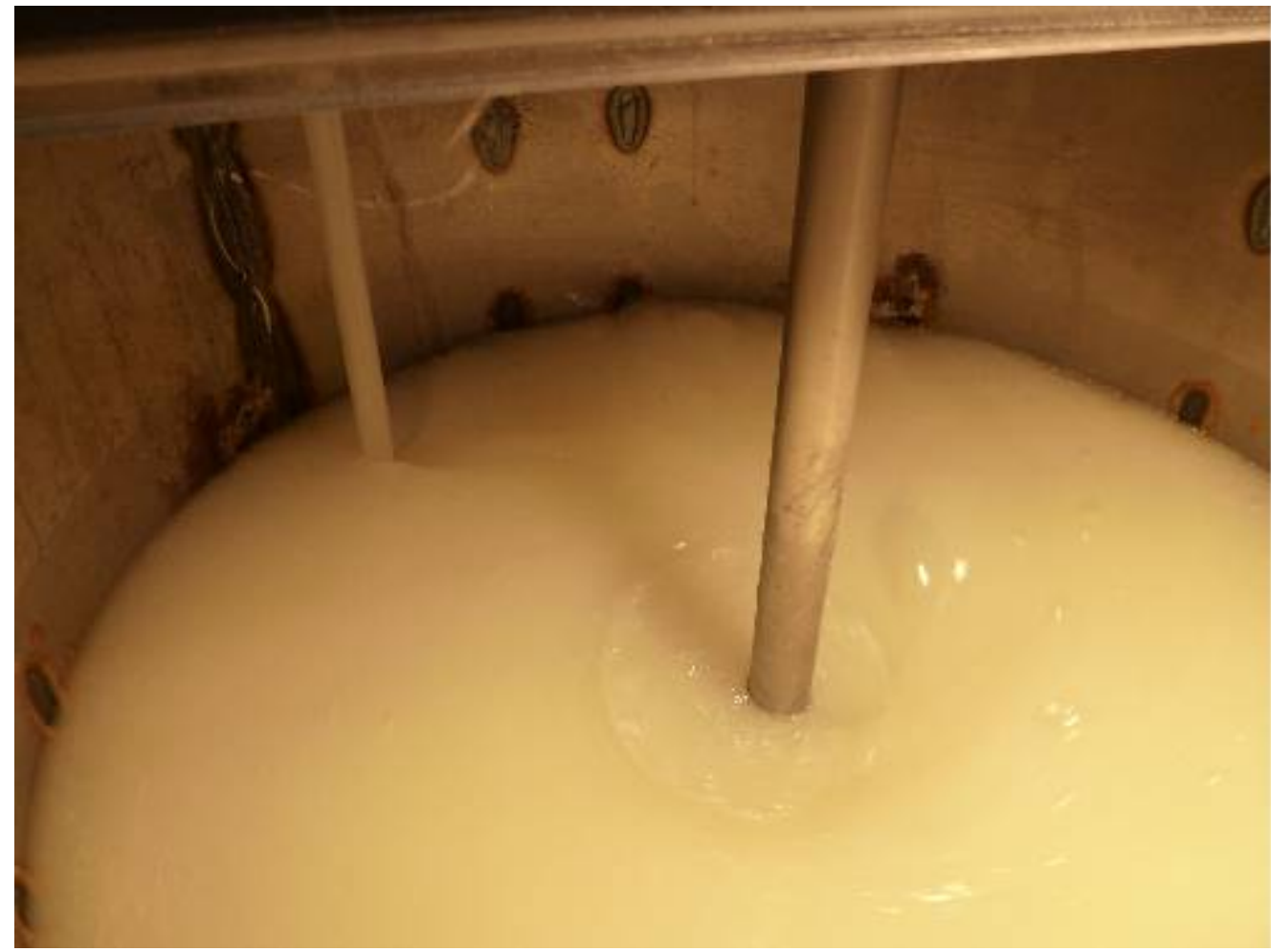

Figure D - 65 Pa Xanthan Gum, 70 RPM, Recirculation 


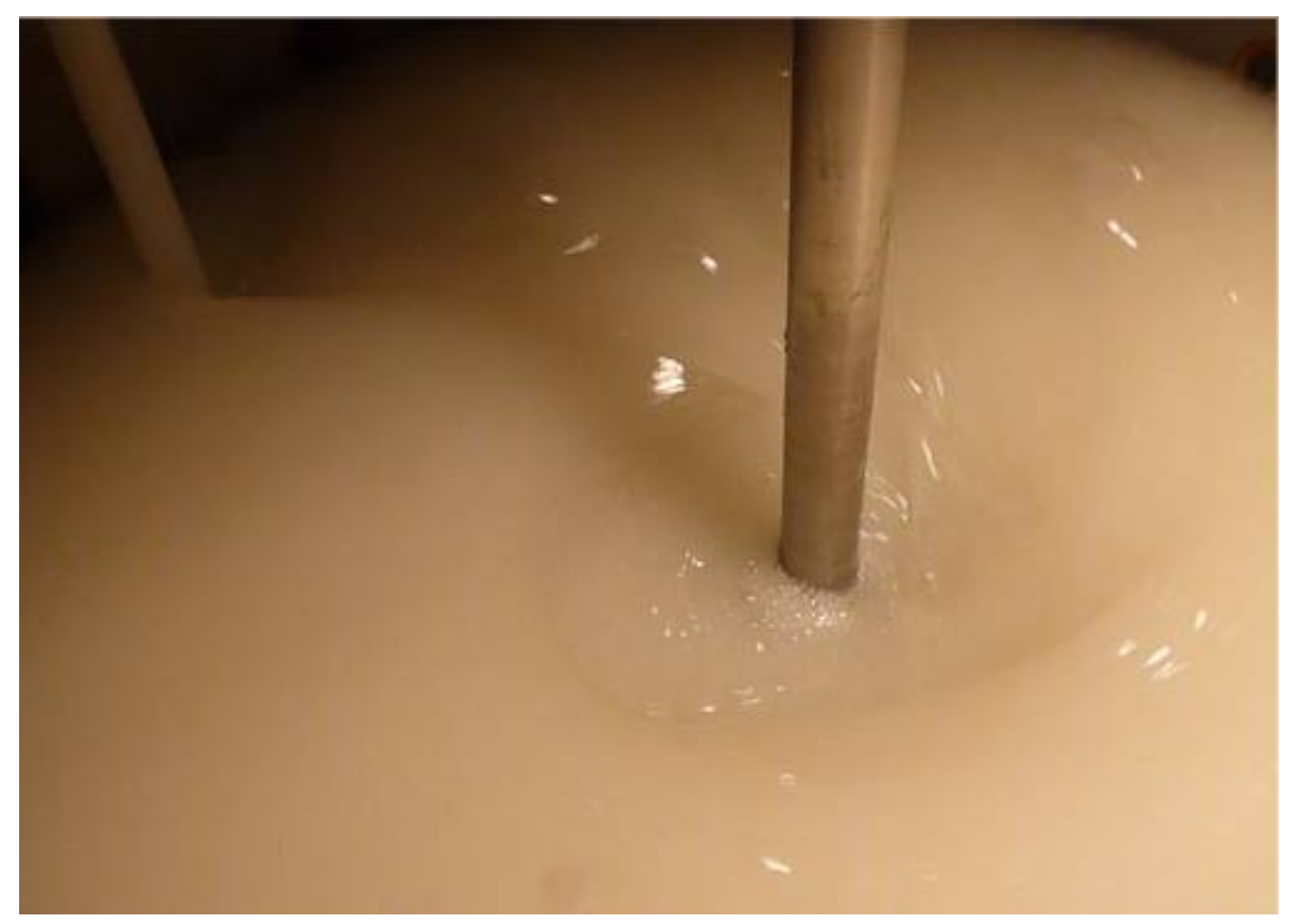

Figure D - 75 Pa Xanthan Gum, 80 RPM, Recirculation

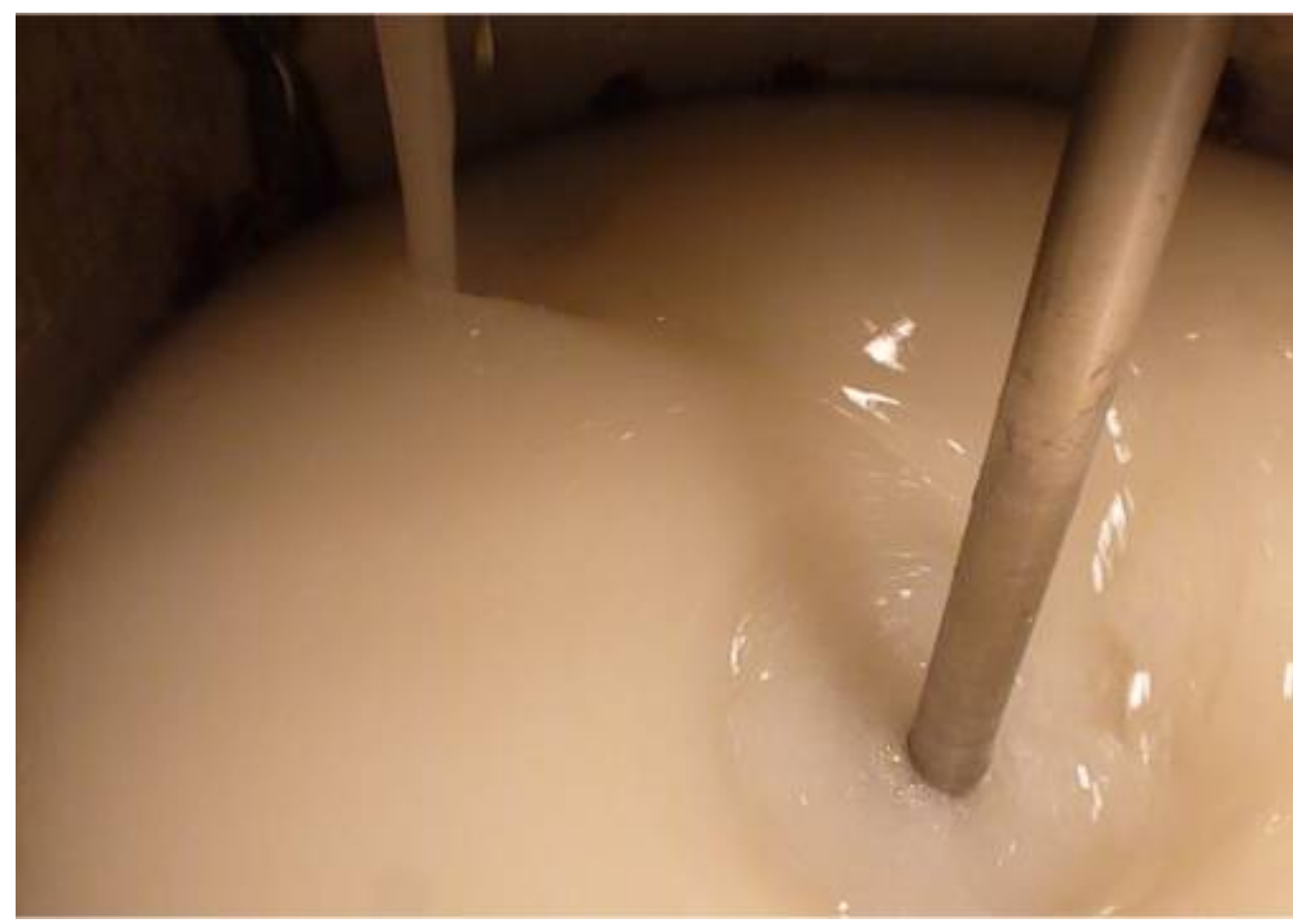

Figure D - 85 Pa Xanthan Gum, 90 RPM, Recirculation 


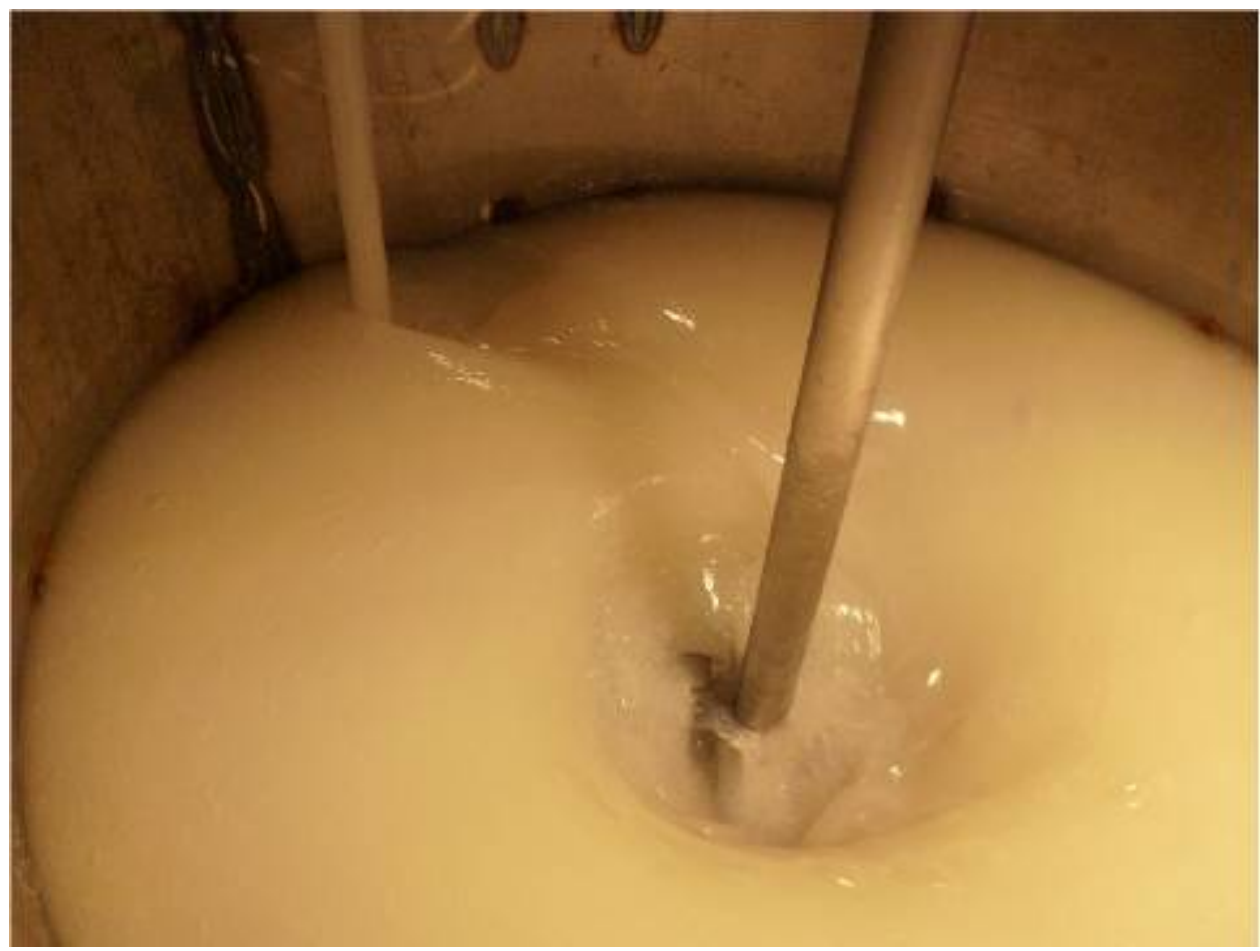

Figure D - 95 Pa Xanthan Gum, 100 RPM, Recirculation

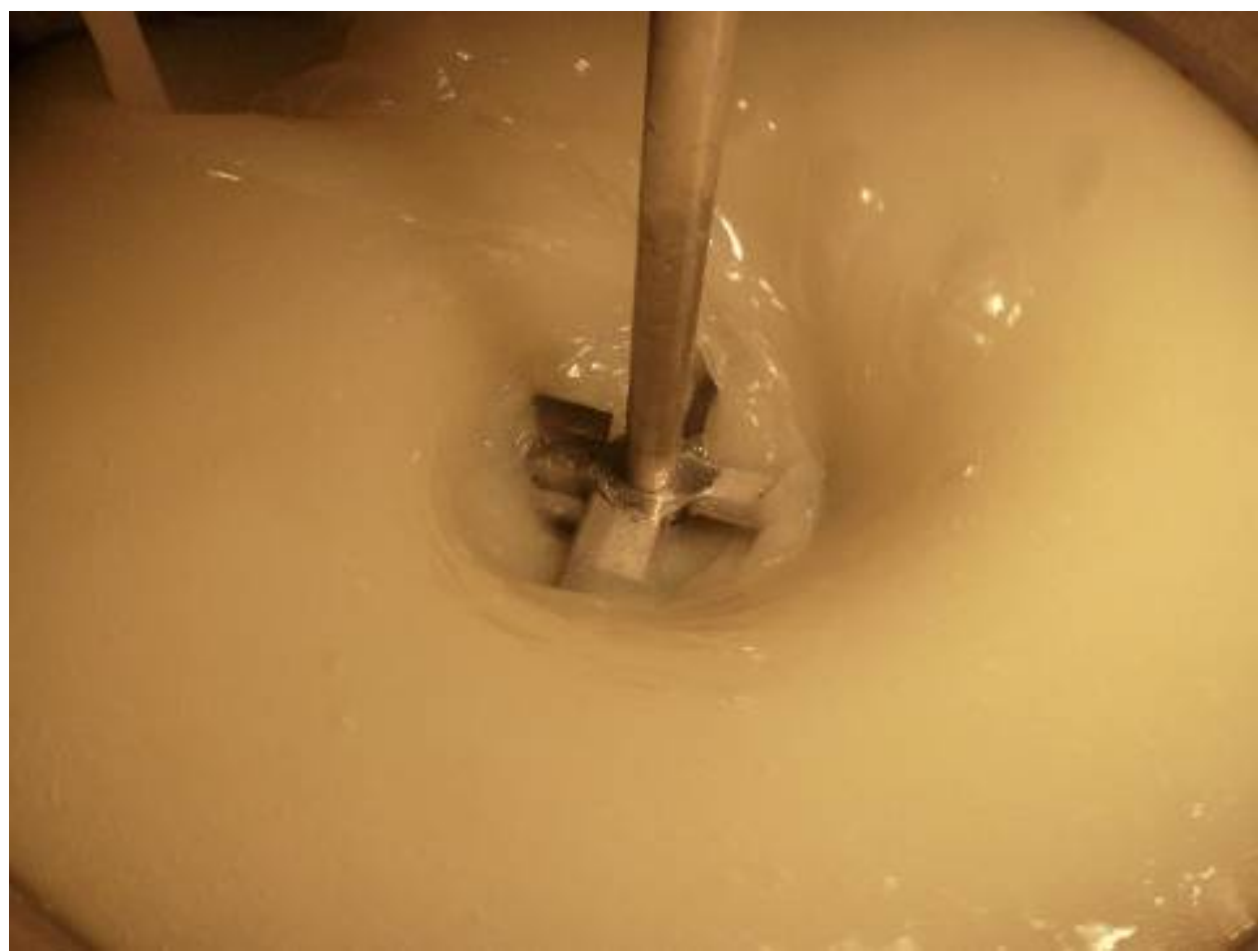

Figure D - 105 Pa Xanthan Gum, 110 RPM, Recirculation 
SRNL-STI-2011-00465

Revision 0

\section{APPENDIX E: MIXING PICTURES FOR STATIC 20 PA XANTHAN GUM RUNS}




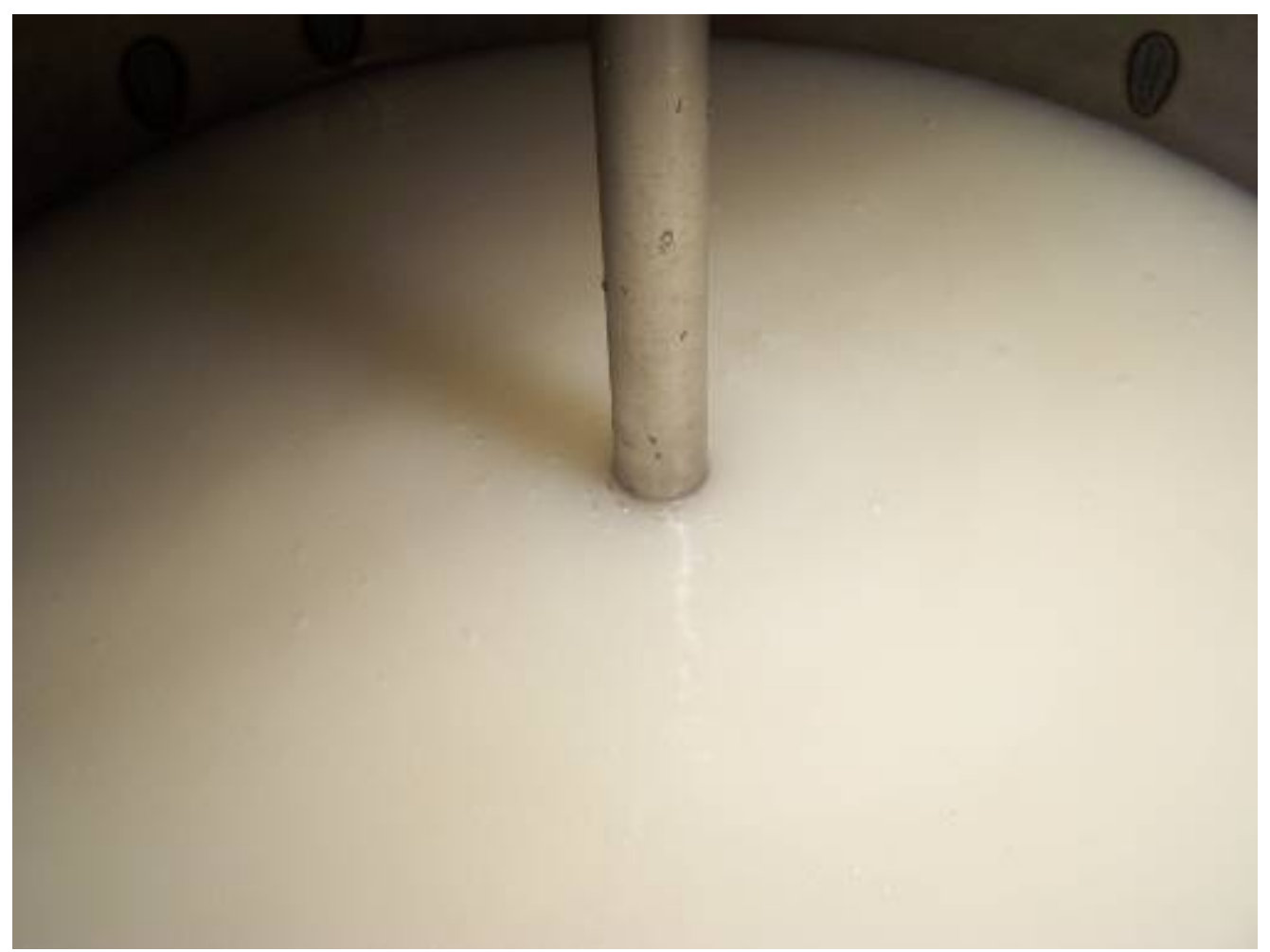

Figure E - 120 Pa Xanthan Gum, 20 RPM, Static

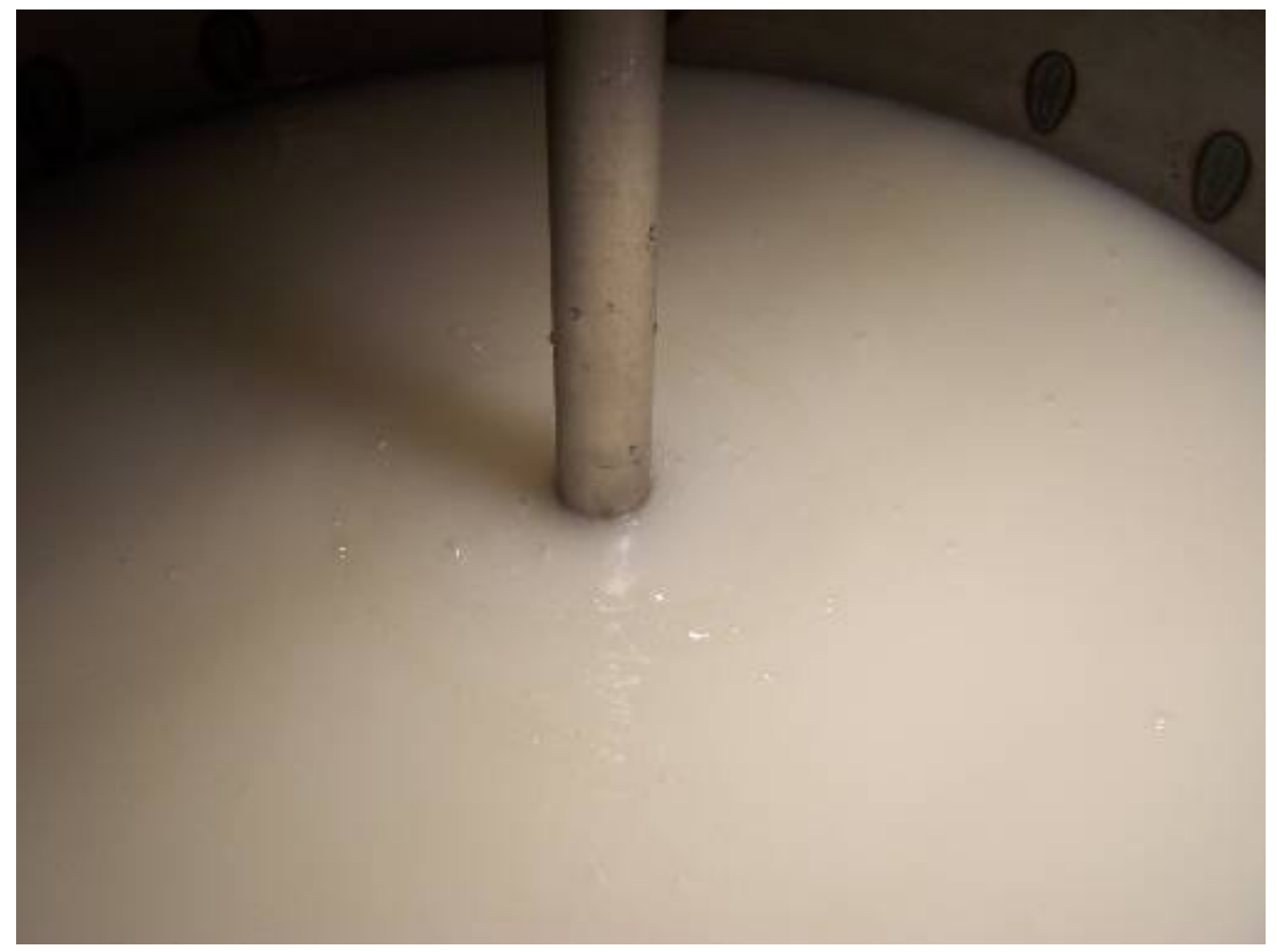

Figure E - 220 Pa Xanthan Gum, 30 RPM, Static 


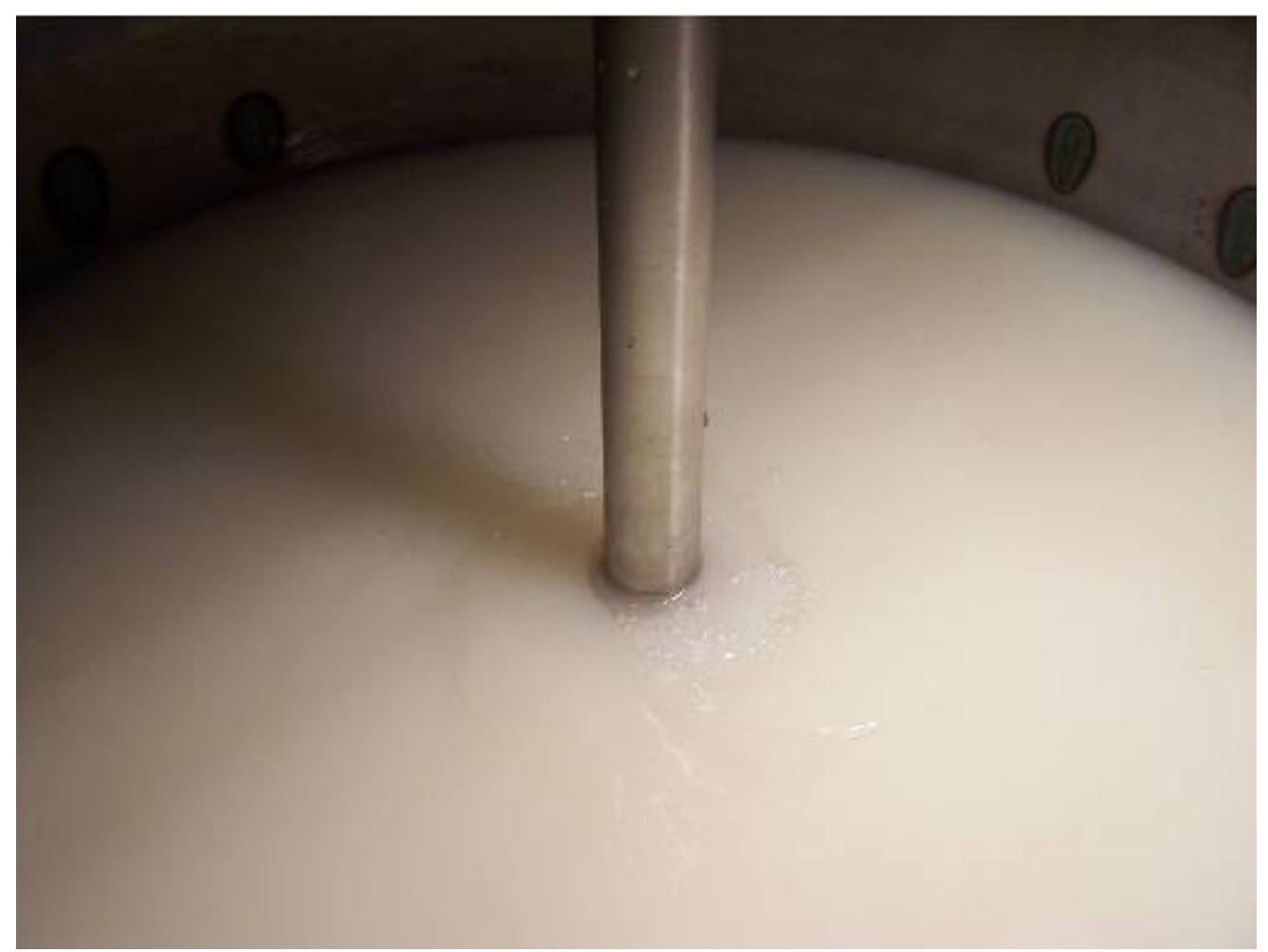

Figure E - 320 Pa Xanthan Gum, 40 RPM, Static

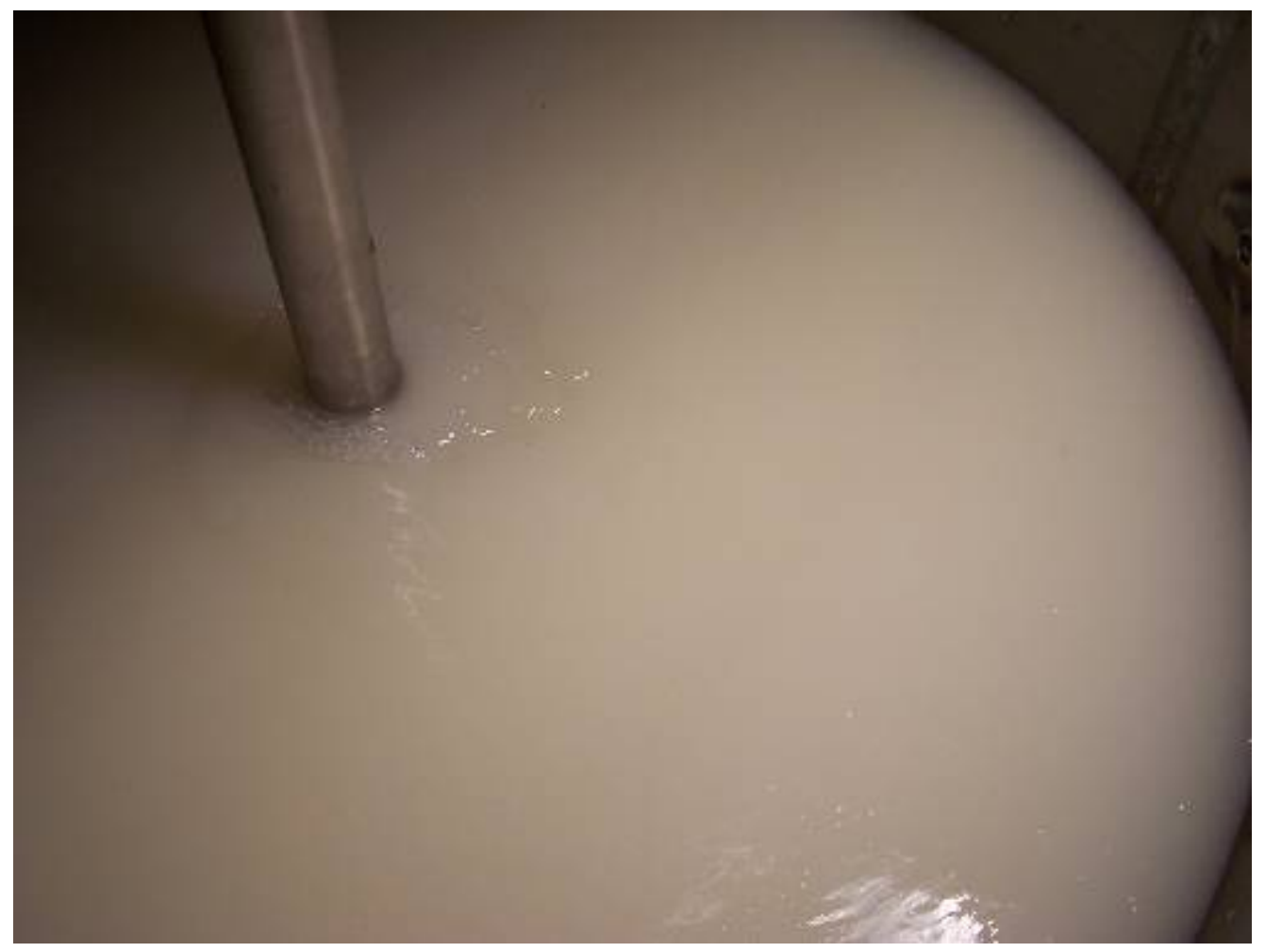

Figure E - 420 Pa Xanthan Gum, 50 RPM, Static 


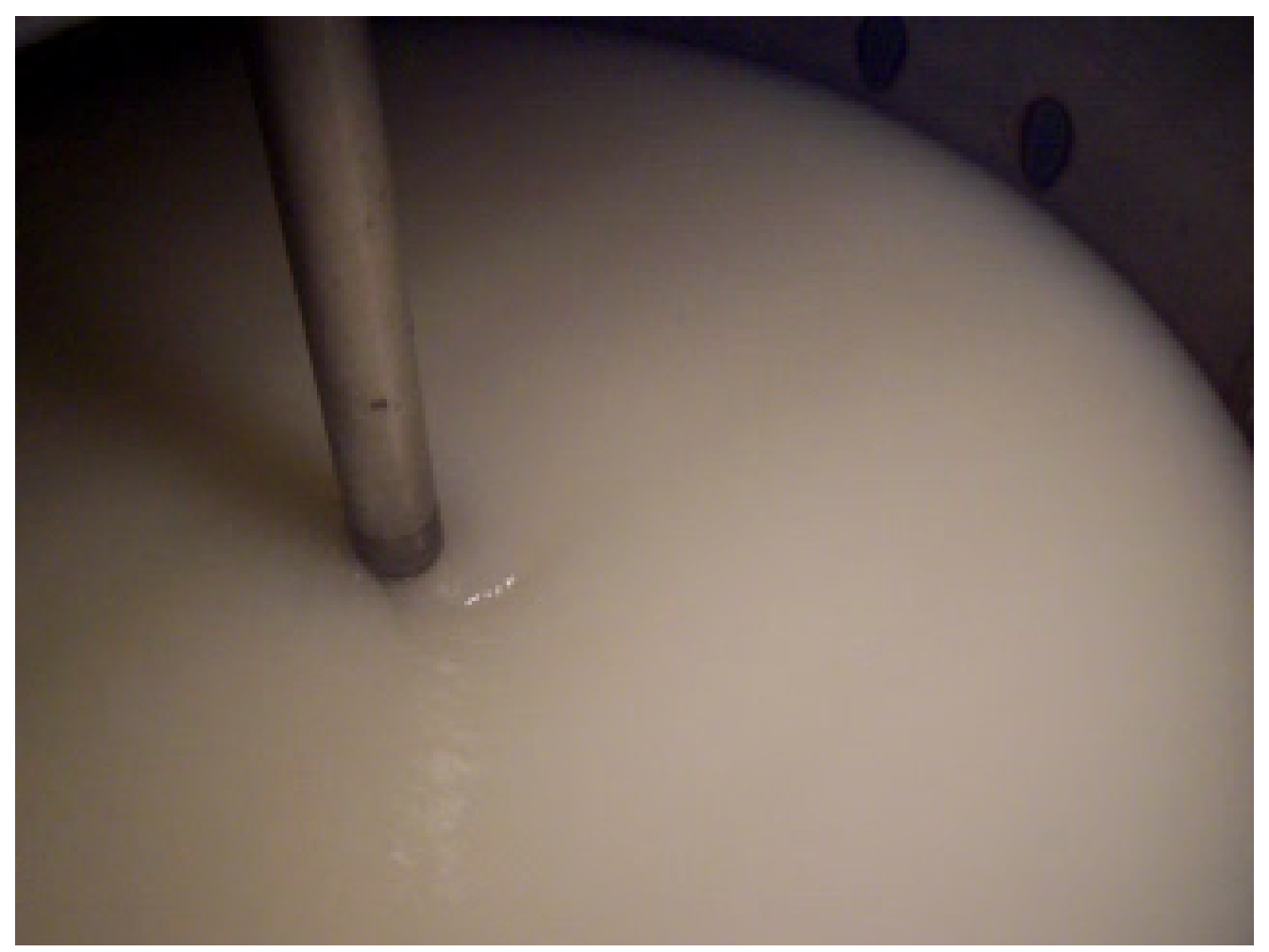

Figure E - 520 Pa Xanthan Gum, 60 RPM, Static

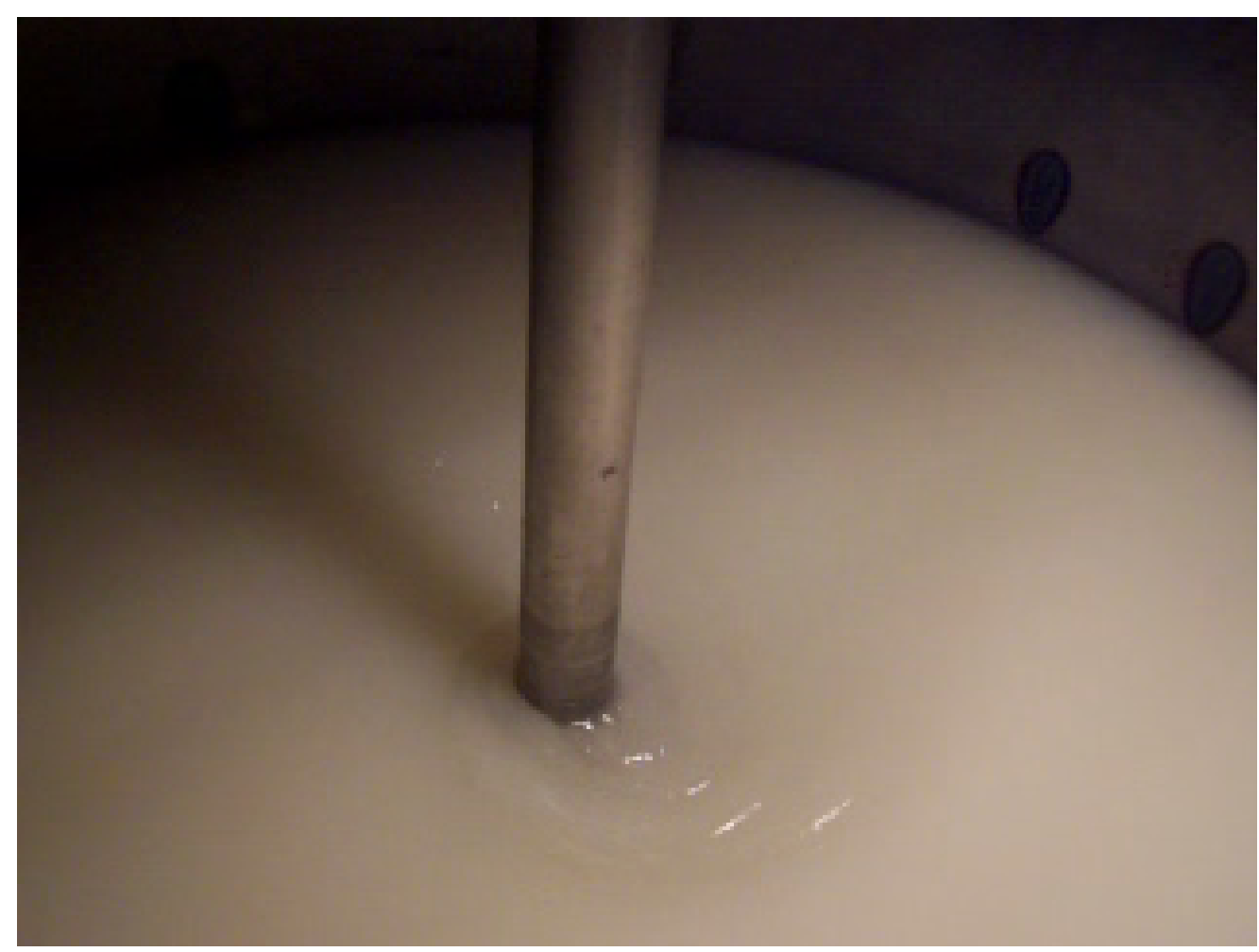

Figure E - 620 Pa Xanthan Gum, 70 RPM, Static 


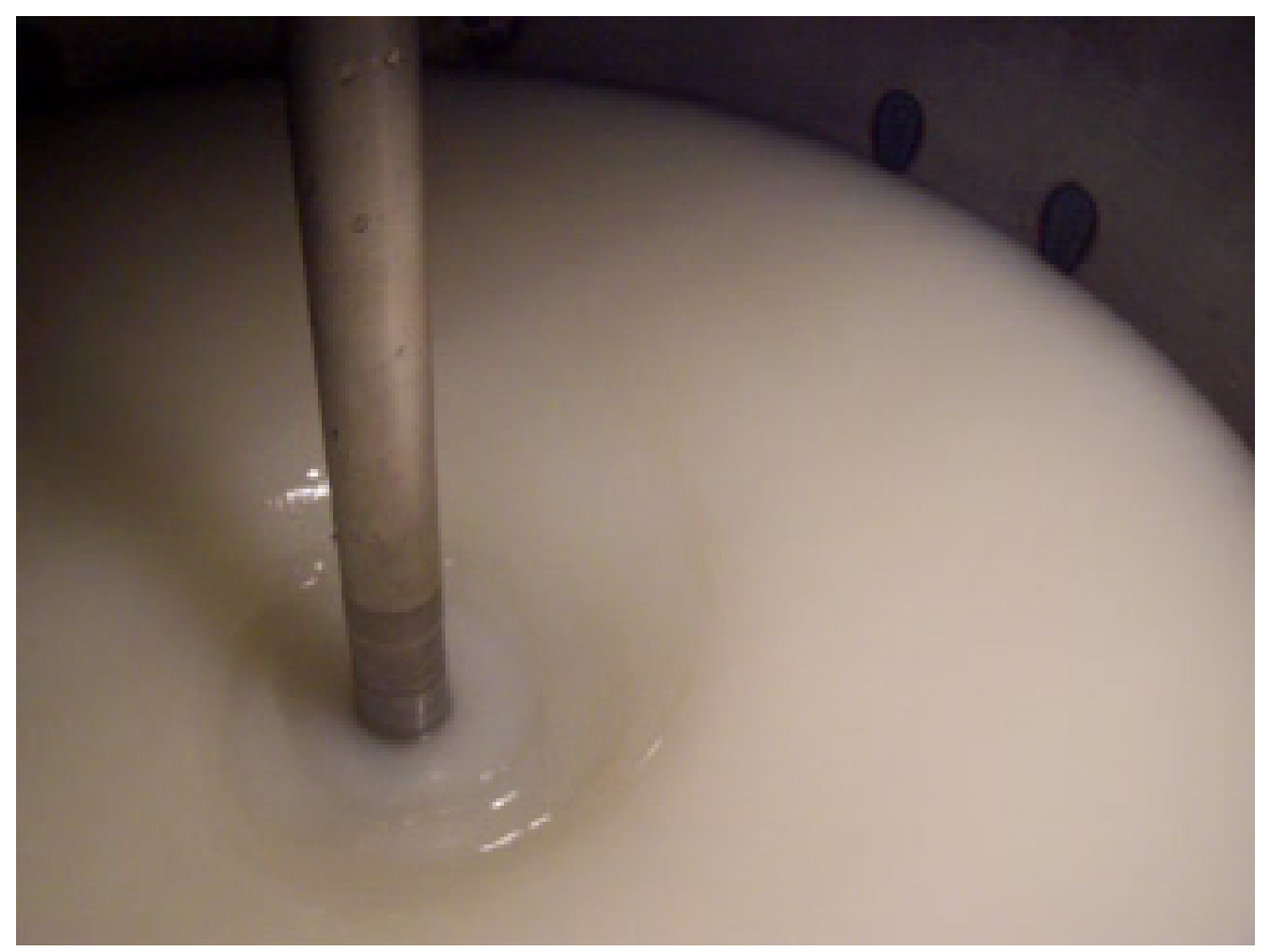

Figure E - 720 Pa Xanthan Gum, 80 RPM, Static

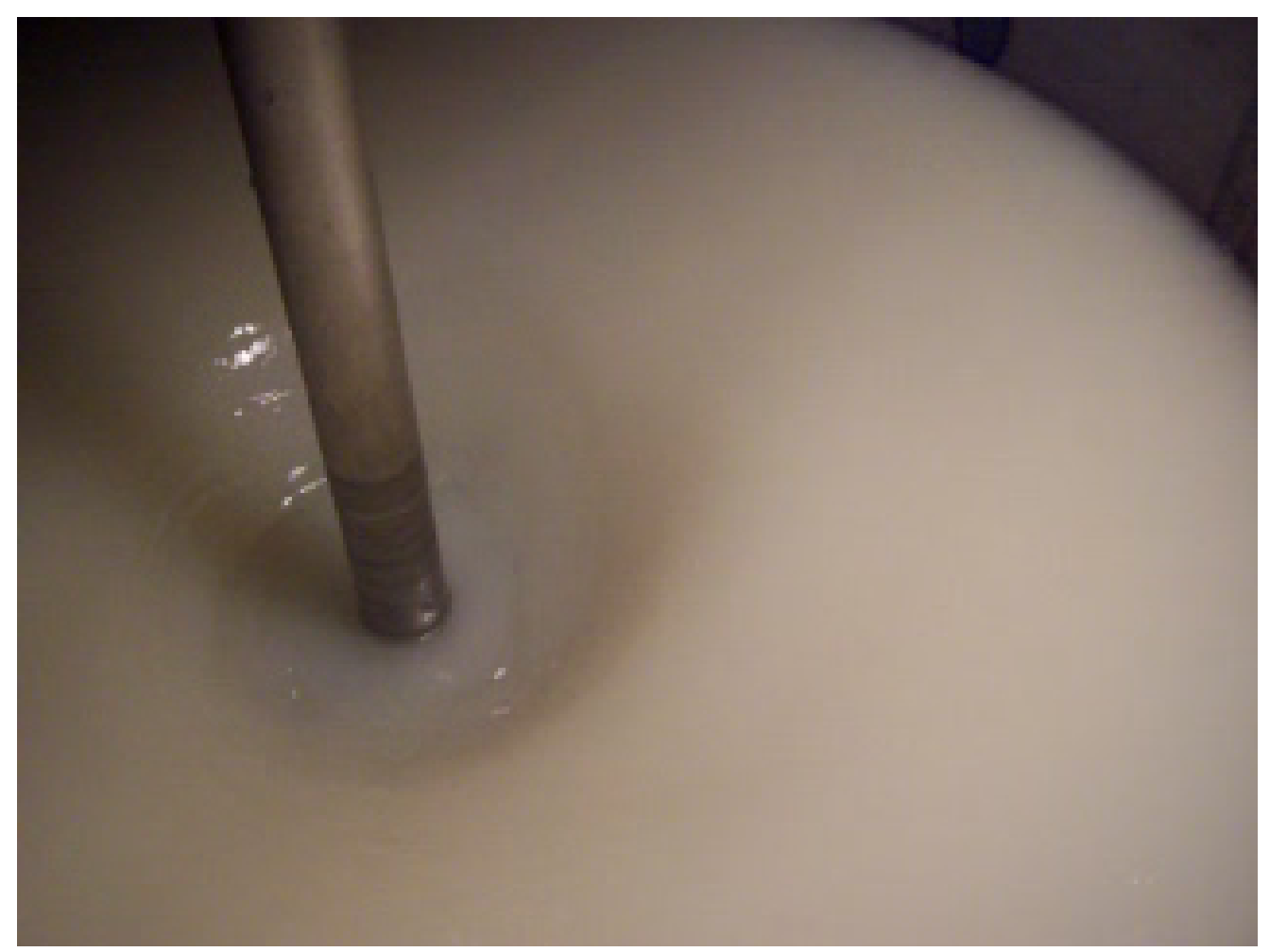

Figure E - 820 Pa Xanthan Gum, 90 RPM, Static 


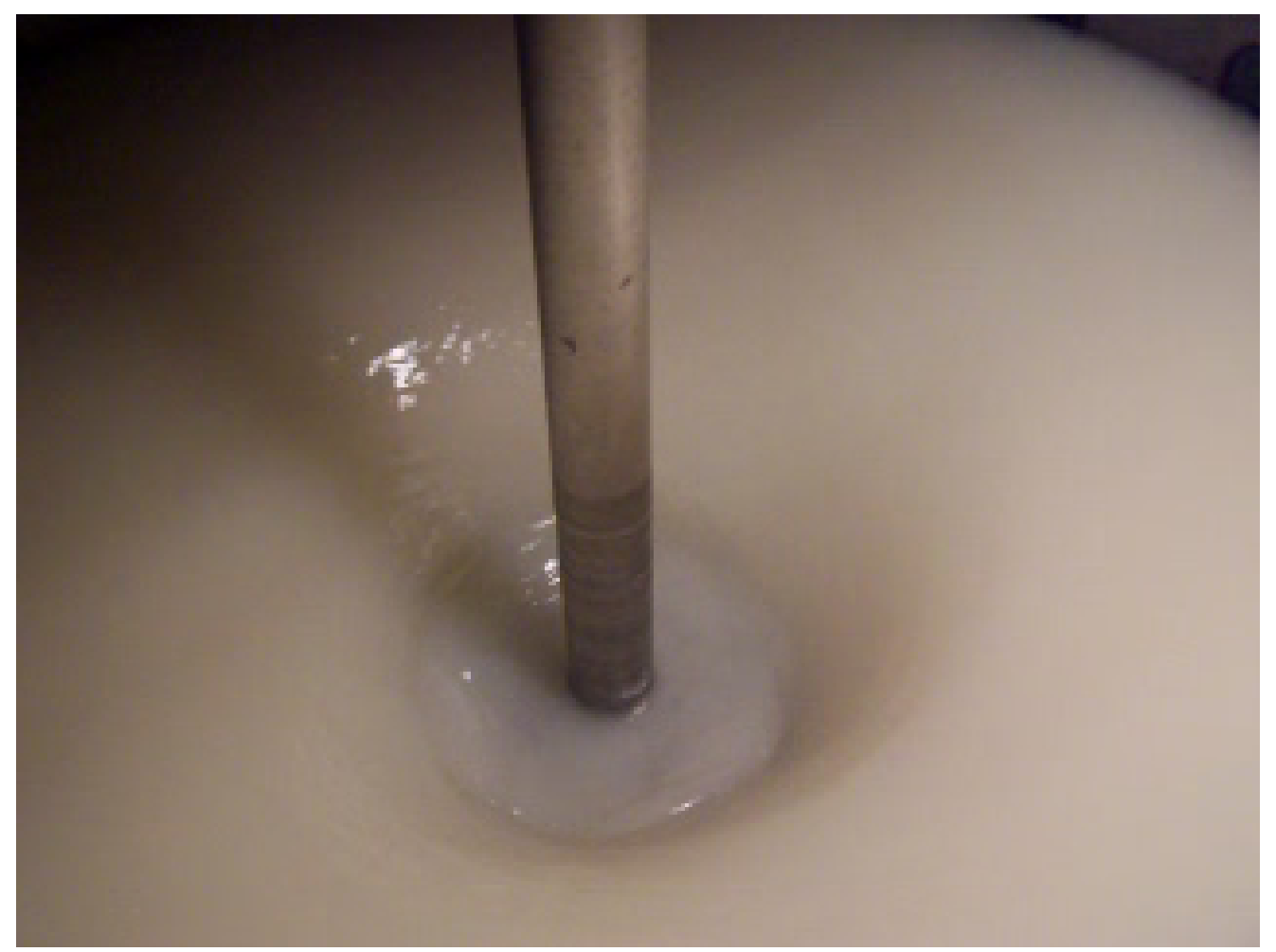

Figure E - 920 Pa Xanthan Gum, 100 RPM, Static

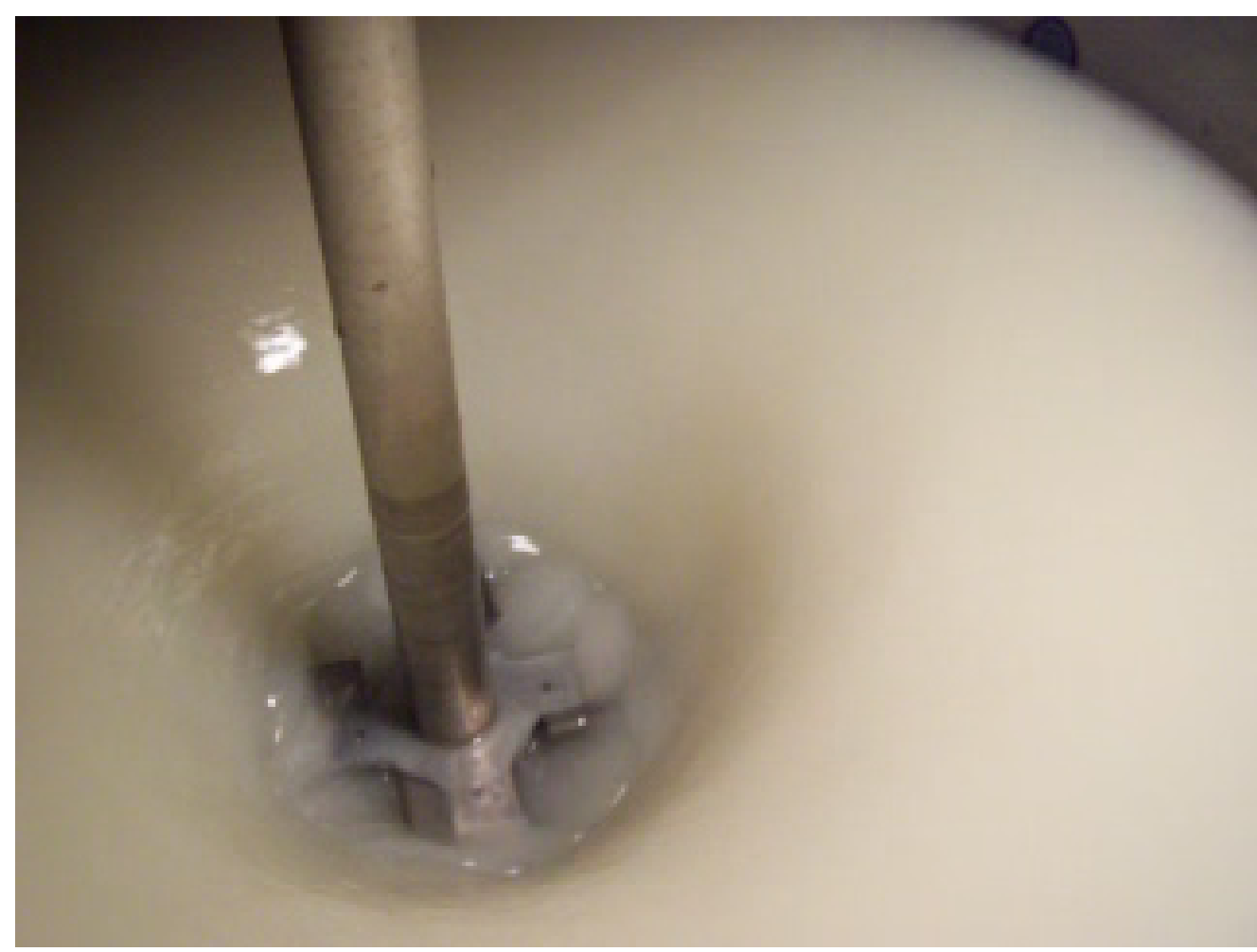

Figure E - 1020 Pa Xanthan Gum, 110 RPM, Static 


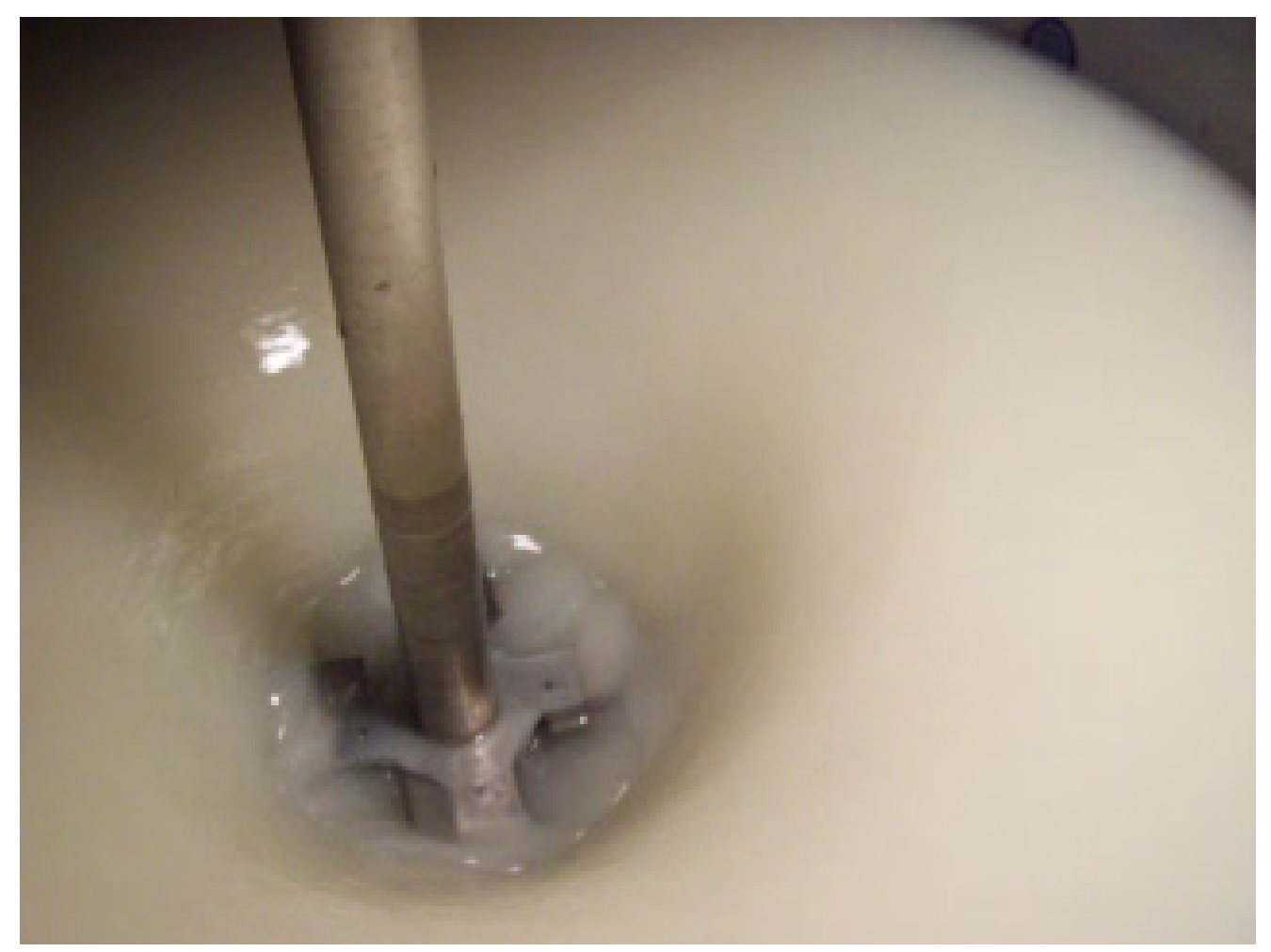

Figure E - 1120 Pa Xanthan Gum, 120 RPM, Static

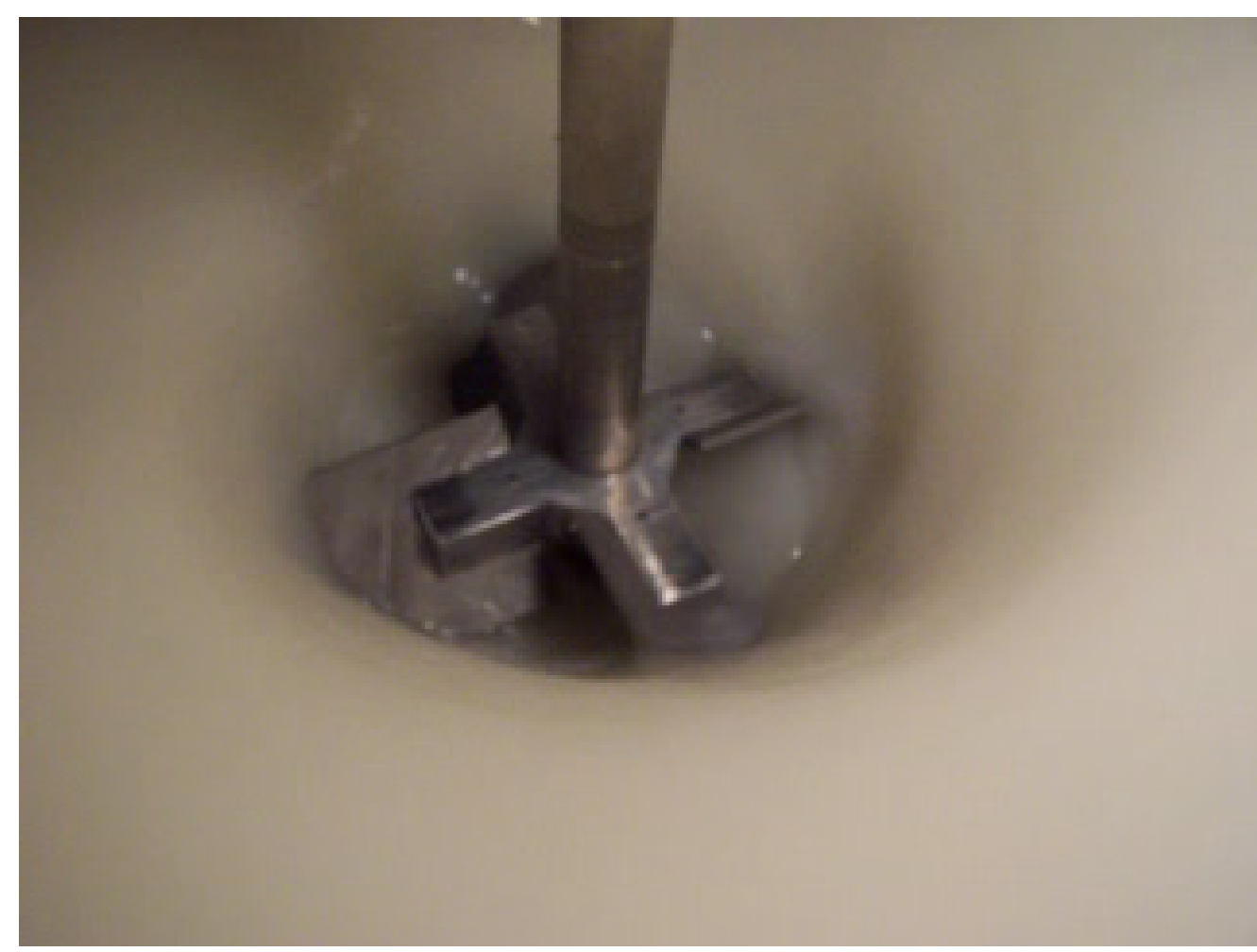

Figure E - 1220 Pa Xanthan Gum, 130 RPM, Static 
SRNL-STI-2011-00465

Revision 0

APPENDIX F: MIXING PICTURES FOR RECIRCULATION 20 PA XANTHAN GUM RUNS 


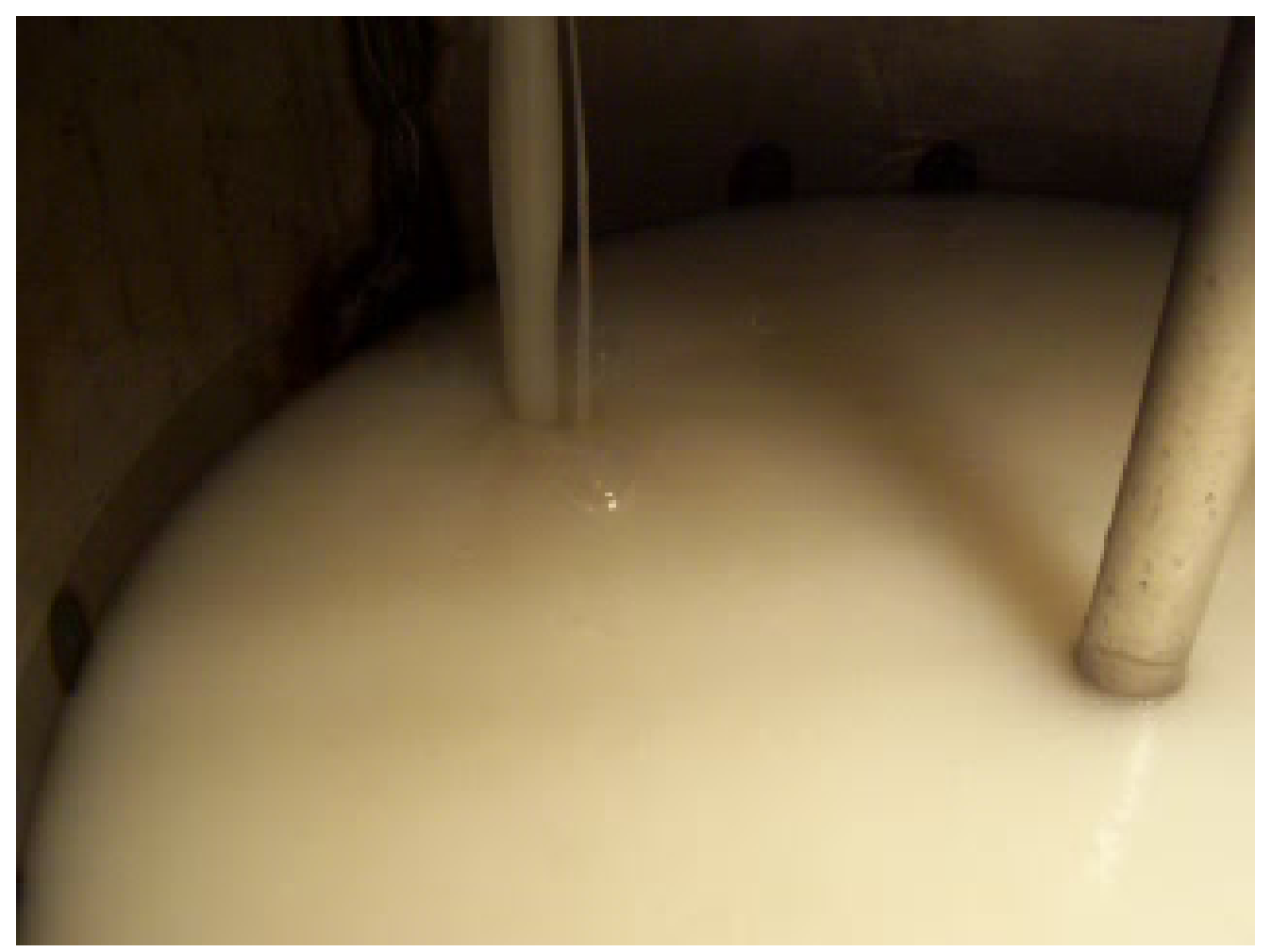

Figure F - 120 Pa Xanthan Gum, 20 RPM, Recirculation

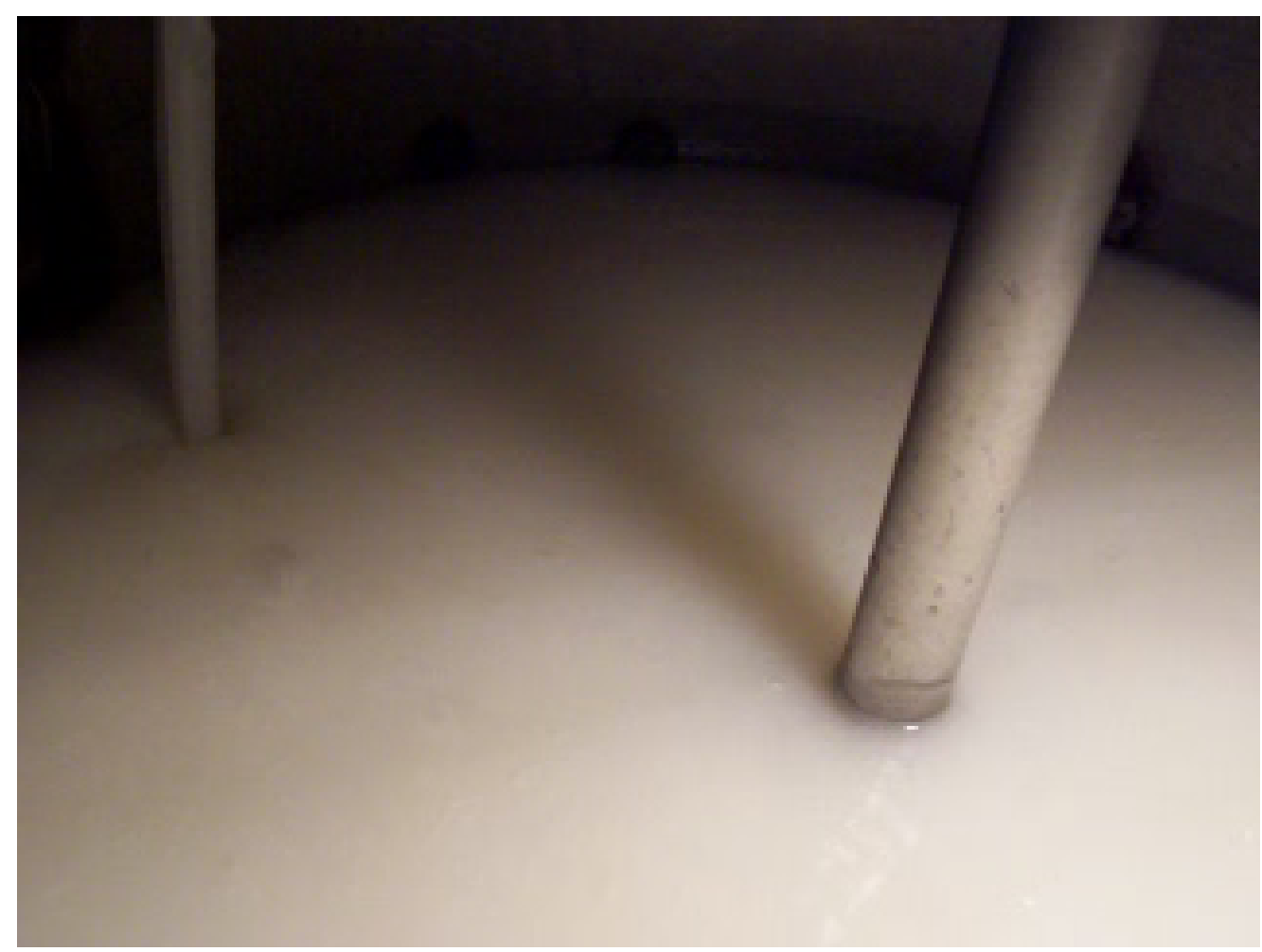

Figure F - 220 Pa Xanthan Gum, 30 RPM, Recirculation 


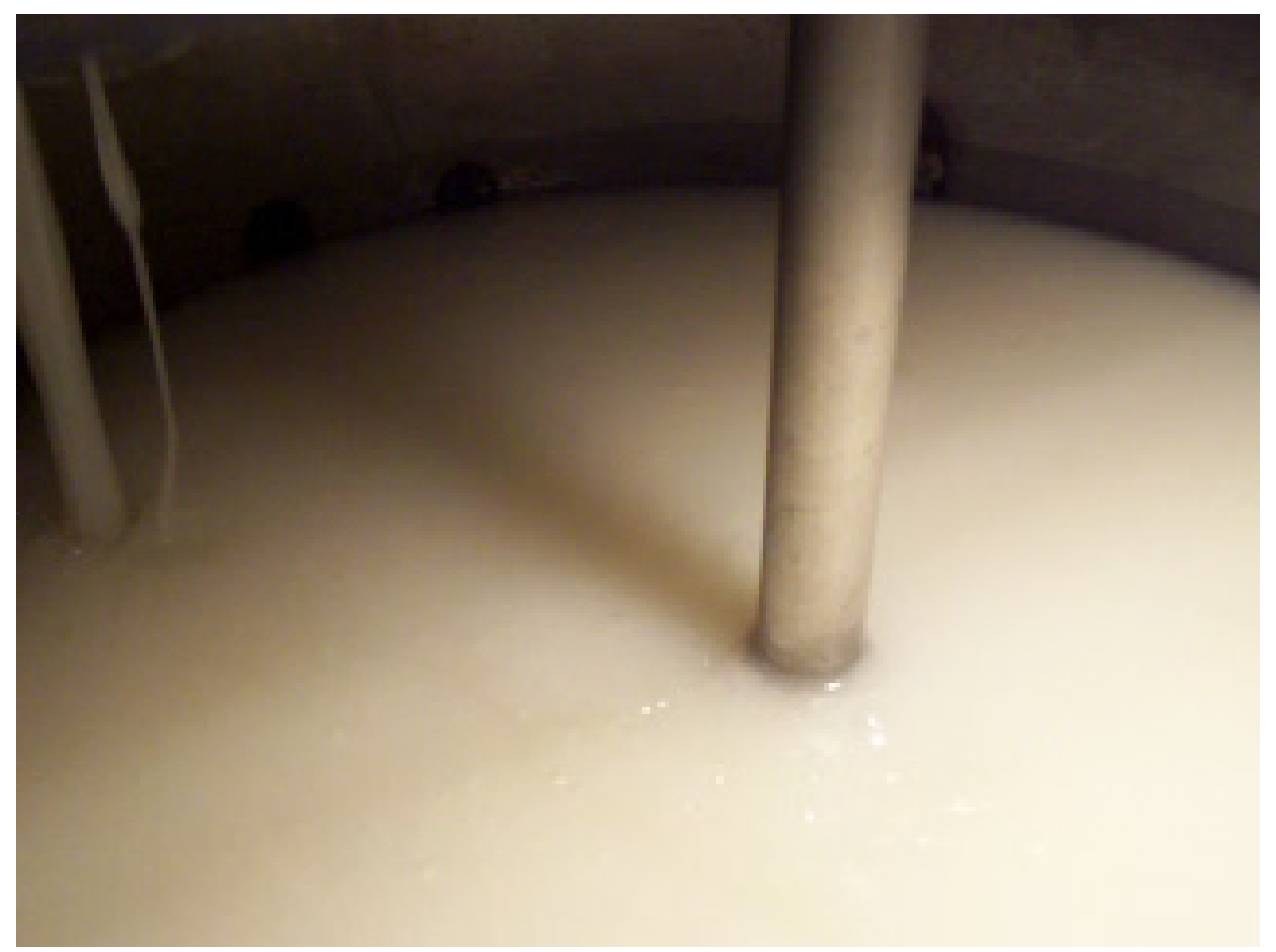

Figure F - 320 Pa Xanthan Gum, 40 RPM, Recirculation

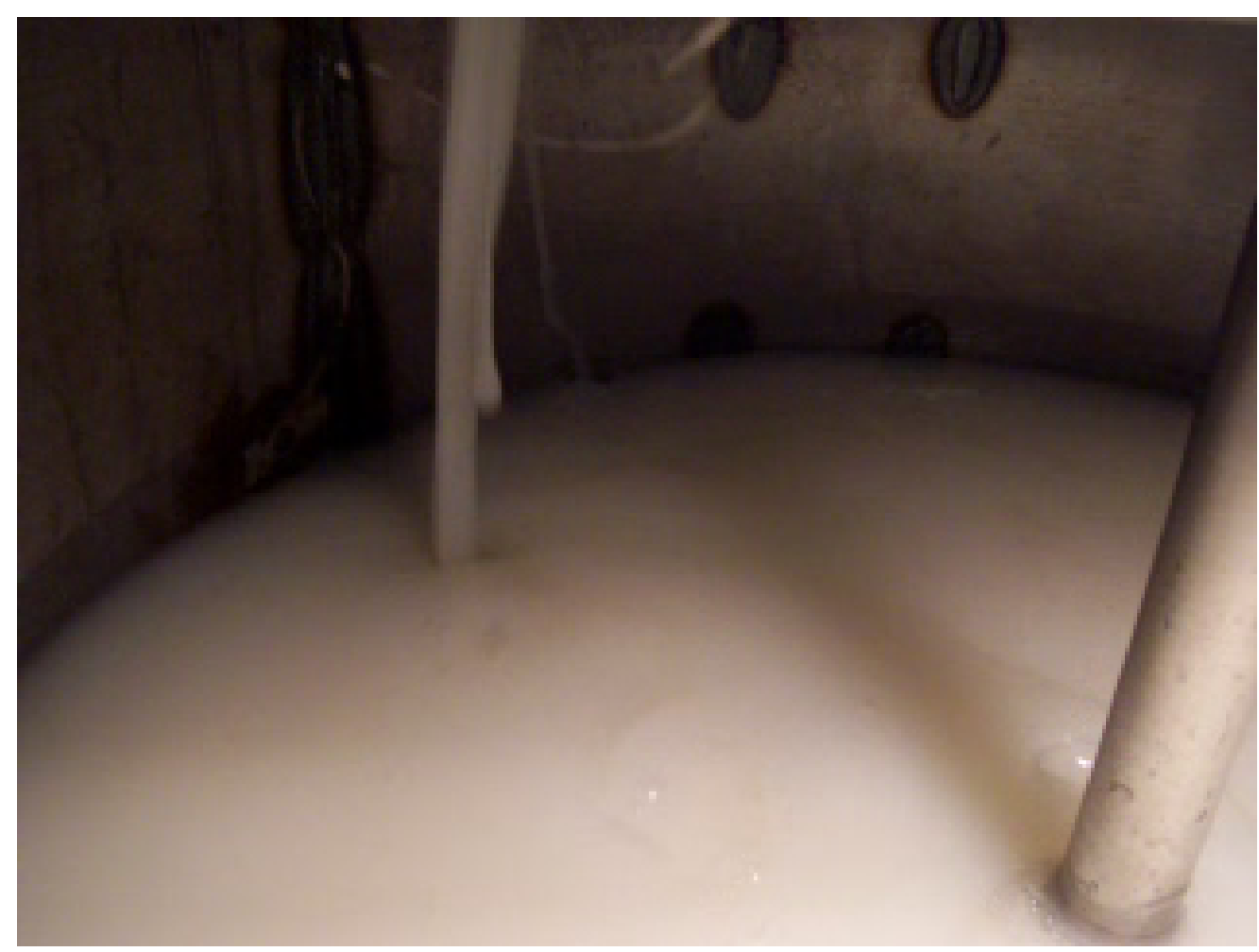

Figure F - 420 Pa Xanthan Gum, 50 RPM, Recirculation 


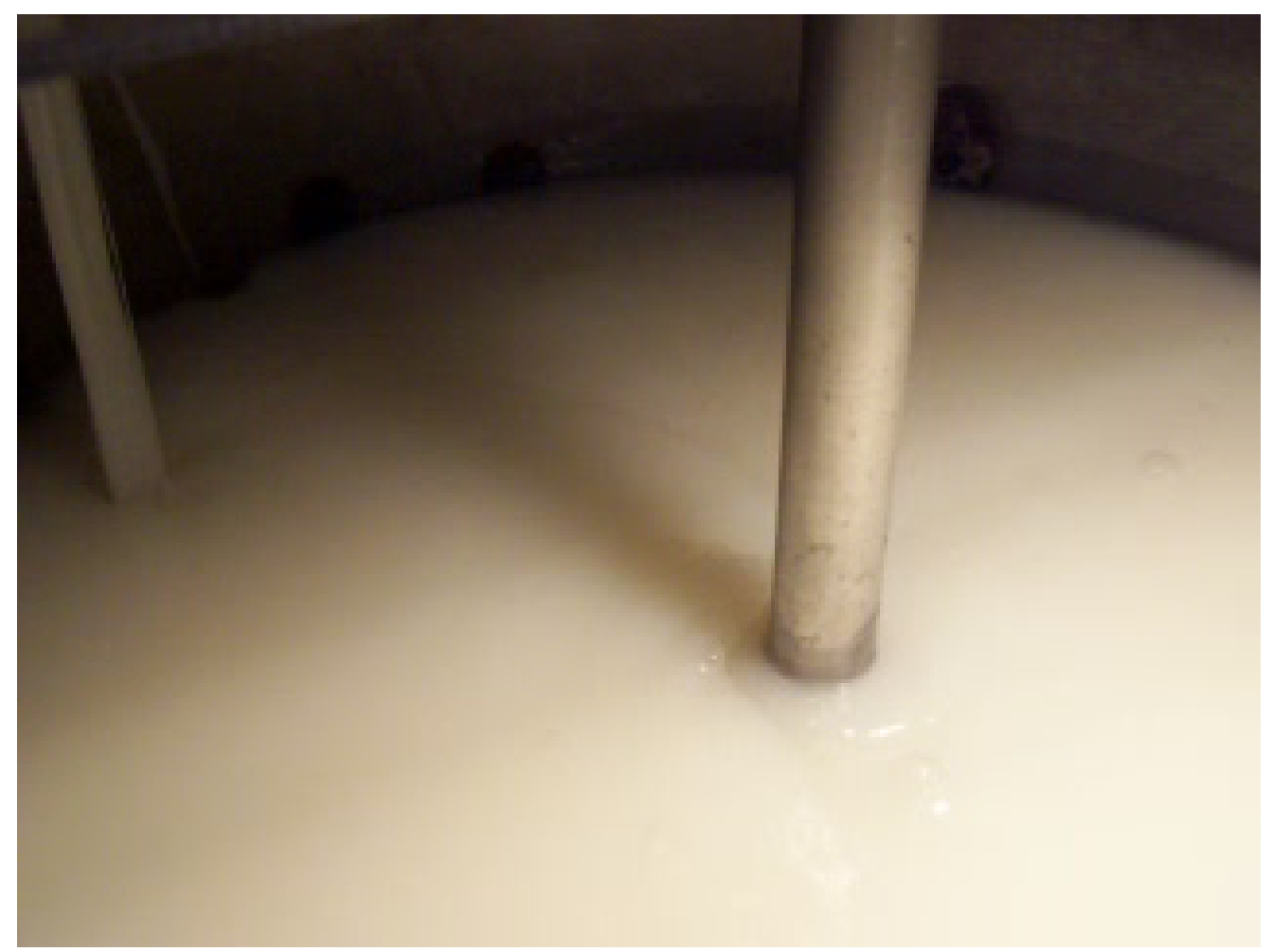

Figure F - 520 Pa Xanthan Gum, 60 RPM, Recirculation

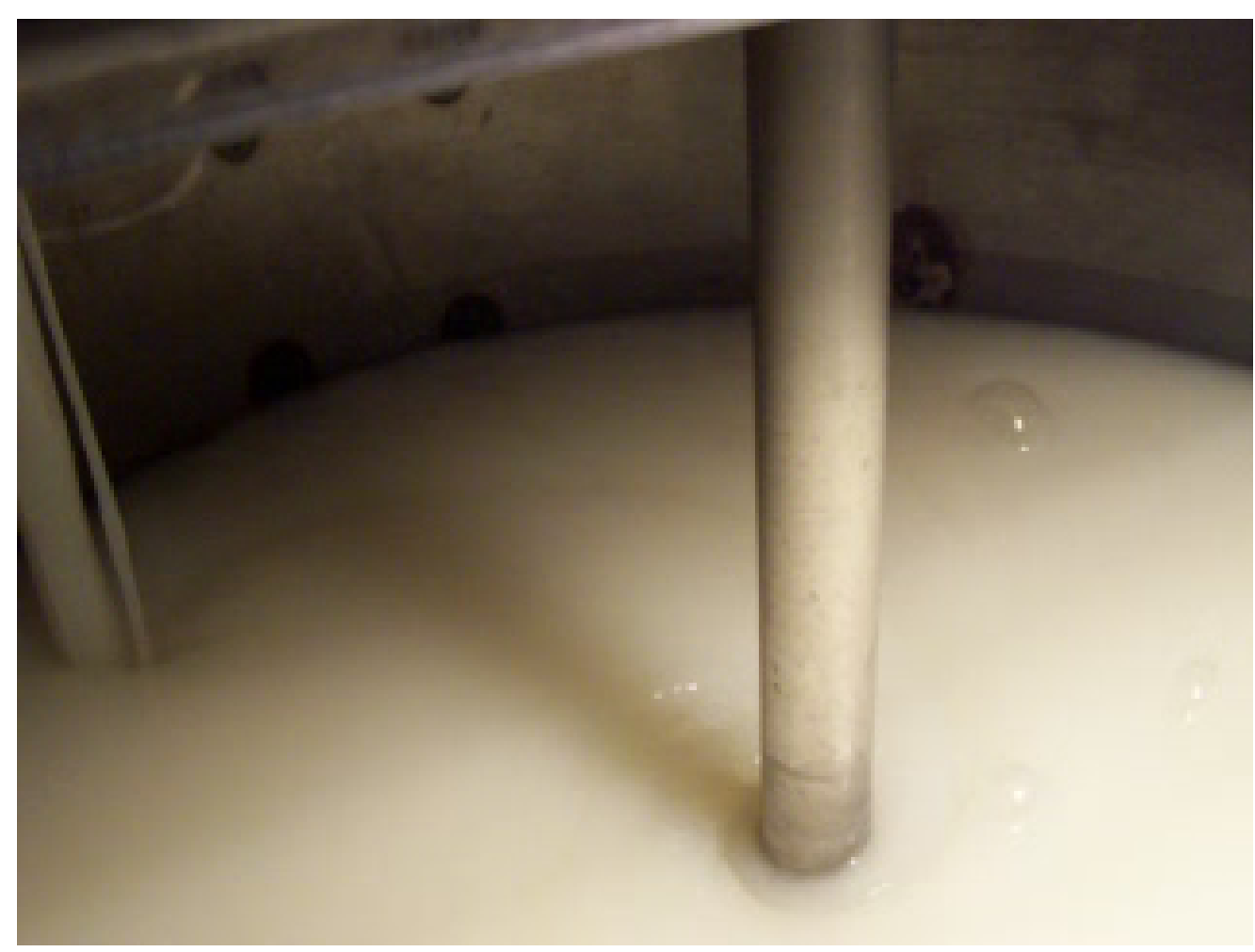

Figure F - 620 Pa Xanthan Gum, 70 RPM, Recirculation 


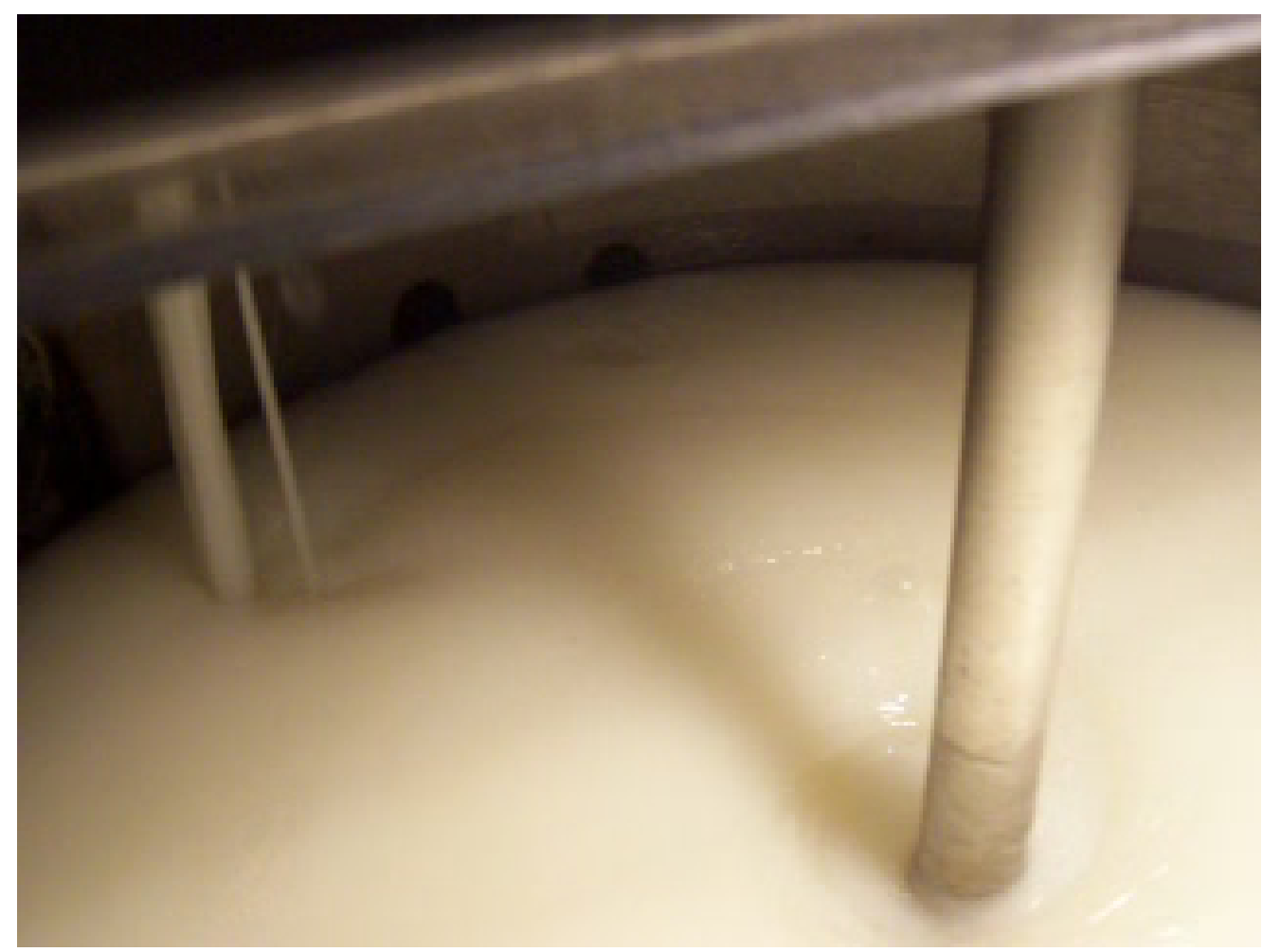

Figure F - 720 Pa Xanthan Gum, 80 RPM, Recirculation

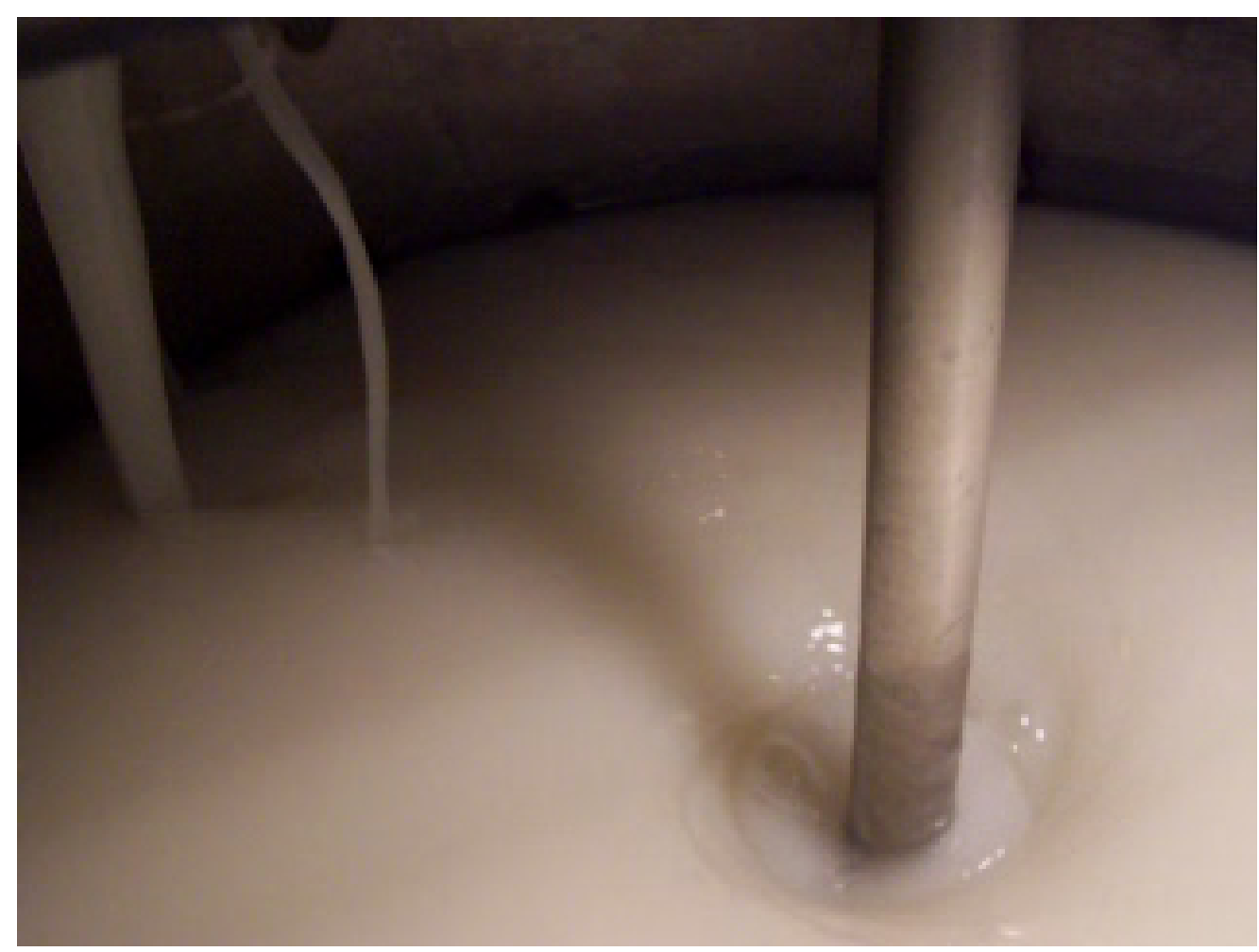

Figure F - 820 Pa Xanthan Gum, 90 RPM, Recirculation 


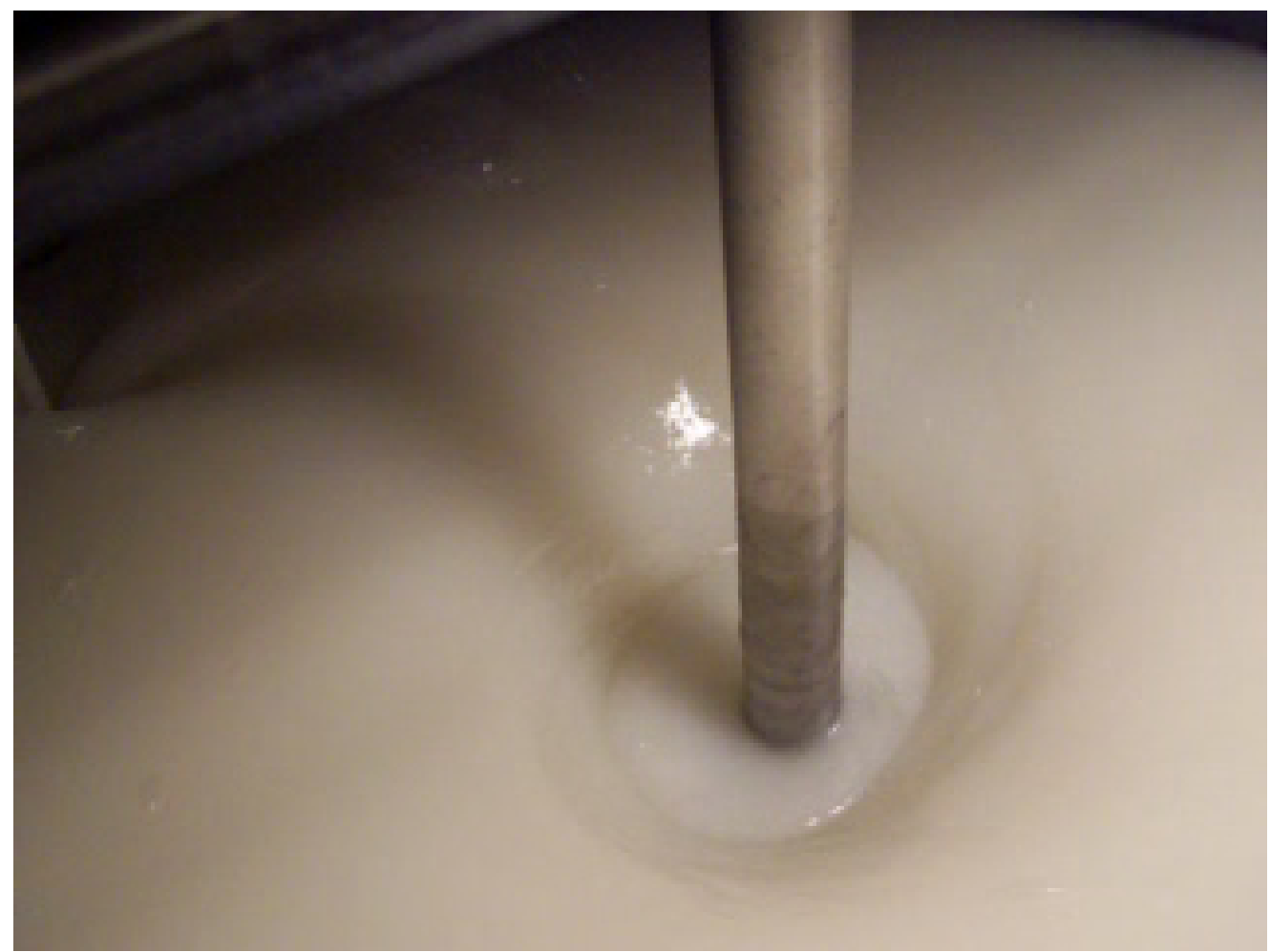

Figure F - 920 Pa Xanthan Gum, 100 RPM, Recirculation

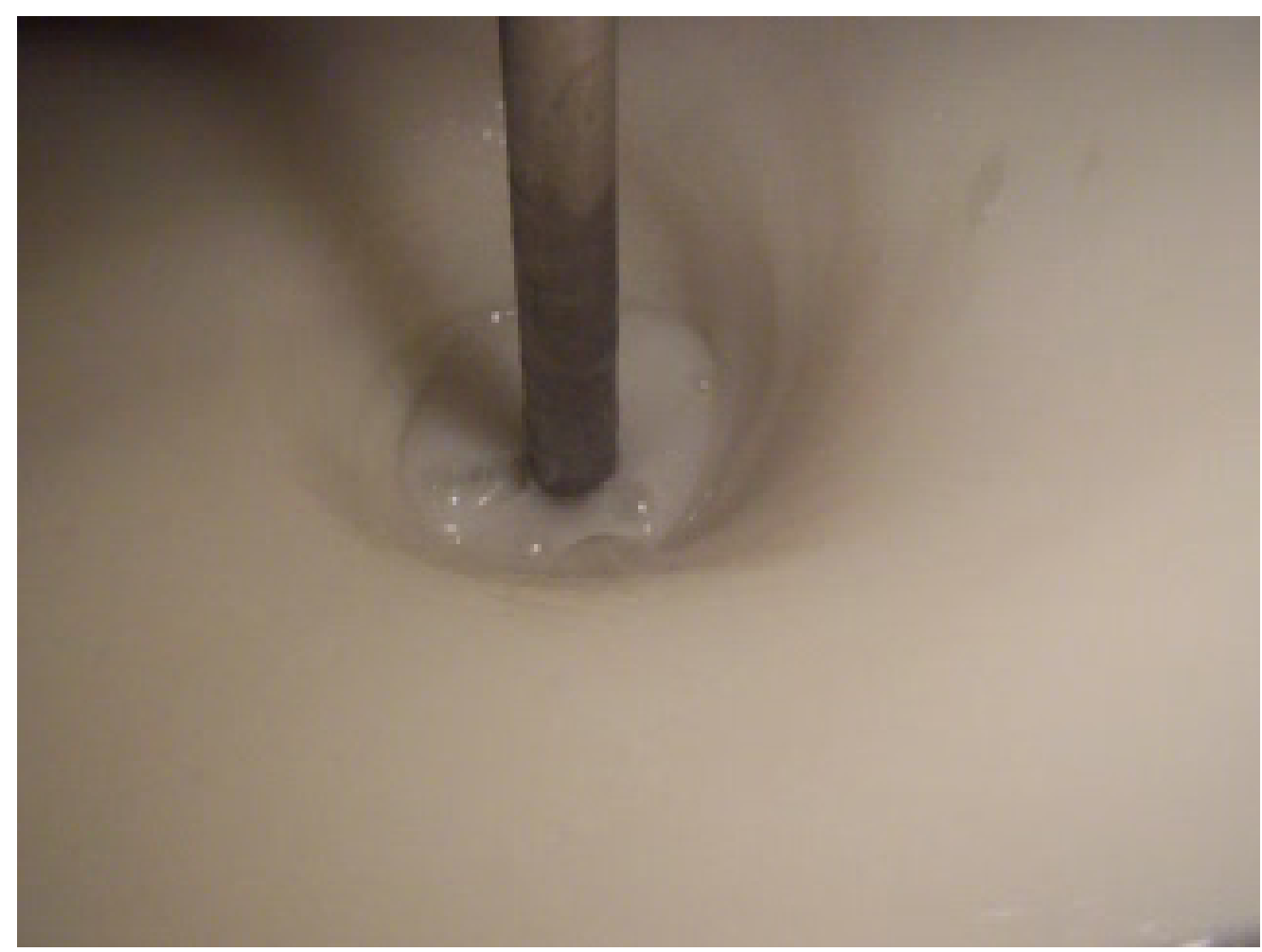

Figure F - 1020 Pa Xanthan Gum, 1100 RPM, Recirculation 


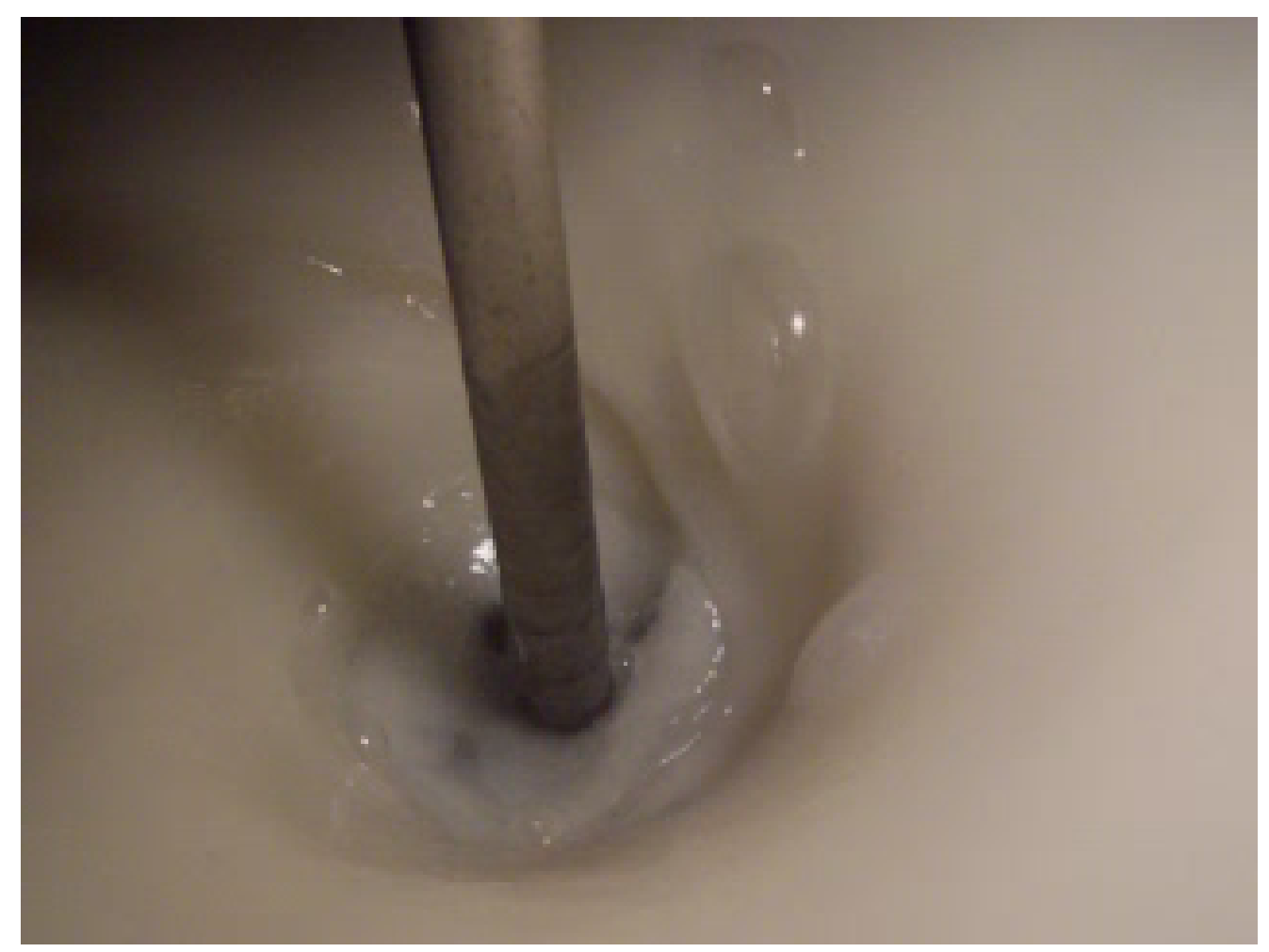

Figure F - 1120 Pa Xanthan Gum, 120 RPM, Recirculation

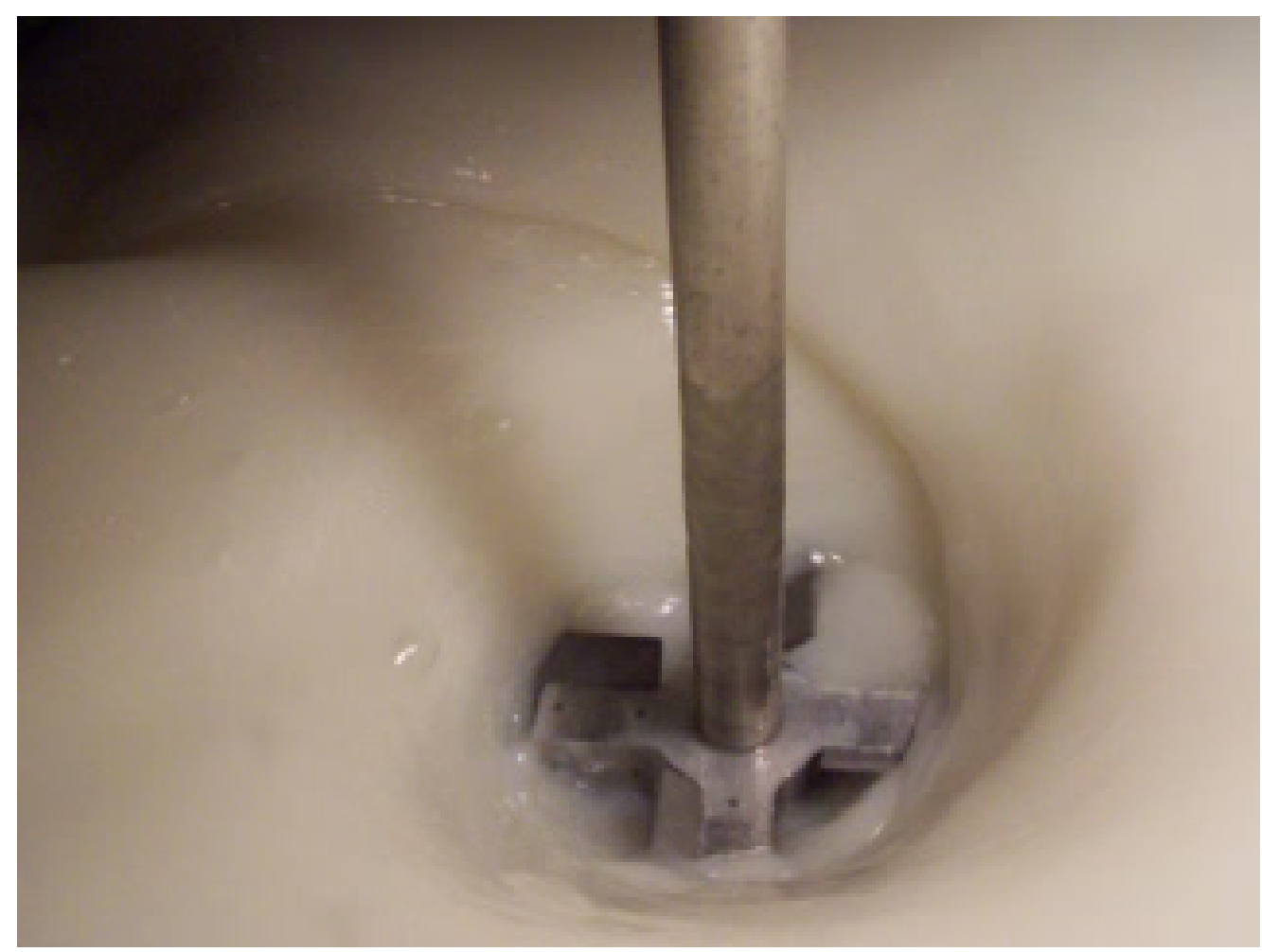

Figure F - 1220 Pa Xanthan Gum, 130 RPM, Recirculation 
SRNL-STI-2011-00465

Revision 0

\section{APPENDIX G: MIXING PICTURES FOR STATIC GROUT RUNS}




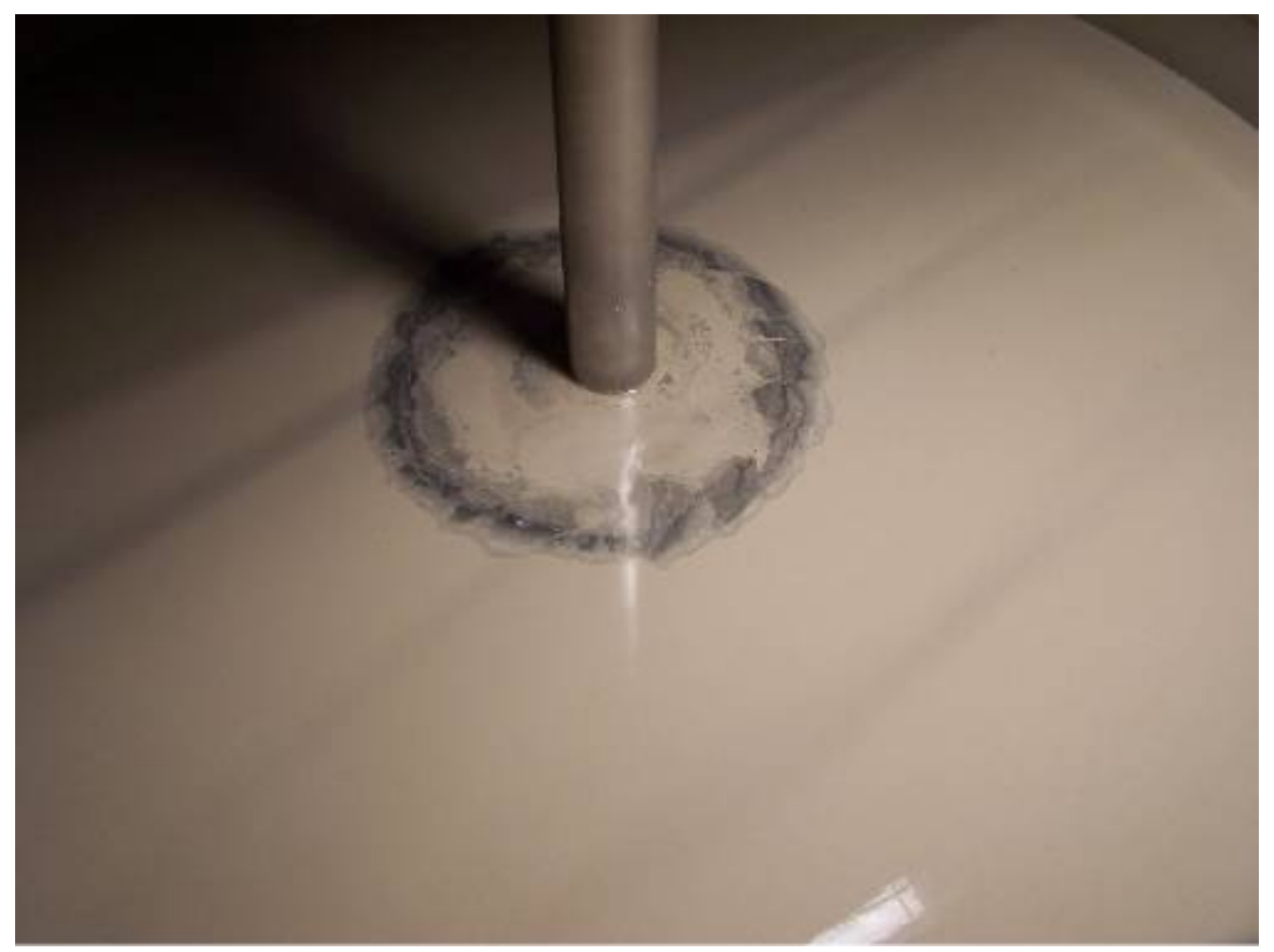

Figure G - 15 Pa Grout, 20 RPM, Static

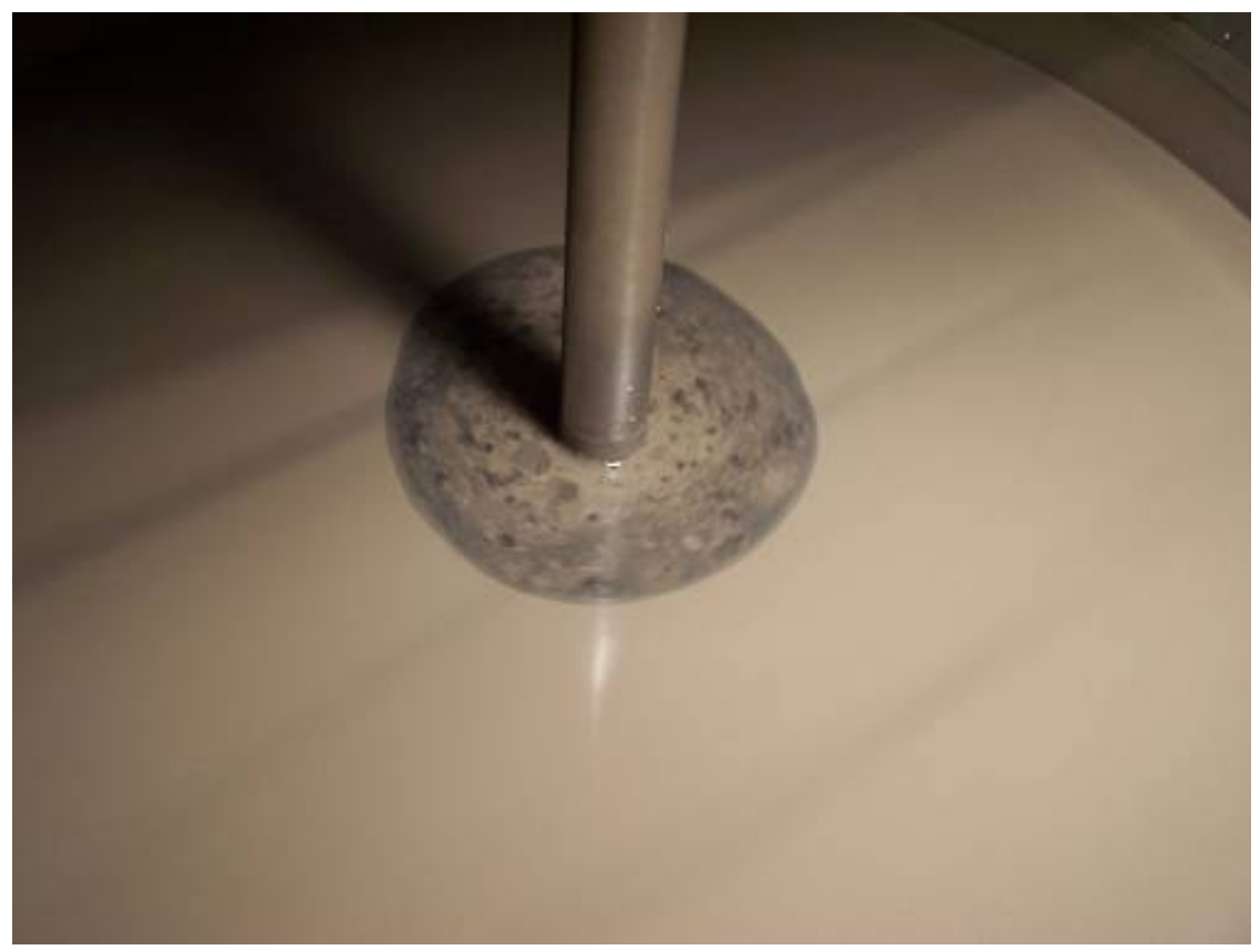

Figure G - 25 Pa Grout, 30 RPM, Static 


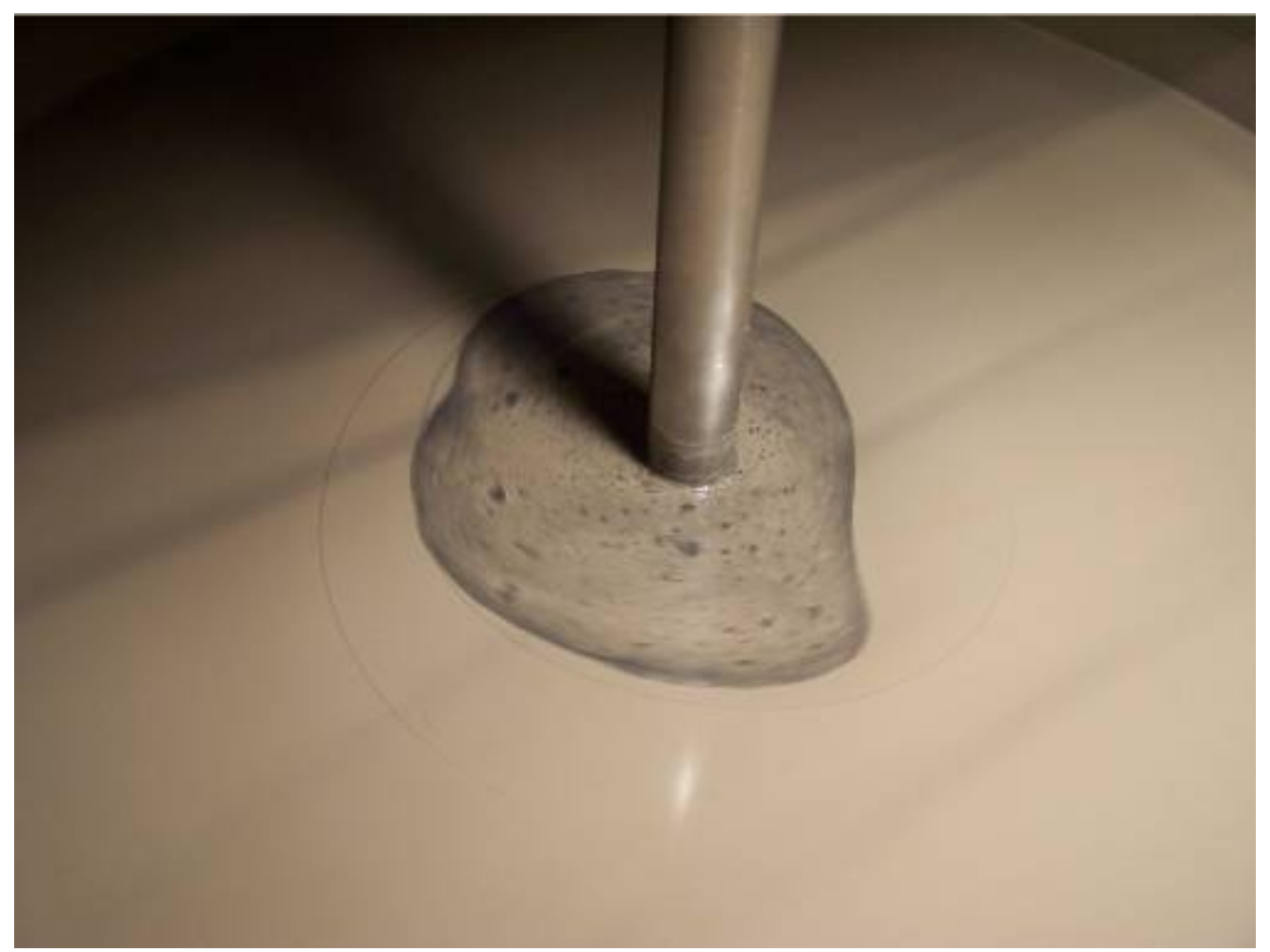

Figure G - 35 Pa Grout, 40 RPM, Static

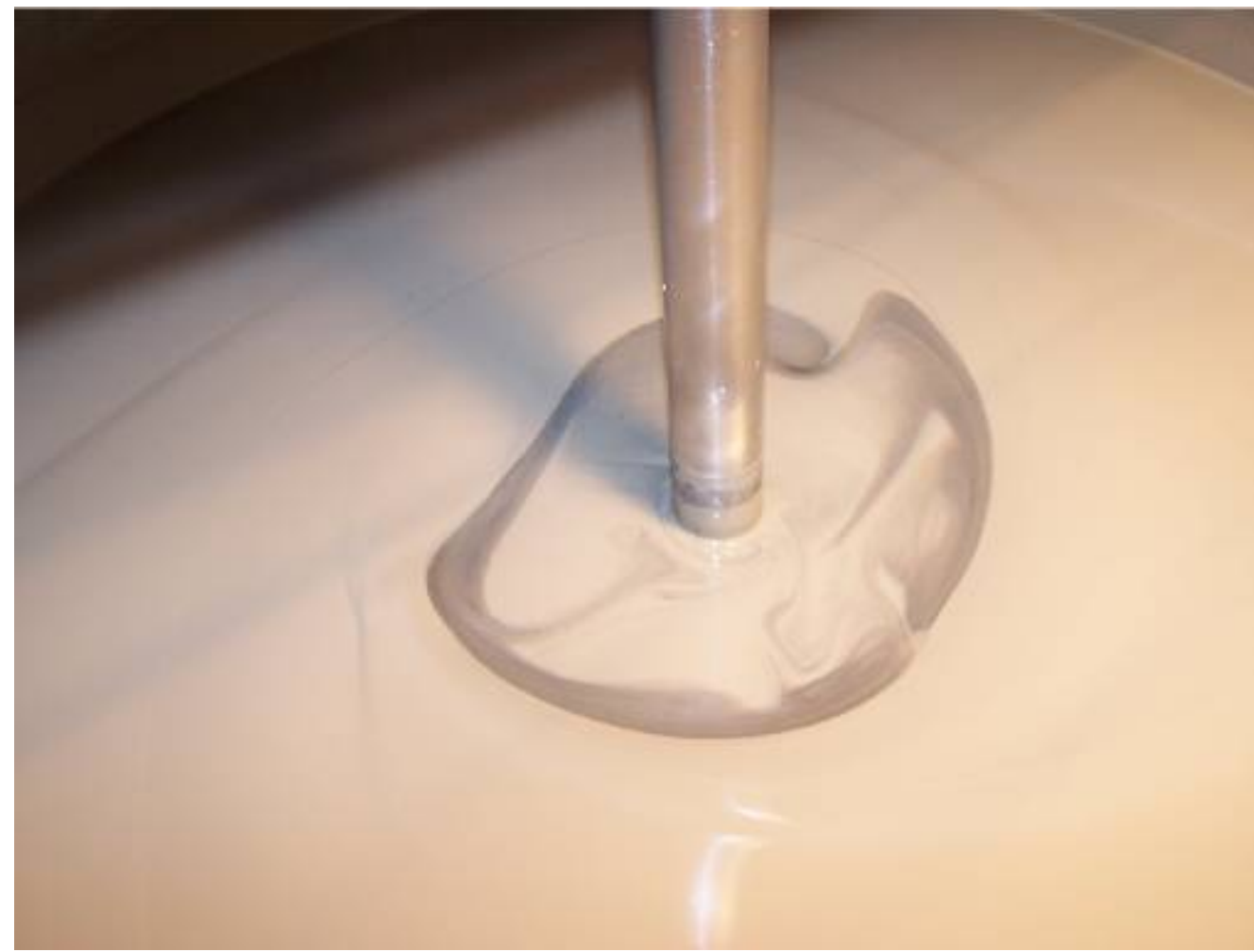

Figure G - 45 Pa Grout, 50 RPM, Static 


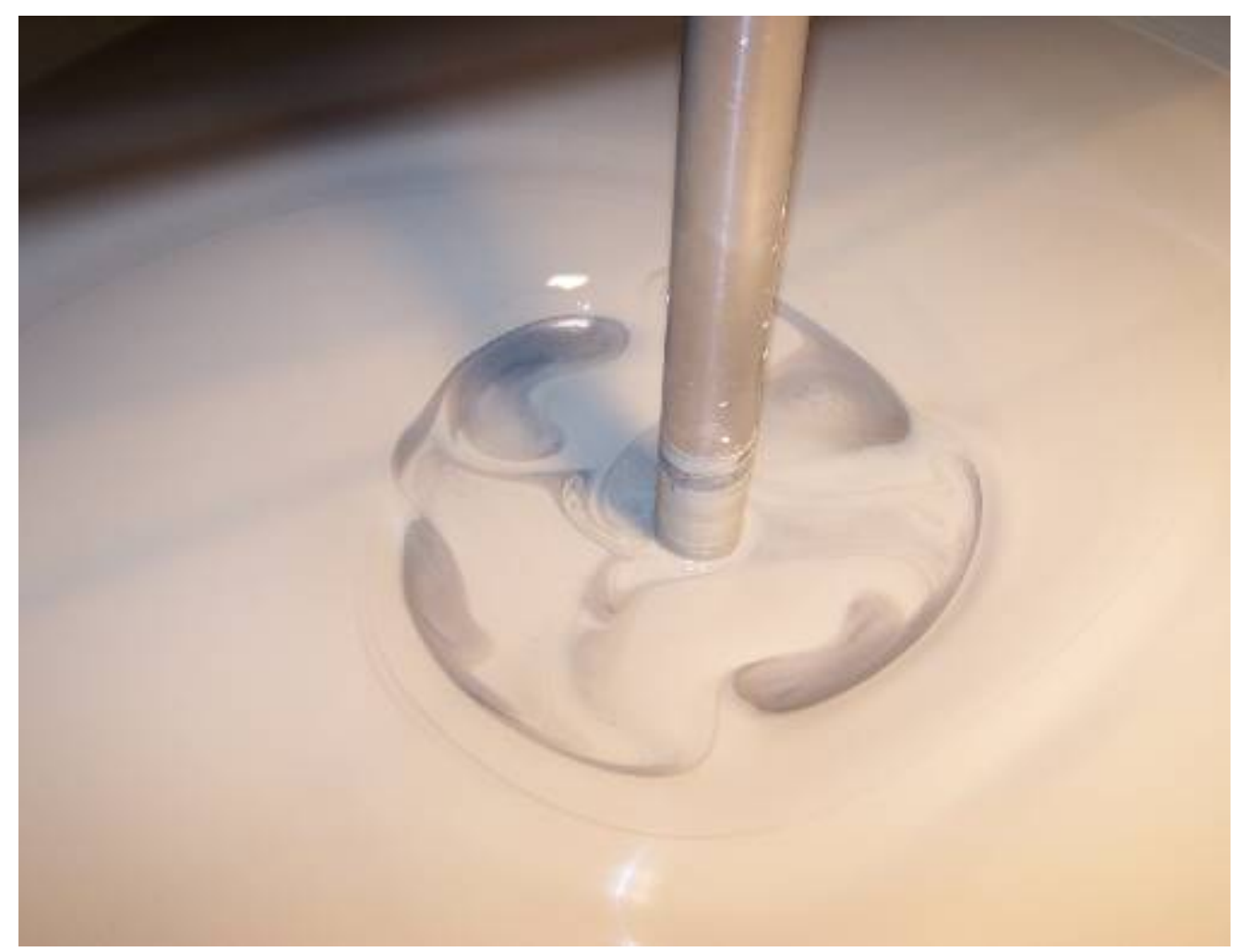

Figure G - 55 Pa Grout, 60 RPM, Static

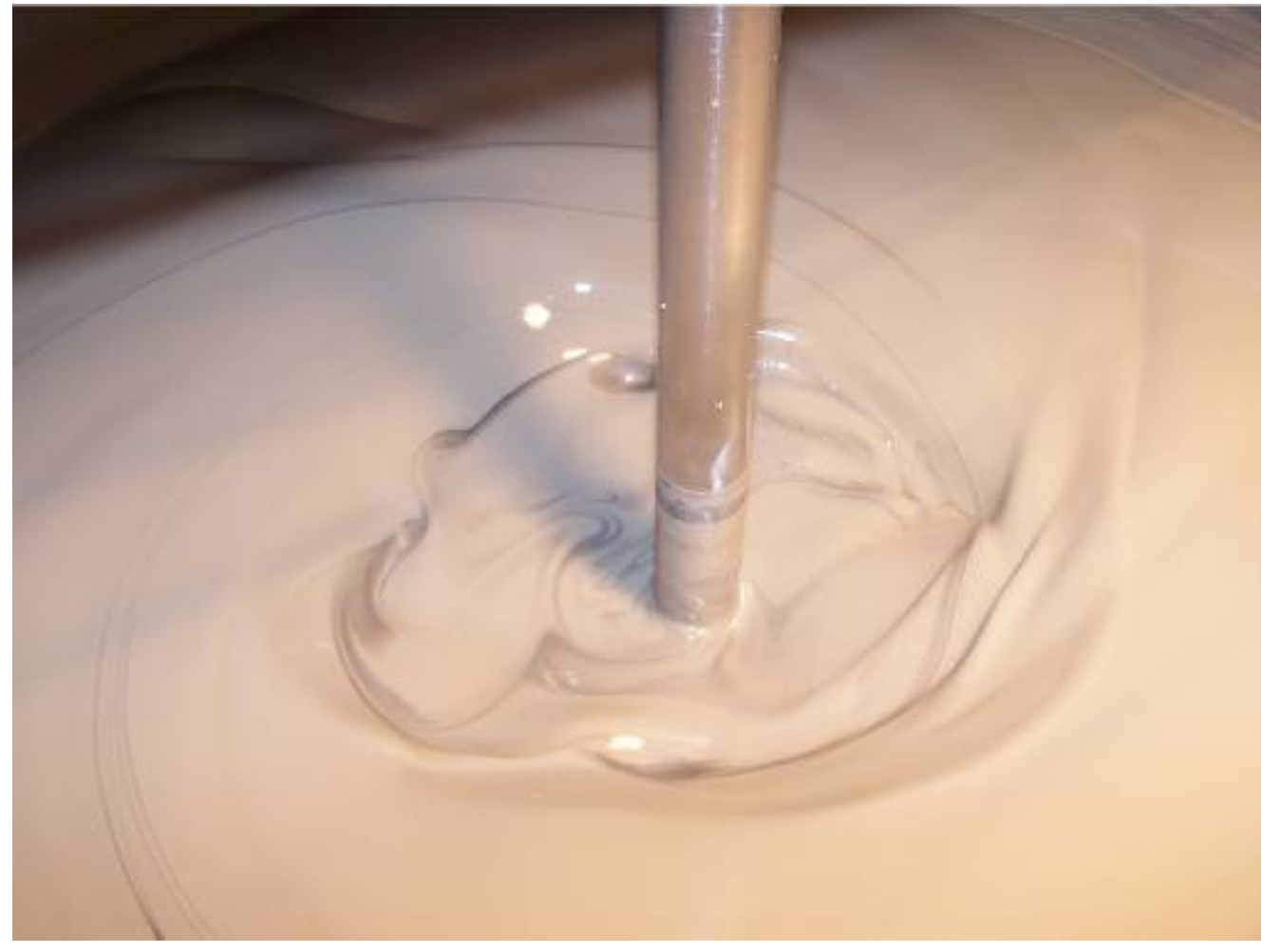

Figure G - 65 Pa Grout, 70 RPM, Static 


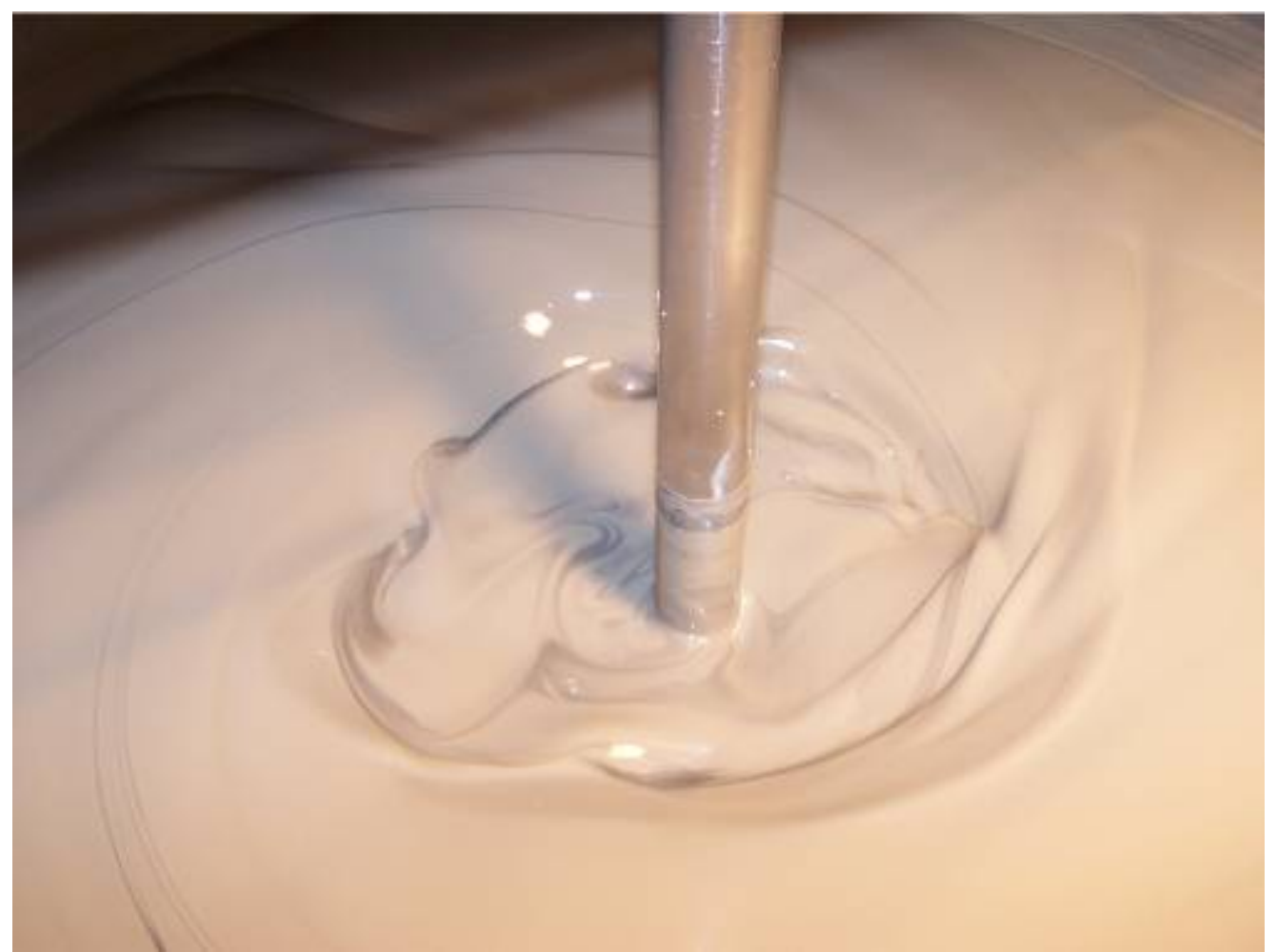

Figure G - 75 Pa Grout, 80 RPM, Static

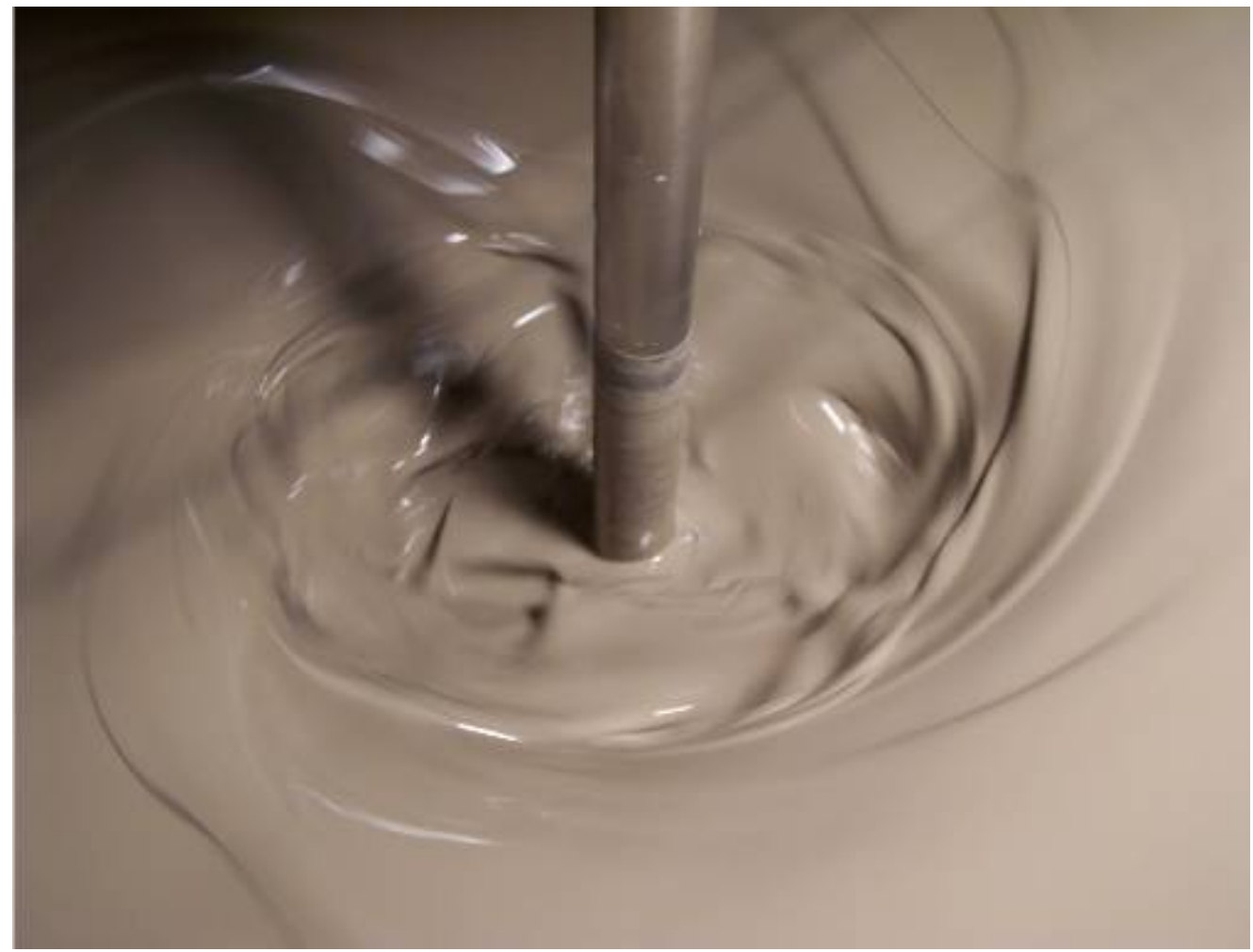

Figure G - 85 Pa Grout, 90 RPM, Static 


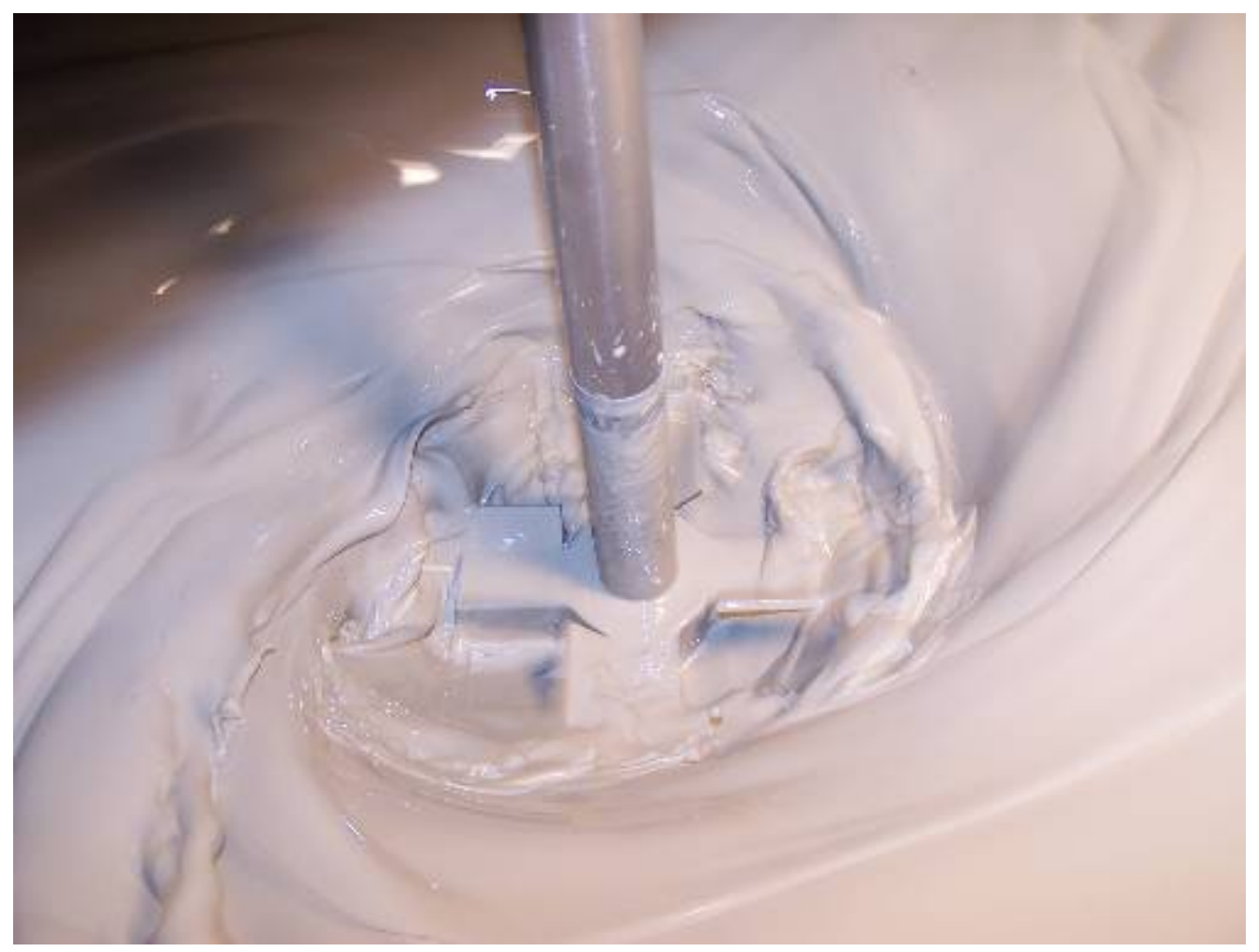

Figure G - 95 Pa Grout, 100 RPM, Static

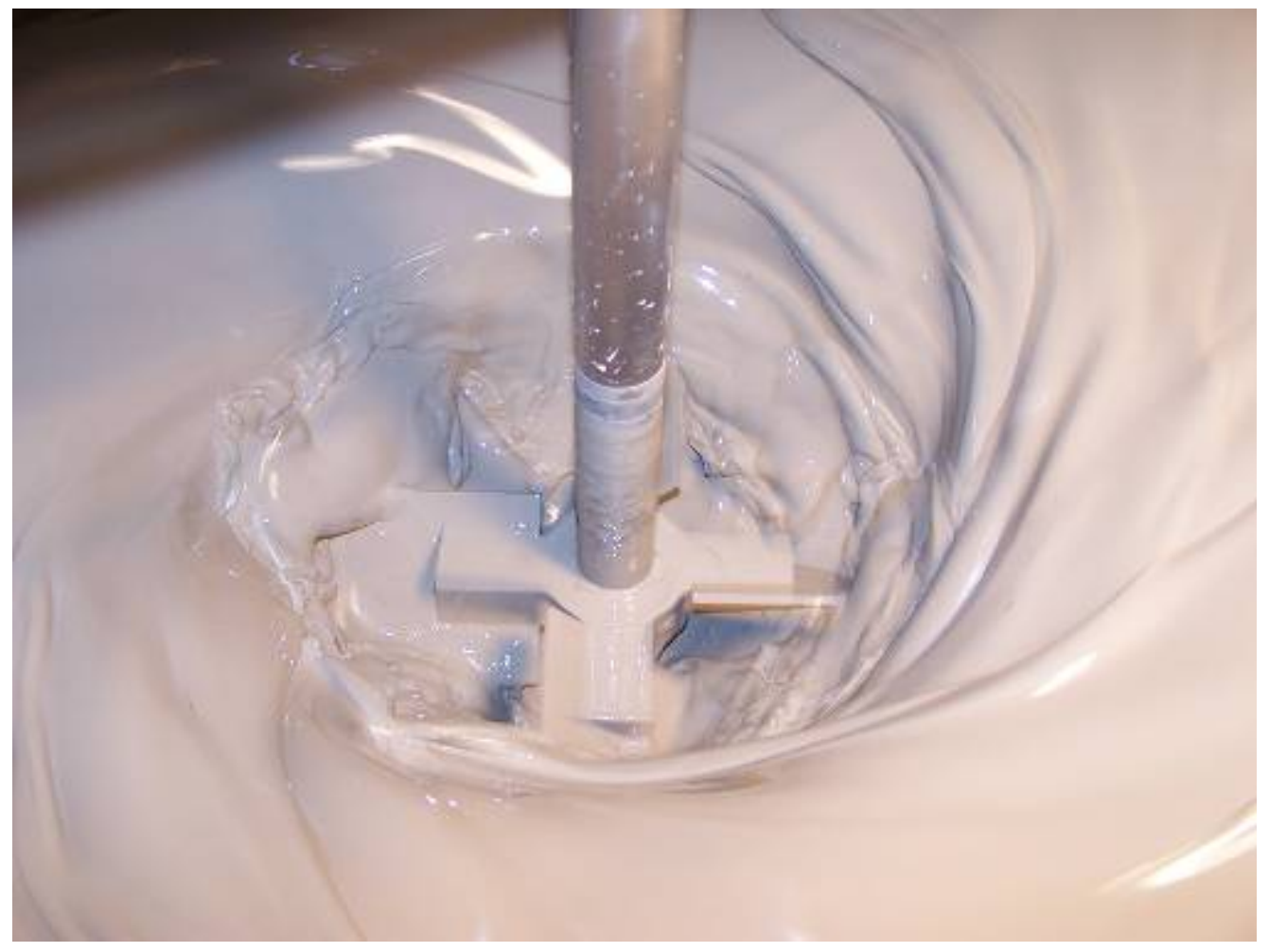

Figure G - 105 Pa Grout, 110 RPM, Static 
SRNL-STI-2011-00465

Revision 0

APPENDIX H: MIXING PICTURES FOR RECIRCULATION GROUT RUNS 


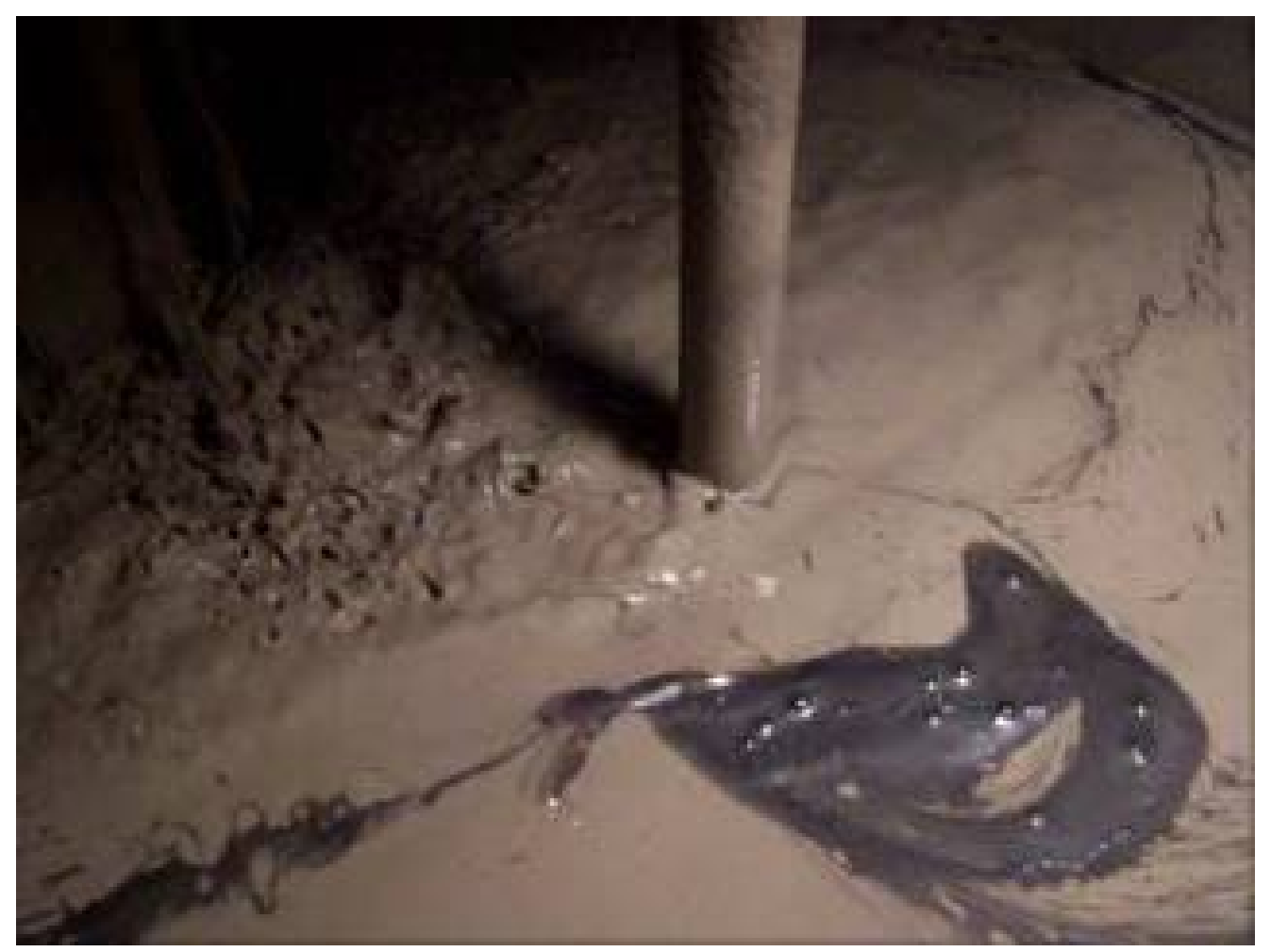

Figure H - 15 Pa Grout, 20 RPM, Recirculation

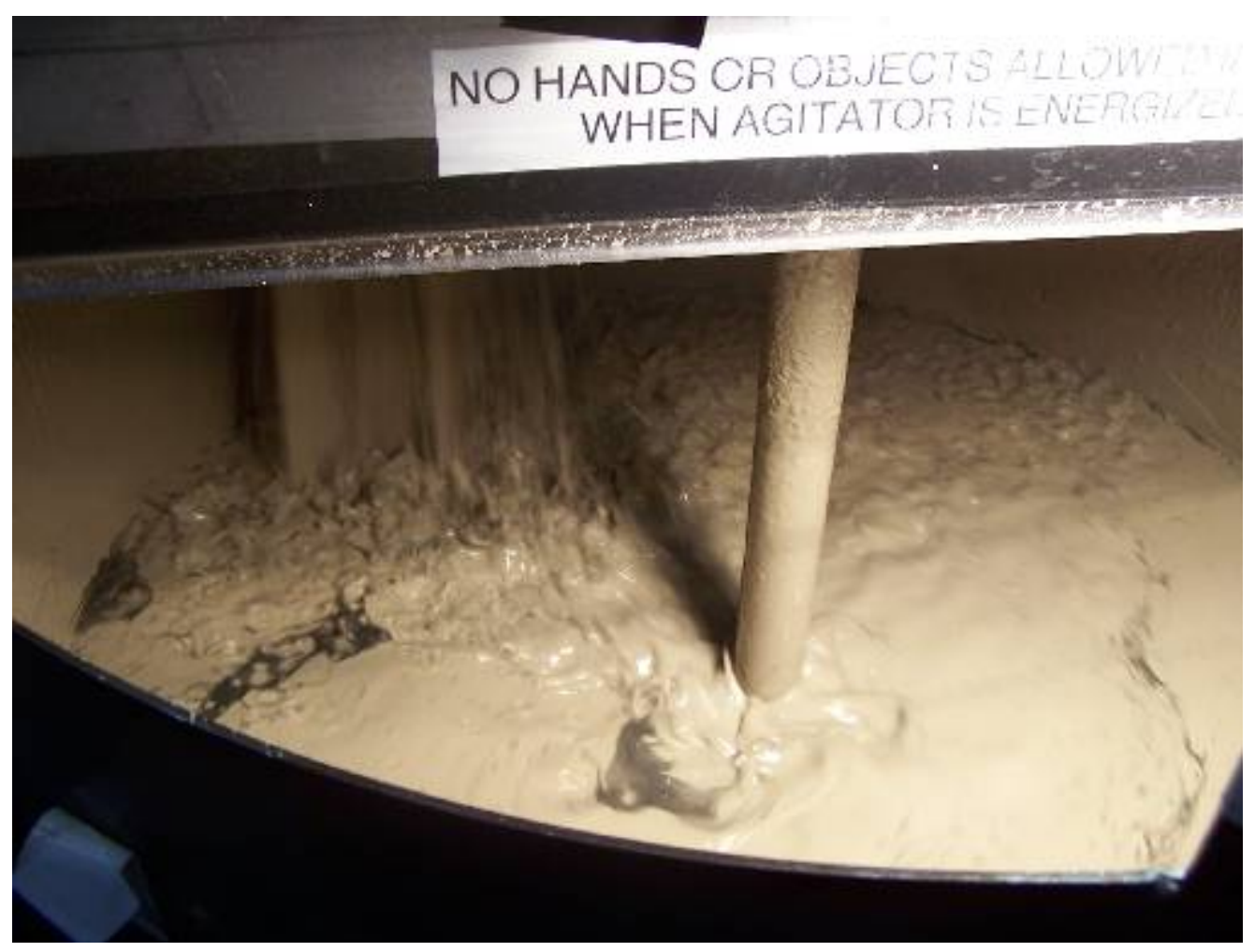

Figure H - 25 Pa Grout, 30 RPM, Recirculation 


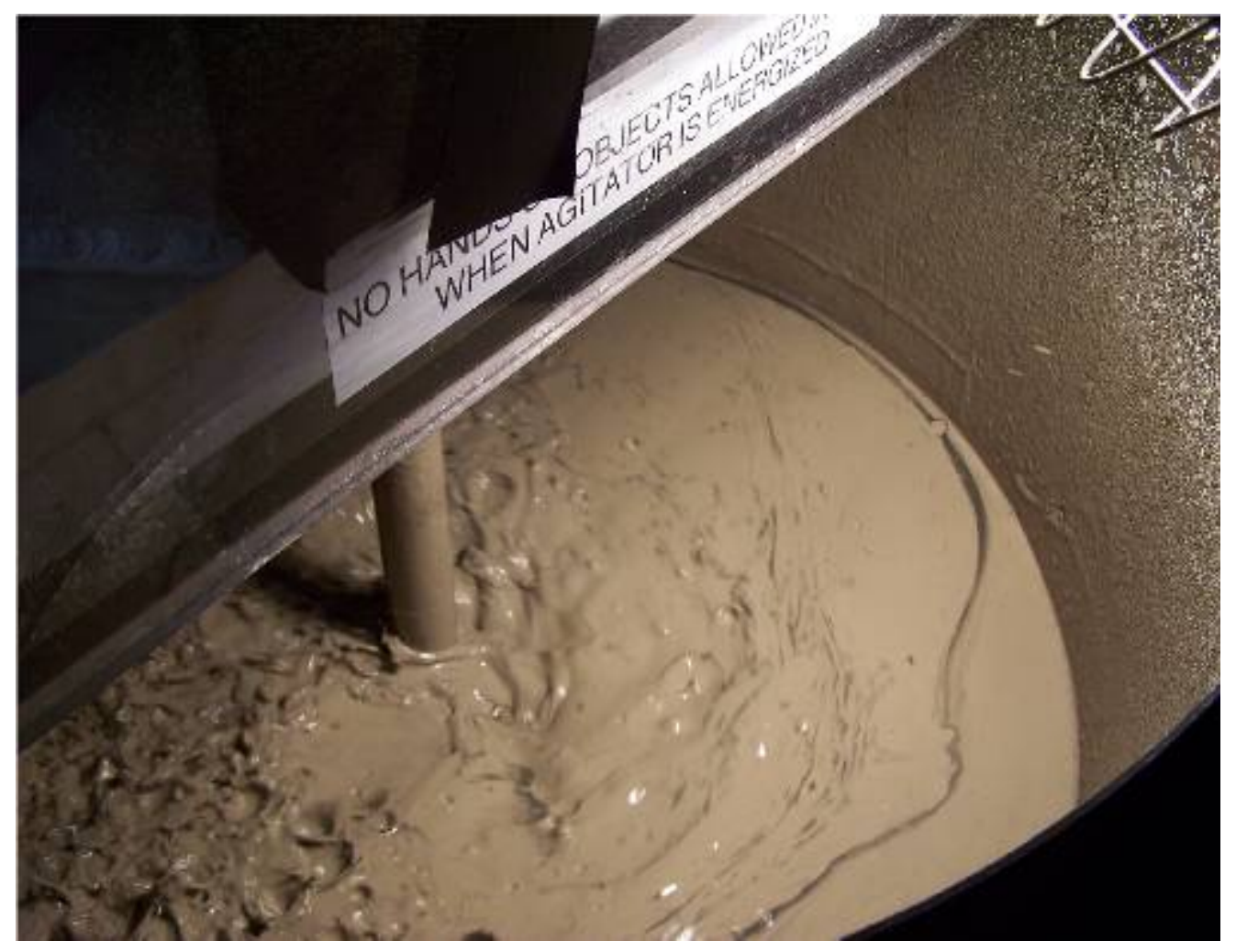

Figure H - 35 Pa Grout, 40 RPM, Recirculation

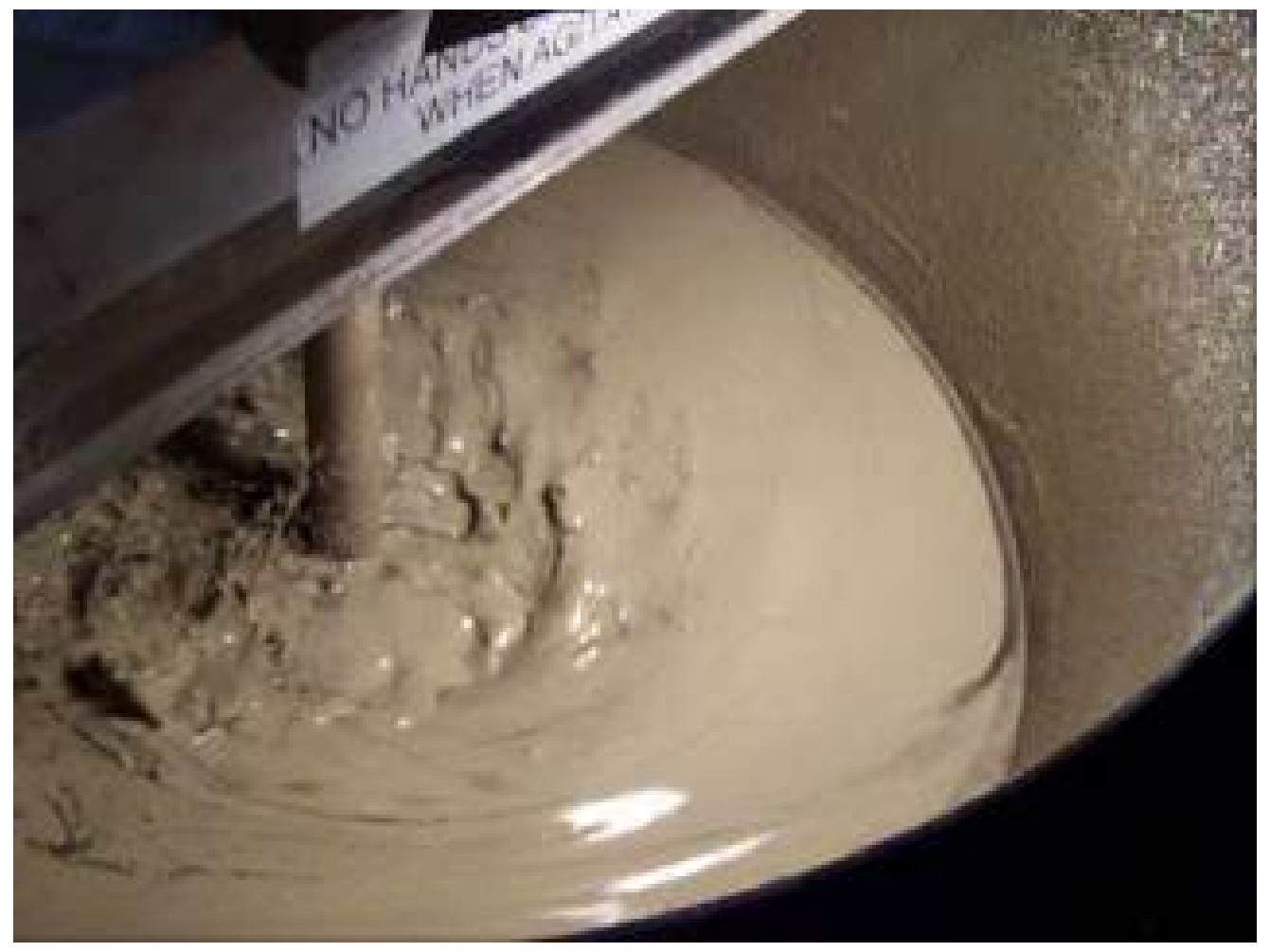

Figure H - 45 Pa Grout, 50 RPM, Recirculation 


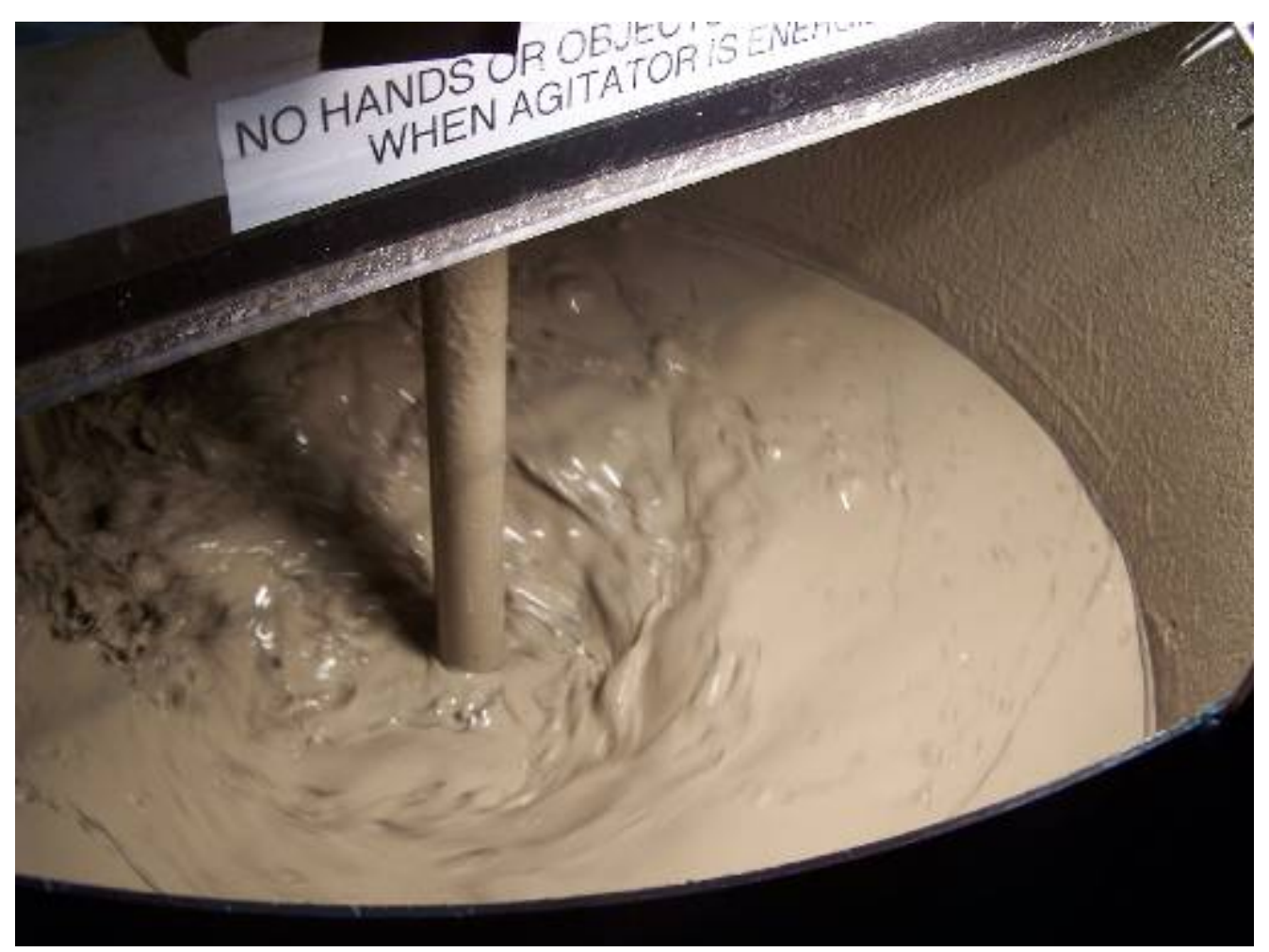

Figure H - 55 Pa Grout, 60 RPM, Recirculation

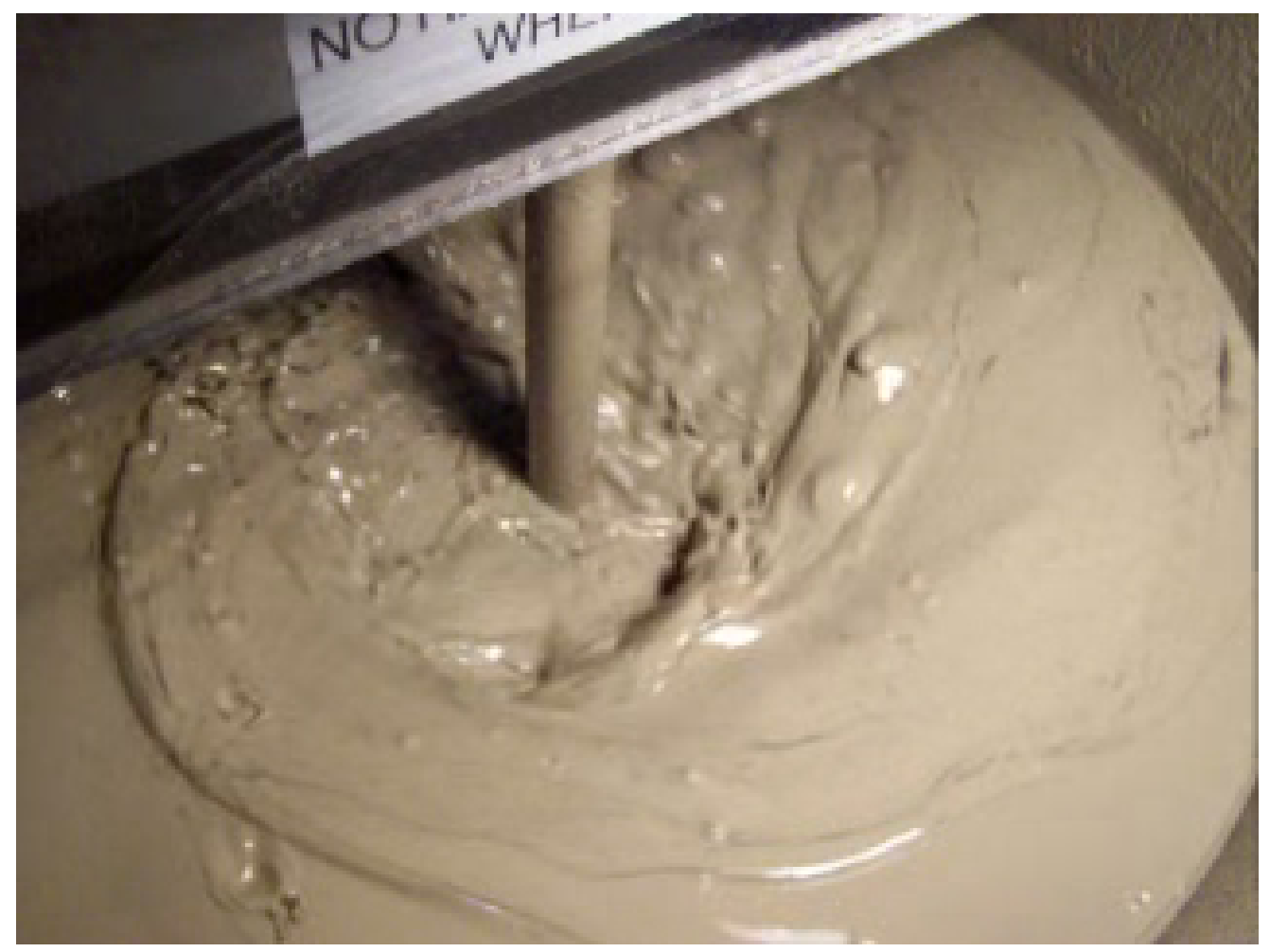

Figure H - 65 Pa Grout, 70 RPM, Recirculation 


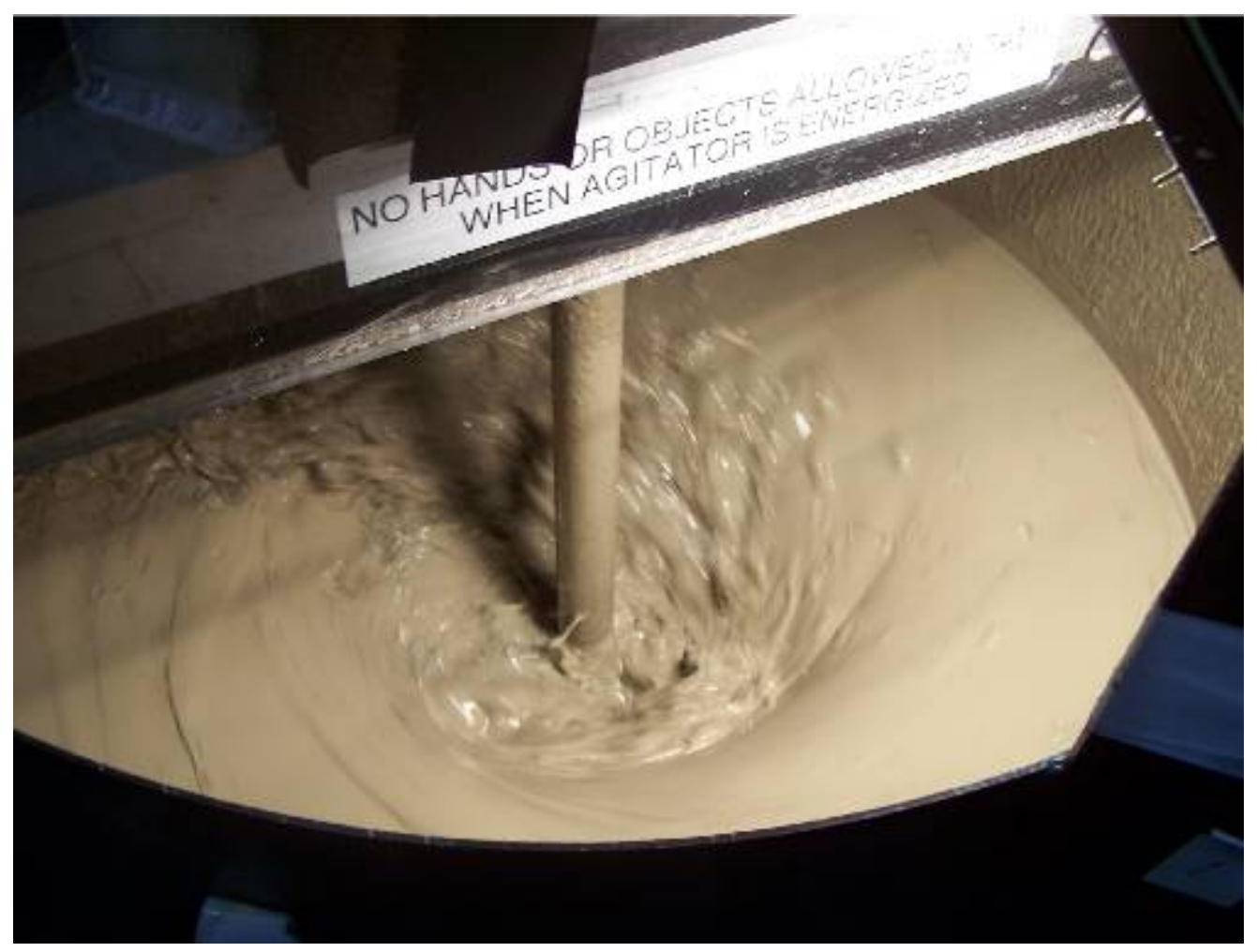

Figure H - 75 Pa Grout, 80 RPM, Recirculation

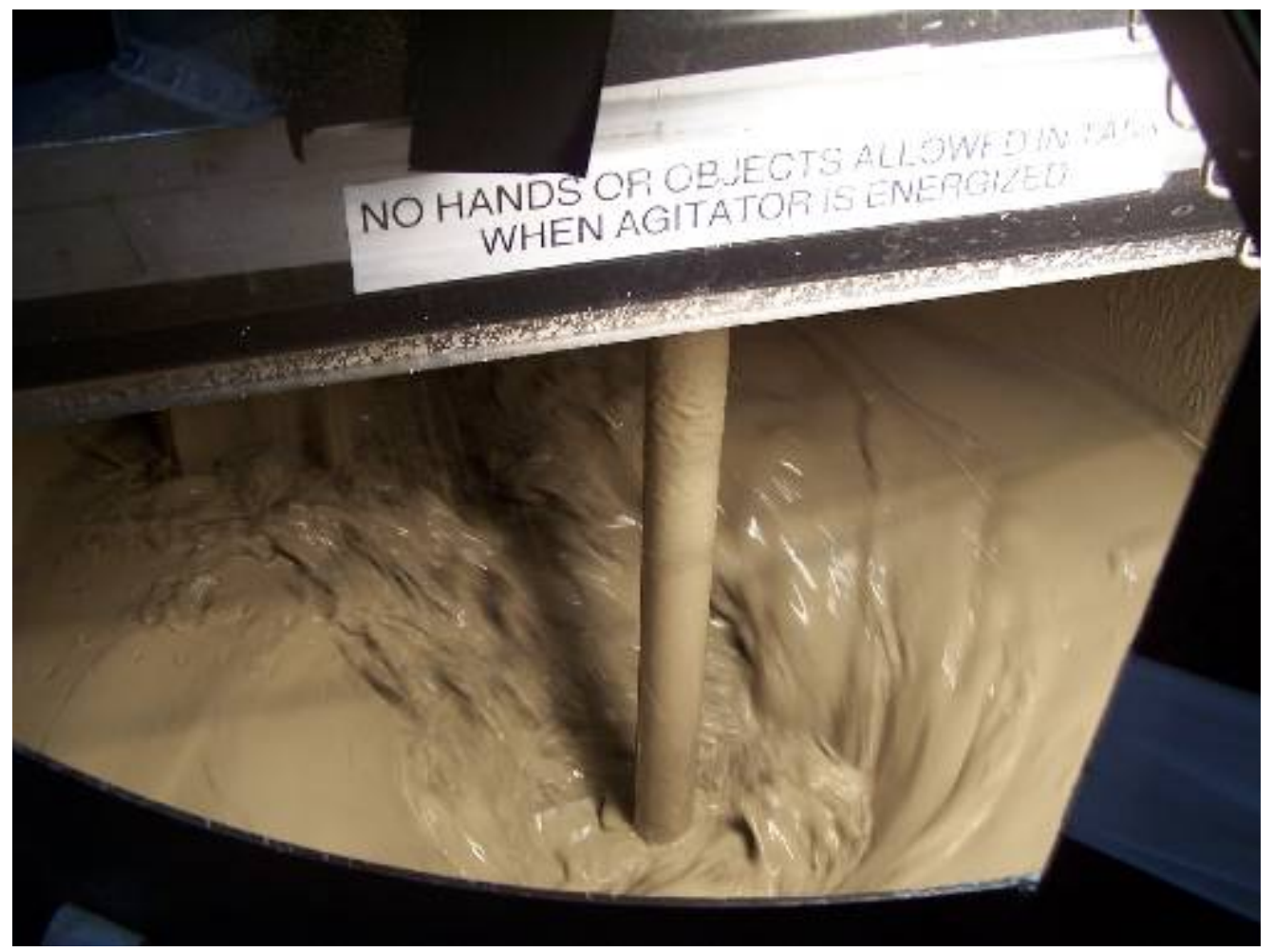

Figure H - 85 Pa Grout, 90 RPM, Recirculation 
SRNL-STI-2011-00465

Revision 0

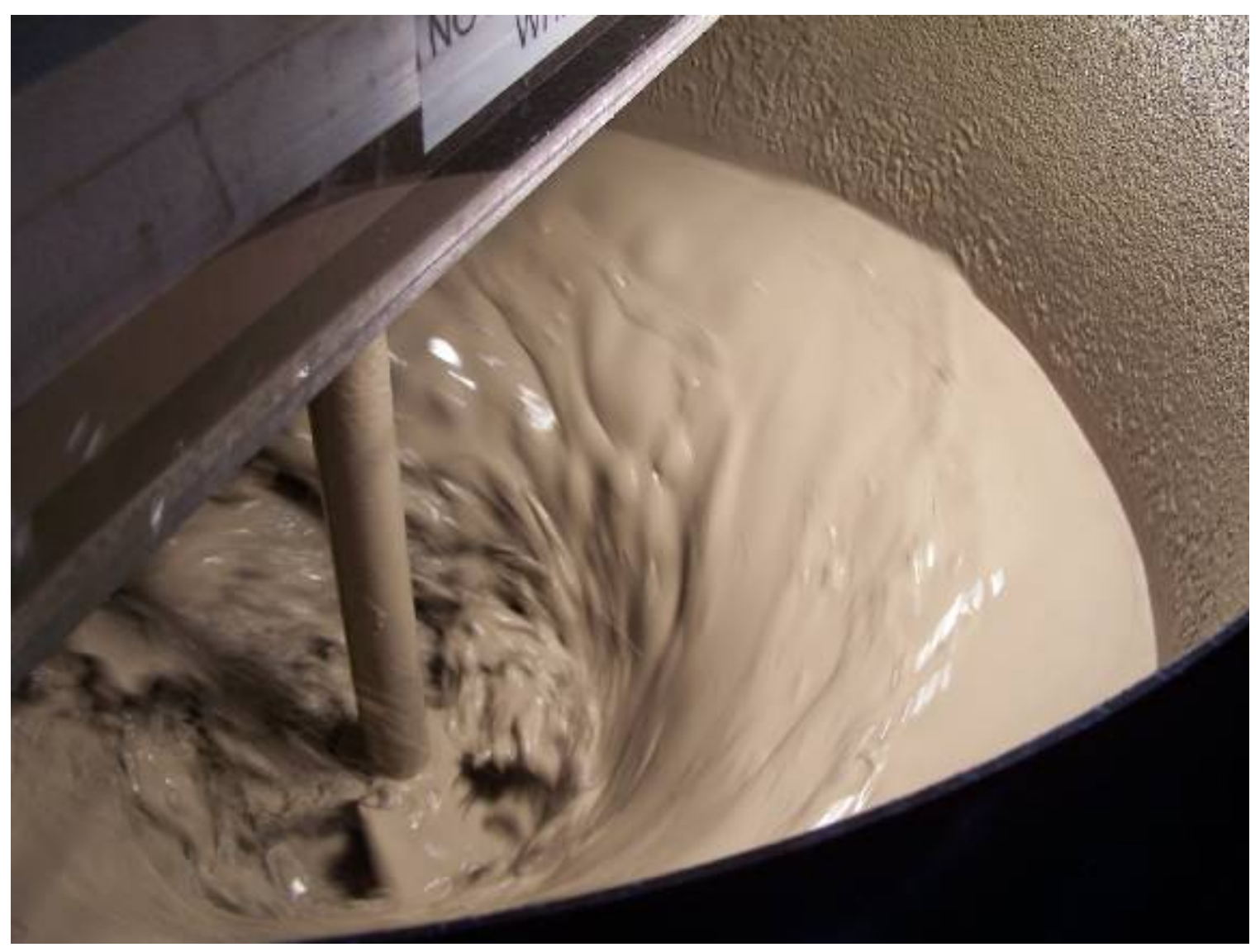

Figure H - 95 Pa Grout, 100 RPM, Recirculation 


\section{Distribution:}
A. B. Barnes, 999-W
D. A. Crowley, 773-43A
S. D. Fink, 773-A
B. J. Giddings, 786-5A
C. C. Herman, 999-W
S. L. Marra, 773-A
F. M. Pennebaker, 773-42A
W. R. Wilmarth, 773-A
L. T. Reid, 730-A
J. E. Occhipinti, 704-S
P. W. Norris, 704-27S
D. H. Ecklund, 704-28S
J. N. Leita, 704-Z
J. R. Tihey, 704-Z 